\title{
of California
}

n Regional

y Facility 
Digitized by the Internet Archive in 2007 with funding from Microsoft Corporation

http://www.archive.org/details/familyherbalorac00hilliala 




\section{THE}

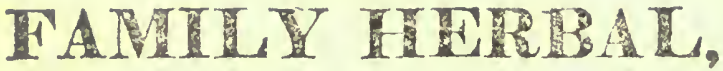

OR AN ACCOUNT OE ALL THOSR

\section{ENGLISH PLANTS,}

WIIICII ARE

\section{REMARKABLE FOR THEIR VIRTUES,}

$$
\text { AND OF THE DRUGS }
$$

WIICU ARE PRODUCED BT

Vegetables of other Countrics;

WITL THEIR

DESCRIPTIONS AND TIEIR USES,

\section{TR PROFED BT EXPERIFNCE.}

\section{AISO}

Directions for the gathering and / use; receipts for making distilled preserving roots, herbs, flovers, and waters, conserves, syrups, electua. seeds $;$ the varions methods of pre- ries, juleps, draughts, \&ce. \&c. with serving these simples for present necessary cantions ingiving them.

INTENDED FOR THE USE OF FAMILIES.

BY SiR JOHN HILL, M. D. F. R. A. OF SCIENCES AT BOURDEAUX.

\section{FIFTY-FOUR COLOURED PLATES.}

\section{BUNGAY :}

RRIXTED AND PUELISIIED BY C. BRIGHTLY,

AND T, KINNERSELY. 



\section{in

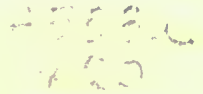 \\ PREFACE.}

M

ANY books liave been written upon the same treated it in the same manner, this would have been rendered unnecessary, and would never have employed the aitention of its author.

It is his opiuion, that the true end of science is use; and in this view, the present work has been undertaken. It appears to him a matter of more conseguence, and a subject of more satisfaction, to have liscorered the virtues of one herb unknown lefore, than to have disposed into their proper classes sizteen thousand; nay, so far will a sense of mility get the better of the pride of mere curiosity, that he should suppose this a thing preferable to be said of him, to the having discovered some unknown species; to having picked from the bottom of some pond an undescribed conferva; or to having fetched, from the most remote parts of the world, a kird of tree moss, with heads laryer than those at home.

It grieves a man of public spirit and humanity, to see those things which are the means alone of the advantagres of mankind studied, while in the end that advantage itself is forgotton. $\Lambda$ nd in this fiew he will regard a Culpepper as a more sipectable person than a Linnaus or a Dille Nilus.

'That Rotany is an useful study is plain; he\& $\%$ 
cause it is in vain that we know betony is good for head-achs, or self-heal for wounds, unless we can distiuguish betony and self-heal fiom one another, and so it runs through the whole study. We are taught by it to know what plants belong to what names, and to know that very distinctly; and we shall be prevented by that knowledge from giving a purge for an astringent, a poison for a remedy; let us therefore esteem the study of botany, but let us know, that this use of the distinctions it gives is the true end of it; and let us respect those, who employ their lives in establishing those distinctions upon the most certain foundation, upon making them the most accurately, and carrying them the farthest possible: these are the botanists; but with all the gratitude we owe them for their labours, and all the respect we shew them on that consideration, let us understand them as but the seconds in this scicnce. 'The principal are those who know how to hring their discoveries to use, and can say what are the ends that will be answered by those plants, which they have so accurately distinguished. The boy collects the specimens of herbs with great care, and bestows ten years in pasting them upon paper, and writing their names to them: he docs weil. When he grows a man, he neglects his usefil labnurs; and perhaps despises himself for the misemployment of so much time: but if he has. to the knowledge of their forms, added aftervard the study of their virtues, he will be far from censuring himself for all the pains he took to that end.

Ho who wishes well to science and to manlsind, must wish this matter molersiond: and this is the way to bring a part of knouledge into credit, inheh, 89 it is combumly proctised, is not a 
int above the studies of a raiser of tulips or a carviation fansier.

When we consider the study of plants, as the search of remedies for diseases, we see it in the light of noe of the most honourablc sciences in the world; in this view, no pains are ton great to have been bestowed in its acquirement; and in this intent, the principal regard ought to be had to those of our own growth. The foreign plants brought into our stoves with so much e:pence, and kept there with so much pains, may till the eye with empty wonder: but it would be more to the honour of the possessor of them, to have found out the use of one common herb at home, than to have enriched our country with an hundred of the others. Nay, in the eye of reaon, this ostentatious study is rather a reproach. Why should he, who has not yet informed hinself thoroughly of the nature of the meauest herb which grow in the next ditch, ransack the earth for foreign wonders? Does he not fall under the same reproach with the generality of those, who travel for their improvement, while they are ignorant of all they left at home; and who are ridiculous in their inquiries concerning the laws and government of other countries, while they are not iible to give a satisfactory answer to any question which regards their own?

I have said thus much to obviate the censures of those, to whom an inquiry into the virtues of herbs may scem the province of a woman. It is an honour to the sex, that they have put our studies to use; but it would be well, if we had done so onrselies; or if, considering that they might, we had male on writings more intelligible to shem.

The intent of vorde is to express our meaning: 
writungs are published that they nay ise under stoud; and iil this branch, I shall always suppose In writ's best, who is to be underaloud most universally Now so far are we from having had this moint in view lu botany, that wore new and more strange words have been introducod into it, than into all the scicnces together: and so remartiable is tire SWLDE inefore mentioned, L!N veus, for this, that mool schelar, nay the hest scholar in the world, shall not be able to understand three lines together in his best writings, although they are witten in latin, a language in which he is ever so familiar. 'The author has not been at the pains to explain his new words bimself, but refers his reader to nature; he bids him seek them in the fiowers, where lic found them.

Wesce, that the mnst curioug botarists have not concorned themselves about the virtues of plants at all; that maily of the others who have written well on plants, have thought it no part of their subject: let us examine the others; those who are of less remute. If we look into the Euglish lerbals in particular, we find them large upon that suhject; indeed they are too large by much. "ikc: say su many things, that we know not which 0 them to credit; and therefore in the uncertainty, ve credit nome of then. There is not the most bithing her?, which they do not make a remedy for shmost all diseases. We may therefore as well take onf plant for any case as anotuer; and the whole of beir libours amount to this, that the Einglish berbs arcinll of virtues, but that they know not what they are.

When knowledge is perplexed with unintelligiille terms, and the menney of the student confomaled with a multiplicity of names; when the ignorant only, who have whilkn concerning plants, 
Have given themselves any trouble about their virtues; when physic is becoming cntirely chynical, and a thousand lives are thrown away daily by these medicines, which might be saved by a better practice ; it appeared a useful undertaking, to separate the necessary from the frivolous knowledge; and to lay before those who are inclined to do good to their distressed fillow-creatures, all that it is necessary for them to know of botany for that purpose, and that in the most finiliar manner; and to add to this, what experience has confirmed of the many things written by ocher's coll. cerning their virtues. 'This is the intent of the following work.

The plants are arranged according to the English alphabet, that the English reader may know where to find thern: they are called by one name only in English, and one in Latin; and these are their most familiar names in those languages ; no matter what CAspar, or JOHN BAUHIE, or LiNNEUs call them, they are here set down by those names by which every one speaks of them in English: and the Latin name is added, under which they will be found in every dictionary. 'To this is subjoined a general description of the plant, if it be a common one, in a line or two; that those who already know it, may turn at once to the uses; and for such as do not, a farther and more particular account is added. Last come the virtues, as they are confirmed hy practice : and all this is deliverci in such words as are common, and to be understood by all.

Every thing that is superfluous is omitted, that the useful part may remain upon the memory : and to all this is prefixed, in a large introduc. tion, whatsoever can be necessary to compleat the good intentions of the charitable in this way. 
viii.

There are rules for gathering and preserving herbs, and their several parts, directions for making such preparations from tl:om, as can conzeniently be prepared in families, and general admonitions and cautions in their respective uses.

If I could have thought of any thing farther, that could tend to the making the book more useful, I should have added it; as it is, the candid reader is desired to accept it, as written with a real view to be of service to mationd. 


\section{INTRODUCTION.}

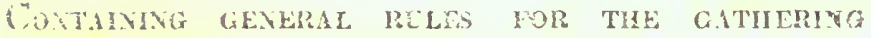
AND PRESFRVING HERES, ROOTS, BARKS, SIEDS, AND FEOWIS ; TOGETHER WHA THE NELHOWS OF DASIA SLCH PREPAIATOXS IROM THEM, AS WIY ISST RETAI THEH VIRTEES, OR NE NOY LSTLI

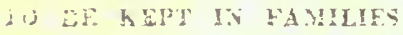

\section{CISP. I}

The design and purpose of this work, and the mi thod observed in it.

TliE intent of the author in publishing this 1. book, is to inform those who live in the rountry, and are desirons of being useful to their fumilies and friends, or charitable to the poor in the rebef of their disnders, of the virtnes of those plunts which grow wild about them : that they may be ahle to supply this necessary assistance, in piaces where aputhecaries dis not at hand; and that they may be able also to do it without putting thenselves to the expense of medicines of price, when the common incrba, that mav be 
had for gathering, will answer the same purpose.

Ilowever, as there are cases, in which more help may be had from drugs brought from abroad than from any thing we can procure at home, an account of those roots, barks, seeds, gums, and other vegetable productions, kept by the druggists and apothecaries, is also added; and of the several trees and plants from which they are obtained; together with their virtues

'This work. theretore, will tend to instruct those charitable ladies who may be desirous of giving this great relief to the gfflicted poor in their neighbourhood, and to remind apothecaries of what they had before studied: but the first mentioned purpose is by much the most useful, and the most considerable, and for this reason the greatest regard is paid to it.

The plants are disposed in the alphabet, according to their English names, that they may be turned to the more readily; and an account is given, in two or three lines, of their general aspect and place of growth, that those who in part know them already, may understand them at once : if they are not perfectly known from this, a more paiticular flescription is added, by observing which, they cannot be mistaken or confounded with any others ; and after this follow, not only their virtues, as others are content to set them down, but the part of each plant which contains them in most perfection is named, and the manner in which they may best be given.

With regard to the virtues of plants, it has been the custom to attribute too many to most of them : so much is said more than the truth on these ocrabions, that those who would be informed, know 
not what they should belinse. Thi is more cautiously regulated here. The reat virtues alone are set down, as they are assured by experience. and the principal of these are always set in the most conspicuous light. Perhaps it may be allowed the anthor, to speak with more ass urance than others of these things, because he has been accustomed to the practice of physic in that way. Very few things are named here that he has not secn tried ; and if some are set down, which other writers have not named, and some, of which they have said most, are slightly mentioned, it is owing to the same experience which has arded to the catalogite in some things, and has found it too great for truth in others.

Nature has, in this country, and doubtless also in all others, provided, in the herbs of its own growth, the remedies for the several diseases to which it is most subject; and although the addition of what is brought from abroad, should not be supposed superfluous, there is no occasion that it should make the other neglected. This has been the consequence of the great respect shewn to the others; and besides this, the present use of chemical preparations has almost driven the whole of galenical medicine out of our minds.

To restore this more safe, more gentle, and often more efficacious part of medicine to its natural credit, has been one great intent in the writing this treatise; and it is the more necessary for the service of those, who are intended most to be directed in this matter, since this is much less dangerous than the other: nay, it is hard to say, that this is dangerous at all, in most instances.

The apothecaries are apt, in their unfeeling mockery, to say, they are obliged to the good 
ladies who give medicines to their sick neighbours, for a great deal of their lusiness; for out of little disorders they make great ones. This may be the case where their shops supply the means; for chemical medicines, and some of the drugs brourht from abroad, are not to be trusted with those who have nist rreat experience; but there wili be no danger ot this kibl, when the fields are the supply. Hhis is the moricine of ma mo, and as it is mane efincacions in most cases it is mone safe in all. fi mpinm may be dangerous in an mexperiencer hand, the fady who wil? sive in its place a sirup of the rild letture. (a plast not known in common placice at this time, but recommendel form experience in this treatise, will fud that is wi!l (ase pain, and that

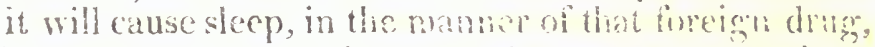
but she will nerer lind aty ill consequereces form it: and the salue might be whid in mang otion in. slances.

As the doscriptions n bis work, wery readits distinguish what are the real plants laat shomld be used, the great care wili remain, in what men. ner to gather and preserve, and in what manner to give them ; it will be useful to add a chipltei or two on thrse heads. As to the former, I would have it perfecily understond, because a great deal depends upon it ; the latter cannot easily be mistakeit.

Having tisplaced the drins broment from abroad in a soreat moasure from this charitable practice, I would have every laty, who has the spirit of this true lenevolenes, krop a lind of dougrast's shop of hel own: hois shomld be sup).

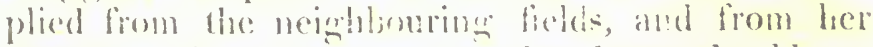
warden. There is no reasom the druns shomld quot ix: as well preserved, and as carcfully laid "lp, 
as if the princt of a different climate, though the une of the fresin phants will in general be best when they ran be biall.

As there are some which will not retain their vitues in a ritied shate, and can be met with only during a small part of the year; it will be proper to add the best methodis of preserving thase in some, way, according to the apohecarys manner; and these chapters, with that which shail lay down the mothod of making the preparations from them for roady service, will be sulfirient to lead to the perfect use of the medicines of onr own growth: ard it wiil be found upon experi-

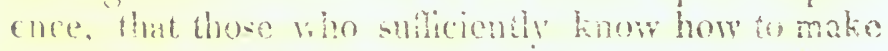

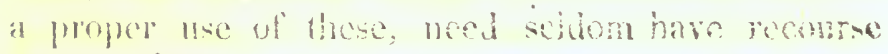
(w) any whices.

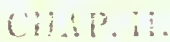

Conerning the merlids of collecting and presoreing jelants and parts of than for use.

Thill virtues of diferent plants residing primeE paly in critain pats of them, ant those different accosding to the nature of the herb, these seretal parts are to be sulected, and the rot left; and there are in some to be used fresh and just gathered; in others, either necesity, or the natual preforence, whe it proper to dry and preserve them.

In some only the leaves are to be wad : in whers the whole plant cut fiom the root: in allers the flowers only; in oflers the fruts; in others the secds; in sume the roots; and if sane trees 
tlie barks; some the woods; and onily the excresences of others: while some vegetables are to be userl entire, whether it be fresh gathered, or dried and preserved. Of all these, instances will be given in great number in the following sheets, and the matter will be specined under each article, as the part of the plant to be usert will always be named; and it will be added whether it be best fresh, or best or necessarily dued or otherwise preserved; but it will be propw in this place to cuter into the full examination of thi inater, to save mnecssary repetitions under tsic several particular arlicles.

The whole of most plants native of our country, "dies oft in winter, except the loot; and in many that perishes also, leaving the species to be rencwed from the fallen seeds. When the whole plant dies, the root is seldom of any virtue; but when the root remains many years, and sends up new shoots in the spring, it immonly has great virtue. This may be a gencral rule: for there is very little to be expected in the roots of anmual plants : their seeds, for the most part, contain their greatest virtues.

In others, the ront lives through the winter, and there arise from it large leaves in the spring, before the staltis appear. These are to be distinguished from those which afterwards grow on the stalk, for they are more juicy, and for many purposes much better. In the same manner, some plants, from their secds dropped in antumn, produce a root and leaves which stand all the winter, and the stalk does not rise till the succeding spring. These are of the nature of those leaves, which rise from the root of other plants before the stalks in spring: and are in the same manner to be distingrushed from those which grow upon the stalks: 
they have the full nourishment from the ront, whereas the others are starved by the growth of the stalk and its branches, and the preparations made by nature for the flowers and seeds ; which are the great purpose of nature, as they are to continue the plant.

For this reason, when the leaves of any plant are said to be the part fittest for use, they are not to be taken from the stalk, but these large ones growilig from the root are to be chosen; and these where there is no stalk, if that can be ; for then only they are fullest of juice, and have their comglete virtue; the stalk running away with the nourishment flom them. This is so nuch done in some plants, that although the leaves growing from the root were very vigorous before the staik grew up, they die and wither as it rises.

When the juice of the leaves of any plant is required, these are the leaves from which it is to be pressed: when they are ordered in decoction, notice is always taken in this book, whether they be best fresh or dried; if fresh, they should be just gathered for the occasion; they should be cut up close from the root, and only shook clean, not washed; for in many, that carries off a part of the virtue: they are to be cut into the pot. If they are to be dried, the same caution is to be used; and they are best dried, hy spreading theri upon the floor of the room, with the windows open; often turning them. When thoroughly dried, they should be put into a drawer, pressing them close down, and corered with paper. When the entire plant is to be used except the ront, care is to be tal en that it be gathered at a proper seavn. Nature in the whole growth of plants, tends to the prociuction of their floners and seceds, 
but when they are ripe, the rest begins to decay, having done its duty ; so that the time when the emtire plant is in to nost fill perfection, is when it is in the bud; when the heads are formed for flowering, but not a single flower has yet disclosed itself : this is the exact time.

When heriss are to be used fresh, it is best not to take them cntire, but on!y to cut ofl the tops ; three or four inches long, if for intusion, and if for other purposes, loss: if they are to be beaten lap vitio silgat, they should be only an inch, or

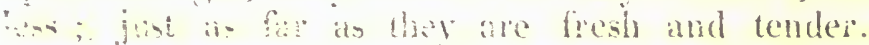
The tips on the lant thus gathered, are al-

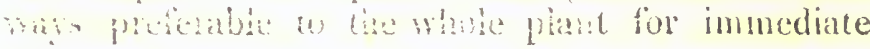
mise

then the entive herly is to be dried, the season fir gathering it is to be as just described, when tae flowers are butding : and the time of the day mant be when the morning dew is dried away 'ollis in a very matorial circumance, for if they be cut wit with the dew, hels will not dry well, mal it they be cut at noon day, when the sum has

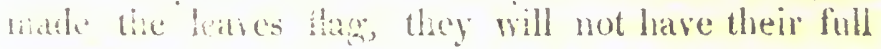
mow

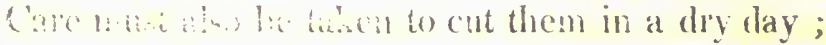
for the wet of zatin will do as much barm, as that of dew.

Whon the herbs are thus gathered, they are to be looked over, the derayed leares picked off, and the dead curis of the stalks rut atray: they are then to be tied np in small binches, (the less the better, and hume npon lines drawn across a romus, where the vinduns and docres are to be fept ancen in gond werther ; the bunches are to an lont a font anbrier, and they are to hanger till

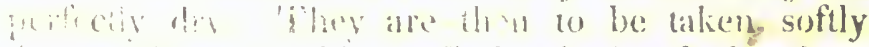
in:m, inthe statimg ofl the buds of the how- 
ers, and laid evenly in a drawer, pressing them down, and corming them with paper. They are thus ready for infusions and decoctions, and are better for distillation than when fresh.

'The flowers of plants are principally used fresh, though several particular kinds retain their virtue very well dried; they are on these different occasions to be treated difierently.

Lavender flowers, and those of stœcha, keep very well; they are therefore to be preserved dry; the lavender howers are to be stripped off the stalks, husk and all together, and spread upon the floor of a room to dry. The stochas flowers are to be preserved in the whole head; this is to be cut off from the top of the stalk, and dried in the same manner: when dry, they are to be kept as the herbs.

When rosemary flowers are dried, they are generally taken with some of the leaves about them; and this is very right, for the leaves retain more virtue than the flowers. Some dry borage, bugross, and cowslips, but they retain very little virtue in that condition. Rose buds are to. be dried, and to this purpose, their white heads are to be cut off; and the full blown flowers may be preserved in the same mancr. The red rove is always meant, when we speak of the dried flowers.

For the rest of tha flowers used in medicine, ther are best fresh; but as they remain only a small part of the year in that state, the method is to preserve them in the form of syrups and conserves. Such as the syrup of cloves and poppies, the conserves of cowslips, and the like. Of these, a sloot general account shall be subjoined, shat mothing may be wanting to make this book 
as useful for families, as the nature of such an one will admit.

Among the fruits of plants, several are to be used frosh, as the hip for conserve, and the quince, mulberry, and black currant; from the juices of which, gyrups are made. As to those which are to be dried, as the juniper berries, the bay berries, and the like, they are only to be gathered when just ripening, not when quite niellow, and spread upon a table or floor, often turning them till they are dry. But of these we use very few of our own growth; most of the fruits nsed in medicine are brought from abroad, and nust be purchased of the druggist or apothecary.

With respect to the seeds and plants, it is otherwise: inany of them are of our own growth, and nothing is so pasy as to preserve them. These are all to be used dry; but nature has in a manner dried them to our hands: for they are not to be gathered till perfectly ripe, and then they need very little farther care. They are ouly to be spread for three or four days upon a clean floor, where the air has frec passage, but where the sun does not come; and they are then ready to be put up.

'The sceds used in medicine. may be referred to three gencral kinds. They either grow in naked neads or unbels, as in fennel, parsley, and the like; or in pods, as in mustard and crosses: or in large fleshy fruits, as in melon and cucumbers. In each case they must he left upon the plant till perfectly ripe; then they are only to be shook from the linads upon the floor, or if in pods, a smart stroke or two of the plant upon the floor, when they are thoronghly ripe, will 
dislodge them. In the other case, the fruit must be cut open, and they must be taken out from among the wet matter, separated from the membranes that are about them, and spread upon a table, in a dry place, where they must be often turned and ruhbed as they grow dry, that in the end they may be perfectly dry and clean.

Among the roots a great many are to be used fresh, but a greater number are best dried. The black and white hriony, the arum, and some others, lose all their virtues in drying; and many that retain some, yet lose the greater part of it: there are others which are excellent botk fresh and dried, as the marshmallow and some more.

As to the few which lose their virtue entirely in drying, it will be best to keep some of them always in the garden, that they may be taken up as they are wanted. The others are to be managed according to their several natures, and they do a great deal toward the furnishing this druggist's shop, which should be filled with medicines, the produce of our own country.

The best season for gathering roots for drying is in the carlier part of the spring : what nature does for plants when they are just going to flower, she does for roots when the leaves are just going to bud: the juices are rich, fresh, and full, and the virtue is strongest in them at this season, therefore they are to be tben taken up.

In the end of February and the beginning of March, the ground should he searched for the first budiding of leaves, and the roots taken up. "They are to be wiped clean, not washed; and, according to their several natures, prepared for drving.

Some are full of a mucilaginous juice, as marsh- 
mallow, and above all other roots the squill, and in some degree nuny others of that kind : these must be cut into thin slices cross-wise, and they will dry best if laid upon a hair clotl stretched across a frame. They inust be frequently turned ; and be very thoroughly $d r y$, before they are fut up, else they will become mouldy : but, rightIy peepared, they kerp very well.

Other roots liave juices, that evaporate more easily. These have the virtue either throughout the whole substance, or only in the outer part, and they are to be prepared accordingly. When roots are of one uniform substance, they generally have the virtue equal, or nearly so, in all parts. These should be split open length-wise, first cutting off the head, and the litile end; or if considerably thick, they may be quartered; when this is rlone, they are to be strung upon a line, by drawing a needle threaded with a small twine through their thickest part, and thcy are then to be hung up to dry in the manner of the herbs; the line being stretched across a room, the doors and windows of which are to be kept open in good weatiner.

When roots consist of a sort of thick rind, or fleshy substance within the rind, and a hard sticky part in the middle, this fleshy substance under it possesers all tine virues, the hard inner substance having none; in this case, the root is to be split long-wise as hefore, and the hard woody part is to he: taken out and thrown away ; the rect is to hestrung as befone described, and dricd in the same manner.

Shea roots consist of fibres, llese are generally ronucted to a hearl, if it be crer so small, and the best way is to split thi: in two, and then sriag up the separate parts for drying.

It is necdless to enumerate tha examples of ina 
several kinds of roots here; they follow in their places : but if the charilable larly would, on first looking over this book to see what are most useful, order her gardener to take out of his ground, and to seek in the fields, the several roots there mentioned, and see them dried and preserved according to thee directions, she would be possessad of a set of drugs of a new kind indeed; but they would save the price of many brought from other countrics, and might be used with less danger.

The barks of trees make but a small part of the English drugs, and most of them are best fresh; but such as will preserve and retain their virtues dricd, are very easily prepared that way: nothing more is required, than to cut them into moderate pieces, and string them up in the same manner as the roots. When they are dry, they are to be put up as the others; and they will keep ever so long; but in all this time they are for the most part losing of their virtues.

It may be prudent to preserve drugs brought from abroad a sreat while becanse of their price; but as these cost only the trouble of gathering and preserving them, I would advise, that the whole shop be renewed every year; what is left of the old parcel of every kind, being thrown away as the fiesh one is collected in its scason.

The place for keeping these shonld he a dry room, neituer damp nor hot; and they shotild mow and then be lowkel at, to sec that they are in order ; that they do not grow mouldy, or small musty turongh damp, or become lighter, and lose their virtue by too sinuch leat.

It may be proper just to mention, that the 
woods which we use are best kept in the block. and shaved off as they are wanted; for being kept in shavings, they lose their virtue: and in the same manner as to the forcign woods, it is best to keep a block of sassafras, and of lignum vita in the kouse, and cut them as they are wanted.

As to the excrescences, such as galls of the oak, and the burr upon the wild briar, they are naturally so dry, that they only require to be exposed a few days to the air, upon a table, and then they may be put up with safety, and will kerp a long time.

Lastly, the funguses, such as Jew's cars and the like, are to be gathered when they are full growu, and struug upon a line, that they may dry leisurely, for else they spoil : they must be very well diried hefore they are put up, else they will grow mouldy in damp weather; and if onre that happen, no art can recover their virtues.

Thus may a druggist's shop of a new kind be filled, and it will consist of as many articles as those which receive their furniture from abroad; and there will be this advantage in having every thing ready; that when custom has made the virtues of the several things familiar, the lady may do from her judgment as the physician in his prescription, mix several things of like virtue together, and not depend upon the virtues of any one sincly, when the case requires something of power. These roots and barks powdered, will make as haudione and as cflicacious boluses and mixtures, as any furnished by the apothecary. 


\section{CHAP. III.}

Concerning the various methods of preparing simples for present use.

TIViRE is no form of medicines sent from 1 the apothecary, which may not be prepared frim the lierbs of our own growth in the same manner as from foreign drugs. Electuaries may be made with the powders of these barks, roots, anci seeds, with conserves of flowers, and of the tops of fresh herbs; and syrups, made from their juices and infusions; the manner of making which is very simple, and shall be subjoined to this chapter, that all may be understood before we enter on the book itself: and in the sne manner their boluses inay be made, which are only some of these powders mixed up wh syrup: and their draughts and juleps, which are mate from the distilled waters of these herbs, with spirit, or without these syrups being added; and the tinctures of the roots and barks; the method of making which shall be also amexed in a familiar mamint.

But beside these several forms of giving them, there are others much more simple, easy, and ready, and thesc are generally more efficacious. I shall arrange these under three kinds, juices, infusions, and decocions. These are the forms of givoug the medicines most frequently mentioned in the course of the work, and there is less trouble in them than in the others. They are not indeed contrived for shew, ror would they unswer the purpose of the apothecary, for his profits would be small uponthem; but whon the design 
is only to do good, they are the most to be chosen uf atily.

Juices are tobe expressed from leaves or roots ; and in order in this, they are to be first beaten vil a mortur. 'There is no fom whatever in which licrbs have so much effect, and yet this is in a mamer unknown in the common practice of phrsic.

'These are to be obtained in some plants from the entire herb, as in water cresses, brook-lime, and otliers that have juicy stalks; in others the leaves are to be used, is in nettles, and the like, where the staik is dry, and yields nothing; but is troublesone in the proparation. When the juire of a ront is to be lat, it must be fresh taken vip, and theroughly beaten. A marble morar and wonden pestle serve best for this purpose, for any thing of metal is improper : many plants wonld take a tincture from it, and the juite would he so impregaated with it, as to become a different medicine, and probably rery in vper in tlec case in which it was about to be givin.

St these juices have sometimes an ill tasto, and as sume of then are apt to he crild upou the stomach, or ofluewwise to disagree with it, there are meihoris to lir. ised, to make thrm sitheter upon it ; and in sonse cases these increase their irtI!ca.

then the thive jaice, fiesh drawn, is too coarse for the person's stomach, it may he sulfered io seftle and erow char: a little sugar may be addedalso in beating the berb, and in many cases, as in those juices griven for the scury, the juice of a seville orange may he added, which will greatly improve the liavour. 
To the roots it is often proper to add a little white wine in the bruising, and they will operate the better for it. 'Thus, for instance, the juice of the flower-de-luce root will not stay upon many stomachs alone; but with a little white wine added in the bruising, all becomes easy, and its effects are not the less for the addition. The same addition may be made to some of the colder herbs; and if a little sugar, and, upon occasion, a few grains of powdered ginger be added, there will be scarce any fear of the medicine disagreeing with the stomach, and its effects will be the same, as if it had been bruised and pressed alone.

Infusions are naturally to be mentioned after the juices, for they are in many cases used to supply their place. Juices can only be obtained from fresh plants, and there are times of the year when the plants are not to be had in that statc. Recourse is then to be had to the shop, instead of the field; the plant whose juice cannot be had, is there to be found dried and preserved; and if that has been done according to the preceding directions, it retains a great part of its virtues; in this case it is to be cut to pieces, and hot water being poured upon it, extracts so much of its qualities, as to stand in the place of the other. Often, inded, the virtues are the same: in some plants they are greatest from the infusion; but then some others lase so much in drying, that an infusion scarce has any thing. But it is not only as a help in the place of the other, that this preparation is to be used, for infusions are very proper from many fresh herbs; and are of great virtuc from many dry ones, of which, when fresh, the juice would have been worth sittle. 
Infusions are the tittest forms for those herhes whose qualities are light, and whose virtue is casily extracted: in tisis case, hot water proured upun them ta! s up cnough of their virtue, and none is lo.t in the opelation; others require to be boiled in the water. From these are thus made what we call decoctions: and as these last would not give their virtues in infusion, so the others would lose it all in the boiling. It would go off with the vapour. We know very well, that the distuled water of any herb is only the rapour of the boiled herb caught by proper vessels, and condensed to water: therefore, whether it be caught or let to fly away, all that virtue must be lost in boiling. It is from this, that some plants are fit for decoctions, and some for infusions. There are some which, if distilled, give no virtue to the water, and these are fit for decoctions, which wis! retain all their virtue, as bistort, and tormontill roots, and the like. On the contra$r y$, an infusion of mint, or pennyroyal, is of a strong taste, and excellent virtue; whereas, a decoction of these herbs is disagreeable or good for nothing.

There aje herbs also, which have so little juice, that it would be impossible to get it out; and others whose virtue lies in the huskz and buds, and this would be lost in the operation. An inforion of these is the right way of giving them. 'Thus mother of thyuc is a dry little herb, from which it would be hard to get any juice, and when fontrn, it would possess very little of its virtues: tut inl iufusion of mother of thyme possesses it entirely.

Infunins are of two kinds. They are either prepared in quantity, to he drank cold; or they netu drank at they are nade, in the manner of tea. 
This last method is the best, but people will not be prevailed upon to do it, unless the taste of the herb be agreeable ; for the flavour is much stronger hot, thisu it is cold.

Infusions in the manner of tea, are to be made just as tea, and drank with a lintic sugar: the others are to be made in this manner:

A stone jar is in be fitted with a close cover; the herb, whether fresh or dried, is to be cut to pieces; and when the jar has been scaldea out with hot water, it is to be put in : boiling water is then to be poured upon it ; and the top is to be fixed on: it is thus to stand four, five, or six lours, or a whole night, according to the nature of the ingredient, and then to be poured nff clear.

It is impossible to direct the quantity in general for these infusions, because much more of some ) lants is required than of others : for the most part, three quarters of an ounce of a dried plant, or two ounces of the fresh gathered. The best rule is to snit it to the patient's strength and palate. It is intended not to be disagreeable, and to have as much virtue of the herb as is necessary: this is only to be kilown in earch kind by trial; and the virtue may be heightened, as well as the flavour mended, by several additions. Of these sugar and a little white wine are the most familiar, but lemonjuice is often very serviceable, as we flud in sage tea; and a few drops of nil of vitriol give colour asd strength to tincture of roses. Salt of tartar makes many infusions stronger also than they would be, but it gives them a very disagreeable taste. It is, therefore. fit only for such as are to be taken at one draught, not for such as are to be swallowed in large quantities time after time.

Among the herbs that yicld their virtues most 
commodiously by infusion, may be accounted many of those which are pectoral, and good in ecughs, as colts-foot, ground-ivy, and the like; the light and aromatic, good in nervous disorders, as mother of thyme, balm, and the like; the bitters are also exccllent in infusion, but very disagreeable in decoction; thus boiling water poured upon Roman wormwood, gentian root, and orange peel, makes a very excellent bitter. It need only stand till the liquor is cold, and may be then poured off for use.

It is often proper to add some purging ingredient to this bitter infusion; and a little fresh polypody root excellently answers that purpose, without spoiling the taste of the medicine.

Several of the purging plants also do very well in infusinn, as purging flax, and the like; and the fresh root of polypody alone is a very good one : a little lemon juice added to the last nauned infusion does no harrin; and it tiakes off what is disagreeable in the taste, in the same manner as it does from an infusion of sena.

Thus we see what a great number of purposes may be answered by infusions, and the are the most faniliar of all preparations. Nothing is required, but pouring some boiling water upon the plants fresh ordried, as alreacy directed, and pouriug it off agrain wlien cold.

i)ecoctions are contrived to answer the purpose of infusions, upon plants which are of so firm a texure, that they will not easily yield forth their usoful parts. In these the ingrodients are to be boiled in the water, as in the ofbers, the boiling water was to be poured over them. In gesueral, leaves, flowers, and entire plauts, whether fresh or dried, are used in infusions; the roots and balks in decoctions.

An carthen piplin, with a close cover, is the 
best vessel for preparing these ; for many of those medicines which are little suspected of it, will take a tincture from the metal; and it would be as improner to boil them in a copper pan, (as it is too common a custom, ) as to beat the berbs and roots in a metal mortar.

Fresh ronts are used in decoction, as well as those which are dried; and the barks and other ingredients in libe mamer. Whon the fresh are used, the rosts are to be cut into thin slices, and the barksand wonds should be shaved dovn; as to the leaves and entire plants, they need be cut but slightly. When dry ingredients are used, the conts and barks are best pounded to pieces, and as to the horbs and flowers, little is to be done to them, and in general, they are best added toward the end of the decoction.

It is always best to let the ingredients of a decoction stand in the water cold for twelve hours, before it is set on the fire, and then it should be heated gradually, and afterwards kept boiling gently as long as is necessary: and this is to be proportioned to the mature of the ingredients. Generallo a quarter of an hour is sufficient, sometimes much longer is necessary. They are then to be strained oft while they are hot, pressing them hard, and the liquor set by to cond: when they are thoroughly cold, they are to be poured off clear from the settlement, for they always become clear as thry cool, and aweetered with a ritie sugar. Frequently also, it is proper to add to them a little white wine, as to the infusivis. 


\section{CIIAP. IV.}

Cuncerning distilled waters, and other preparations to we kept in the house.

SHALI bring the charitable lady farther in this - matter than perhaps she was aware at the first setting out : but it will be with little expence, and little trouble. She will find, that I now intrud she should kecp a sort of chemist's or at least an apothecary's shop, as well as a druggist's : but it will be founded upon the same materials. No drugs brought from abroal, or to be purchased at a great price, will have place in it ; they are all natives of our own comlry; and the preparation of these medicines from them will cost only a little spirit, a little sugar, and the labour of a servant.

That spirit is best which is called molosses spirit; it is to be bought at a small price at the dis1illers; and as to the sugar, the most ordinary Joaf kind will do for most purposes; where other is necessary, it will be particularly named.

Few fanilies are without an alembic or still, and that will be of material service. With that instrument the simple waters are to be made, witin no expence beside the fire; and it will be proper to heep those of the following ingredients.

Mint wafer, pepper-mint water, and penny. rovil water, are (o) be male of the dry herbs. 'There pormeds of each is to be put into the still, with fonr gallons of water, and two salloms is (1) be destilled oft. Milk water is to be made: thme; a promed and half of apear-mint, a pourat

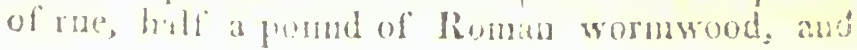


lalf a pound of angelica leaves are to be put into the still with five gallons of water, and three gallons are to be distilled off. Common mint water is good in sicknesses of the stomach, pepper-mint water in colics, and pennyroval to promote the menses. Milk water is good in fevers, and to make juleps. It used to be malle with milk, but that answers no purpose. Only one simple water more need be kept, and that for colics: it is best made of Jamaica pepper: a pound of Jamaica prpper is to be put into the stull over night, with three gallons of water; and the next morning two gallons of water distilleci off.

It has been customary to keep a great many simple waters, but these are all that are necessary or proper. 'The other herbs are better to be given in infusion and decoction.

As for cordial waters, they are made as the others, only with the addition of spirit. It nay be proper to licep the following; and no more are necessary.

1. Cimmamon water; which is made by putting into the still a pound of cimamon, a gallon of spirit, and a gallon of water, and the next day distilling off a gallon. This is good in sickness at the stomach, and is a fine cordial.

2. Spirituous milk water; made from a pound of spear-mint, half a pound of angelica, and a quarter of a pound of homan wormwood, all green. Tothese is to be put a gallon of spirit, and a gallon of water, and a gallon to be distil. led off; to which is to be added a pint of vinegar: this is good to promotesweat, and is used insteal of treacle water, boing bettor.

3. Strong pennyroyil water, which is used instead of hysteric water, in all hysteric cases, 
and to promote the meuses, is made of a pound and half of dry pennyroyal, a gallon of spirit, and six quarts of water, drawing off a gallou.

1. Annisect water, which is good in the colic, and is made with a pound of amiseed, a pound of angelica seed, and two gallons of spirit, with one allum of water, distilling off two gallous. No nive of these are recessary: but before I close this articte of distilling, I shall add the making of lavender water, spirit of lavender, and Inufary water, which are preparations of the same kind, and very easy.

l.avender water, is made from a pound of fresh lavender flowers, and a gallon of molosse spirit, with two quarts of water; five pints are to be isstilled off. Hungary water is made of a pound and half of roscmary tops with the flowers, a gallon of spirit, and a gallon of water, distilling off tive pints: and to make the spirit of lavender, or palsy drops, mix three pints of lavender water, and one pint of Hungary water, and add to this lualf an nunce of cinuamon, the same quantity of nutmegs, and three drams of red samders wood; these are to stand together tili the spirit is well coloured.

'ithis is all the family practitioner will need witl distilluer: a short account, but sufficient.

As fir tinctures, which are a great article with the apothecary and chemist, making a guat shew, and reilly very useful; I would hibe sereal of then lippt, and they are as culiv made as tho waters, nay, more casily. Mnomess spritit is all that is necessary for this

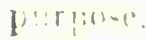

It in!l! be we!l to kerp tinctures of all rous and larks, which are said to be groorl dried 
in lise course of this work, for a tincture will (1)itain nore or less of the virtue of eves one of tiste, and be often inaverit, where the povder w decuction could not be iniver. It is now diss to enumeraie these, and one ru' of makme, servek ior them ail: two ounces of ine ingrafient is to be cut to thin slices, or oruisrd in a mortar, and put isto a quart of spirit; it is to stand a fortright in a place a little warm, and be ofter shoov; at the end of this time, it is to be taken out, strained off, and made to pass thromgh a finnel, lined with whitish brown paper, and put up with the rame of the ingredient.

To theie tiuctures of the English rocts, barks, and seeds, it would be well to add a few made of foreign iugradients. As,

1. The bitter pincture for the stomach, is made of two onuces of gentian, an ounce of dried orange peel, and half an ounce of cardamom seeds, aut a quart of spirit: or it may be made in white wine, allowing two quarts.

2. Tincture of castor, gond in hysteric complainte, and made with two ounces of castor and a quart of spirit.

3. 'Tiucture of bark, which will cure those who will not take the powder, made of four ounces of bark, and a quart of spirit.

4. Tincture of snot for fits, made with two ounces of wood-soot, one ounce of assafcetida, and a quart of spirit.

5. Tincture of steel, for the stoppage of the menses, made of flowers of iron four ounces, and epirit a quart.

6. Tincture of murrh, inade of three ounces of myrrh, and a quart of spirit, good for curing the scurvy in the gums.

7. Tincture of rhubarb, made of two ounces 
of thubab, half ail ounce of carramom sceis, and a quarter of an munce of sarron, with a quart of epirit.

s. Elixir salutis, made of a pound of stoned raitina, at yound of ecura, an ounce and balf of carruway serds, and half an wunce of cardamoms, in a gallon of spirit.

9. Elixir of vitriol, made of six drams of cinnamon, three drams of cardamoms, two drams of long pepper, and the same of ringer; and a quart of spirit: to a pint of this tircture strainal clear ofi, is to be added four ounces of oil of vitrio! : this is an excellent stomachic. Lastly, to these it mav be well to add the famous frier "s balsam, which is made of three ounces of henjamin, two ounces of strained storax, one ounce of halsam of Tolue l.alf an ounce of aloes, and a quarte" sisit of nine. such as is bunt under laing. This spirit way be made by pultive a gullon of molosses sprit into the still, and dratijig of tivo quarte, and this will be usoful fy spirit of wine and camplive, which is matie by dissnlving an ounce of camphire in a glant of the spinit. Tastly, we are to add what is called the astimatic clixir, male with fower of herjamin ald mpiom, of cach a dram, camphire two scrupiles, vil $:$ miseed forty drops, liguricice root hif an ounce, lioney one ounce, and a ylant af spirt. This is a gentle opiate, aud is andit bien in fanilies than the strong laudaritun?

As: to lif: tioctures made with white wine instead ur spririt, a few are sufficient. Sitrel wise is made of a quarter of a pound of filimes of iron, and lalf an ounce of mace, and the sarise quancity of cinnamon, put into fwo quarts of Rhenish. Ilicra licra is made of lialf a pouml 


\section{INTRODUGTON.}

of aloes, tro ounces of winter's bak, and five guarts of white wine. The first is a rourative cordial and strengthener; the latier is survently known as a purge, Lanuanum is made of two cunces of opium, a dram of chres, and a dram of cinnamon, and a pint of wine. Viper wine is made of two ounces of dried vipers, and two ruarts of white wine; and the tincture of ipecacuanha for a vomit, of two ounces of that rent, half an ounce of dry orange peel, and a quart of sack. Lastly, what is called elixir proprietatis is made of aloes, mvrrh, and saffon, of each an ounce, sal armoniac six drams, and salt "f tartar eight ounces, in a guart of mountain wine.

These are all the tinctures and wives that need be kept in a family, whose charity is dosigned to be verv extensige; the expence of the whole is a trifle, not worth naming, and the trouble scarce any thing. Pook are full of directions ii particular for every tincture, as if every one were to be made a difierent way; but the best method is to give a good deal of time, and frefornt shaking, and that will stand in the place of leat in most things of this kind: novertheless, I advisc that they should stand in a room where a fire is kept while they are making; and those which require heat, that is, those that take a colour most slowly, are to be placed nearest to it.

Fisy a $\mathrm{tl}_{\text {iese }}$ are, they are by far the most difficilt part of the task, the rest is as it were nothing. Consolves, syrups, and ointments will be wanting ; but in the same manner one direcsinn will serve for the making the rhole assorin ment of each, and the ingredients will be at lant. As to plaisters in seneral, they do more 
l:arm than gond. Surgenns at this time make very little use of them; and in the course of this woik, many lierbs will be named, the bruised leaves of which are better than all the plaisters in the world.

Conserve's shnuld he mate of rue, mint, scurvygrass, wood-sorrel, and Roman worumood. As to the four first, the leares are to be picked off from the stalks, and beaten up with three times the reight of sugar. The tops of the yonse shouis of the latter are to be cut off, and they are to be beat $u p$ in the same manner. In the course of this work, many plints will be named, the treen trps of which contain their virrue, these may ail be made into conserves in the sutue manmer, or as many of them added to thuse here named, as shall be thought proi)

Conserpes of the flowers of rosemary, mallows, archangel, and laventer, are to be made also in the same manter, and of red rose buds. These last are to be picked from the husk, and the white lieels are to be cut off. 'They art all to be beat up with three times their weight of sugar; and in the same manner may be made conserves of cowslip flowers, and of those of man:i other plants mentioned in the following pas.".

'liev outer riuds of Seville oranges aud lemong, sie alen to be made into couserves in the sane masure $r$, beating them first to a pulp, and then ahdiner the atigior; and to these must be added the conefere of hijes and sloes, which are to be marle in a particular manucr. The hips are to be gatherest wisen fully ripe, afterwards set by in a chliar, till they arom rery suft; then tiey are to be lad upou the back of a large hat sieve, 
a dish bcing nut underneath; they arc to be broke with the hand or a wooden pestle, and rublied about till all the soft matter is forced through the hair-cloth, the seeds and skins only reinaining. This soft mattri is in be weighad, and to be beat up in a mortar rith twice its weight of loaf sugar, firat poviderá.

Sloes are 1.) be gathered when they are moderately ripe, and they are to be set orre the fire in water, till thoy swell and are softened, but not tili the ekin bursts : they are tile? to be laid upoin a sieve, and the soft matter drivers through as in the other case, and thrce times the quantity of sugar is to be mix with this, that it may make a conserve $3 y$ beating together.

Syrups are to be made of many ingredients: they may he mallo inleed of any infusion, with sugar added to it in a duc quantity; and the way to add this so that the yrups shall kecp and not candy, is to proportion the surar to the liquor very exactly. One rule will serve for all this matter, and save a great deal of repetition. The liquor of which a svrup is to be made may be the juice of some herb or fruit, or a decoction, or an infusion; which ever it be, let it stand till quite clear; then to evory wine pint of it, add a pound and three quarters of loaf sugar, first beat to powder : put the sugar and the liquor together into an earthen pan that will go into a large saucepan; put water in the saucepan, and set it over the fire. Let the pan stand in it till the sugar is perfectly melted, scum. ming it all the time; then as soon as it is cold, it may he put up for use, and will kecp the year round without danger.

This being set down as the general method of 
making the liquor into a syrup, the rest of the descriptinus of them will be cusy. They are to be made in this manner. For syrup of cloves, weigh turee pounds of clove $J$ uly fowers piched from the huska, and with the white heels cut ofl: pour upon them five gints of boiling water. I.et them stand all night, and in the mornirg more or the clear lirian, and make it into a symp as birected sbove: in the same manner are to be mute the string of lobes and red poppres: nu: low oi ine qule llovers ill do, and more

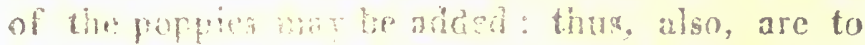

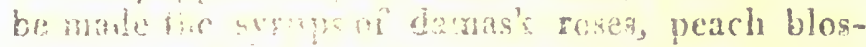

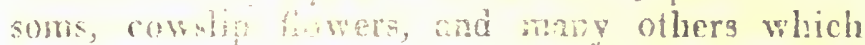
will bo romenemed for that frurpose in this bout.

syrtp of hat ?.thom, is to be made by boiling the ingertown 0 haif is quantity, wilh a lithe cingmon, ruger, and sutmeg, and then adding the sti.tin.

The surym of lenor-juice, mulberies, and fise libe, are to bo mude with a pound and halt of semar to crery pint of the clear juice, whit: is in be nelted 6.5 in the former manner.

Srup of garlic, lceks, orange-pecl, lemonpecl. mut, and many of her thirgs are to be mace. of sironer infusions of those ingredients, made as beture directed, with the first mentioned quantity of sucar added to them, when they have stomel fis coltle.

myin of mar himallows, and of poppy licads, rni sume oflere, are to be made in the ame mamu: with the stromerest decoctions that can posibily be male from those ingredionts, witl the sans: quantity of sugar as is first men. tiotued. 
Syrm of balgam is made by boiling a quarter

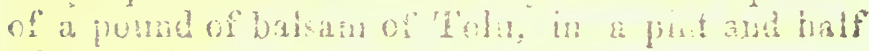

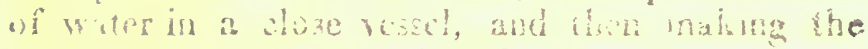

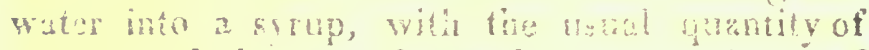
siagar: and thus way be mate sylup it any of the balsams.

Syrup of safron is made of a strong tincture of sation in wine. An ounce of saftion being put to a pint of mountain, and this, when strainch of, is to be made into a syrup, with the usual quantity of sugar.

At one time it was a custom to keep a quantity of syrups of a particular kind moder the name of honeys. They were made with boncy instead of - ugar, and some of them, which had vinegar in the comporition, were called oxymels. A few of the first hial, and very few, are worth keeping, and two or three of the latter, for they liate very farticular virtues. The way of making then is much the same with that of making syrups ; but to be cract, it may be proper just to gire some iustance of î.

Foncy of roses is the most useful, and it is in be made of an infusion of the lovers and homey in this manner. Cut the white heels from some red rece buds, and lay them to dry in a place where there is a draught of air; when they are dried, put half a pound of them into a stone jar, and pour on them three pints of boiling water; stir them rell, and let them stand twhe hours; thon press of the liquor, and when it har settied, and to it ho pounds of lomey, boil it well, and wher it is of the

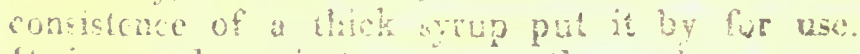

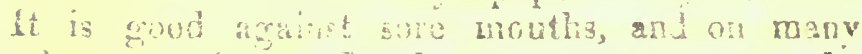
wher weave the sarse manzer mav be mate the lowey of ats flower; or with the 
juice of any plant thus mixed with loney and boiled dramo, mav be made what is called the

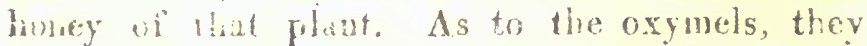
are alos note in a ery wiform manuer. The follewing are so uasinl, that it will be proper alw \% to na them in teadiness.

Fur oxmel of realice put half a pint of vi. negar intio an carshen pirkis, boil in it a quartes of an nunce of caraw areds, and the same quan-

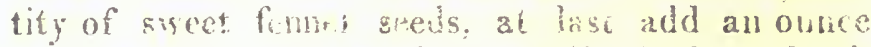
anil baif of fresh sarlic root lic d thin; let it boil a misule or tro louger, shan cover it up in stand lill cold, then pros cut the liquor, and acid teil ounces of homey, and woil it to a consistence.

For vinegu! of squills, pat into a pint of vinegar tirce ounces of dried squilis; let it stand two day's in a renlie beat, then purso out the vinegar, bui when it nas strocito sfttle, add a pound and a half of howey, su boil it to a consistence. Both these are axcoliente in astlimas.

ro thase also should bro aded, the common simple oxymei, which is matr of a pint of vinegar, and two prounds of hency boiled together to the consisterice of a syrup.

Finally, as to ointments, mothing con be so easy as the making them of the common herbs, and the expence is only so much hog's-lard. 'The lard is to be melted, and the fresh gathered leaves of the lierb are to be chopped to pices, and thrown info 洁: llo are to be briled till the leaves begin tofepl crigp, and then the lard is to be strained off. Li will be weren, and will have the virtues of the !nebl. ant muat ba called ointment of such an hub. 'lo theoe I shall take the opportunity of adding the way of making two or threc more, which, though not the produce of English herbs, 
are very useful, and our charitable shop should not be without then.

1. The white outment, called unguentum ; this is nuade by melting together four onices of ahite wax, and three ounces of speinacet, ma a...t if sallad oil, anl addug, if it be desired, thute cunces of ceness, and a dram and half of camplire: Put it is better for all commen purposes without thiese.

2. Yellow basilicon, which is made by melting together yellow wax, resin, and burgundy pitch, of each lalf a pound, in a pint of oil of olses, and arding three ounces of lurpentine.

3. Black basilicon, which is made by melting together in a pint of olive oil, yeliow wax, resin, and pitch, of each nine ounces.

4. The mereurial ointment, which is thus made: rub together in an iron mortar, a pound of quacksilver, and an ounce of turpentine; when they are well mixed, add four pounds of hog's-lard melted, and mix al! thoroughly together. The nintment of tulty is prepared with levigated tutity, and as much viper's fat as will make it into a soft ointment: these are only to be mixed together upon a marble, by working them with a linin kuife. This is for disorders of the eycs, the foregoing for the itch, and many other complaints, but it must be used cautiously. And those which were before named for old sores.

Of the same nature with the ointments, are, in some degree, the oils made by infusion of herbs and flowers in common oil. These are also very casily prepared, and an instance or two will serve to explain the making of them all. The most regarded among these is the oil of St. Jolun'swort, and that is thus made; pick clean a quarter uf a pound of the flowers of common St. John's- 
wort, poue unon them a ouart of olive oil, and let them stand toresher till the oil is of a redulish co' ur. Dil of cider is made of a pound of elder flowers, which are to be put into a quart of olive oil, and boiled tiil they are crisp, and the oil is to be then str: red off.

3. What is called the green oil, is thus nade, bruiso in a marble mortar three ounces of green chanomile, with the same quantity of bay leaves, seis-wormwoud, rue, and sweet inarjoram; then boil them in a quart of oil of olives, till they are a little crisp. "The oil is then to be poured off, and wen cold put up for use.

'These oils are used to rub the limbs when there is pain and swellings; their virtues will be found at large, under the several herbs which are the principal ingredients: and after one or other of srose methods, may be made the oil by infusion, or by boiling of any plant, or of any number of plants of like virtue.

Lastly, though herbs are now left out of the composition of piaisters, evell the melelot being now made without the herb from which it was first named: it may be preper to add the way of preparing a fur that are most useful, and ought to be kept in fanilies.

1. The common plaister is ihus made; boil tonetlier a gallon of oil, five pounds of powdered litharger, and a quart and four ounces of water. Fhen the wates is boiled away, the rest will be waited ints a plaister, bui it must be stirred all the time: thas, : d to be called diachylon. "To make diactiynt with the gomm, add to a pound of the last desribul, two ounces of galbanum, and an

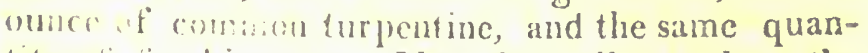
tify ot finktian Bell them all together, the

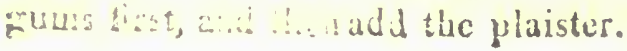


2. For a strengthning plaioter, meli two pounds of the common plaister, and aci to it half a pound of fraukinceuse, and three ounces of dragon's blood.

3. For a drawing plaister, melt together yellow $w \rightarrow$ ind yellow resin, of each three pounds, and a sound of mutton suet. This is used instead of the old riclilot plaister to dress blisters; and the blister lanister itself is made of it, only by adding half a pint of vincgar, and a pound of Spanish fies in powder, to two pounds of it, just as it begins to cool from melting. The quicksilver plaister is thus made; rub three ounces of quicksilver, with a dram of balsam of sulphur, till it no longer appear in globules, then pour in a pound of ti: common plaister melted, and mix them well togêther.

To close this chapter, I shall add a few waters made without distillation, which are very cheap and very serviceable, and the fumily shop will then be quite compleat.

I. Lime water. This is made by pouring gradually six quarts of water upo: a pound of quick lime; when it has stood to be clear, it must be poured off. If a pound of ligrnun vita wood, an ounce of liquorice root, and half an ounce of sassafras bark be added to three quarts of lime water, it is called compound lime water; and is excellent in foulnesses of the blood.

2. The blue eyc water. 'This is made by putting a dram of sal ammoniac into a pint of lime water, and letting it stand in a brass vessel, till it is of a sky blue colour.

3. Alum water is made by boiling lualf an ounce of white vitrinl, and the same quantity of alum in a quant of water, tili they are chissolved.

Ehus have we described all the drugs and com- 
positions that need he kept in the charitable shop of the fanily, which intends to relieve a neighbourhood of poor in their greatest of all distresses, that of sicliness. The diseases for which these remedies are to be used will be found enumriuted at large under the several heads of the principal ingredienis, as described in the succeerl. ing pages. It only remains to say a few works abuut the manuer of putting these things most convenientiy together, and we then shall have prepared for all that follows.

\section{CHAP. V.}

Concerning the best mathods of putting medicincs together for present taking.

W the first place, although tlicse several forms 1 of syrups, conserves, and the like, have been named, as what will be sometimes necessary. The xreat practice in the country will lie in the infusions and decoctions of the fresh plants and ronte.

The strength of these infusions and decoctions is to be froportioned to the taste: for as they are made to be swallowed in quantities, if they be made so strong as to be very disagrecable, that end will he defated: they may be rendered more pleasant by sweetening them with sugar, about an ounce of which is to be allowed to a quart; and ocrosumalls a little white wine, or a small quantity of sorrie of the cordial waters may be added to thron. The dose of either decoction or infuson, will be: in general about halt a pint, excent 
where they are intended to purge or vomit; there they mut he more carefully and exactly proportioned to the strength, than can be told in this general maner.

Of th: simple waters, about a quarter of a pint is a dose, and of the cordiul waters, less than half that guantity. 'These may be occasionally given alone; hut they are mostly intended for mixisg with other ingredients.

The ticictures are to be given in drops, from ten to an humbed, accoding to their strength and nature: but to name a general dose, it is about five and trenty drops. These, however, will be also more serviccable in mixtures, than singly. Of the purging tinctures in wine, and the elixir salutis, three, foun, or more spoonfuls is the dose.

It would be weli to keep tinctures of many of the rovis recrmmended ii rerrous cases, as cordials, avrligents, and of many other kinds; and also t: keep powcius of those roots in readiness: and thus the rommon forms of meilicines, as sent from aptharies, will be very easy.

For a julep, six anuces of one of the simple waters, two ounces of ote of the empound waters, or those made with spicit, two drams of a syrup, and fifty drops of a tincture, make a very agreable one Thus for an hysteric julcp, let the simple water be pennyrowal, the strong water the strong penucroval, the syrup that of saffron, and the tincture of castor, and it is a very pleasant julep : asid so of all the rest. If a pearl cordial be desired, it is only mixing the simple and strong waters without syrup or tincture, and adding $\mathbf{t}$ wo drams of sugrar, and half a dram of levigated oyster-shells. The apothecaries will not he pleased with this disclosing the mysteries of their pro- 
fession, but the public good is of more consequence than their pleasure.

Uraughts are only little juleps, with more powerful ingredients arded to them. An ounce and half of a simple water, three drams of a strong watro, cue dram of a syrup, and forty drops of a tincture, make a draught; but to these may be arder a simple of some power to increase the virtuc. What waters, tinctures, syrups, or powders shall be used will be determined from the case itself.

Boluscs are mado with these powders in a certain dose. A scruple or half a dram, is made into a sort of paste with syrup. The custom is to cover it with a little leaf-gold, but this is better let alone: some use leaf-brass, which is abominable.

Electuaries are to be made of powders, conserves, and syrups, they differ from boluses in this, as well as in the size, that the dose is smaller, aithough the piece taken he as large; which is owings to the conserve, that having in general little virtee in comparison of the oilier ingredients. This is the form nost convenient for inedicines that are to he taken for a contiunance of time, and the the of which needs not be so very punctually menteil.

'Whi Pron an clectuary against an habitual looseness, when it exceeds the proper bounds; mix foncether an nunce of conserve of red roses, and six drams nits sop of roves, add to these two drins of prowticed bistort root, one dram of powdered tomentill, and half a dram of toasted thubarb. Thig makes an electuary, a piece of whith, of the hicencsa of a nutmer, taken once in 1wo deyr will chect the abundance of stools, with-

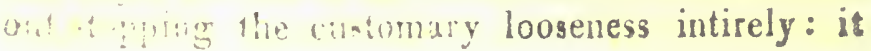




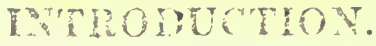

will also be a pleasant medicine. If a draught of tincture of roses, which will be described in the following pars of this work, unler the article red rose, be taken after this, it will increase the power.

In this manner the charitable lady may supply the place of the apothecary, to those who could not afiurd such assistance: and experience is so grood a cruide, that she will be able in most cases to save the expence of the doctor also: aud there will be this satisfaction in her own mind, that while she deals principally with those innocent surt of medicines which the fields afford her, she will be in very little danger of doing harm. The galenical physic perhaps will be found effectual in many more cases, by those who stick to it soleif, thal hey are aware who do not use it; as to the mirnier of medivine, that is almost entirely tiemical. It world be ide to say that chemical merlirias do not do great good; but they require $t$, be in skiful bands: when the ignorant employ them, death is more likely to be the consequence, than the relief from the disorder any other inis.

Ule useful observation may serve well to close this introduction. Opiatcs, and medicines of that lind, to compose persons to rest, and to take off pain, rill be often nucessary; but os they are the most porcefu: medicines the charitable practitioner will have to do witlal, they are the most capable of doing harm: the great care will therefore the in the right use ot these.

As there are three diforent preparations described in this book for answering this purpose, beside the opium, and that solution of it in wine, which is called laudanum, I would advise that these two litter be used very selum. A syrup 
a!.

\section{INTKDDUCTION.}

made of the juice of the wild lettuce, is an ex. cellent medicine; the suup of diacodinm, which is made of a strong decoction of polpy heads, is a litule :moner than this; and if sincthing more powerfil this: these is required, there is the asthmatic elixir. (. " or other of these nay al. most on everyoccanius sorve he purpuse; and it is almost injossible that the use of them strould be attende! with anger. I would tirerefore alvise, that opium or laublanm be very rarely used: perhaps it might be well to say, not used at all, for the others will be able in almost all cases, if not universal!y, to answer the purpose. 


\section{FAMILY HERBAL.}

A.

Acaci Tree. Acacia vera sive spina Agyptiaca.

TTHE acacia is a large bit not tall tree, with 1 prickly branches: the leares are winged, or composed if several small ones set on each side a middle rib; and the flowers are yellow. The trunk is thick, and the top spreading:

The leaves are of a bluish green; and the flowers resemble in shape pea blossoms; many of them stand together. These are succeeded by long and flatted pods. The seeds contained in each are from: four to seven; and the pod between them is very small and narrow: the breadih is where they lie.

The tree is frequent in Egypt, and there are a great many other kinds of it. No part of the ancial tree is kept in the shops; but we have firm it two drugs:

1. 'The acacia juice, and 2 . The gum arabic.

The acaria juice or succus acacia, is like liquorwe juice, hand and black. They bruise the unripre pods and seeds, and press out the juice which they erapmint to ti:is consistence. The gum

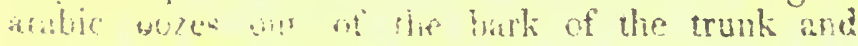


branches, as the plum-tree and cherry-tree gum do with us.

The acacia juice is an astringent but little used. The gum arabic is good in stranguries, and in coughs from a thus sharp rheum; it is to be given in solution, an ounce boiled in a quart of birley-water, or in porver in electuaries or otherwive.

What is called the German acacia is the juice of unipe sloes craporated in the same manner.

\section{Icosire. Anthora sice aconitum salutiferum.}

There are many poisonons aconites, not used: but there is one medicinal and kept in the shops: this is called the wholesome aconite and antithora.

It is a small plant, a foot high, with pale green divided leaves and yellow flowers. It grows erect, and the stalk is firm, angular, and hairy; the leaves do not stand in pairs. The flowers are large and hooded, and of a pleasant smell : the seed-ressels are membranaceoms, and the seeds black; the root is tuberous, it sometimes eonsists of one lump or knob, sometimes of nore. It is a native of Germany, but re have it in gardens. The ront is the only part used; it is sup. posed to be a renedy against poisuns, but it is not much reserded at this time.

\section{Andras-tovite. Ophioglossnm}

- InDrR mexubw: It consists of a single leaf, with is linle spilite of seeds rising from its bottom, which is supposed to resemble the tongue of a sterjent.

like toat is of an oval shape, and of a fins 
bright green colour ; it is thick and fleshy, and has no ribs or veins. The stalk on which it stands rises from a ront composed of small fibres, and is four inches or more high. 'The spike rises to ahout the same height above it; and the tongue or seedvessel is notched on each side. The whole plant is huried among the grass, and must be sought in April and May, for it dies off soon after; and nothing is seen of it till the next season.

It is a fine cooling herb, and an excellent ointment is made from it. The leaves are to be chopped to pieces, and four pounds of them are to be put into three pounds of suet and one pint of oil melted together. The whole is to be boiled till the herb is a little crisp, and then the ointment is to be strained off: it will be of a beautiful green. Some give the juice of the plant, or the powder of the dried leaves, inwardly in wounds; but this is trifling.

\section{Agrinowy. Agrimonia.}

A common English plant: it flowers in the midst of summer. It grows to a foot or more in height ; the leaves are winged, and the flowers are yellow. The root is perennial; the leaves are hairy, of a pale grcen, and notched at the edges: the stalk is single, firm, and round; the flowers stand in a long spike: they are small and numerous, and the seed-rescels which succeed them are rough like burs. 'The plant is common abuut hedges.

The leaves are used frech or tried; they have been recommended in the jaundice; but they are found by experience to be gond in the diabetes and incontinence of urine. The plant is also one of the B 2 

are fibrous. The whole plant has a peculiar and strong smell, it should be gathered when in flower.

It is an excellent vulnerary, outwardly or inwardly neerl; a conserve may be made of it in spring : and it may be given by way of tea. It is excellent in all disorders of the breast and lungs, and in those of the kidneys, and against bloody and foul urine.

\section{Allimear, or crown's allheal. Panax Coloni.}

A conmox herb in ou wet grounds with long hairy leaves and little red flowers. It grows to a foot and a half high, but the stalk is weak, sciuare, and hairy: the leaves stand two at a joint, and are of a pale giveen, notelied at the edgres, and of a strong smell; the flowers stand in clusters round the stalk at the joints. They are like those of the dead nettle kind, but smaller; the root is perenmial, and creeps.

It is an excellent wound herb, but must be used fresh. The leaves are to be bruised and laid lipon a new-made wound, without any addition; they stop the bleeding, and cure.

\section{Almoxi trie. Amygdalus.}

Butrer and sweet almonds are very different in taste, but the tree which produces them is the same; it is distinguishable at least only by the taste of the almond.

'Tis a moderately large tree, with long narrow leaves, of a beautiful green, and notched at the edges; the blossoms are large, of a pale red colour, and rery beautiful. The fruit is composed of 
three parts, a lough matter on the outside, a stone. within that, and in this shell the almond, by way of kernel. They cultivate almond trees in Fiance and Italy.

Swect almonds are excellent in emulsions, for stranguries and all disorders of the kidneys and bladeler: they ought to be blanched and beat up with barley-water into a liquor like milk ; this is also crood, in smaller quantities, for people in consump. tions and hectics.

Bitter almonds are used for their oil ; this tastes sweet, and what is called oil of sweet almonds is commonly made of them. But the cakes left after pressing afford by distillation a water that is poisonous, in the same manner as laurelwater.

Aloe puivt. Aloe.

Turne arr a great many kinds of the aloc prescried in our green-houses and stores. They are all natives of warmer climates; but of these there are only two that need be mentioned here, as the aloe kept by apothecaries, though of three kinds. is the produce of only two species. These two are the socotrine aloe-plant and the common alue.

The smontrine alue is a very heautiful plant; the kaves are like those of the pine-apple, eighteen or twoty inches lotier, prickly at the sides, and armed wih a large thom at the end. The stalk is half at vard high or more, naked at the bottom. but ormaminted at top with a long spike of tlowers: theos ale uf a longr shane and hollow, and of a beautiful red rolomr.

'T'le' socotrine or finest alus: are produced from this 
plant; the leaves are pressed gently, and the juice received in earthen vessels : $i$ is set to settle, and then dried in the sim.

The common aloe is a very fine plant; the leaves are above two feet long, and an inch thick; they are dented at the edges and prickly, and have a very sliarp thorn at the point. The stalk, when it Howers, is five or six feet high, and divided into several branches; the flowers are yellow streaked with green.

From the juice of the leaves of this plant are made the hepatic and the caballine aloes; the hepatic is made from the clearer and finer part of the juice, the caballine from the coarse sediment.

The socotrine aloes is the only kind that should be given inwardly; this may be known trom the other's, by not having their offensive smell. It is a most excellent purge; but it must not be given to women with child, nor to those: who spit blood, for it may be fatal. The best way of giving' it is in the tincture of hicrs picras.

\section{Aloes Wood. Ligmum alocs.}

Ir may be necessary to mention this wnod, as it is sometimes ned in medicine, although we are not acquainted with the tree which attords it. We are whld that the leaves are small, the fhwers modeintely large, and the fruit as big as a pigeon's egor, and woolly; and we read also that the juice of the ree, while fresh, will raise blisters on the skin, and tren cause blindness: but these accounts are very imperfect.

We see three kinds of the wond in the shops, 
and they are distinguished by three different names, calambac, common lignum aloes, and calaubour; of these the calambac is line finest and the most resinous, the calambour is almost a mere chip, the other is of a middle value between them.. They are all of the same virtue, but in diflerent degrees. They are said to be cordial and strengthening to the stomach, but we use them rery little.

\section{Trex Ayoncy. Amomum verum racemosum.}

Anonem is annther of those drugs we receive from abroad, and do not know the plants which produce them. The fruit itsolf, which is called amommm, is like the lessor ardamom, but that it is round; it consists of a slimmy husk and secels within, and is whitish, and of the bignesis of a horsc-bean. several of these sometimes are fonnd growing togrether to onc stalk in a reme brody.

The old phinicians need it as a cordial and carminative, but at present it is much nogrlocted.

\section{Consox Anowur. Amomum vulgare.}

Thougu the amomum before mentioned be not used in prescription, it is an ingredient in sone old compositions; and, being often not to be net with, it has been fomm necessary to substitute another carminative seed in its place; this grows on an Janglish plant, thence called also amomum.

The common amommu, otherwise called bas. fard stonce parsley, is frepuent about our hedgeres; it renows to three fect 'in height, but the stalk is slender, and divided into a great many branches The leaves are of a bright preen and winged, or composed of doultar rows of smaller, with au 


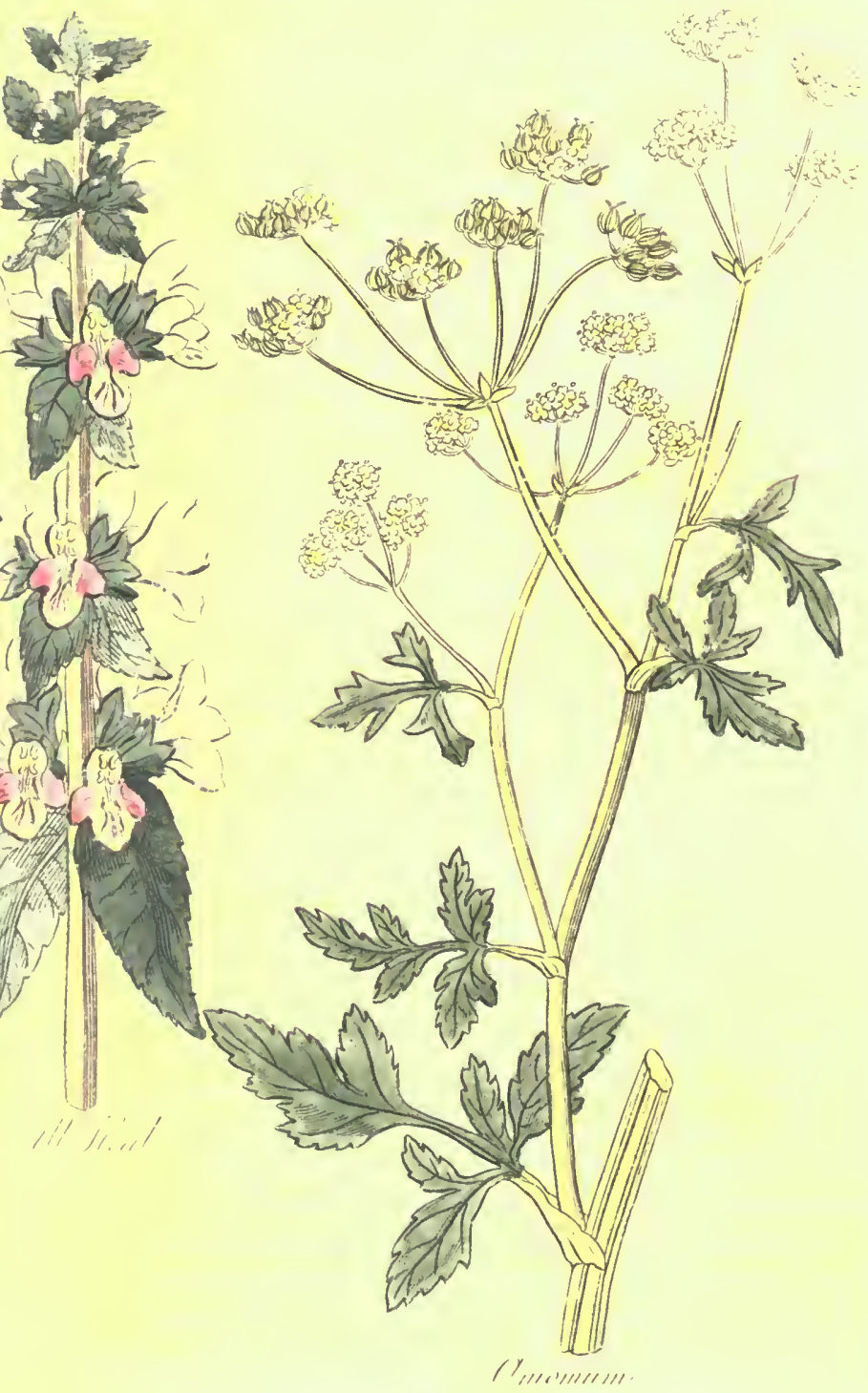



odd one at the end. There grow some large and very beautiful ones from the root; those on the stalks are smaller. The flowers grow in little umbels or clusters, at the extremities of all the branches. They are small and white. Two seeds follow each flower, and these are striated, small, and of a spicy taste: the plant is distinguished at sight from all the others of its kind, of which there are many, by the slenderness of its stalks and branches, and the smallness of the umbels; and more than all by the peculiar taste of the seeds, which have a flavour of mace.

It is proper to be particular, because the plant is worth knowing, Its root is good for all dis. eases of the urinary passages, and the seeds are good in disorders of the stomach and bowels, and also operate by urine. The quantity of a scruple given in cholics often proves an immediate cure, and they are a good ingredient in bitters.

\section{Alravet. Anchusa.}

ALKANET is a rough plant, of no great beauty, cultivated in France and Germany for the sake of its root. It grows to a foot and half high: the leaves are, large, and of a rough irregular surface, and bluish green colour; the flowers are small and purplish; the root is long, and of a deep purple. It is kept dried in the shops. It has the credit of an astringent and vulnerary; but it is little used. The best way of giving of it, is to add half an ounce to a quart of harts. horn drink; it grives a good colour, and increases the virtue 


\section{Angelica. Angelica.}

A LARGE and beautiful plant kept in our gardens, and found wild in some parts of the kingdom. It grows to eight feet in height, and the stalks robust, and divided into branches. The leaves are large, and composed each of many smaller, set upon a divided pedicle; they are notched at the edges, and of a bright grreen. 'The flowers are small, but they stund in vast clusters, of a globose form : two seeds follow each flower.

Fvery part of the plant is fragrant when bruised, and every part of it is used in medicine. The root is long and large: we use that of our own growth fresh, but the fiue fragrant dried roots are brought from Spain. The whole plant possesses the same virtues, and is cordial and sudorific; it has been always famous against pestilential and contagious diseases. The root, the stalks randied, the seeds bruised, or the water distilled from the leaves, may be used, but the sreds are the most powerful. It is also an ingredient in many compositions.

\section{Arise. Anisetm}

'TuE' aniseed used in the shops is produced by a small plunt cultivated in fields for that purpose in the island of Malta and elewhere. It grows to half a yard high, the stalks are firm, striated, and branched; the leaves which grow near the ground are rounded and divided only into three parts; those on the stalks are cut into slender divisions. The finwers are small, but they grow in large umbels nt the top of the branches, and two seeds follow kuch; these are the aniseed. 
As much bruised aniseed as will lie on a sixpence is excellent in cholic. 'Tis also good in indigestions, and other complaints of the stomach.

\section{Apples of Love. Poma Amoris.}

These are large juicy fruits, but they are produced not on a tree, but on a small and low plant. The stalks are weak, and divided into many branches; the leaves are large, but they are com posed of many small ones set on a divided stalk, and they are of a faint yellowish green colour. The flowers are small and yellow, the fruit is large, and, when ripe, of a red coluur; it contains a soft juicy pulp and the seeds.

The plant is a kind of nightshade, we cultivate it in gardens. The Italians eat the firuit as we do cucumbers. 'The juice is cooling, and is good externally used in eruptions on the skin, and in diseases of the eyes, where a sharp humour is troublesome.

\section{Archisgei. Lamizm Album.}

A comon wild plant, more vulgarly called the dead-nettle. It grows about our hedges, it is a foot high, and has leares shaped like those of the nettle, but they do not sting. The stalk is square, and the leaves are hairy; the flowers are larse and white; they stand at the joints where the leaves are set on, and are very pretty. The leaves stand in pairs, and the root creeps under the surface.

'The flowers are the only part used; they are to be gathered in May, and made into conserve. A pound of them is to be beat up with two pound 
and a half of sugar. They may also be dried. They are excellent in the whites, and all other weak: nesses.

There is a little plant with red flowers called also the red archangel, or red dead-nettle. It is common under the hedges, and in gardens; the stalks are square and weak, the leaves are short and notched at the edges, and the flowers small and red; the plant is not above four or five inches high, and these flowers grow near the tops among the leaves. They are in shape like those of the white archangel, but small.

The herb is used fresh or dried, and the flowers. The decoction is good for floodings, bleedings at the nose, spitting of blood, or any kind of hemolshaçe. It also stops blood, bruised and applied out. wardly.

Arrach, or Sminerng Arrach. Atriplex olida.

A sMare wild plant that grows about farm-yards, and in waste grounds. The stalks are a foot long, but weak; they seldom stand upright; they are striated, and of a pale sreen. The leaves are small, short, and rounded, of a bluish green colour, and of the breadth of a shilling or less. The flowers are inconsiderable, and the sceds small, but they stand in clusters at the tops of the branches, and have a greenish white appearance. The whole plant is covered with a sort of moist dust in large. particles, and has a most unpleasant smell. It is in be used fresh gathered, for it loses its virtue in drying. A syrup may be made of a pint of its juice and two pourds of sugar, and will keep all the year. 'The leaves also may be beat into a consesve, with three times their weight of sugar. In An of these forms it is an excellent medicine in 
all hysteric complaints. It cures fits, and promotes the inenses, and the necessary evacuations after delivery.

There is another kind of arrach also mentioned by medical writers, and called gurden arrach ; it is an annua! raised from sced, for the use of the kitchen. It grows to a yard high, and the leaves are broad: those which grow from the root have a little leaf also on ach side of the base. They are covered with a wet dust like the other kind. These leaves are cooling and softening; they are good in clysters, but they are less used, and less valuable than the other.

\section{Arov. Arun.}

A verY common plant under our hedges, and more vulgarly called cuckowpint, and, by the children, lord and lady. The root is of the bigness and shape of a wahnt, brown on the outside and white within, and this, as well as the whole plant, is of a sharp and acrid taste. This root lies deep. The leaves are large and shaped like the bearded head of an arrow, of a strong green colour, and sometimes spotted. In April and May rise among these thick stalks, supporting a very singular kind of flower, the pointal of which is long, thick, fleshy, and of a red or white colour, and the whole surrounded with a green membranaceous case. Afterwards this case and the pointal fall off, and there remains only the stem supporting a quantity of berries, which are ripe in autumn, and are then of a fine red colour.

The root is the part used. It is an excellent medicine in palsies. Half one of the roots, fresh 
grathered and bruised, will sometimes restore the specch at once; and a continucd use of them goes a great way toward a curc. It is also good in scorbutic cases, and in all inward obstructions. Sone dry and powder it, but it then loses almost all its virtue.

\section{Arsmint on Water-pepper. Persicaria Crens.}

A comson wild herb, neglected, but of great virtues. It grows every where about ditches, and in watery places. It is a fout and a half high ; the stalks are weak, green or reddish, and jointed. The leaves are loug and narrow, like those of the peach tree, of a bright green, not spotted, and even at the edges. The flowers stand at the tops of the stalks in slender spikes, of a greenish white. As there are sereral other kinds of arsmart, and most of them different from this in their nature and qualities, great care is to be taken to gather the right. It must have no spot upon the middle of the leaf. 'There is another common kind of arsmart with such a spot, and with thicker stalks, and thick pikes of reddish flowers, which has none of its virtue.

The right arsmart is an excellent medicine in nbstructions of urine, in the gravel and stone: and in the jaundice and begiuning of dropsies it has done prreat cures. The juice of the fresh gathered plant is the best way of giving it. Outwardly it is good to cleanse old ulcers.

\section{Amtrnoke. Cinata.}

The: ront of the enmmon articlinkre, or liartichoke, cullivated for our tables, is an excellent medicine. The plame itself is of the thistle-kind. and its 
head, which we see at table, owes much of its bigness and fleshiness to culture. The leaves are large, and divided into many parts, and often they are prickly. The stem is robust and striated, and the head is formed of large scales; the flowers are of the thistle-kind, and the seerls are, as in the thistles, winged with down.

The root fresh gathered, sliced, and boiled in water, six ounces to a cuart of the water, makes a decoction, which works by urine, and I have known it alone cure a jaundice.

\section{Asaribicca. Aselizm.}

A veny little and low plant found wild in many farts of Lurope, and commen in our gardens. The roots creep aboit the surfare of the ground, the leares grow singly from them, and there is no stem or stalk. Fach leaf has its separate footstalk three or four inches long, and the leaf itself is roundish, of a dark green, and fleshy : the flowers small and of a dusky colour, and they stand near the grromind.

The roots are the most valuable part; the juice of them may be griven in small dases, or they maty be ury and given in powder or infusion. It works very powerfully by urine, and is good in obstructions of the menses, and in jaundices and aropies.

\section{Trix 1six. Fraxinus.}

i comon tree in our hedges and wonds. The bark of the branches is grey, and the leaves are winged; the small ones of which they are composed are oblong and dented. The Howers ure of a whitish green, and come before the leaves. 
the sceds are what they call ash-keys, these ripen in september.

The bark of the young branches is good in olstructions of the liver and spleen, and there. fore is of great service in dropsies, jaundice, and other complaints of that origin: it works by urine. The sceds have the same virtue, but in a less degree.

\section{The Maxis 1sir. Hraximus minore folio.}

Tus is a lower tree than the cominon ash, and is not a native of our kingdom, but is frequent in Italy, where the manna is gathered from its leaves and branches.

The bark of this tree is paler than that of our common ash, and the leaves are composed of smaller and narrower parts, but the flower and fruit differ very litle.

They lave also in Calabria another low ashtree, which has the backs of the leaves smaller than onrs, and Hatter and more rounded, and from this also they collect mama for the use of the apotherariss. The manna is a sweet or honey juice that maturally sweats ont of the bark and leaves in hot vadther. 'The' finest manna of all is that whici onzes ont of the leaves; this is in small pieces. It flows ont of the ribs of the leapes in August, in the heat of the day, and soon hardens into this form. They get the greateat quantitien of all, by cutting the bark of the trunk and branches, and this is often larege and flaky. but it is yellowish. That which is llaky, white. and hollow, has issucd out of itsolf, and is much better.

Manma is a nost cxcollent purge, very gentle, and without any after astringency. There is at 
kud of manna used in France, called the Briancon minina; this is produced by the larch-tree : and therce is another lind more rare, called Persian mania; this is produced by the shrub callea allagi, a kind of broom, or nearly allied to it. But these are ocarce with us.

Asparagls. Asparagus satizus.

TH1E asparagus plant is one whose root is urcful in medicine, although a different part of it be eaten at the table. Its virtues are not unlike those of the artichoke root but grenter.

The asparagus is a wild plant in many parts of Englaud about the sea-coasts; and its root, in this wild state, is better than that of the cultivated plaus, but its shoots have not that fine fleshy fuluess. The plant, whon full grown, is three fect high, and very much branched, and the leaves are fine and of a pale grcen; the flowers are snall and greenish, but the berries which succeed them, are as big as pease and red.

The root is a powerful diuretic, and is good in all obstructions of the viscera. It has been known singly to perform cures in jaundices and dropsies. It is best given in decoction.

Aspuodel. Asphodelus terus ramosus albus.

AN clecant garden flower, a native of Italy, and preserved with us more for its beauty than its use, though sometimes taken as a medicine. It grows to three feet in height, and the stalk divicies info three or four branches towards the top. The flowers are white, and they stand in spilice nn the tops of these divisions. Tlicy are 
streaked with purple on the top, and have yel. low threads in the middle. The leaves are long arir? narrow, hollowed and sharp-pointed; the root is composed of several oblong lumps. The roce is the part used in medicine, and it is said to be good against all obstructions, particularly against those of the menses.

There is another kind of asphodel with yellow flowers, the root of which is said to possess the same virtues, but it is more rarely used than the other.

\section{The Asafortida Prant. Asafoctida herbe.}

THIS is a Persian plant, and is a very fall and robust one. It grows 10 nine feet higi, and the stalks are as thick as in child's leg; they are hollow and divided toxiand the fops into several branches. The luves are very large, and cormposed of mut smillor set unon a divided rib. Whey resmble in some degiee the ieaves of the piuny. The lare ones rise immediately tion the root, and smiller of the same form swand at distances upon the stalks, one at each foint. The flowers are singly very small, but they stand in vast clusters or umbels at the tops of the stalks; and the seeds follow two after each thower; they are large, broad, and striated, and have the same smell with the crum, but not so stroing. 'The root is very long and thick; it is black on the ontside and white within, and is full of a thick juice of a strong imell, which, when hardened, is asafoetida such as we see.

No part of the plant is used but only this gum or hardened juice of the root. Ther cut off the top of the root and let the juice thet rises ism the wound dry. It becumes 
reduibl on the ontside and white within, and is the asafoetidia of the shops. An excellent medicine in all terrous disonders; it may be giren alone rolled up inte pills, no way better.

\section{Avens. Carryophyllata.}

A COMMON wild plant neglected, but worthy of our notice. It grows about hedges, and rises to fourteen inches high; the stalk is firm and slender, and is divided into several branches. The leaves are large and rough, the stalk also hairy. The leaves that grow from the root are insucd they consist of three pair of small ones, and nue mula larger at the end. Those on the stalk are smaller, and consist of fewer parts ; but ctherwive they are like. The flowers are small and clitow; they are sicceeded by rough heads, as big as a horse bean, composed of many seeds with houked flaments. The root is longish and large, of a firm substance, reddich colour, and very fragrant spicy smell; it is better than many drugs kept in the shops.

It is a cordial and sudorific. It is good in nervous complaints, and I have known it alone cure intermittent fevers, where the bark has been unsuccessful.

\section{B.}

\section{BaLm. . Nelissa.}

A PLINT common inour gardens. It grows to swo feet in height, and the stalks are robust, square, and hairy. 'The leaves are oblong, broad, pointed at the end, and dentated about the edges, and they stand two at a joint; the flowers are small 
and white, but they have large rough tops, which remain after they are fallen. "They stand in circularclusters round the stalk at the upper joints: the whole plant is of a fragrant smell. The root creeps and spreads abundantly, the plant is in flower in July.

Fresh balm is much better than dry, for it loses its fragrancy in drying. The best way of taking it is in tea ; it is good for disorders of the hoad and stomach.

\section{The Balm of Gilead Shrub. Bulsamum syri- acum rutée folio}

THIS is an eastern shrub; it grows to five or six feet $h g_{i}$, and the branches are very tough, and, when broken, iave a fragrant smell. The learis are like those of rue, only larger and of a deper green; the flowers are moderately large and like pea-bu.ssoms; they are of a pale purpiat? hue mixed with white. 'The seeds are yellow and very fragrant, they are contained in a. kiwid of pods.

In part of the shrub is used, but only the balsan which is obtained from it ; the finest kid ruas from the tree, of itself: there is a second sort obrained by boiling the twiga and young shoots: and a third, coarser, which rises to the top of the water, after the purer sort has been taken off. 'This last is almost the only hind we see, and even this is very fiequently adulterated.

It is a very fine balsamic and detergent; it is sood in the whites, and all wealinesses; and it is cordial af the satne time that it acts as a balsam : it is bu'st taken alone upon sugar. 
"The Balsam of Capivi-Tree. Arbor balsamifera fructu monosperino.

THIS is a large trec. The wood is of a red colour, and fine grain; the bark is brown; the leaves are broad, short, and pointed at the end, and are of a dark green on the upper side, and a mealy white underveath. The flowers are as large as apple blossoms, and of a pale colour; the fruit is a pod containing only one seed, which is as big as a nut, and the kernel is sweet ant of a good taste.

The tree is frequent in the Brasils. Wre use no part of it, but ofiy the balsam which runs out at wounds they make in the trunk in sumner; it is thin like oil. Jt has the same virtues with turpentine, but is more powerful; it is excellent in the whites, and it is good in all complaints of the urinary passages. It may be taken alone on sligar.

The Balsam of Peru-Tree. Arbor balsamifera Peruriana.

'THIS is a shrub of eight feet high, with *lender and tough branches. The leaves are very long and narrow; the flowers are yellow and large, and the fruit is crooked. The whole plant has a fragrant smell, especially the young shonts and the buds.

The balsam of Peru is procured from the fragrant tops of this shrub, by boiling them in water; the blackish liquor rises like oil to the top, and, when cold, it is the balsam of Peru. There is a white balsam of Peru, very fragrant and fine, but it is scarce. This is the produce of 
the same tree, hut it oores natura!ly from the cracks un tlie bark.

The black balsan of Peru is a cordial as well as at halsam; it is excellent in disorders of the breast, and in all obstructions of the viscera; ton drops at a time griver on sugar, and co:tinued daily, have cured astimas and begimingr consumptions. It also promotes the masese, and is exvellent in suppressions of urine. Cutwardly applied it heals firesh wounds.

The Barsam of Tolu-Tree. Ábor balsamifera I'olutuna.

THIS is a kind of pine tree. It does not grow to any great heiglit, but spreads into a great quantity of branches. The leaves are long and very siender, and of a deep green; the bark is of a reddish white, and the fruit is a small cone, brown and hard.

No part of the iree is used but the balsam only which comes from it. They wound the trumk in lot scitsons, and this liguid resin flows out, which they jut up into shells for exportafion: it is thick, brown, and very fragrast It is excellent in consumptions, and other disord: of the breast, and way be griven in pills balsamic syrup of the apsthecaries is made fou it, and possesses a great deal of its virfues.

The Banung-lisen. Bublis.

TIITS is a will himel in some parts of Englant, but it is common every where in gardens; it arows to eight or ten feet high in an ir16 sular manuer, and much branched. 'The bark 



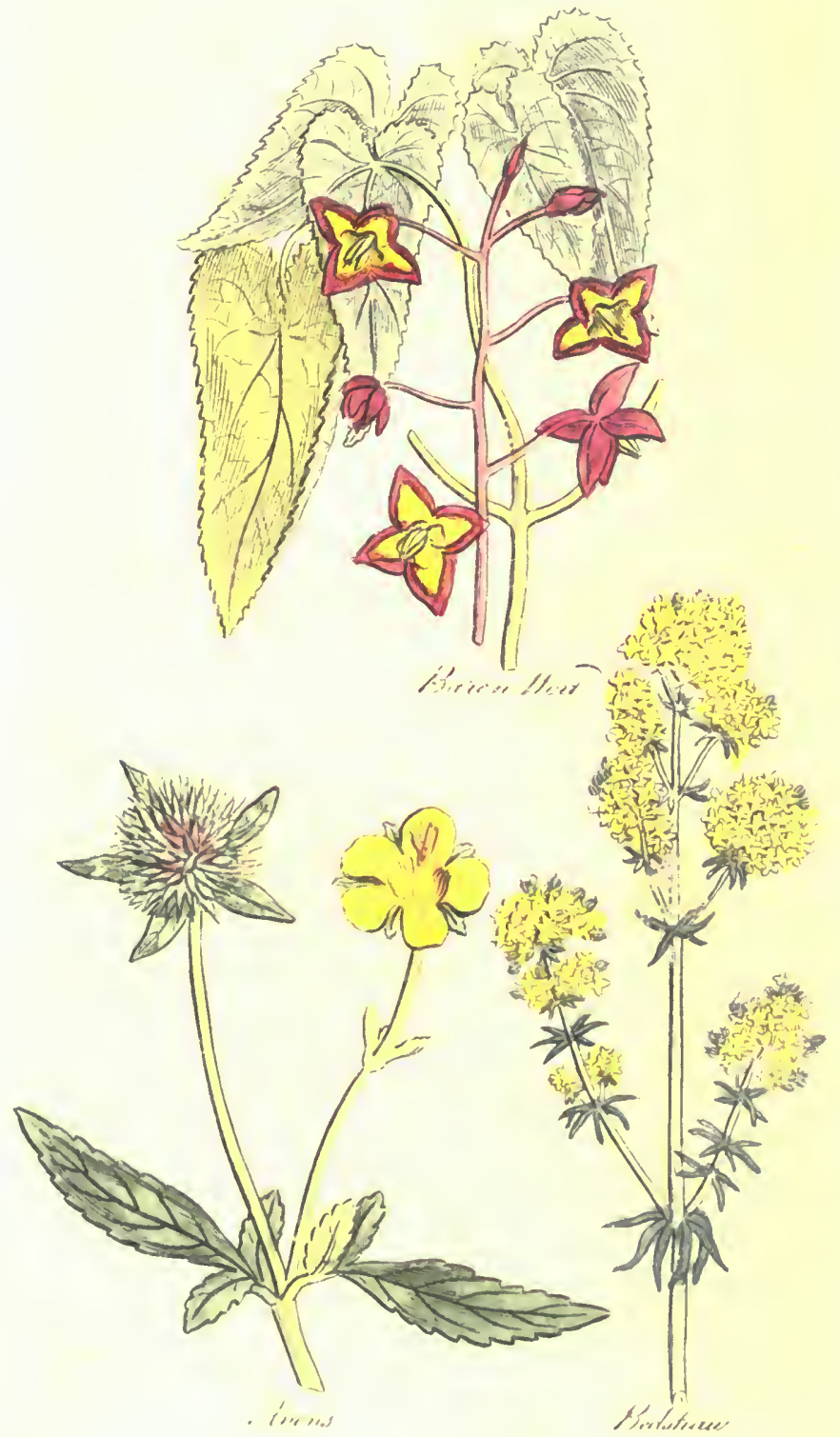


is whitish, and there are abundance of priskles shont the branches. The leaves are of an oval curve, and strong green colour; and are indented about the edges. The flowers are small and of a pale rellowish colour; the fruit is sufficiently known; the berries are oblong, red, and of a simr taste. The branches are bittle, and, under the pale outer rind, there is another ycllow and thicker. This is the part used in medicine; it is excellent in the jaumilice, and has often cured it singly. It is also good in all obsiructions. The best way to give it io infuserin boiling water.

\section{Barley. Hordeum.}

THE hariey uacd in medicine is the same with that of which bread is made, and which serves the brower and distiller in their several capacities. It is known at sight from wheat, when growing, for it is not so tall, and the leaves are smaller and narrower. A long beard grows from rach grain in the car and the car is composed of two ivis of them.

We use this grain in two forms, the one called French batley, and the other pearl barley. The French harley is skinned, and has the ends ground off : the pearl barley is reduced by a longer grimegry to a litte round whitelump. The pear! barley makes the funer and more elegant barleywater, but the French barley makes the best. It is excellent in leat of urine, and in all gravelly cases, and is a good drink in most acute diseases, where diluting is requireu: it is also in some degree sourishing.

BarReN wort. Epidemium.

A SIVGLLAR and very preity plent, nstive of 
liugland, but not common. It grows in woods, and has beanitifu! purple and yellow flowers. It is a foot high, 'The leaves are oval and heart-fashioned, deeply indented at the edgres, and of a dinsky green. The stalks which produce the flowers, are weak, brittle, and generally crooked; the flowers stand in a kind of very longe spike, ten or a dozen upon the top; they are small, but very sungular and conspicuous; they are purple on the back with a red edge, and yellow in the midde. The root is fibrous and crecping.

It was an opinion with the old writers, that this plant produced no flowers; but the occasion is casily known. When it stands cxposed to sun, it seldom does flower; we sce that in gardens where it is planted in such situations, for it will stand many vears withont flowering; but our roods favour it, being dark and damp: the old nesple saw it in warmer climates, and under an unfayourable exposure. 'Theycailed it from this circumstance, as well as from its virtues, by a nane, which expressed being barren and fruitless.

The people in the north give milk in which the roots have been boiled, to the females of the domstic animals when they are ruming after the males, and they say it has the certain effect of stopping the natural motions. Platin sense leadis these sort of penple to many things. 'They lave from this been tall to give it to young wome: of́plust habits, subject to violent bysteric complaints. and I am assured with great sucress; they grive the decoction of the root made strong and swetenel. "Twas a coarse allusim that led the fo the practice, but it succeds in cases that foit all the parade of common practice. It is said that, if they take it in too large quantity, it ren!- 


\section{FAIILY HERBAL.}

ders them stupid for some hours, but no ill consequence has attended this.

\section{The Bay Tree. Laurus.}

THE bay is a native of Spain and Italy, where it grows to a large tree: we kecp it in gardens, but it scldom rises to more than the figure and height of a shrub with us. The wood is not strong but spongy and friable; the leares remain green all winter; the bark of the large branche's is of a dusky brown, that of the twigs reddish; the leaves are long and somewhat broad, pointed at the cud and very fragrant : the flowers are very small and inconsiderable ; their colour is whitish, they appear in Mar, but are not regraded: the herries are ripe in the latter end of aunum, and are large and black, consisting of two parts within the same skin.

Whe berries are dried, and arc the part of the tree mostly used; but the leaves also have great virtue. The berries are given in powder or infusion; they are good in obstructions, and in cholics. They promote urine, and the evacuations after delivery. The leares are cordial and grood in ald nervous complaints. Paralytic people would find great benefit from small doses of them often repeated; and four or five doses have somerimes cured agnes. They are to be put fresh into an oven, and, when they are crisp, reduced to powder.

Basil. Ocumum rulgare majus.

IBASIL in a small herb, native of warmer cruntries, but not uncommon in our gardens; it is bushy and branched; the stalks are square. 
aisl the leaves stand two at each joint. They art: broad and short, and somewhat inderitcd at the edges. The flowers are smali and white, and are of the shape of those of the dead nettle; they stand on the upper parts of the branches in loose spikes. The whole plant has a very fraroant smell.

Basil is little used, but it deserves to be much more. A tea made of the green plant is excellent against all obstructions. No simple is more ef fectual for gently promoting the mirnses, and for removing those complaints which naturally attend their stop page.

There are two or three other kinds of basil, but they have uot equal virtue.

The Boeling Tref. Agbor biellium fercus.

WE are very well arquainted with the gum, or rather gum resin called bdellium, but we know very little of the tree from which it is produced; the best description we have of it, amounts to no morc than that it is moderatety lasge, bushy, and full of branches with pricklea upon them, and will oblong and broad leaves deeply indruted at the edges, so that they resemble oak-lcaves; and that, wheu the young shoots are hronen, they yield a milky juice. But even this dres not come upon certainty, that is, we are not assured that this tree produces the very gum vie sce. This is of a red brown colour, and bitterish taste.

It is a good medicine in obstructions of the liver and spleen, but it is not much used. 
The Bean. Fabe.

THE common garden-bean is sufficiently known; it grows to a yard high, its stalks are angular, and the leaves, which are of the winged kind, stand one at each joint; the flowers are white spotted with black, and are finely scented. The pods aud their seeds need not be described.

It has been customary to distil a water from bean-flowers, and use it to soften the skin, but common distilled water does as well. It is otherwise with the water of the bean-pods. These are to be bruised, when the beans are half ripe in them, and distilled with water in a common glembic. The water is a very gentle carminative, without any heat or acridness; this is excellent for children's gripes.

The Malacca Bean-Tree. Anacardiam l: gitimum.

THIS is a large tree, native of Malabar and the Plilippine islands; it grows to the height and bigness of our tallest elms, and has much oif their manner of growth, as to the branches. The leaves are vastly large, of an oblong figure, and obtuse; the flowers are small and white, they grow in bunches, and have somewhat of the smell of the syringa flower but fainter. The fruit is of the bigness of a pear, and much of the same shape; it is of a deep red, when ripc, and of a pleasant taste; the kernel is not within this, as is commonly the case in fruits, but it haugs out louse at the end. This kernel or seed is of the shune of an heart; it is as big as an olive, 
and has a dusky red cont or shell, but it is white within. This is the part used in medieinc, for the whole fruit is not regarded. The anacardium, or kernel, is said to be a cordial, and a strengthener of the nerves, but we do not much use it. There is a very sharp liquor between the outer and inner rinds of the shell, which will take away freckles from the skin, but it is so sharp that the ladies must be cautious how they use it.

\section{The West-India-Bean, or Cashew Nut-Tree. Arbor acvjou vulgo cajou.}

I' $\mathbf{T}$ appears by the description of the anacardium how very improperly it is called a nut, for it is the kernel of a large fruit, though growing in a singular mamer. 'The case is just. the same with respect to the Cashew unt, for it is neither a nut nor a bean, any more than the other: but it is necessary to keep to the common nomes, and it is proper they should be mentioned together.

The tree which produces it is large and spreading: the bark is of a pale colour, rough and eracked, and the wood is brittle. "Ilue leaves are half a foot long, and two or three inches broad, blunt at the eud, and of at fine green colour. 'Tlue flowers are smail, but they grow in tufts angether. The fruit is of the ligness and shape of a pear, and of an orange and purple colour mixt toguther; the Cacluev nut or bean, as it is called. langs maked from the buttum of this fruit. It is of the higness of a marden bean, and indented in the manner of a lifuey; it is of a greyish colour, and consists of i shelly covering, and a fine white fleshy sul. 
stance within, as sweet as an almond. Between the two coats of this shell, as between those of the anacardium, there is a sharp and caustic oil. which serves in the same manner as the other to take off freckles, but it must be used with great caution. It actually burus the skin, so that it must be suffered to lie on only a few moments : and ten when used ever so cautiously, it sometimus causes mischief.

\section{The Bengat Bean-tree. Fala Bengalensis.}

A LARGE trec, native of the East, and not mulike our plum-tree. It is thirty or forty feet bigh; the leaves are roundish, bet sharp-pointed, and of a deep green; they are finely indented, and of a firm texture. The flowers are large and white; they resemble, in all respects, the blossoms of our plum-trees. The fruit is a kind of plum, of a loug shape, with a small quantity of fleshy matter, an! it very large stone. It is a kind of myrobolan, but is not exactly the same with any that we use.

'The Bengal bean, as it is called, is an irregular production of this tree: it is very ill-named a bean; it is truly a gall like those of the oak; but it does not rise like them from the wood or leaves, but from the fruit of this particular plum. It is as broad as a walunt, but flatted, and hollowed in the center; its original is this: There is a little black fly frequent in that cou:ltry, which lodges its eggs in the unripe fruit of this particular plum, as we have insects in Eng-land, which always choose a particular plant, and a particular part for that purpose. The fly always strikes the froit while it is green, and has but the rudiments of the stone. It grows dis- 
tempered from the wound, and the stone never ripens in it, but it takes this singular form.

It is an excollent astringent. It is of the nature of the galls of the oak, but less violently binding. It is gnod in all purgings and bloody fluxes, and argainst the overflowing of the menses.

\section{Bein's-Brefch. Acanthus.}

A VERY bcautiful plant native of Italy. and some other wam parts of Europe, and kept is: our gardens. It grows a yard high; the stalk is thick, round, and fleshy; the leaves grow from the root, and are a foot long, four inches broad, very beautifully notched at the etires, and of a dark glossy green. The flowers stitnd in a kind of thick short spike at the top of the stalks, intermixed with small leaves ; these flowers are large, white, and gaping. The whole plant, when in flower, makes a very beantiful appearance. "The root creeps.

This plant is not so much kunwn in medicine as it decerves. The root being cut in slices and boiled in water, makes an excellent diuretic decotion. It was a great medicine with all eminent apothecary of Peterborough, and lie gave more relief with it in the gravel and stone, than any other medicine would allurd.

\section{Brill's-root. Helleborus niger.}

A I,OW and singular plant, but not without its beatel: it is a mative of many parts of Fonropre, hut we have it ouly in gardens: the leaves are larme; emels rises from the root ingly, on a funt-ctall: of six inches long, and is the suded inte nise patata like fingers on a liand: 


\section{FAMITY MEREAL.}

somotimes the divisions are fewer. The nowers are buy large and beautiful, they are as big as a common single rose, or nearly so ; they are white, reddish, or greenish, according to the time of their having been open; and they stand each on a single stalk, which rises from the root, and has nn leaves on it. It flowers in January.

The root is an excellent purge, it works briskly but safely; it destroys worms, and is good in dropsics, jaundice, and many other diseases, and even in madness. But it is very necessary to kcep it in one's own garden, for, if the root be bought, they commonly sell that of the green flowered. wild or bastard hellebore in its place, which is a rough medicine.

\section{Ladies' Bedstraw. Gallium luteun.}

A PRETTY wild plant, frequent about hedges in June and the succeeding months. The stalk is weak and two feet high; the leares are of a blackish green, and small; and the flowers are yellow. The stalk is angular and whitish, rery trittle, and seldom straight; the learcs stand a great many at each joint, and are small, narrow, and dieposed about the stalk like the rowcls of a spur: the flowers grow in great tufts on the tops of the stalks, so that they make a very conspicuons afpearance, though singly they are very small.

This herb is little regarded, but it has very great virtue; it should be gather d. when the flowers are not quite blown, and dried in the shade. An infusion of it will cure the most violent Wheedings at the nose, and alnost all other evacuations of blood. 


\section{BeEt. Bata alba.}

A COMMON garden plant caten at wur tables, but these often afford medicines as in ll as food. The white beet, which is the nedicinal kind, grows three or four feet high. The stalk is robust and strong, the leaves are broad and undulated, the flowers are inconsiderable, they are of a greenish white colour; the ront is larget and long.

The juice of fresh beet-root is an exceilcut remedy for the head-ach, and tooth-ach whes the whole jaw is affected; it is to be snuffed up the nose to promote sncezing.

The red bect-root is good for the same purpose, but it is not so strong as the white.

\section{Whate Behen. Behen album.}

A COMMON wild plant in our corn fields. It is two feet ligh ; the stalks are weak and often crooked; but they are thick enough, round, and of a whitish green colour. 'The leaves are oblong, broad, and of a fine blue green colour, not dented at all at the edges, and they grow two at every joint; the joints of the stalks where they grow, are swelled and large, and the leares have no stalks. 'The flowers are white, moderately large, and prickly. They stand upon a husk which seems blown up with wind.

This is one of those plants of our own growth, that have inore ritue than people inacrime. The ront. which is long, white, and woody, is to be gathered lefore the waths rise, and dried. An infusion is one of the but renedics known for nervous complaints: it in iil not take place against 


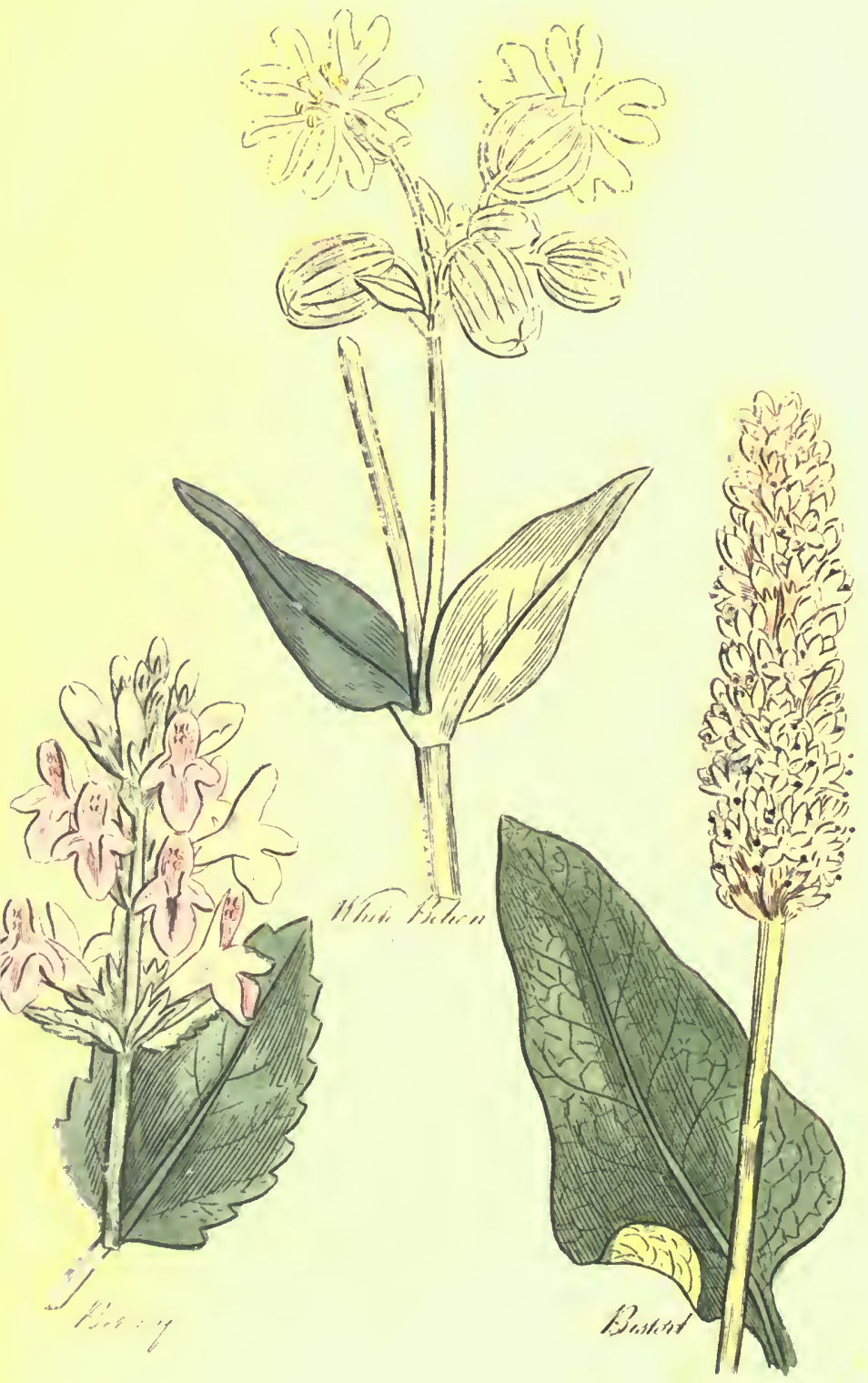



siblent present disorder ; but is an exollent pre. servative, taken cautiously.

\section{RED Beres. Limonium majus.}

A COMMON wild plant abont our sea-coasts, and a very pretty one. It grows to a foot in height; the stalks are naked, and the flowers red; and, in their disposition, they somewhat resemble lavender, whence the plant is also called by some sea lavender. About the bottoms of the stalks stand clusters of large and broad lcaves, rounded at the ends, of a deep green colour and fattish substance; these rise immediately from the root, and the stalks grow up among them. The stalks are very tough and strong, and branched, and of a paler green : the root is long and reddish.

'The people in Essex cure themselves of purgings, and of overflowings of the menses, with an infusion of this root; and it is a very great medicine, though little known. It is to be gathered, as soon as the youg leaves appear, cleaned and dried; it mav be taken in powderhalf a drachm for a dose. These are not the white and red behen wits of the old witers on physick, but they are better.

\section{The Bey-Nut-tree. Balamus myrepsica.}

Tlits is an Arabian tree, not very large, but exceedingly singular in the nature of its leaves. 'Tisey are composed of a great number of small rodinlish parts, growing at the extremities of string branched fiot-stalks. The leaves fald first, and these fort-stalks long after. When the leaves are fallen, and the stalks remain, 
the tree makes a very singular appearance. The fruit is a pod, long, but slender, and containing two seeds: these are what we call the ben-nuts. 'They are of an oblong figure, and irregularly rigid; the shell is liard, but the loernel fat, soft, and oily, and of a bitter taste.

The kernel operates by vomit and stool violently, and is seldom used. It affords an oil which has neither smell nor taste, and which will keep a loug tiune without growing rancid.

The Bensands Tree. Arbor benzionifera.

A BEIU'IIFUL tree frequent in the East, and there affording the fine fragrant resin of its name: it is also of the growth of America, and thrive there, but it yields no resin. It is a moderacely tall tree; the bark is smouth and brown; the leaves are broad, oblong, and not unlike those of the lemon-tree. The flowers are whitish, and very inconsiderable. The fruit is as big as a nutmeg, and consists of a fleshy substance on the outside, and a kernel inclosed in a thin and brittle shell within. 'The tree is properly of the baytree kind.

They curt the branches of the benjanin trees, and the juice which flows out hardens by de. grees into that redish and white fragrant resin we see. It is an excellent medicine in disorders of the breast and lungs: and a tiucture of it macie with spirit of wine makes water milhy, and this mixture is called rirgins'-milk; it is good to cleanse the skin.

Won Peтory. Butonica sgluesiris.

A COMMON whld herb, unt of very great rir. 
tue. It is frequent in our woods and among bushes. and flower's in June. 'The stalks are almost naked ald a foot high, and the flowers are purple. incre grow many leaves from the root; they have ling stallis, and are broad, abore an inch long, of a blackish green colour, and hairy, blunt at the point, and indented about the edges. The stalks are square, of a dark colour, hairy, and not very strong. The leares of them are very few, and very distant; but they stand two It it joint, and are like the others. The flowers atand at the fops in form of a kind of thick short srike; they are small and purple, and of the shape of the flowers of mint.

Betony is to be gathered when just moing to flower. It is excellent for disorders of the head, and for all nervous complaints. The habitual use of it will cure the most inveterate heal-aches. It may be taken as tea or dried and powdered. Somemix it with tobacco and smoke it, but this is a more uncertain method.

Where is a tall plant with small purple flowers sorowing by waters, thence and from the shape of the leaves called water betony, but it has none of the virtues of this plant; it is a kind of tig-wort, Bind pessesses the virtues of that plant, but in an inferior degree.

\section{Bixd Meed. Conrolvulus major.}

A COMMON wild plant which climbs about onr hedges, and bears very large white flowers. The stalks are weak and slcuder, but very tough, sis or eight fect long, and twist about any thing that can support them. The leaves are large, and of the shape of an arrow-head, bearded at the base, and sharp at the point: they staud 
singly, not in pairs, and are of a pale green cou lour. The howers are of tho breadth of a crownpiece at the mouth, and narrower to the base, bedl. fashioned, and periestly white. The root is long and stender.

In Northamptonshire the poor people use the root of this plant fresls gathered and boiled in ale as a purge; they save the expence of the apolhecary, and auswer the purpose better than any one thing would do for them. It would nauseate a delicate stomach, but, for people of their strong constitution, there is sot a betier purge.

\section{'The Brluberr Bush. Vaccinia nigra.}

A I.TTCLE tough shäubly plant, common in vur bugary woods, and upon wet heaths. T'he stalks are tough, angular. and green; the leaves are small; they stand singly, not in pairs, and are broad, short, and indented about the cdges. The flowers are small but protty, their colour is a faint red, and they are hollow like a cup. Wine berries are as farge as the biggest pea, they are of a blackish colour, and of a pleasant taste.

A sylup marle of the juice of billberries, when not over lipe, is cooling and hindiug ; it is a pleasant and gentlo medicine for women whose nenses are: apt to be too redundaut, taken for a week before the tiule.

The Bircu-'Tres. Beiu'u.

A 'TALl, and handsone tier, common in our woods and hedees. The bark is smontls and white. The yomer shoots are redelisil. aud thev are small and longe 'The leaves are beantiful; the are shant, rumalish, of a line browht errest, 
enrl notched about the edges. The flowers are inconsiderable; the fruit is a little scaly globule, preceding the leaves inspring.

'The juice of the birch-tree, procured by boring a hole in it in spring, is diuretic, and good against the scurvy. The leaves, fresh gathered, and boiled in water, afford a decoction, which acts in the same manner, and is good in dropsies : and in all cutaneous disorders, outwardly used.

Rovid-rooted Birtiswort. Arislolochich rotund $九$.

A WILD plant in Italy, and the south of France; but with us fond only in the gardens of the curious. It has no great beauty, or even sincrularity in its appearance, tili cxamined. The utallas are a foot and a half loug, but weak; they are square, and of a dusky green colour. The leaves are short, broad, and roundish, of a dusky green; also the flowers are long, hollow, and of an odd form, not resembling the flowers of other plants : they are of a dusky greenish colour on the outside, and purple witilin: the frut is fleshy, and as hig as a small walliut. The root is large and roundish.

The root is the only part used in medicine, and that we have from conntries where the plant is native; it is a rough and disagrcenble medicine; it often offends the stomach, but it is an excellent trug for promoting the necessury eracuations after detivery.

Where are two other kinds of birthwort, the not of which are also kept in the shops; the one He! the hon birthwort; the other the climbing ribust. "iley possess the same rirtues with the 
romd, but in a less degree, and are therefore less regarded.

\section{Dismorsweed. Ammi.}

a WILD plaut in France and Italy, but kept only in our gardens; in its external figure, somewhat resembling parsley when in flower. The stalk is round, firm, and striated; it grows two liet high. The leaves are of the compound kind, and formed of many smaller, which are broad, short, and indented at the edges. The flowers are small and white, but they stand in such large tufts at the tops of the stalks that they make a considerable appearance. Each flower is surceederl by two seeds; these are small and striated, of a warm aromatic taste, and not disagrecable.

The seeds are the only part of the plant used in medicine; they are good against the colic, as all the other caminative seedia are; but theF are also diuretic, so that the; are particularly prover in these colics which arise from the stonc in the kidneys and ureters; they also promote the lisellsers.

There is another sort of binhops-weed called retick ammi, the seeds of which are used in menteine: ther are of the sane virtues with these, but are less med. 'They have a more spiey smell.

\section{Bistort. Bistorta.}

A VRR beantiful wikplant : it mows in out ancaldows, and, when in flower, in VIay and June, is verv conspicuons, as well as very elegant in is nimearance. It is abost a foot and a halt 
high; the leaves are broad and beantiful, and the flowers grow in a thick spike or ear, at the top of the sialls, and are of a hright red colour. There rie immediately from the root a number of large and beatifiul leaves, long, broad, and of a fine mreen colonr. The stalks on which they stand, have also a rim of the leat running dowin them; the stalks are round, firm, and erect, of a pale green, and have two or thrce leaves, like the others, but smaller, on them, placed at distances. The spike of the flowers is as loug, and as thick as a man's thumb : the root is thick and rontorted, blachish on the outside, and red within.

If we mincied our own berbs, we should need fewer medicines from abroad. The root of biscort is one of the best astringents in the world : not violent, but sure. The time of gathering it is in March, when the leaves begin to shoot. String several of them on a line, and let them dry in the shade. The porder or decoction of them, will stop all fluxes of the be!ly, and is ore (; the safest remedies known for operflowing of the menses. They are also good in a diabrtes. 'Le nse of this root may be obtained without danger, till it effects a perfect cure.

\section{Bitter-Sweer. Solanbm lignosum.}

A C'OMMOM wild plant, with weak, but wordy stalka, that runs among our hedges, and ivears bunches of very pretty bluc flowers in summes, and in antumn red berries. The stallis rmo to ton feet in length, but they camot supmort themselves upright: they are of a bluish chlour, and, when broken, have a very disagreeshe smell like rotter egg. The leaves are ovel, 
but sharp-pointed, and have each two little onos near the base; they are of a dusky green and indented, and they grow singly ou the stalks. The flowers are small, and of a fine purplish blue, with yellow threads in the middle. 'The berries are oblong. This is little regarded in medicine, but it deserves to be better hinown; we account the night-shades poisonous, and inany of them are so; but this has no harm in it. "The wood of the larger branches and the young shoots of the leaves, are a safe and excellent purge. I have known a dropsy taken early cured by this single medicine.

\section{Brood-wort. Lapathum sanguincum.}

A BEAU'TIFUL kind of dock kept in gardens, and wild in some places. It grows to four feet high; the stalks are firm, stiff, upright, hranched, and striated. The leaves are very long and narrow, hroadest at the base, and smaller all the way to the end. They are not at all indented at the edges, and they stand upon long footstalks: their colour is a deep green, but thry are in different degrees stained with a beautiful blood red; sometimes the ribs only are red, sometimes there are loug veins of red irregularly spread over the whole leaf; sometimes they are very broad, and in some plants the whole leaves and the stalks also are of a blood colour; the flowers are very numerous and little. 'They in all repects resemble those of the common wild docks. The root is long and thick, and of a deep blood red colour.

'The roots are used : they are hest dry, and they may be riven in decoction, or in powder: They are a powerfully astringent: they stop bloody fluxes. 
spitting of blood, and the orerflowings of the menses. It is also good against violent purgings and against the whites.

\section{Bramble. Rubus vulgaris.}

THE most common bush in our hedges. The stalks are woody, angulated, and of a purplish colour; and they are armed with crooked spines; the leaves are rough, indented, and stand either five or three on a stalk. The flowers are white, with a very faint tinge of purplish, and the fruit is composed of a number of small rrains.

The most neglected things have their use. The buds of the bramble-leaves boiled in spring syater, and the decoction sweetened with honey, are excellent for a sore throat. A syrup made of the juice of the unripefruit, with very fine sugar, is cooling and astriugent. It is good in immoderate fluxes of the meuses, and even in purgings. The berries are to be gathered for this purnose, when they are red.

\section{Ble Bottle. Cyamus.}

A VERY cominon and a very pretty weed among our corn; the leaves are narrow, and of a whitish green ; and the flowers of a very beautiful blue and large. The plant is abont a foot high, and, when in flower, makes a conspicuous and clegant appearance. The root is hard and florous; the stalk is very firm, and white angulated, and branched. The leaves that grow from the root have some notches on the edges; those on one the stalk have none, and they are narrov like blades of alass; the fluwers stand only on the 
tops of the branches, and they grow out of scaiy heads. The secds are beautiful, hard, white, and shining.

The leaves which grow on the stalks of the blue-bottle, fresh gathered and bruised, will stop the bleeding of a fresh wound, even if a large vessel be cut. They are not suficiently known for this purpose, but they exceed all other things: and may save a life where a surgeon is not to be had in time for such an accident. A distilled water of the flowers used to be kept in the shops, but it was of no value. An infusion of them works gently by urine.

There is a largekind of this plant in gardens, which is called a vulnerary or wound herb. But it is not so good as this.

\section{The Box Trie. Buxus.}

A COMMON little shrub in our girden, and a native of our own country, though net common in its wild state. With ns it grows but to a small height; in some other parts of Europe, it is a tolerably large shrub. The bark is whitish, the wood yellow; the leaves small, roundish, smooth, of a very dark green colour, and very numerous. The flowers are sinall and greenish yellow; the fruit is litke, round, and furnished with three points.

The wood of the box-tree, and particularly of the root, is an excellent medicine in all foulnesses of the blood; it has the same virtues with the guiacum, but in a greater degree. It is to be given in decoction not made too strong, and confimued a long time. There lave been instances of what were called leprosies cured entirely hy this medicine. There is an oil mate from it liy 



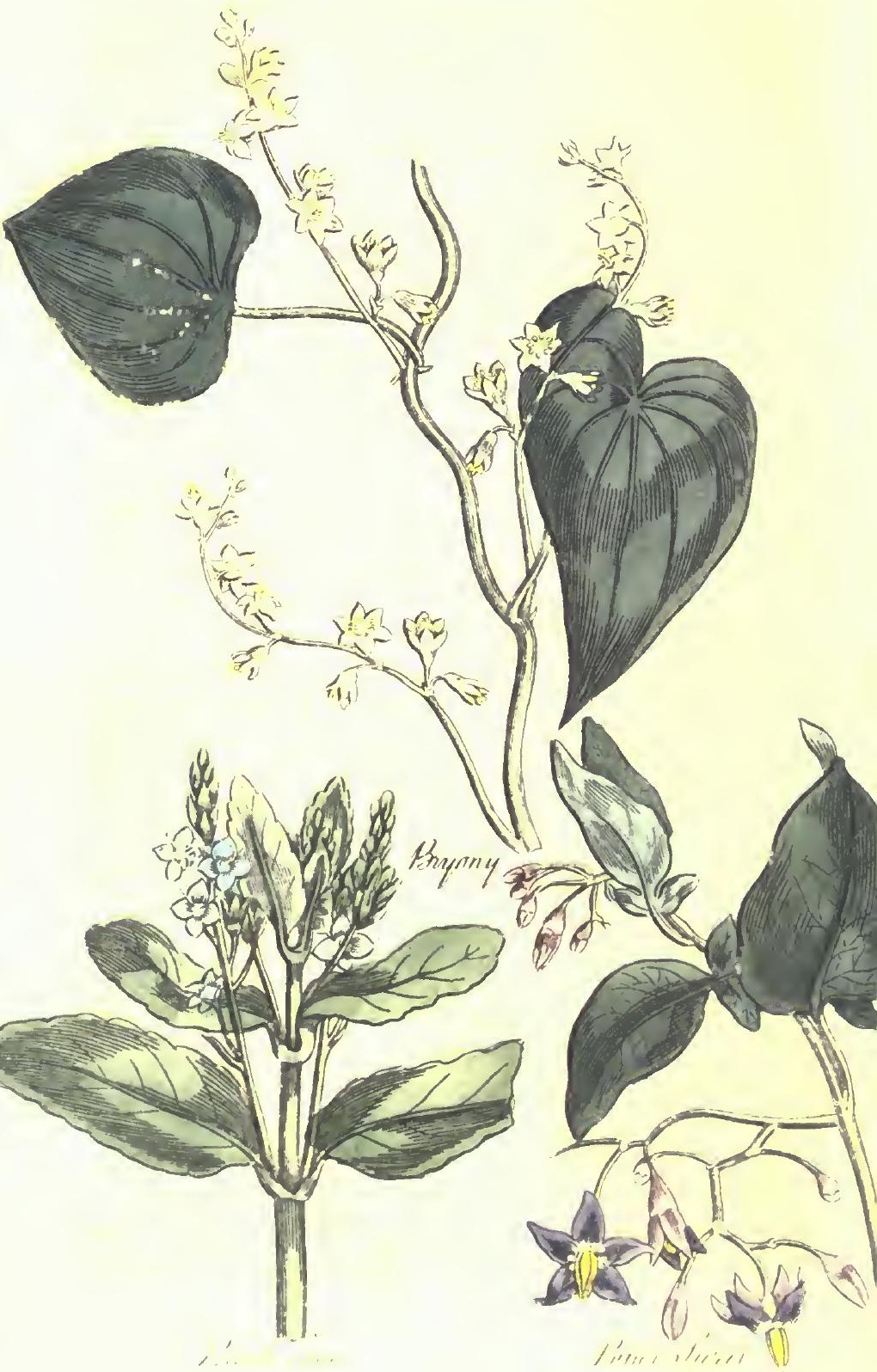


distillation, which is good for the tooth-ach. It is to be dropped on cotton, and to be put into the tooth,

\section{Borage. Borago.}

A ROUGII plant common in our gardens, with great leaves, and beautiful blue flowers. It grows two feet high; the stalks are thick, round, fleshy, and juicy; and covered with a kind of hairiness so sturdy that it almost amnunts to the nature of prickles. The leaves are oblong, broad, very rough, and wrinkled; and they have the same sort of hairiness, hut less stiff than that of the stalk; the largest grow from the root, but those on the stalks are nearly of the same shape. The flowers are placed toward the tops of the branclies; they are divided into five parts, of a most beautiful blue, and have a black eye as it were in the middle.

Borage has the credit of being a great cordial ; but if it possuss any such virtues, they are to be obtained only by a light cold infision; so that the way of throwing it into cold wine is better than all the medicinal preparations, for in them it is nauscous.

Weate Bryony. Bryonia alba.

A TALL, climbing, wild plant, which covers our longes in many places. The leaves are somewhat like those of the vine; the flowers are inconsiderable; but the berries are red, and make a reat shew. The root is vastly large, rongh, and Chitish; the stalks are tough, ien or twelve feet ing ; but weak and nnahle fo support themselves; they have tendrils at the joints, and by these they sif themselyes to buelies. The leaves are broad, 
and divided deeply at the edge, and they are hairy. 'The towers are of a greenish white and small, but the berries are moderately large and full of seeds.

The root is the ouly part used in medicine; the juice of it operates very strongly by vomit and stool, ard that in a smail dose. All constitutions cainnt bear it, but, fur those that can, $i$ is cxcellent in many severe riseases; dropsies have been cured by it. It is also good against hysteric rompiaints, but for this purpose it ts to be given in very small doses and frequently repeated.

\section{Pilack Bryony. Brionianigra.}

TILRE is not any instance which more blames ourneglect of the medicines of our own growth, than this of the black bryony, a medicine scarce known or heard of, but equal to any.

'The plant climbs upon bushes and hedges like the former, but this by twisting its stalk about the branches of trees and shrubs, for it lias no tendrils. It runs to fifteen feet in height, the stalk is tongh and angular: the leaves are broad, and of a heart-like shape, and ale perfecily smooth and shining, and of a glossy and very deep blackish grce'r. The flowers are very small aid of a greenish white; the berries are red 'The root is black without, white within, and full of a slimy juice.

The root of black briony is one of the best diuretics known in redicine. It is an excellent remedy in the gravel and all other obstructions of urine, and other disorders of the urinary passages.

Brooknime. Anagallis aquatica, becabunga.

A COMMON wild berb frequent about shallow 
waters, with a thick stalk, roundish leares, and spikes of little bright blue flowers. Brnoklume grows to a foot high. The stalk is round, fleshy and large, yet it does not grow very upright: it strikes root at the lower joints. The leaves are broad, oblong, blunt at the end, and a little indented on the edges. The flowers stand singly on short foot.-stalks one over another, so that they form a kind of loose spike; the roots are fibrous.

Bronklime has great virtues, but must be used fresh gathered, for they are all lost in drying. The juice in spring is very good against the scurvy; but it must be taken for some time. It works gently by urine, but its great virtue is in sweetening the blood.

\section{Broom. Genista.}

A COMINION naked-looking shrub that grows on waste grounds, and bears yellow flowers in May. It is two or thrce feet high. The stalks are very tough, angular, and green. The leares are few: and they are also small; they grow three together, and stand at distances on the long and slender stilks. The flowers are numerous, they are shaped like a pea-blossm, and are of a beautiful bright yellow. 'The pods are flat and hairy.

The green stalks of bronn, infused in ale or beer for the common drink, operate ly urine, and remove obstructions of the liser and other parts; they are famous in the dropsy and jaundice. It is a common practice to burn them to ashes and infuse. those ashes in white-rine; thus the fixed salt is extracted, and the wine becomes a kind of lee. 'This also works by urine more powerfully than the other, but the other is preferable for removing obstructions. 


\section{Butchens-Broon. Ruscus.}

A LITTLE shrubby plant frequent on our waste grounds and heatils, with sonall prickly leaves and bushy tops. 'The plant grows a foot and a In: f high. The stalks are roundish, striated, thick, and very tough. They are naked towards the bottom, and divide into some branches towards the anp: they are there covered with leaves. These Ladves are short, broad, oval, and pointed, the point ruming out in a priclile; they are of a bluish grecu, and very thick and fleshy. The flowers arescldom regardal ; they grow in a singular manier upon the backs of the leaves; they are very small and purylish : these are snceceded each by a single berry, which is red, round, and as big as a pea. The roots are white, thick, and numerous.

The ront is the pait used, and it is an excellent medicine to remove obstructions. It works powerfuily by urine, and is good in jaundices, and ir. stoppages of the menses, and excellent in the gravel.

\section{Buck-benns. Trifulium palustre.}

$A N$ herb better known by the common people, than among the apothecarics, but of great virtue It grows wild with us in marshy places, and is of so very singtilar appearance, that it must be known at sight. It grows a foot high, the leaves stand three upon each stalk, and these stalks rise immediatcly from the roots. They are thick, soind, swooth, and fleshy; and the leaves themselve's ate large, oblong, and have some resemblance of those of enilden-beans. The flowers stand upon baked stalks, which are also uhick, round, A. alsy, and whitish : they are small, but they gros 


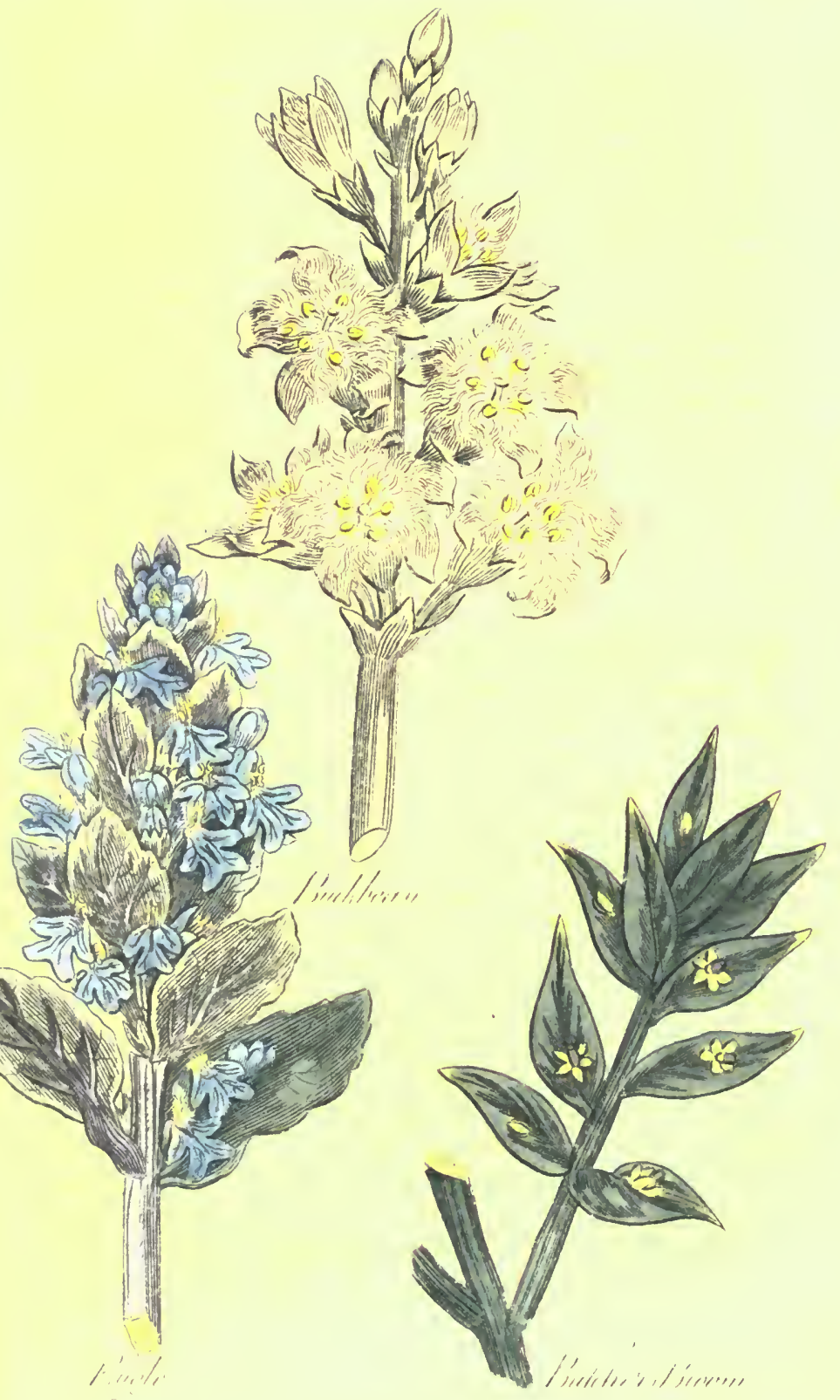



together in a kind of thirk short spike, so that in the chater they make a conspicuous appearance : they are white with a very fitur tinge of purple, and are hairy within; the root is whitish, long, and thick.

The leares of bucli-bean are to be gathered before the stalks appear for flowering, and are to be dried; the powder of them will cure agnes, but their great use is against the rheumatism: fivr this purpose they are to be given for a contimuance of time in infusion, or in the manner of tea.

\section{Buchthors, Spiza corrines.}

A PRICKLY sinub, common in our hedges, with pale green leaves, and black berries. It srows to eight or ten fect high. The bark is dark coloured and glossy, and the twigs are tuugh. The leaves are oval, of a very regular and pretiy figure, and elegantly dented round the cdges. The flowers are little, and inconsiderable; they are of a greenish yellow, and grow in little clusters. The berries, which are ripe in September, are round, glossy, black, as big as the largest pepper-corns, and cuntain each three or four seeds.

The juice of the berries, hoiled up with sugar, makes a good purge; but it is apt to gripe, unless some spice be added in the making: It is a rough purge, but a very good one.

\section{Beckshorn Plantare Coronopis.}

A VERY pretty little plant, which grows in our sandy and harren places, with the leaves spread out in amer of a star, all the way rown 
from the root; and in the heads like other plantains, although so very unlike them in its leaves. The root is long and slender; the leaves which lie thus fiat upon the ground, are narrow and long, very beautifully notched, and divided so as to resemble a buck's horn, whence the name, and of a pale wlitish green, and a little liairy. 'The stalks are slender, six inches long, but seldom quite erect: they are round, hairy, and whitish, and have at the top a spike of flowers of an inch or two in length, altogether like that of the other plantains, only more slender.

This plant las obtained the name of star of the earth, from the way of the leaves spreading themselves. These leaves bruised, and applied to a fresh wound, stop the bleeding and effect a curc. It is said also to be a remedy against the bite of a mad dog, but this is idle and groundless.

Bugre. Bugu!a.

A COMMON wild plant and a very prets one, with grossy leaver, creeping stalks, and blue flowers; it is frequent in damp woods. The stalks, wben they rise up to bear the flowers, are fight or ton iuches high, square, of a pale green colour, often a little purplish; and have two leaver at every joint, the joints being somewhat distant. These leaves are of the same form with those which rise immediately from the root; oblong, broad, blunt at the point, and of a decp green rolour, sometimes also a little purplish, and are slightly indented round the odges. The flowers are snall and of a lieantiful blue, in shape like those of botouy; they erow in a sort of circles. roned the upper part of the stalks, forming a kind 
of loose spikes. The cups remain when the flowers are gone, and hold the seeds.

The juice of this plant is esteemed good for inward bruises; it is a very good diuretic.

\section{Buglose. Buglossum hortense.}

A ROCGIi and unsightly plant kept in our gardens for the sake of its virtues, but very rarely used. It grows to a foot and a laalf high; the leaves are rough like those of borage, but they are long: and narrow, of a deep green colour, and rough surface. The stalks are also covered with a rough and almost prickly hairiness. The bane sort of leaves stand on these as rise inmediately from the root, only smaller. The flowers stind at the tops of the branches, and are very prettrin, though not very largex they first open, but they atterwards become blue. the root is long and brown. It flowers in June and July.

Bugloss shares with borage the credit of being a cordial; but perhaps neither of them have any great title to the character; it is used like borage, in cool tankards; for there is no way of making any regular preparation of it, that is possessed of any virtues.

There is a wild hind of bugloss upon ditchbanks, very like the garden kind, and of the same virtues.

\section{Burdock. Barduna.}

IF the lasi-mentioned plant has more credit for medicinal rirtues than it deserves, this is not so much regarded as it ought. Providence has made some of the most useful plants the most combion; 
but, becanse they are so, we foolishly neglect thent.

It is lardly necessary to describe the common burdock. It mar be cuough to say, that it grows a yard high, and has vast leaves, of a figure approaching to triangular, and of a whitish green colour. 'The stalks are round, striated, and very tough: 'The flowers are small and red, and they grow among the hooked prickles of those heads which we call burs, and which stick to our clothes. Even this seems a provision of nature in kinduess to ns. In pulling ofl these we scatter the secds of whirh they are composed, and give rise to a most useful plant in a new place. The root of the burdock is long and thick; brown on the ontaide, and vhatish within; this is the part used in medicine, and it is of very great virtues. It is to be boiled, or infused in water, the virtue is diuretic, and it is very powerfully so. It has cured dropsies alone. The seculs have the same virtue, but in a less degree. The root is said to be sudorific and grood in fevers ; but its virtue is operating by urine is its great value.

\section{Burser. Pingrinclla sanguisorba.}

A COMIMOY wila plat. It grows by way. vides, and in diy places, and flowers in July. The fraves which rise inmediately from the root are very beantiful; they are of the winged kind, bcine composed of a great number of smaller, growine on cach side a middle rih, with an odd one at the 'md. 'They are broad, short, romulish, and elegantIr serrated round the cdges. The stalks are a foot high, round, striated, purplini, or green, and nluast maked; the few leaves they bare are lite tho-s at the bottom. On the tops of these stalks 


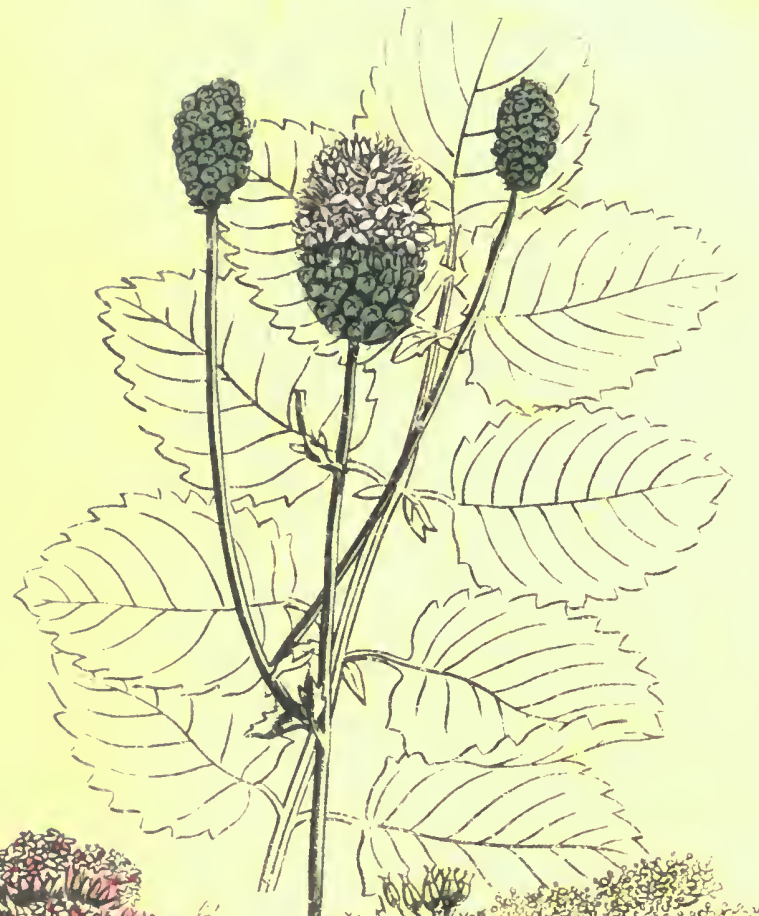

Gir 0,120

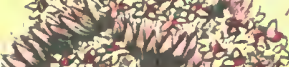
20145

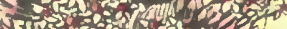

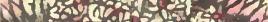

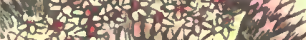

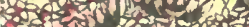

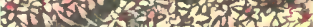

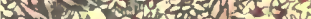
D-ato

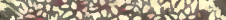
Cn

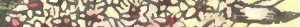
Q38 58 ind

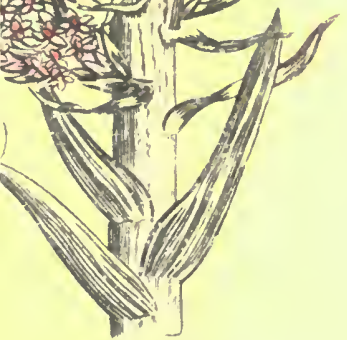

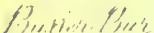

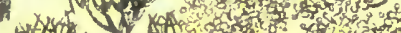

4062 2010

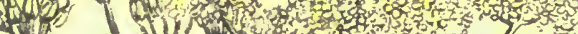

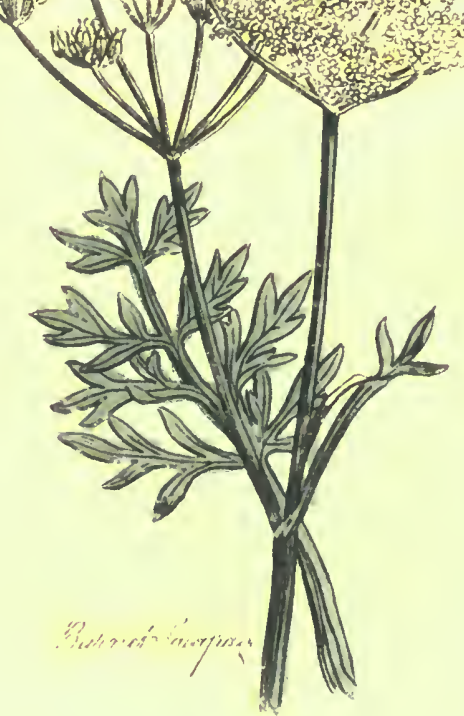



stand the flowers; they are disposed in little round clusters, and are small, and of a pale reddish coJour, and have a mmber of threads in the middle.

bumet is caller a cordial, and a sladorific, and is recommended in fevers. They put it also into cool tankadi, like borage. The root is a good astringent; iried and powdered, it stops fluxes, and brerflowings of the menses.

Burnet Sixmrage. Pimpinella saxifiagr.

A PRETTY piant, wild in our dry pastures, and under hes!eses, but not very common in all parts of the kinghdom; it grows two feet ligh, and laas the foncers in unbels. The staik is firm, striated, and branched; the leaves rising from the root are pimated, and the lesser leaves of which they are componct, are hard, of a decp green, narrow, and indented. The leaves upon the staiks are smaller and natrower ; the flowers are little and white, lout they stand in so large cinsters, that they make a figure: the root is white, and of a hot burning taste; the seeds are etrialed.

The ront is the only part used; it should be taken up in spring before the stakis shoot "1p, and dried; it is very good in colies, and disorders of the stomacl, and it works by urine.

\section{Butren-Bure. Petasites.}

A VERY singnlar and very conspicuous plant, not unfrequent with us in wht ylaces. The flowcrs appear before the leares, and they would lardly be supposed to belong to the same plaut. 'The stalks are round, thick, spungy, and of a whitish colour, and have a few filuns by way of 
ieares unon them. On the top of each stands a apike of flowers, of a pale reddish colour; the whole does not rise to more than eight inches in height. These appear in March. When they are dead, tlo leaves grow up ; these are roundish, grem on the upper side, and whitish underneath, of a vast bigness, and stainl sinely upon hollowed foot-sta!ks, of a purplish, whtish, or greenish colour; they are often two fcet broad. The ront is white and long, it crecps under the surface of the ground.

The root is the part used; it is praised very highly, ag a remedy in pestilential fevers ; but, whether it deserves that praise or not, it is a good diuretic, and excellent in the gravel.

\section{Bur-REed. Sparganium.}

A COMMON water plant, with leaves like flags, and rough heals of seeds: It is two or three feet ligh. 'The stalks are round, green, thick, and upright. The leaves are very long and narrow, sharp at the edges, and with a sharp ridge on the back along the iniddle; they are of a palo green, and look fresh and beantiful. The flowers arc inconsiderable and yellowish: they stand in a kind of circular tufts about the upper parts of the stath : lower down stand the rough fruits called burs, from whence the plant obtained its name; they are of the bigness of a large nut megr, srrecu and rongh. The root is composed of a quantity of white fibres.

The moripe fruit is used: they are astringent, and good against fluxes of the belly, and bleedingers ofll kinds: the best way of eriving them is iufued in a rough red wine, with a little cinsomon. Thley use them in some parts of Engrand 


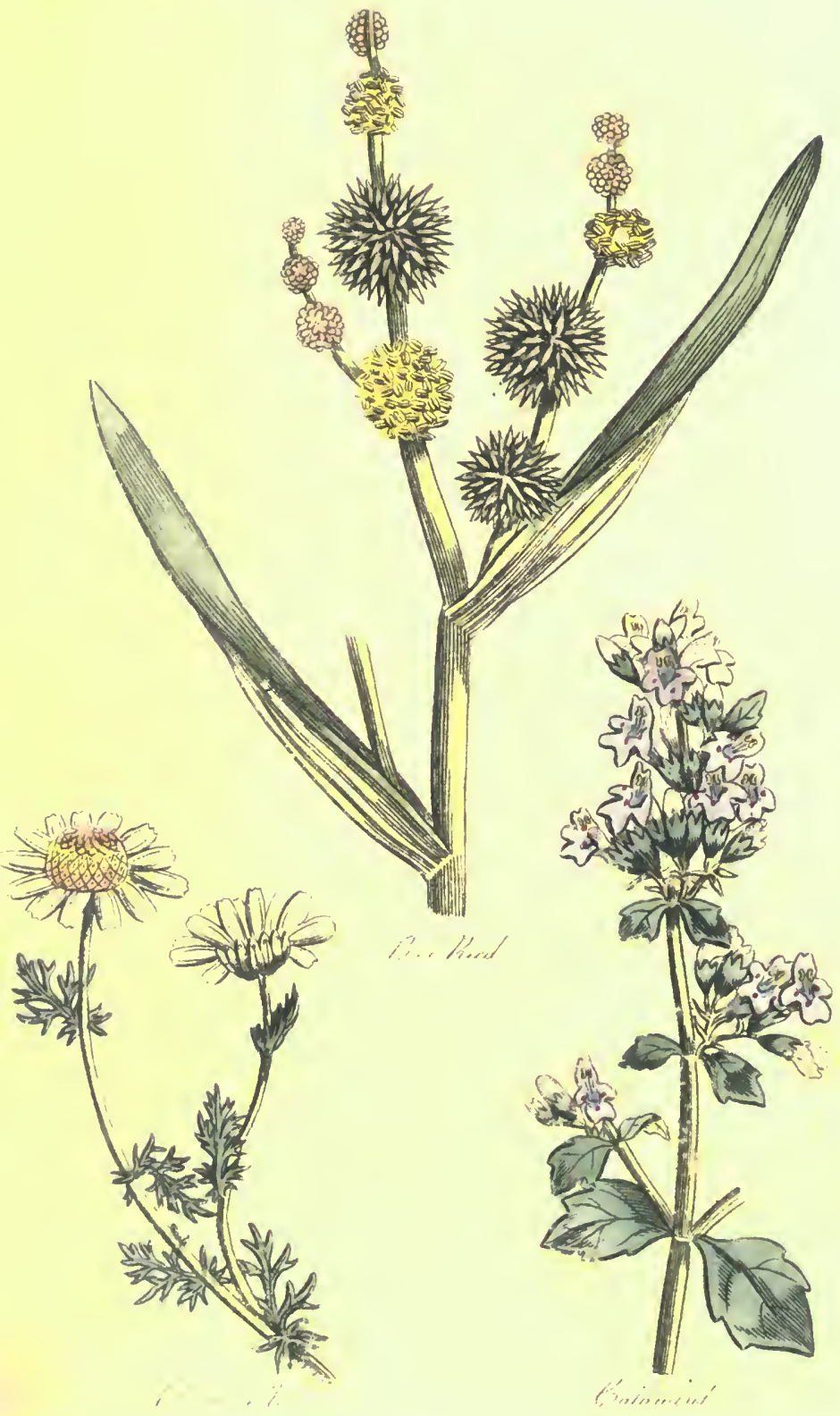



exicrially for woubls. A strong deroction of them is wade to wash old ulcers, and the juice is applied to fresh hurts, and they say with great success.

\section{C.}

The Chocorate Nut-tree. Caclio.

THES is an American tree, very bentiful, as well as rery valuable for its fruit. 'The trunk is of the thiskness of at man's $\operatorname{leg}$, and the haight of fiftem foet; but in this it diffis greatiy arcorting to the coil; and the size of the fruit also wili fifle from the same cause, whence some have taiks of four different kinds of the chocolate nut. The tree erows very regularly. The surface is uncren, for the bark rises into tuberclez; the leaves arehalf a foot long, three inches hroud, of a fune strong green. and pninsed at the ends, the fowers are suaill and reilowinh, and they gron in clusters from the branches, and cren from the trmk of the tree; but each has its separate stalk. Whe fruit is of the shape of a cucumber, half a foot lones. and thicker than a man's wrist; this is ridged, and, whou ripe, of a purplish colour, with some tinct of yellow. The cacio nuts, as they are called, are lodged within this fruit; every finit coitains between twenty and thirty of them. They are of the bigness of a large olive, but not so thick: and are composed of a wondy shell, and a lare kernel, which affords the chocolate.

Whe conmon way of taking this in chocolate is not the ouly one in which it may be given; the nut itself may be put into electuaries. It is verynourishing and restorative. 


\section{Calnysir. Calamintia.}

A COMBMSN wild plant of great virtues, but too mach neglected. It is frequent by our hed jes, and in dry places, and is a very robust herh. It is eight or ten inches high, and has monuigh dark sreen leaves, aid white flowers. The Gialks atse square, and very much linanched: the laries are of the birnes of a man's thmonmal, somerbat hairy, and bligidy indented abont the eiges. 'The flowers stand in lithe clisters

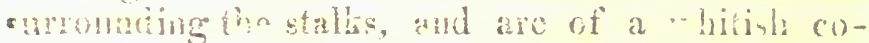
lonr, a litite thed will parplish. The root is compecd of a few fibres. Calamiat should be arar thered when just coming into flower, and careful1y dried; it is afterward, to be wiven in the manner of tea, and it will do great service in wraknesses of the stomach, and in habitual colics. I have known efectual and lasting cures performed by it.

\section{Pexay-roral Calanitr. Calamintia odore} yialigh.

A I.ITTIR plant of the same kind with the other, and found in the same places, but more common. It is a foot himb: tile stalks are robust and firm: the leaves are small, and of a whitish greencolour, and moredairy than in the other: the Howers are small and white, will a linge of purple ; the plant wrows mone erect and is less banched than file other: and it has a very stroug and ant a resveresable mell ; the other is strongsermind and plestant.

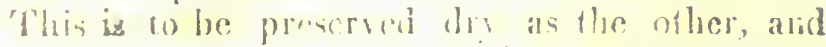
taken in the same manber. It is crevllent agatust stoparges of the mineses, andid, if taken constantly, will bring then to a rewerlar conr... 


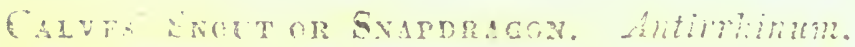

l combox wil plont in many pats of

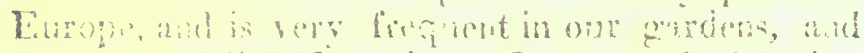
npon the nalls of gardens: lis matura! situation is on hills among harron rocks, and mobing comes so nea that, as the top of an cld wall with us: the sceds are light and are casily carried thither by the wind, and they never fail to strike, and the plant flourishes. It is two feet high, the statks are round, thich, firn, and tolerably upright, but generally a lible bent towards the botton; the leaves are very bumerous; thes are chlong, narrow, not indented at the edges, bunt at the ende, and of a hush grem colour. The fowers are laree and red, they stand in a lind

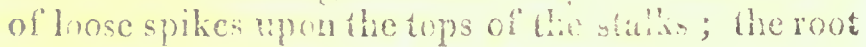
is whito and oblous:

Thefresh top; are used; an infusion of them works by urine, and has been recomended by some in the jamblice, and in ofler di-cases arising irom obetructions of the viscen; but we have so many tunglish plants that axeel in this particular, and the taste of the infuime in so far from ateresable, that it is not worth while to have recourse to it.

\section{Caner's mat, Schonduthes.}

A S() R'l of erass of a fragrant smell, ferquent in many parts ot the iast, and bronght ores to wa dried for the lase of meticine oft erow to

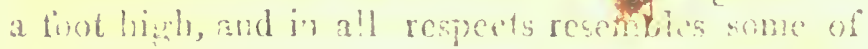
our common kinde of grans, particularly the darnel. The leaves aze lobig aid narrow: tle

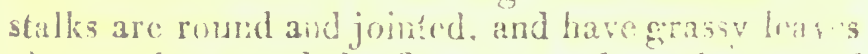
also on thom, and the flowers stand on the tops of 
the stitiks in a double series: they are not unlike those of our grasses, chafify and orsatuented vith a few filaments.

It was at one time in great esteen as a medicine; they called it a cordial, and a promoter of the nenses, but it is now very litile regarded.

\section{Chanomine. Chamomclum.}

A COMMON low wild plant, of a beautiful sreen, a fragrant smell, and with flowers not unlike daisies. It is frequent on damp hoaths, andgets no good by being brought into gardens. It grows larger there, but has less eflicacy. In its wild state it spreads its branches upon the ground, taking root at the joints. 'The stalks are round, grcen, and thick ; the leaves are very fincly divided, and of a dark blackish green colour. 'ithe flowers grow upon long foot-stalks, and are white at the edge and yellow in the middle: the flowers are most nsed. Those which are rajed for sale are double, and they have very little virtue in comparism of the single ones. 'They are to be taken in tea, which is a pleasant bitter; or in powder they are excellent fior insorders of the stomach, and have sometimes cured agues, as many other bitters will. The tea made of them is also good against the colic, and worke by urine,

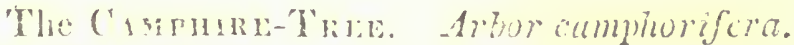

Trles is a kind of has-tree of the East Indir's. but it grows to the lie ipht of our tallest trees. The bark is brown and uneven on the trunk, but it is sunouth and green on the young branches. The leaves are like those of the common hay-tree, mily a little longer; and they are curled at the cogros. 
The dowers are small and white, and the fruit is a beiry, altogether like our bay-berries, and of the bigress of a litrge pea. Whe wood of the tree is white or a little reddish, and veined with black, and smelis of the camphire. The leaves also, when thes are bruiaed, smell of camplire; and the fruit niont of all.

The only product of this tree, used in medicine, is the resin called camphire; and this is not a natural, but a sont of chemical preparation. They cut the wod to pieces and put it into a sort of sublirning vessel with an earthen head full of straw. 'They mhe fire underneatl, and the camphire rises in form of a white meal, and is found among the straw. This is refined afterwards, and becomes the camplire we use.

It is sidurific and works by urine; it also promotes the nenses, and is good in disorders of the bla!der.

\section{Write Camprox. Lychnisfore albo.}

A COMPrO wild plant in our hedges and dry pastures, with hairy leaves, and white fiowers. it grows to a foot and a half high: the stalks are round an! hairy ; the leaves are of an oval form, and also hary; and they grow two at cvery joint: they are of a dusky green, and are not indented about the edges. The flowers are moderately large, and white; they prow in a kind of small clusters on the tops of the branches, and each has its separate foot-stalk.

This is a plant not inuch remarded for its virtues, but it descrves notice; the countiry people gather the flowers in some places, and give them in the whites and other weaknesses with success. 


\section{The Canel Bark-Thee, catefad the Winter'G} Bark-Tree. Cuncilla cilba.

1 TEPY beantiful Amerimn tree. It grows fifly fit hinh, and is commonly much brambet. 'the bark is of a grevinh boun: the Iranes are yed like toute of the bay-tree. and the flowors are

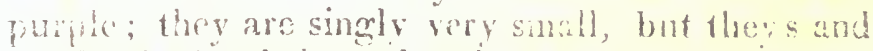
ina had of unbels and mate a ver prote figure: the fint is a berry whirit stads in the cup of the flower: It is of the bigness of a pra, aw of a deep batioh purple whoip ripe. It is frequent in Jamaica in wet places.

The inner ribd of this tree is the part ased in medicine; if is brolighte us rolled up in quills. in the mannei of chalamon, and is of a spicy taste, and of a whitish colour. Itsproper name is carella alba, white canel; but the drugusts have acculofomed themselves to call it coutex winteramus, wiuter'sbarl. It has the same virtues with that, but in a mach less degree; and they are casily known astmcer, that bens; the whole bark of the treo, and romposed of two coats; this being ont? the inmer bark, and therefore compeed only ai one. It is good in weakneses of the somath, and in

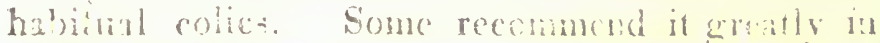
paisies and all nervous complainls, lont its virtaz of this kind are not so woil established.

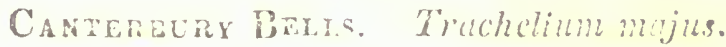

A VRP r benntifnl will plant with leaves like

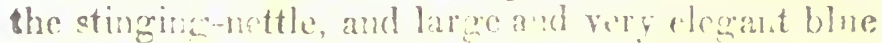
tlowers. It grrows by inad-aides, and in dry pastures and is two or three forthinh. The stalks

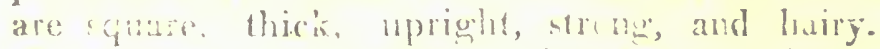

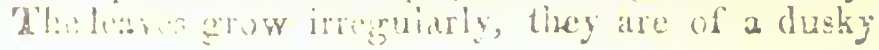


creen, and stand upon long foot-stalks; they anc broad at the bose, and sharp at the point, and a!l the way indented very sharply at the edges. They are hairy and romoly to tike tonch. The flowers grow ten or a dozen tegether at the top of every brunch; lisey are very large and of a beautilut blue colour: hollow and arided intes several parts

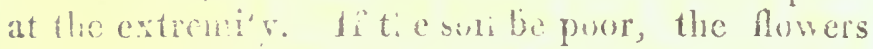
will fars in cheir colour to a pale blue, recidish, or white biat the plant is oill the same.

'ive iresh cops, with the buds of the fowers upon them contum most virtue, but the dried laves ma; be ned. An infusion of them sharpened witi a few drops of spirit of vitiol, and s....tend with honer, is an exreileat medicine

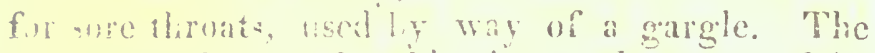
I: a.t is oo lamolie fir this vilue. thitt one of its

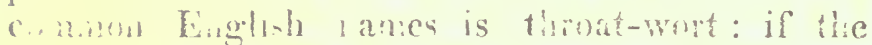
madicise be swallow al, there is no hama in it ; but, 3. ? ? $\mathrm{u}$ o of every thumg in this way, it is lest to

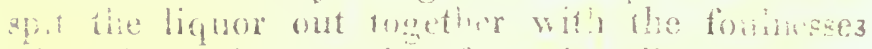

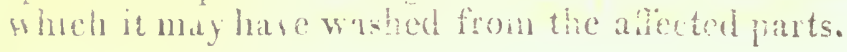

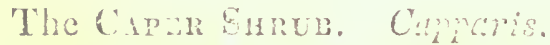

A COMI $10 \mathrm{y}$ shrub in Frane and Waly, and

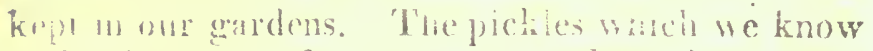
muder the name af capers, are made of the buds of the flowers, bat the part to be used in necieise is the bark of the roots.

Whe shrub grous to no great liciont ; tie branche are wok, and ill able to steprot than-

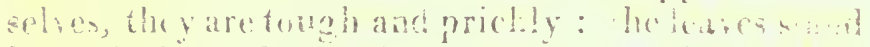

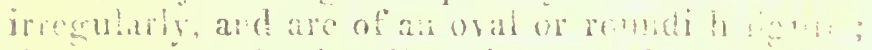
the thorist are bogked lite these of the brain. the flowers, whon fuil opend, are puplisti very !retly: the fruit is roundisin. 
The hark of the root is to be takeil in powion, or unfusirn; it is good againt obstructions of the liver and spleen, in the jaudice, and hypochondriac complaints : it is also conmended in indigestions.

\section{The Caranna Tree. Caranua arbor.}

A TALL East Indian tree, and a very beautiful one: the trunk is thick, and the bark upon it is brown and rough; that ou the young branches is smooth and yellowish. The lcaves are long and narrow, like those of somle of our willow-trees. The flower is small and of a pale colour, and the fruit is of the bigness of an apple.

The resincalled gum carama, is a product of this tree; it is procured by cutting lae branclies; they send it in rolls covercd with licaves of rushes; it is blackish on the ontside, and brown whlin.

It is surnosed a good nervous medicinc, isut it is sarely used.

The resser Cardamon Prixit. Cardumomum aninis.

AN East Indian plant, in many respects resembling our reeds. It gुrows to ten or twelte fect highl. The stalk is an inch thick, romol, snouth, green, and hollow, but with a pilh within. Ple Peares are half a yard long, and as hood as a man's

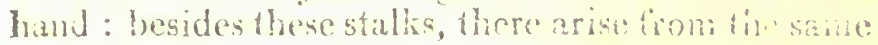
root others which are weak, tuder, and ahrst

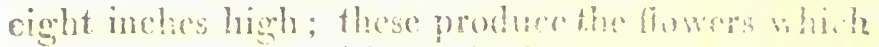

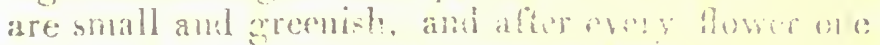

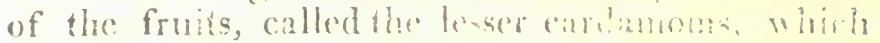

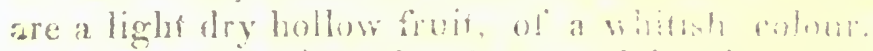

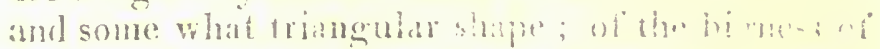

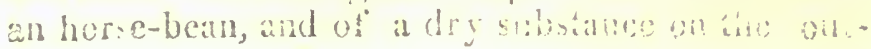


sid? but wi! seremal sceds within, which are reddish and sory acrid, but pleasint to the tuste.

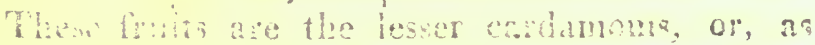
they ar gneralis called, the cardamon seeds of Hae sums. Thery are cacellent to sirusthen the

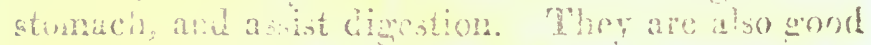
for disoders of the hend, and thef art tqua! to any thing against colice: they ane best taken bu

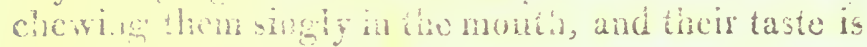

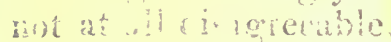

rhe wher hin!s are the midule cardamom, a lon foit rery racely met whin, and the great cartuan, otherwise called the gran of paradise, mand betas than the cardamons.

\section{The Carased Tree. Coragna.}

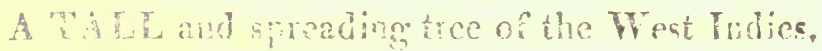
the banches are numerome, and irmegular; the

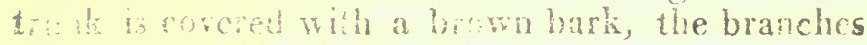

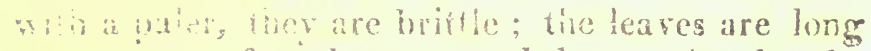

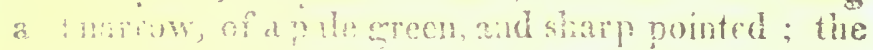

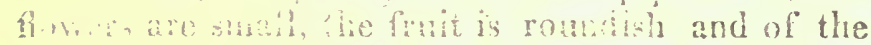

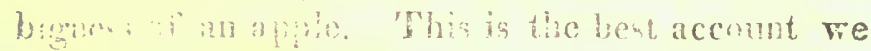
Lave wh hat this is far from verlect or satisfachuri in werespect.

Al t at wo use of it is a resin wheh nozes not oi the has, in the great heats ; this is brown, solucturt suft, and we liare it in oblong pieces, round ip in runhes; we put it only externally ; a

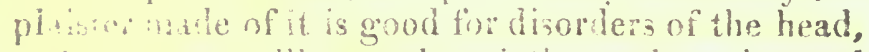
and ane sav will cure the sciatica withont internal nedicitis, wut this is not probable.

\section{Canesa Thrste. Corlina.}

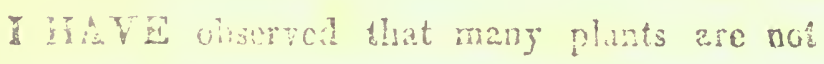


so muck resarded for their virtues as the numbe to be ; thare are on the contrary some which are colobated more than they destrve: the ramion thivle is of this last number. It is not vhol!y wathot intues, but it has not all that are aresibed to it.

This is a plant without any stalk. The leares are long, narrow, of a dark green coline, divided and prithly at the riges; and they lie spred upou

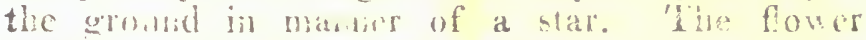

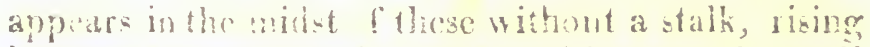
immediandy fonm the root, with efforal sma!l leaves monel in bont it. It is the hrad of a tlistle. and the howrey palt is white on the refere, and ret-

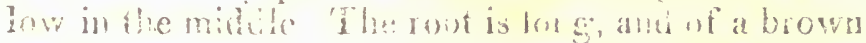
colous rn the ont ide, and reddish withia; it is of a warns alomatic taste.

This is the ouls part of the plant used in medicine. They un is is a resiedy fon the plasue: but however thin mat be, it is and in lactous com!-

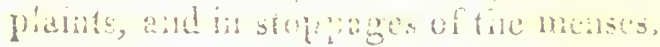

$$
\text { whe CARAWY PAAXS. Limm. }
$$

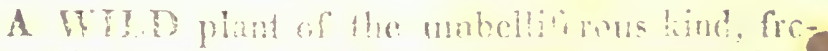

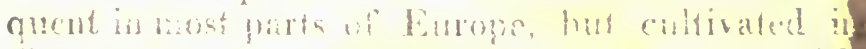

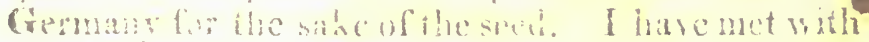

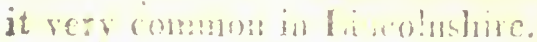

It ereifs fo a sard bluh; the sia!le are striated

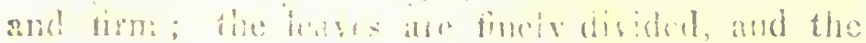
fower are white and anail, the eren in infis, or umber

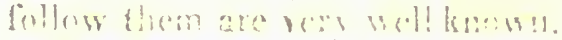

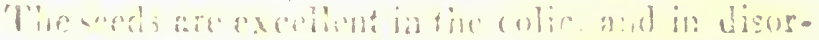

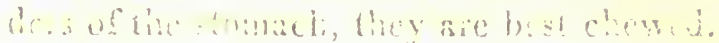





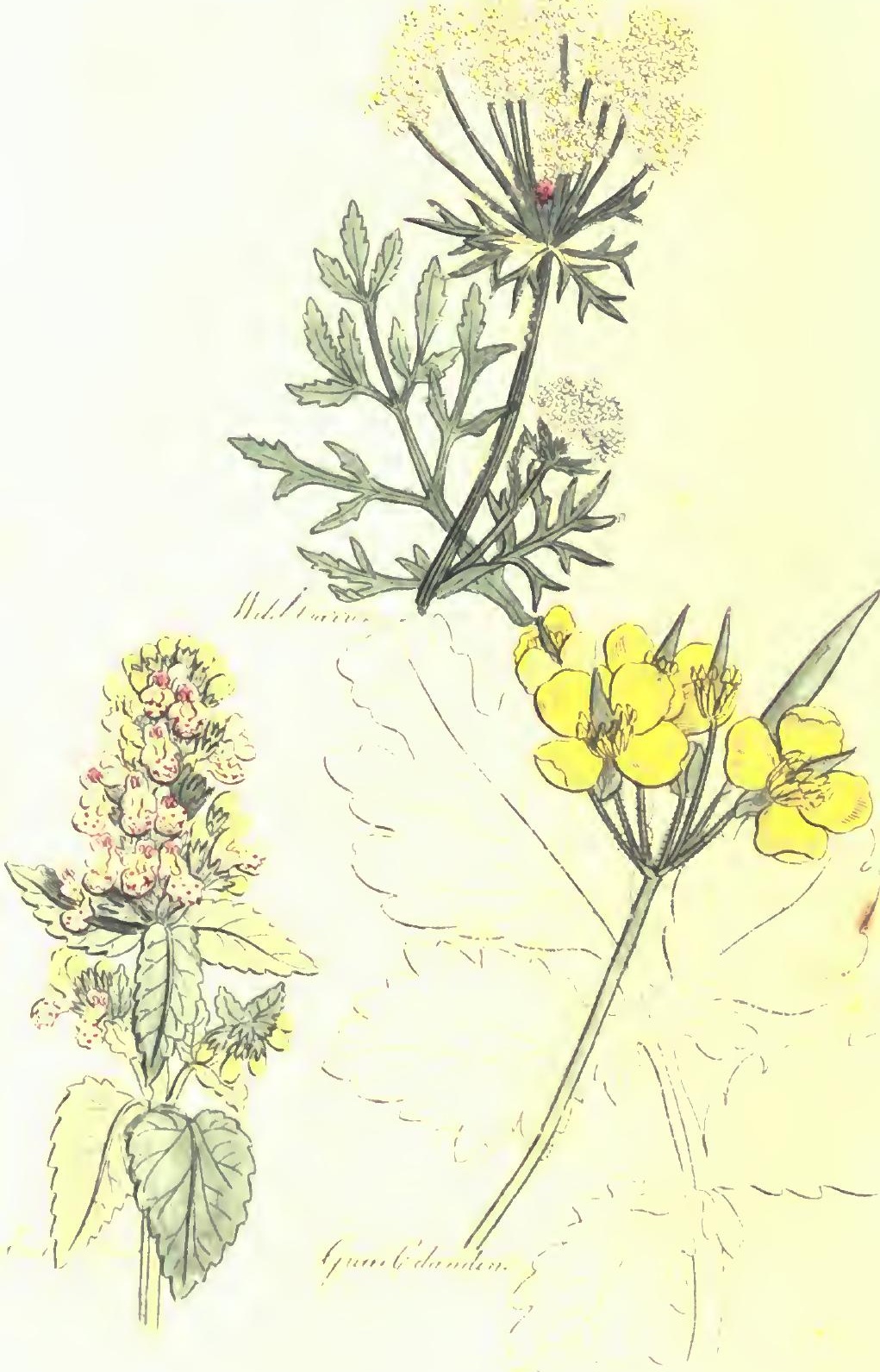


accomm?s, thoumh we are very well arguainted with the hatk of its young branches. Whhat we have low told of it is, that the bramches are numerons, an! spread irregularly; that the lcaves are oblong, graeen on the upper silde, and whitish underanth; ant the fowers small, fracrant, and placed in a sort of lansters.

The bark which our dergegints vell, is greyish on the outside, hembn witin, and is of an agrecable smoll: when burnt they call it Eleutlerian bark, and batard jesulis bah : it is cordial and astringont. It is rery propenly givon in fevers attentid with purging. And many have a custom of smoking it among tobacen, as a remedy for head-achs, and disolders of the nerves : it also does rood in plentision and peripneumonies: some lare reesmmended it as a sovercigna remedy in tlose cases, but lhat goes foo far.

\section{The Chson Mistularen. Cassiafistula.}

Tlys is a larec tiec, mative of the East, and a very beantiful one when in fower. It grows encuty or linety fect hion. and is rery mucis branclued. Whe leares are large, and of a decp green, and rach is composed ot three or fomr pairs of smaller, with an otid one at the end. 'The fiowers are of a gresish yellow, bint they are very bright, and rery mumerous, so that they nable a fine appearance, when the roce is full of them: the poits follow these, they are two feet long, black, and wooly, having within a black, sofit. pulpy matter amb the seeds.

This yulpy matrel is the only part used in medicius. It is a rentle and rexcollent puree, the

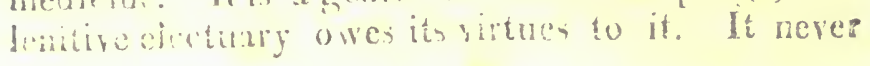


i)inds afterward, and therefore is an excellent medicine for those who are of costive luabits; a small dose of it being taken frequently.

The Chssa Bark Tree. Cassia lignea.

THIS is a large spreading tree, frequent in the East Indies, and very much resembling the cinnamon tree in its appearance. The branches are covered with a brownish bark; the leaves are oblong and pointed at the ends. and of a deep green colour, and fragrant smell. The tlowers are sinall, aud the fruit resembles that of the cimamon tree.

The bark of the branclies of this tree is the nnly part used in medicine; it is of a reldish brown colenur like cinnamon, and resembles it in smell and taste, or'iy it is fainter in the smell, and less. acrid to the taste; and it leares a glutinous or mucilaginous matter in the mouth. It is often mixed among cinnamon, and it possesses the same virtues, but in a less degree. However in purgings it is betwer than cinuamon, because of its mucilaginous nature. It is an cxcellent remedy given in powder in these cases, and is not so muchl used as if ought to be.

The Cassia Caryophythata, or Clove Bark Tree. Cassia caryophythata.

THIS is a large and beautiful tree, frequent in South America. The trusk is covered with a dusky bark, the branches with one that is paler coloured and more smooth. The leaves are like those of our bay-tree, only larger, and when bruised, they have avery fragrant somell the flown 
ers are small and blue, and have a white eye in the middle.

The only part of this tree used in medicine, is the inner bark of the branches. This is brown, thin, and rolled up like cinnamon; it is hard in colour, of a spicy smell, and in taste it has a mixed tharsur of cimnamon and clores, and is very hot and bungent.

It is good in disorders of the stomach, and in colies, but it is not so much used as it de. serves.

Cassibosy, or Arabran Strechas. Stechas Arauica.

A VERY fragrant and pretty shrub, native of Spain, and many other warm parts of Europe. It grows much in the manner of lavender, to a yard or more in height, and is not uncommon in ous gardens. The branches are firm and woody: the young shoots are pliable and square, and are naked to the top. 'The leaves stand upon the branches two at each joint, they are long, narrow, and white. The flowers stand in little clusters or heads, like those of lavender; and there are two or three large and beautiful deep hlueleaves upon the tops of the heads, which give them a very elegant appearance.

The flowers are the only part used : they are of the nature of those of lavender, but more aromatic in the smell: they are very serviceable in all nervous complaints, and help to promote the monses. They are best talon drich and pow. dered 
The Cassuanar Plant. Celssumunar.

A COMMION plant of the East Indies, but of which we do not seem to have yet so perfect a description as might be wished. Its leaves are large, long, and like those of our flags, and they involve one another in a singular manner abnut therr bases. The flowers are small, and they are in shape somewhat like those of certain of our orchises. They are mottled with'purple and yellow: the seed is little and browis, the root creeps under the surface of the ground, and is of a vellow colour, and tracrant smell, and of a warm taste.

The roct is used: we have it at the druggists. It is of the same nature with zedoary, and has by some been called the yellow zedoary. It is a very grood medicine in nervous and hysteric complaints. It is warm and strengthening to the stomach: it is remarkably gond against the hearlach and in ferces. It operates quick by urine and by sweat.

\section{Cатмант. Nepcta.}

A COMMON wild plant about our hedges, jut of very great virtues; it grows a yard high, and has broad whitish leaves, and white flowers like mint. The stalks are square, whitish, bairy, and erect: the leaves stand two at a joint : they are broadest at the base, and terminate in an obtuse end; they are a little indented at the edges, and of a whitish grcen on the upper side, and very white underneath. The flowers are small and white; and they grow in a kind of spiked clusters, surrotinding the stalks at certain distances. The whole plant has a very strong and not very agreesble smull. 
Catmint should be gathered just when the llowers are opening, and oried. Io is an excelient wiman's medicine; an infusion of it is good against hysteric complaints, vapours, and fits, and it moderately promotes the menses : it is also good to promote the evacnations after delivery.

\section{Great Celandine. Chelidonium majua}

A COMIMON wild plant with large leaves, ard yellow tiowers: which, when brokell in apy part, stalk, or leaves, emits a vellow juice. It grows thrce fect high, but the stalks are uot very robust, tho are round, grem, and naked, with thick joints. The leaves stand two at each joint; Hey are large, long, and decply divided at the edros, and are of a yellowish greeu. 'The flowers are small, but of a heautiful yollow, and they stand on long fontstalks several togrether.

Celandiue shorild be used fiesh, for it lonses the greates part of its virtue in drving: The juice is the hest way of giring it and his is an excellent mevicine in the jambles: it is also good against all obstivctions of the viscera, and if continued a time, will do great service against the scurvy. The juice also is used successfully for sore cyes.

\section{Litte Celandine. Chelidonium minzs.}

THE rreat and the little celandine, are plants so perfect!y different, that it is hard to conceive. what could induce the old writers to call then borll by fles same name. They hardly agree in any thing, exrept it be that they have both yellow fluwers. The great colandise approaches to the mature of the poppy; the smal! celandine to that 

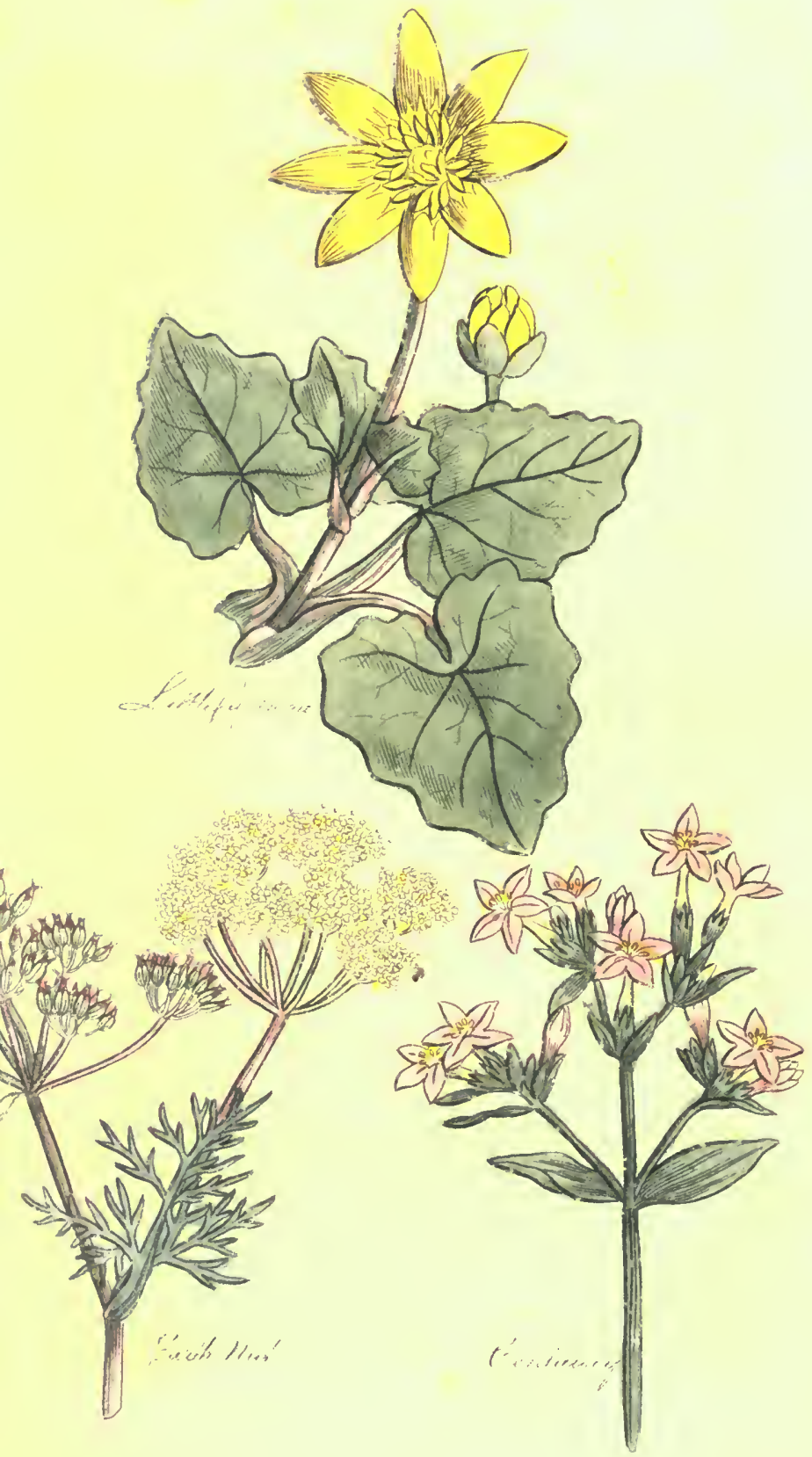

of the crow-fout; nor are they any more alike in virtues than in form.

Little celandine is a low plant, which is seen almost cvery where in damp places in spring, with br a leep green leaves, and glossy yellow flowers. It : wes not grow to any height. 'The leaves are an inch long, and nearly as broad; they somewhat resemble those of the garden hepaticas, and are of a dark green and frequently spotted; they rise singly from the root on long, slender, and naked stalks. The flowers rise also singly from the root on long, slender, aud naked stalks; they are as broad as a shilling, of a fine shining yellow colour, and composed of a number of leaves. The root is fibrous, and has small white tuberous bunps connected tothe strings.

'The roots are commended very much against the piles, the juice of them is to be taken inwardly ; and some are very fond of an ointment m : of the leaves, they chop them in pieces, and buil them in lard till they are crisp; then stiain off the lard, which is converted into a fine green cooling ointinent. The operation of the roots is by urine, but not violently.

\section{Litthe Centacay. Cinta:urium minus.}

A PRETTY wild plant which flowers in antuma, in our dry places. It is eight or ten inches high; the leaves are oblong, broad, and blunt at the point; the stalks are stifl, firm, aud erect; and the flowers are of a fine pale red. There grows a cluster of leaves an inch long or more from the root; the stalks diviled toward the top into several branches, and the flowers are lnug aud slender, aul stand in a rluster.

This is an excellent stomatic; its taste is is 
pleakant bitter, and given in infusion; it streugthi. ens the stomach, creates an appetite, and is good also arainst obstructions of the liver and spleen. It is on this last account greatly recommeided in jaundices; and the country people cure agues with it dried and nowdered.

As there are a greater and lesser celandine, there is also a great as well as this little centaury ; but the large lind is not a native of our country, nor used by us in medicine.

\section{Cungte Tree. Agnus castrus.}

A LITTLE shrub, native of Italy, and frequent in our gardens. It is five or six fect high; the trunk is rough, the branches are smooth, grrey, tough, and long; the leaves are fingered or spread like the fingers of one's hand when opened: five, six, or seren, of these divisions stand on each staik, they are of a deep green above, and whitish underneath; the flowers are small and of a pale reddist lue; they stand in long loose spilics; the fruit is us bim as a pejper-rorn.

the seculs of this shrub were once supposed to allay venery, but no bodr regards that now. $\Lambda$ droction of the leaves and tops is good againint sobstructions of the liver.

The Panch Cherry Tuen. Corasus fructu nigro.

THIS is a well known tall tree, and well sliaped. The baves are broad, roundish, sharp at the point, and indented round the ederes. The flowers are white, the fruit is well cnough known. The medienal part of this is the kernel whihin the stone. This has

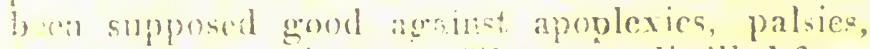
and ali hervuns cliseascs. 'The water distilled from 
te was, for this reason, in coustant use as a remedy for children's fits. But a better practice has now obtained : it is highly probable that this water occasioned the disorders it was given to remove. Laurel water, when made of a great strength, we know to be a suddeu poison: when weak, it tastes like black-cherry-water, and is not mortal; in the same manner black-cherry-water, which used to be given to children when weak drawn, has been found to be poisonons when of great strength. There in therefore the greatest reason imagimable to suppose that in any degree of strength, it may do mischief. Very piobably thousands of children have died by this misuspected medicine

The guin which liangs upon the branclies of cherry-trees, is of the same nature with the gum arabic, and may be used for the same purposes, as in heat of uriue, dissolved in barley-water.

Winter Cherry. Allekengi.

A VER I singular and prelty plant kept in our gardens; it grows two feet high, not very erect. nor inuch branched; the stalk is thick, strong, and anculated: the leaves are large, broad, and gharp pointed; the flowers are moderately largुe. find white, but with yellow threads in the middle; the fruit is a round red berry, of the bigness of a commun red cherry, contained in a green hollow husk, round, and as big as a walnut.

The berries are the only partused, they are to be separated from the husks and dried; and way be then given in powder or decoction. They are very grod in strangmies, heat of urine, or the gravel: they are also given in jaundices, and dropsies: they will do good in these cases but are not to be depended upon alone. 


\section{Chervin. Chorefolium.}

A SAILAD herb caltivated in gardens, but not without its medicinal virtue. It is like parsley in its manner of growth, but the leaves are more divided, and of a paler colour. 'The stalks are round, striated, hollow, and of a pale grcen; they divide into several branches, and are about two feet high : the leaves on them are like those from the root, but smaller. 'The flowers are bitter and white, they stand in large tufts at the tops of the branches. The seeds are large and smooth.

'The roots of chervil work by urine, but moderataly; they should be given in decoction.

\section{The Chesnut Tree. Castanca.}

A 'TALL, spreading, and beantiful tree. The trark is smooth and grey : the leares long and moderately broad, deep, and beautifully indented round the edges, and of a fine strong green. The flowers are a kind of catkins, like those of willows, long and slender, and of a yellowish colour; the fruits are covered with a rough prickly sholl, and, under that, each particular chesunt has its firm brown coat, and a thin skin, of an austere taste, a) ver the liernel

'This thinskin is the part used in medicine; it is to be separated from the chesust, not too ripe, and dried : it is a very fine astringent; it stops pureings and overflowings of the menses.

\section{Iarth-Chfsnut, or Farth-Nut Bubluocastamumb.}

A COMMON wild plant, which has the name from its roint. 'This is of the higness of a clesuntr 
- Gindish, brown on the outside, and white withm. and of sweet taste. 'The plant grows to a fout bigh ; the leaves are divided into fine and numerous particions; the stalk is firm, upright, round, striated and green; the fiowers are white aod little, but they grow in great tufis on the tops of the branches.

The root is the part used; it is to be roasted in the manner of a chesmut and eaten. It is spid to lave great virtues as a provocative to venery, bus this is not well confirmod.

\section{Cunck-were. Alsinc media.}

THE commonest of all weeds, but not withost it ; virtue. The right sort to use in medicine ("ior there are several) is that which grows so common in our garden-beds: it is low and branched. The stalks are round, grcen, weak, and divided; they commonly lean on the ground. The leaves are short and broad, of a pleasant green, not dented at the edges, and pointed at the end: these grow two at every joint. The fowers arewhite and small.

The whole plant, cut to pieces and boiled in lard till it is crisp, converts the lard into a fine green cooling ointment. The juice taken inwardiy, is good against the scurry.

'I'he China-root Plant. Smilax cujus radis China officiorum.

A NAILING plant frequent iu the Fast Indies. It grows to ten or twelve feet in length, but the stalks are weak and unable to stand erect; the are ridged, of a brown colour, and set with book" ed yellow prickles. The leaves are oblong and broad, largess at the stalk, abd blunt at the points, 
of a shimug green colour, and lissy surfice; the flowers are small and yellowish; the fruit is a round yellowish berry. "Whe root is large, irregular, and knotly; brown on the outside, and redish within. "his is the part used, they send it over to our druggists: it is a sweetcner of the bloorl, and is used in diet-drinks for the venereal discase and the scurvy. It is also said to be very grood against the gout, taken for a long time together.

There is ancther kind of this root brought from Anerica, paler on the outside, and much of the same colour with the other within; some have supposed it of morevirtue than the other, but most suppose it inferior, perhaps neither has much.

\section{Cur Cicer.}

A LITTLE plant of the pea kind, sown in some places for the fruit as peas. The plant is low and branched; the stalks are round and weak, and of a pale green. The leaves are like those of the pea, but each little leaf is narrower, and of a paler green, and hairy like the stalk: the flowers are small and white, and resemble the pea blossom. The pods are slort, thick, and hairy, and seldom contain more than two, often but one seed or chich in each.

They are eaten in some places, and they are gentle diuretics.

\section{Civeveroil. Pentaphyllum.}

A CREEPING wild plant common about waysides, and in pastures. The stalks are romd and smooth, and usually of a reddish colour: they lic unon the ground, and take root at the joints; the leaves stand on long foot-stalks, fre on each stalk; 
they are above an inch long, narrow, of a deep dusky green, and indented at the edres, the flowers also stand on long foot-staiks, they are yeliow and of the breathe of a shilling, very bright, and beantiful. The root is large and long, and is covered with a brown rind.

'The ront is the part used; it should be disg up is April, and the outer bark raken of and drited, the rest is nscless; this bark is to he giren mpondre for all sorts of fluxes; it stops pareging and the overflowings of the menses; fer druggs are of cyuat yower.

\section{The Cinganox Trer. Cinnamon.}

A LARGE tree frequent in the Eat, and not an sike the bar-tree in its flowers, fruit. leaves, or manuer of arowth; only larger. The bark is angh on the trunk, and simootin on the brunches; it has little tane whilefresh, but becomes aromatic and sharp, in that degree we pererive, by drving. The leares are of the shape of bay laves, bit twice as big; the howers ate snalt and whitish; the berrire are little, oblong, and of a bluish colour, epotted with white.

'The root of the cinnamon trecsmells strongly of canplitre, and a iery fane hind of camphite is nade from it in the Tast: the wood is white and inspid. The leave; are fraerant.

Whe root is the onl $r$ part used, and this is an excoilent atstrigent in the bowels; it is cordial and poovi to promore appretite: it alse promotes tho

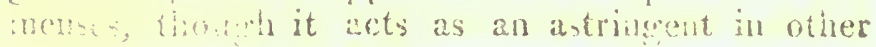
cais

The tran's Bare Tere. Cortex winteranus.

A ? the callud by maing winte's bark, has been 
already described under its true name canella alba; in this place we are to inquire into the true winter'sbark, called by many writers cinnamon. The tree which affords it is a tree of twenty fect high, very spreariag, and full of branches, the bark is grey on the ontside, and brown within. The leaves are two inches long, and an inch broarl, small at the stalk, and obtrise at the end, and diviled a lithle. The flowers are white and sweti-secuterl, the fruit is a snali berry.

Whe baf is the part used, they send orer the two rinds encether: it is very frament and of a hot aromatic taste. It is a sndorific, and a cordial, and it is excellent arainst the seurvy.

The Crstus Sin rub, fiom which labianum is procureal. Cistus lodtumifort.

A VID pretty shrub, fiequent in the Greek islands, an in ofher warm climates. It is two or three fect isch, wry much branclied, and las broad leaver, and benotiful larre flowers. The frunk is rough; ine twigs are reddinh; the learesare almost of tibe slape of thinse of sage; they stand two at every jomt, and are of i dark arrenculoun Jhe diviss are of the lireulth of half a crown, nud of a prale red colous. "The gum labdanum is pacared foun this shrub, and is its onls produce

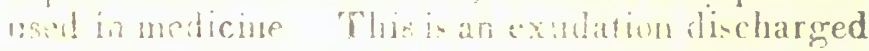
from the leaves in the: maniers of manna, more

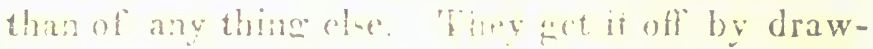

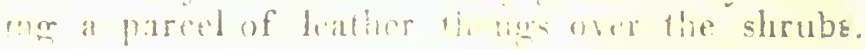
It is nut much used, bat it is a mood cephalic.

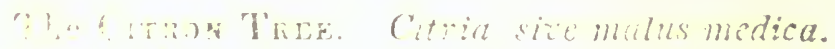

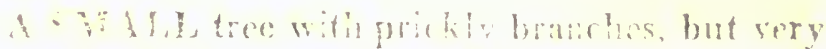

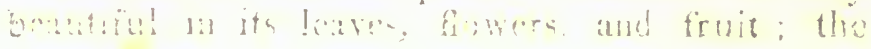


sank is $r$ rey and rough; the twigs are rrecu.

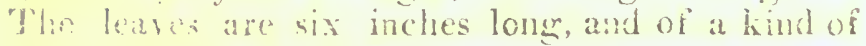
oval figme, and of a most beautulal green colour. The loners are white like those of the lemon tree, and the fintit rembles a iemon; but it is larger, and ofien fill of protuborances. 'lhe outer rind is of a pale fellow, and very fiagrant; the iner rind is exreecingly thick, and white ; there is very litile pulp, thongh the fruit be so large. 'The juice is like that of the lemon; but tice yellow cuter rind is the ony part used in medicine : this is an excellent stomachic, and of a very pleasant flavour. The Parlados water owes its taste to the preel of this fruit; and there is a way of making a water very nearly equal to it in England, by the adtition of spice to the fresh peels of good lemons; alle method is as follows:

Put into a sirall still a solion of fine molasses "pirit. pat to it six of line pects of very fine lemons, and hite an onnce of nutmeges, ant one dram of innamun bruised, let them stand all sight, then add $1 x 0$ quarts of water, and fasten on the head ; distii five pints and a llalf, and add to this a quat and half a pint of water, with five ounces of the incot sugal disolved in it. This will he very nearly equal to the finest Barbadoes water

\section{The Crastin. Citrullus.}

3 CIREPING plant of the melen kind, rulqivated in many parts of finrope and the Fas.

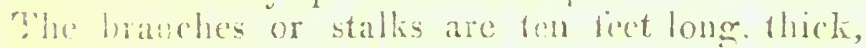
angular, fleshr, and lary : they trail ipon the proment unless supported. The leaves are larege, and taud singly on long fort-stalks: lleey are di-

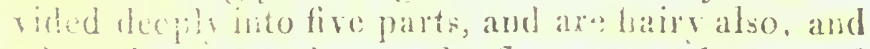
ot" it pute erecen colour ; the lowers are large and 
yeliow: and very like those of our cucumijers: the frut is also like the melon and cucumber kinds, romadis's, often flatted, and composed of a fleshy part under a thick rind, with seeds and juice within.

'The seeds are the only part used, our drugeists kerplien ; they are coling, and they work by urine gently; they are best given in torm "ff an emulsim, beat up with harleg-water.

\section{Chale Horminnm.}

(') I I Y is a common plant in our gardeus, not ver: beautiful, but kept for its virtues. It grows two feet and a half higis; the leaves are rubgh, and the fowers of a whitish blue. 'The stalks are thick,

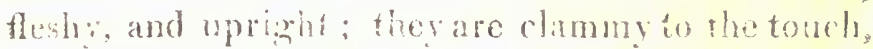
and a litic hair. 'I he leate arc large, wrinkled, and of a dusky green, brond at the base, and subiller to the point, whirh is obtuse; the flowers stand in long loose spike; they are dispo-ed in circhesound the "uper parts of the stalles and are gaing and larere. the rups in whirh the' stand are robust and in serne degree prickly.

The whole herb is meed fresh of drios. It is cortial, and in some derroc astringent. It atengt?-

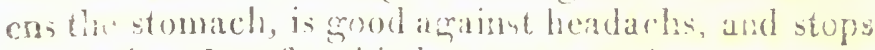
1!n white; but lop this lant puppos, it as vecessary to tabr it a lowg line; and there are mant rencdies more povertul.

'Mlare is a kind of wid clary on mor dith banks,

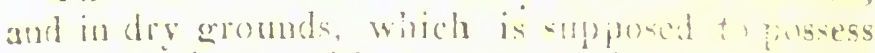

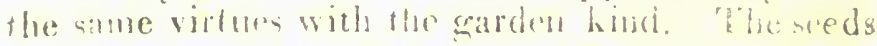

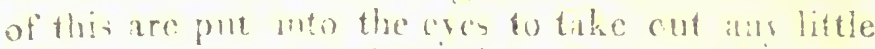

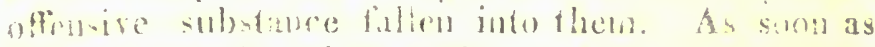

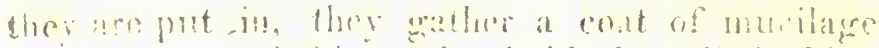

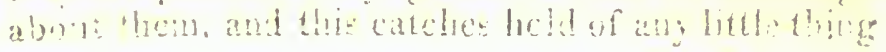


it meets with in the eve. Dar. Parms has perfectly explained this in his book of seeds.

\section{Clapera, Apariné.}

A WIJD herb common in all our ledges, and known by sticking to people's cluthes as they touch it. The stalks are square and very rough, two feet long, but weals and unable to support theniselves; they climb anong bushes. The leares are long and narrow, and of a pale green ; they grow several at every joint, encompassing the stalk in the manner of the rowel of a spur; they are rough in the same manner with the stalk, and stick to every thing they touch. The flowers are small and white; the sceds grow two together, and are roundish and rough like the rest of the plant; the root is fibrous.

The juice of the fresh herb is used; it cools the body, and operates by urine; it is good against the scurvy, and all other outward disorders. Some pretend it will cure the cril, but that is not true.

The Crove Bark-Tinef. Cassia caryophylatap

A TALL and beantiful tree, native of the West Indies. The trunk is covered with a thick brown bark, that of the branches is paler and thinner. The arms spread abroad, and are not very regularly disposed ; the leares are oblong, broad, and sharppointed; they are like those of the bay-trce, but twice as big, and of a deep green colour. The flowers ane small and blue; they are pointed with streaks of orange colour, and are of a fragrant smelt; the fruit is roundish; we use the bark, which is aken from the larger and smaller branches, b) ut that from the sinaller is best. It is of a fragrant 
smell, and of a mixed taste of cimmamon and clives; the cimamon flavour is first perceived, but after that the taste of cloves is predominant, and is so very strong, that it scems to burn the mouth. It in excellent against the colic; and it warms and - Prengthens the stomach, and assists digestion : it is also a cordial, and in small doses joined with onther medicines promotes sweat. It is not much saed fiairly in practice, but many tricks are played with it by the chymists, io imitate or adulterate the several productions of cloves and cimnamon, for u is cheaper than either.

The Clove July Flower. Caryophyllus ruber.

A COMMON and very beautiful flower in our gardens; it has its name from the aromatic snifll, which resembles the clove spice, and from the time of its flowering which is in $J u l y$. It is a carnation only of one colour, a deep and fue purple. 'The plant grows two feet high: the leaves are grassy; the stalks are round and ininted; the flower grows at the tops of the irranches, and the whole plant besides is of a bluish greon.

'The howers are usfi t they are cordial, and wood tor disorders of the head; they may bo dried, and taken in powder or in form of tea, mat the best firm is the syrup. This is made. ing ponring five pints of boiling water upon three roming of the flowers picked from the husks, and with the white heels cut off: atter they Satie atood twelie lours, straining of the clear lignor without pressing, and dissolving in it two punud of the finest sugar to every pint. This, malsos the most beantiful and plassant of ald Exr!:! : 
The Clore Spice Tree. Caryoprizllics coromaticus.

A BEAU'TIFUL tree, native" of the warm counlies: it grows twenty or thirty feet high, and very much branched. 'The bark is greyish; the leaves are like those of the bay-tree, but twice as large; they are of a bright shining green, and stand upon long foot-stalks; the flowers are mot very large, but of a beautiful blue colour, and the cups that contain them are oblong and firm; these are the cloves of the shops. They srather them soou after the flowers are fallen:; when they suffer them to remain longer on the tree, they grow large, and swell into a fruit as big as an olive.

The cloves are excellent against disorders of the head, and of the stomach; they are warm, cordial, and strengthening ; they expel wind, and are a grood remedy for the colic. The oil of cloves is made from these by chemists; it cures the tonth ach ; a bit of lint beihg wetted, with it, and laid to the tooth.

\section{Cockne. Pseudomelanthium.}

A TALL, upright, and beatiful plant, wild is our corn-fields, with red flowers, and narrow leaves. It is two feet high: the stalk is single. slenter, round, hairy, very firm, and perfectly nprigint. The leaves stand two at a joint, and are not rery numerous: they are long, narrow. hairy, and of a bright green colour : the flowers stand singly, we at the top of each bianch. THey are very large, and of a beautifnl red. They have an elerint cup, composed of five narrow haily leaves, whicts are much longrer than the flower 
Thesed ressel is roundis?, and the seecis are biack. They are ant to le mixed andong grain, aid trive the funr an lit foste.

The sends are rised; they work by uranc, aud

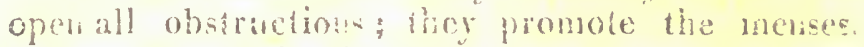
and are good in the cropur and jaundice; the best way of gryil:a tlicm is powdered, and pus into an electuary fo be falien for a coltinumec of time: for these radicines, whose vitues are

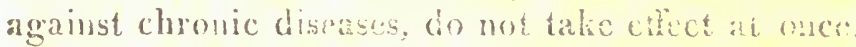
Many havediocontinued them for that reasun: and the world in general is, from the sanc camse, become, fond of chymical medicines, bit tiese are safer, and they are more to be lepended mon; and if the awo practices were lairly tried, chymical medicines would loose theri credit.

\section{The Cocuris ixi Trev. Arbor coculos Indi- cos ferens.}

A MODERATELY large tree, native ne the warmer parts of the world. It is irreatas in its growth, and full of branches; the losves are shurt, broad, and of a heart-like shape; they are thick. fleshy, small, and of a lasky greon: the fowers are ran!l, and stand in unsters; the fraits

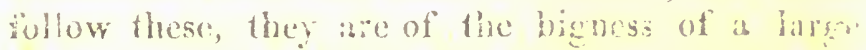
gex, Fomblish, but with a deis on one sids wrimkled, frialole, and biown in colour, and of an iil smell

'The powder of these strev ro non ribithen's heads that have vermin destroys hinem, penple alos intoxicate fish by it. Make a jonund of paste, with flotir and water, and ade a littio red led to colomi it, adri to it uwo onnces of bist coenlus blidi powdored. Seo where roach and other fish rise, and thow 
recolid, and they wili be intexicated. They will stim tipon the surface with their belly upward, antm nube taken ont with the hands. They are Lit the worse for eating.

\section{The Codaga Sirper. Colusce pall.}

A LIT'TLE shrub frequent in the East Indies, and rervbcautiful, as well as reseful. It grows ten or fiftecn feethigh; the branches are brittle, and the wood is white. 'The leares are long and narrow, not at all woiched at the edpes, aus of a beatifnl greten on both sides; the flowers ane targe and white, and somewhat resemblethore of bemebay, or acrinm, of which some make it a dutl. Each fower is succerted l.v two large pods, which are joined at the ends, arsd twist we chout the other; fary are full of a cottony matter about lie seeds. The whre plant is full of a milky juict, which it rields ple:thu!ly when broken

The buth is the onty parinsed; it is but nowly introduced inte medicine, but nay be lart of the druggints; it is an oxcellent ronedy for pureings. It is to be given in powder for thee or fon dace, amd a vomit or blecding before hic use of it, as mai. he found necessary.

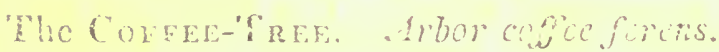

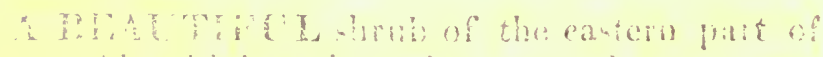

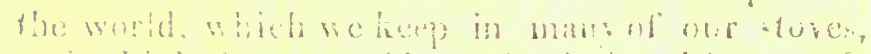

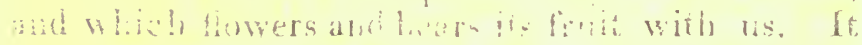

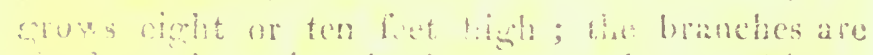

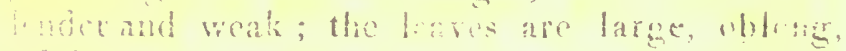

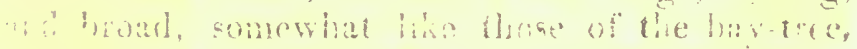

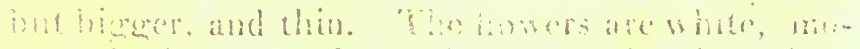

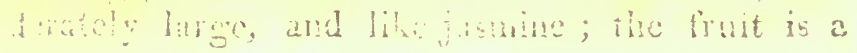


Aarge berry, black when it is riple, and in it are two seeds, which are what we call coffee; they ape whitish, and of a disagreeable faste when raw.

Cofiec holps dicestion, and dispels wind anc it works genls.y by urine. The best way of dang it is as we commonly cirnis 1t, and there are constitutions for which it is very proper.

Ges Colewort, or Sea Brnimeed. Soldzilla.

A PRETTY wild plant that we have on the sea coasts, in many places; and that deserves to be much more known than it is as a medicine. The stalks are a foot long, but weak and unable to support thomselves upright. They are round and areen or purplish: the lcaves are roundish, but shaped a little heart fashioned at the bottom; they siand upon long foot-stalks, and are of a shining grcen. The flowers are large and red, they are of the shape of a hell ; the roots are white and small, a milky juice flows from the plant when any part of it is broken: especially frem the root.

The whole plant is to be gathered fresh when about howering, and briled in ale with some nutmers and a clove or two, and taken in quantities ar protioned to the person's strength ; it is a strong perare and it sometimes operates also by urine, but there is so harm in that. It is fittest for country mente of robust constitutions, but it will cure dropsies and rloumatism. Nay I have known a clap ciared on a combly fillow, by only two dosen of it. The juire which onzes frotis the stilk and ronts mas be salyed, it lardens into a mbotance like scainmony, and is an cycellent purge 


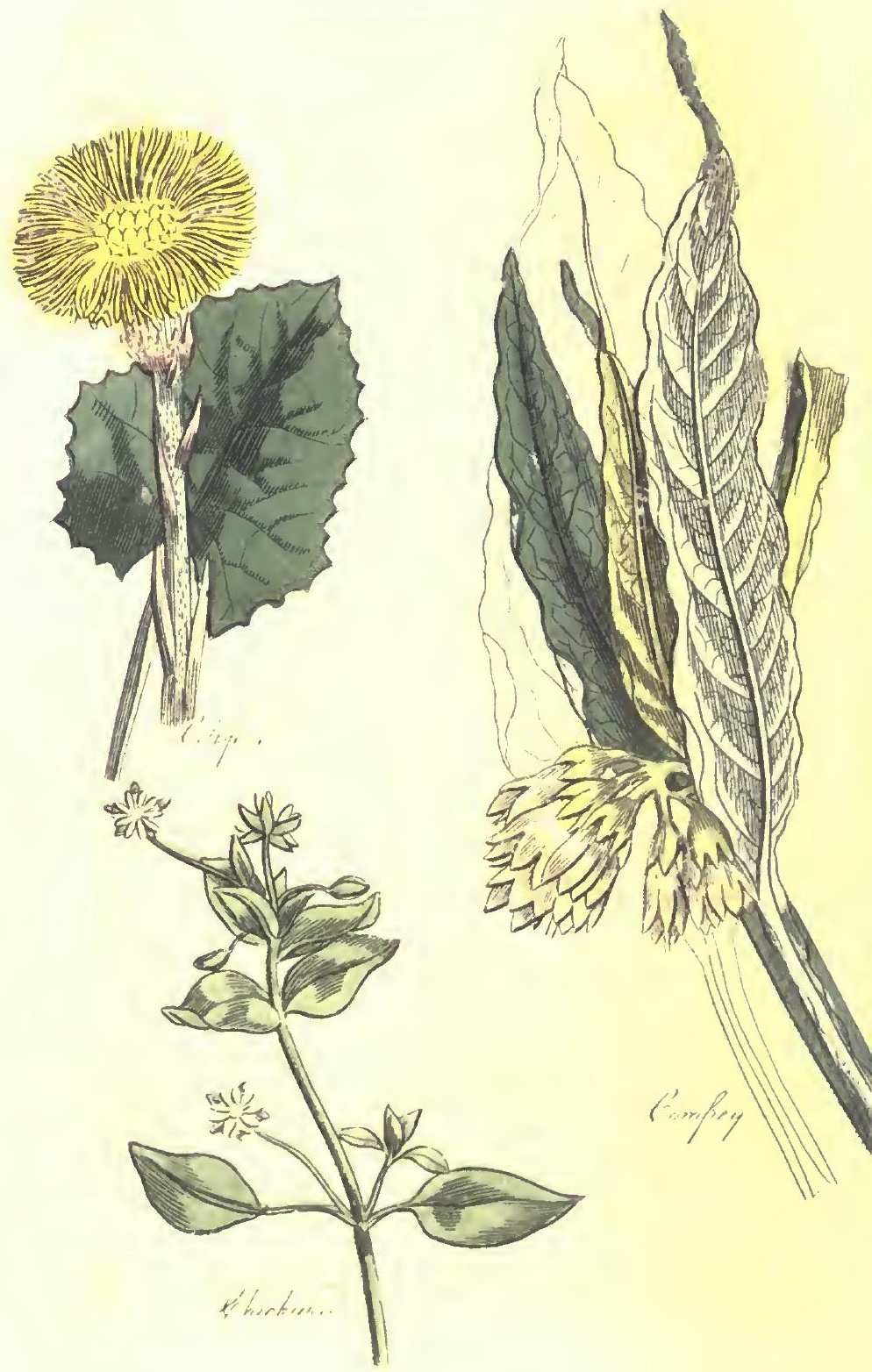


\section{FAMIIT HERBAL}

Contsfoot. Tussilago.

A COMMON wild herb, of excellent virtues, but so different in the spring and summer, as that it is scarce to be known for the same. The flowers appear in spring without the leaves; they grow on stalks six or eight inches high, round, thick, fleshy, and of a riddish colour, on which there stand a kind of films instead of leaves. The llowers grow one at the top of each stalk; they are vellow, and as large as those of the dandelion, and like them.

The leaves come up after these are decayed, the are as broad as nnes hand, roundish, and suppurted cach on a thiek hollow stalk, they are green (n) the upper side, and white and downy underneath. The flowers are not minded, these leaves only are Heded.

Columbere. Aquilegit.

A COMMOON garden flower, but a native alac of our country. It grows two feet light ; the teaves are divided into many parts, generally in a threefold order; the stalks are romit, firm, up-rightit, and a litile hairy ; the flowers are blue and large; the seeds are contained in a kind of horned rapsules. The leares and the seeds are used; a decoetion of the leaves is said to be gond against sore throats. The seeds npen obstructions, and are excellent in the jaundice, and nther complaints from like causes.

\section{Comfrer. Symphytum.}

A COMMON wild plant, of great virtue; it is frecluent by ditch sides; it grous a foot and half 
high : the leares are larme, long, not very hroal, rough to the tonch, and of a decp disarreeable grenen: the stalks are green, thick. angulated, and upright. The flowers grow along the topes of the branches, and are while, sometimes reddish, not Fery large. and hasg often downwards. The root is thick, biack, and irregular: wheir broken it is found to he white within and fuil of a sliny juice. This root is the part used. and it is best liresh, but it may be beat uip into a conserve, with three times its weylt of sugar. It is a renedy for that ter be disease the whites. It is also good again: spiting of bloos, bluody thxes, and purgings, and for inward bruises.

\section{The Coverayerva Prantar. Contriyeria.}

A $\mathrm{VE}$ 登 singular plant, native of Amerio,

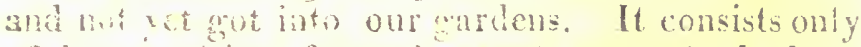
of than rang from the rout, upon single footstents, and flowers of a moular kind, standing also ons sighe and separate foot-stalks, with no leaves mpon them. 'Jhe laves are larpe, oblong, very Brond, and deeply divided on cach side ; their rolone is a duskr ereen; and the footestalls on wethey stand are small and whitish, and ofter benil monder the weight of the leaf. 'The. stalhs shich shoport the fowars, are storter and weaker than litere; and the flowers are of a very pecu-

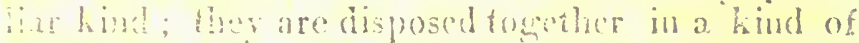
the form, and are very small and inconsiderable. ita led on wheh they are situnted is of an oval surne, and is colled the placenta of the plant; it is of a nale rolour and thin.

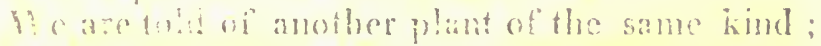

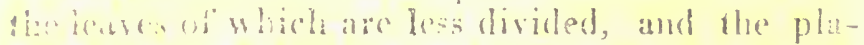
E.nta 1s sunare, but the rones of both are allowed 
to be exactly althe $3 ! 3$ it is therchore mis pro bable, that this is are anuther plant, but tue sanse in a ditferent stage of growis?

We use the ronts; ondruggist lieep them, and they are the principal ingredient in that famous powder, called, from it bring rolied up into balls, lapis contrayerva. It is an excellent cordial and sudorific, goud in fevers, and in lierous rases; and against indigestions, colies, and weaknesses of the stomacts. It may be taken in powder or in tinciure; but it is brifcr to give it alone, than with that mixture of crab's claws and other useless ingrediens, whicl: go into the contraverve stom. Pu ferers anc leervous disorders, it is beses

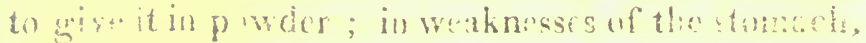

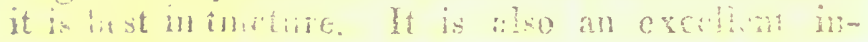

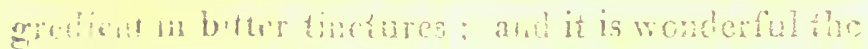

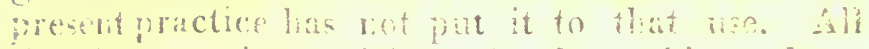
the wh prescribers of forms for these things have nut some warm root into thom; but rene is eo froper as this; the most usiat has hecin the gaiarwul, but that has a most risarrecable farcur in incture: the contraverva has all the virtacs expurted to be found his that, and io grite litexery tionable.

\section{The Copar Tres. Arbor copalifips}

\section{IARGE tree of South America. It groms} (1) a great height, and is tall. waight, and thlerabi regnlar ; the bark of the trunk in ot a derp brow. The branches are bitter. 'The lcaves are larga an whong, and they are blunt at the ends ; thers aro werjy cut in at the clges, and in it wore wot thes the are a creat deal longer in proportion to the: brearthe they would be rery lite three of the nat: the flowers are mederetny latge, and full r: 
threads; the fruit is round, and of a blood ral when ripe.

We use a resin which oozes from the bark of large trees of this species in great plenty, and is called copal; it is of a pale yellow colour, sometimes brownish, and often colourless, and like gurs arabic ; we have a way of calling it a gum, but it is truly a resin; and the yollow picces of it are 80 bright and transparent, that they very much resemble the purest amber.

It is grood against the whites, and against wearnesses left after the venercal discase ; but it is not so much used on these occasions as it deserves. It is excellent for making varnishes; and what is cormonly called amber varnish among our artists is made from it. Amber will make a very fine varnish, better than that of copal, or any other kind; but it is dear.

We sometimes sec heads of canes of the colonrless copal, which seem to be of amber, only they want its colour ; these are made of the sane resin in the Last Indies, where it grows harder.

\section{Cural. Corallinim.}

A SEL plant of the hardness of a stone, and with very liftle of the appearance of an lwerb. The red coral, which is the sort used in medicine, trows a foot or more in beight ; the trunk is as thick as a man's thumb, and the hranches are mumerous. It is fastened to the rocks by a crust which spreads over them, and is covered all over with a crust also of a coarse substance and striated texterce. Fowards the top there are flowers and seads, but rery small; from these rise the youign plants. The scels hase a mucilaginots matter abont them, wheh sticks them to the rochs. The 


\section{FAMILY HERBAL,}

whole plant appears like a naked shrub without leaves or risible flowers.

It has bcen supposed lately that coral is made by small insects, but this is an error; polypes live in coral as worms in wood, but these don't make the trees nor the other the plant. Coral is to be reduced to fine powder, by grinding it on a marble; and then it is given to stop purgings, to destroy acid humours in the stomach, and to swecten the blcod. They suppose it also a cordial. Probably for all its real uses, chalk is a better medicine.

There are several sorts of white ooral, which have been sometimes used in medicine; but all allow the red to be better, so that they are not kept in the shops.

\section{Coralline. Corallina.}

A LITTIE sca plant frequent about our own coasts and of a somewhat stony texture, but not like the red or white coral. It grows to three inches high, and is very much branched, and young shoots arise aiso from different parts of the branches: there are no leaves on it, nor visible flowers, but the whole plant is composed of short joints. It is commonly of a greenish or reddish colour, but when it has been thrown a time upon the shores, it bleaches and becomes white; it naturally grows to shells and pehbles. The best is the freshest, not that which is bleached.

It is given to children as a remedy against worms ? a scruple or half a dram for a dose.

\section{CorIANDER。 Coriandrum.}

A SMALL plant, cultivated in France and 
German, for the sake of its seed. It is two fect high, and has clusters of white or reddish fower: upon the tops of the branches. The stalks are round, upright, and liollow, hut have a pith in them; the leaves, which grow from the root, hare rounded tops, those on the stalks are divided into narrow parts; the seeds follow two after each flower, and they are half round.

The seed is the only part used : the whole plant when fresh has a bad smell, but as the seeds dry, they become sweet and fragrant. They are excellent to dispel wind; they warm and strengthen the stomach and assist digestion. It is good against pains in the liead, and has some virtue in stopping purgings, joined with other things.

\section{The Cornes Tree. Cornus mos.}

A GARDEN trec of the bigness of an apple iree, and branched like one; the bark is greyish, the twigrs are tough: the leaves are obloig, broad, and pointed, of a fine green colour, but not serrated at the edges. The flowers are small and yellowish, the fruit is of the bigness of a cherry, but oblong, not round; it is red and fieshy, of an astringent bark, and has a large stone. 'The fruit is ripe in autumu; the flowers appear carly.

The fruit is the part used; it nav be dried and used, or the juice boiled down with sugar ; either way it is couling and moderately astringent; it is a gentle pleasant medicine in fevers with purgings.

There is a wild cornel tree, called the female cornel, in our liedges; a shrub five feet high, whth broad leaves, and black berries; it is not lised in medicine. In some parts of the West Indies they iutoxicate fish with the bark of a shrub of this kind, by only putting a quandity of it into the water 



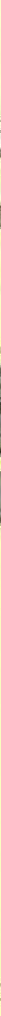


of a pond; we have not tried whether this of ours will du the same.

\section{Conv Marigond. Chrysanthemum segestum.}

A ER Y beatiful wild plant growing in cornfrelds, with large bluish leares, and full of flowero like marigolds. It is two feet high; the stalks are numerous, round, stiff, tolerably upright, and branched; the leaves stand irregularly, and are long, very broad, and of a bluish green; they are smallest towards the base, and larger at the end, and they are deeply cut in at the sides. The flowers are as broad as half a crown, and of a very beautiful yellow; they have a cluster of threads in the middle. The root is fibrous.

The flowers, fresh gathered and just opened, contain the preatest virue. They are good against all obstructions, and work by urine. An infusion of them, given in the quatity of half a pint warm, three times a day, lias been known to cure a jaunlice, without any other medicine; the dried herb has the same virtue, but in a less degree.

\section{Costmary. Costus hortorum.}

A GARDEN plant kept more for its virtues than its beauty, but at present neglected. It grows a foot and hali high, and has clusters of naked yellow flowers like tansy. The staiks are firm, thick, green, and upright; the leaves are oblong, narrow, of a pale green, and beantifully serrated; the flowers consist only of deep yellow chreads.

It was nuce greatly esteemed for strengthening the stomach, and curing lead-actis, and tor opening obstructions of the liver and splecn, but more seems to have been said of it than ii descrven! 


\section{The Costus Plint. Costus.}

A N Indian plant, which bears two kinds of stalks, one for the leaves, and the othe: for the flowers and seeds ; these buth rise from the sameroot, and often near one another.

The leaf-stalks are four feet high, thick, hollow, round, upright, and of a reddish colour.

The leaves are like those of the reed kind, long, narrow, and pointed at the edges, and they are of a bluish green colour. The stalks which bear the flowers, are eight inclies high, tender, sofit, round, and as it were scaly. The flowers are small and reddish, and they stand in a kind of spikes, interrnixed with a great quantity of scaly leaves.

The ront is the only part used; it is kept by our druggists; it is oblong and irregularly shaped. It is a very good and safe diuretic, it always operates that way, sonetimes also by sweat, and it opens obstructions of the viscera. But unless it be new and firm, it has no virtue.

\section{The Corton Tree. Gossypizm sive xylon.}

A SMALI, shruh, with brittle and numerous branches, and ycllow flowers: it does not grow more than four feet ligh ; the leaves are large, and divided cach into five parts; and of a dusky green colour The llowers are large and beantiful, they are of the hell-fashioned kind, as broad as a half crown, deep, if a ycllow colour, and with a purple bottom; the seed-vessels are large, and of a roundish figcire, and they contain the cotton with the seeds ammig it. When ripe, they burst open into three or folir parts.

The seeds are used in mediciue, hut not sn murt! as they dcservo; they arc excellent in cough, 
and all disorders of the breast and lungs; they cause expectoration, and are very balsamic and estringent.

\section{The Cotron Turste. Acanthiunn.}

A TALL and stately wild plant, common by our way sides, and known by its great white prickly leaves and red flowers. It is four or five feet high. The leaves which grow from the root are a foot and a half long, a foot broad, deeply indented at the edges, and beset with yellowish thorns; they are of a whitish colour, and seem covered with a downy matter of the nature of cotton. The stalks are thick, round, firm, and upright; and winged with a sort of leafy substances which rise from them, and have tise same surt of prickles that are upon the leares. The ordinary leaves upon the stalks are like those which grow from the root. only they are more deeply indented, and more prickly; the flowers are purple; they stand in long prickly heads, and make a beautiful appearance. The root is very long, thick, and white.

'The root, is the part used, and that should be fresh gathered. It opens obstructions, and is good against the jaundice, and in dropsies, and other disorders arising from obstructions. It also moderately promotes the menses. It may be dried and given in powder for the same purposes. But the virtues are much less.

Covch Grass, Gramen caninum.

A VERY troublesome weed in fields and gardins, but very useful in medicine. Niture. bas marie those plants which may be most useful 
to us the niosi common, and the most ditseult to be remored. Cinch errass grows two foet high, and is a robust kind of grass: the stalk is round and poninted: the leares are grassy, but broad, arei cit a ficsh green colour; the spike at the top s like an car of wheat, oniy thin and lat. It consints of ten rows of grails. The root is white, slouder, very long and jointed, and it takes fresh mold at every joint; si that if but a piece is lefi in pulling it up, it grows and increases ver quictily.

The roots are used, and they are to be fress taken up and boiled. The dccuction is excellent in the gravel and stone; it promotes urine strongiy, jut not forcibly or roushly. 'iaken fin a continuance, the same decoction is good against obstructicns of the liver, and will cure the jaunuice.

\section{Cowsurp. Paralysis.}

A PPETry wild plant in our meadnws. The leares are broad, oblong, indented, rough, and of a whitish grom colour; the stalhs are round, upright, firm, thick, and downy; they are six or cinit incises light, and are nalied of leaves. At the teip of each stand a number of pretty yellow Howre, rach npon a separate foot-stalk, and in its own separate cup.

Whe fowers are the part used. T!er have becs colebrated rery much against apuplexics, palsics, and nther terible dispases, but al procent in strel cases we do mut trust such rouches. 'lley have

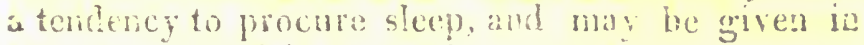
zacor brescricá in form of a cuncerre. 
Cowship of Jerusalem. Pulmonaria machlats.

A LOW plant, but not without beauty, kept in garfens fore the credit of its virtues, which are indeed mure and greater than the present negiect of it wn!ld have one to supponse. It grows to eight or ten unclus high; the leares are long and broad. hairy, of a deep green, and spetted with white spots on the upperside, but of a paler colour, and wot spotted lunderieath. The statrs are slender, angulated, and hairy, and have smaller luares on them, but of the same fogure with these iring the rout. The fiowers are suall and reddish, and grow several in a claster at the top of the stalk. The root is fibrous.

The leaves are used; they should be gathered before the stalks grow up, and dried; they are excellent in decocrion for coughs, shortness of breath, and all disorders of the lungs; taken in powder, they stop the overhowing of the menses; and when fresh bruised and pat into a new made wound, they stop the bleeding and heal it.

\section{Cow-whese. Cratcogmulim.}

A COMMON wild plant in our woods ant? thickets, with narrow hlarkish leaves, and brigh: yellow flowers. It is eight or ten inches high. The stalks are square and slender; very brithe. weak, and seldom quite upright. The lenves are oblong and nerrow; sometimes of a rusky grent? colour, but oftener purplish or latkigh; they are broadest at the base, and small all the way to the point; and they are conmouly, but not always indented a little about the eages. The flowers stand, or rather hang, all on one side of the stalis. in a lind of loose spike; they are small and yellow. 
and grow two together. 'The sceds which follow these are large, and have something of the aspect of wheat, from whence the plant has its odd name.

'These seeds are the part used; they are to be dried and given in powder, but in small doses. They have virtues which few seem to inagine; they are a high cordial and provocative to venery; but if given in too large a dose, they occasion the head-ach and a strange giddiness. I knew an instance of a woinan who had boiled the fresh tops of the plant in a large quantity in water, as a remedy for the jaundice, (I know not by what information, ) and having drank this in large draughts, was as a person drunk and out of her senses; she complained of numbness in her limbs, and seemed in danger of her life, but nature recovered her after * few hours without other assistance.

\section{The Crab Tree. Malus sylecstris.}

A COMMON hedge shrub, and when in flower very beautiful. The trunk is nneven, and the bark rough; the branches are knotty, the wood is firm, and the bark of a dark colour; the leaves are broad and short, the flowers are large and reddish, very beautiful and sweet, and the fruit is a small apple.

Verjuice is made from the crab; and it is a reonedy for the falling down of the uvula, better than most other applications : it is also good. against sore throats, and in all disorders of the nuquth.

Cranesbill. Cieraniubiz robertianim?.

CRANESPILL is a little lierb, very frequent 
tinder hedges, and in uncultivated places: there are many hinds of it, but that which has most vis. tue, is the kind called leerb robert; this is a pretty and regularly growing plant. The stallis aro a foot loug, but they suldin stand guite upright; they are round, branches, and jointed, and are often red, as is frequently the whole plant: the leaves are large, and divided into a great number of parts, and they stand upon long foot-stalks, two at crery joint. The flowers are moderately large, and of a bright red, they are very conspicuous and pretty; the fruit that follows is long and slender, and lias some recomblance of the loug beak of a bird, whence the niame.

The wholeplant is to be gathered root and all, and dried for uee; it is a most excellent astringent: scares any plant is equal to it. It may be given dried and powdered, or in decoction. It stops urerthowing of the inenses, bloody stools, and all other blecdings.

It is to be obscrved that nature scems to have set her stamp won several herbs which have the tintue to stop bleeding. This and the tusan, the two best remedies the felds aford for outward and mard bleedings, become all orer as red as blood at a certain scason.

\section{The Gannes Caess. Nasturtiun horense.}

a COMWON garden plant, raised for sallads. It sowo fect high: the staik is remet and firm, and of :a blush greer: the leares are livided into scerments, and the fowres are mail and white; wot the fintl grom plant is not seen at nur tables; vo ent wits the leases rising iandiately from the roct. the nro lare e, fitely divided, of a bright greer. 
and sharp. Cresses eaten in quantity are very good sgainst the scurvy. The seeds open obstructions.

Water Cress. Nasturlium aquaticum.

A WILD plant common with us in ditches, and shallow rivers. It is a foot high, the stalks are round, thick, but not very upright, of a pale green, and much branched; the leaves are of a fresh and bright green, divided in a winged manner and obtuse; the flowers are small and white, and there is generally seen a kind of spike of the flowers and seeds at the top of the stalks.

The leaves are used; they may be eaten in the manner of garden cress, and are full as pleasant, and they are excellent against the scurry. The juice expressed from them has the same virtue, and works also powerfully by urine, and opens obstructions.

\section{Sciatica Cress. Iberis.}

A PRET'TY wild plant, but not frequent in all parts of the kingdom. It is a foot high. The stalk is round, firm, and upright; of a pale green colour. The leares are smali, longish, and of a pale green also; and the fowers stand at the tops of the branches, into which the stalk divides in its upper part; they are white and little. The leaves that grow immediately firom the ront, are four inches long; narrow and serrated about the edges, and of a deep green.

The leaves are used; they are recommended greatly in the sciatica or hip-gont; they are to be applied externally, and repeated as they crow dry. the best way is to beat them with a little lard. It 



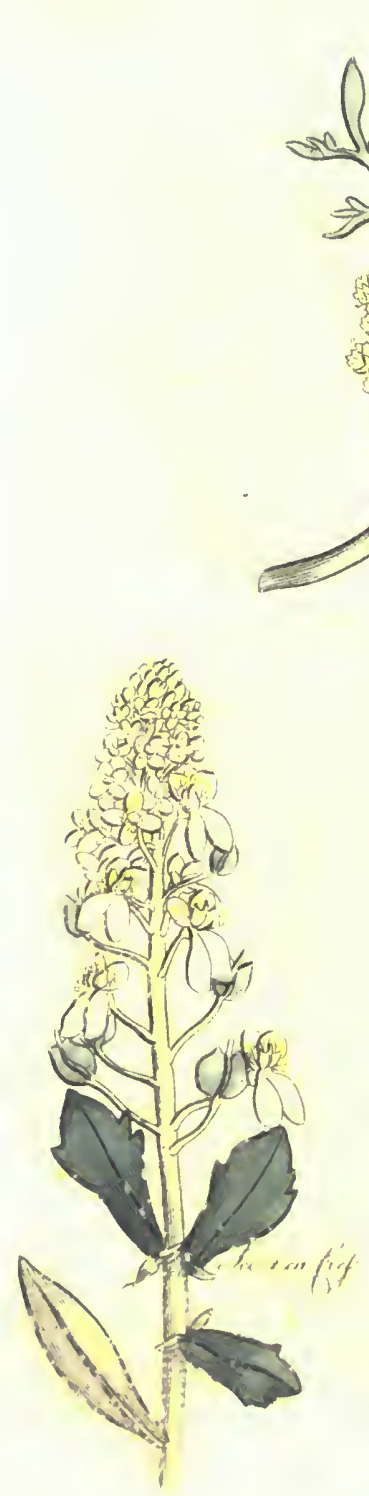


is an approved remedy, and it is strange that it is not more in use.

\section{Wart Cresses, or Swine's Cressrs. Coronopue ruellii.}

A LITTLE wila plant very common about our felds and garlens. It spreads upon the ground. The stalks are five or six inches long; firm, and thick, but usually flat on the earth; very much branched, and full of leaves. The leaves that rise immediately from the root are long, and deeply divided: and those on the stalks resemble them, ouly they are smaller : they are of a deep glossy green colour, and not at all hairy. The flowers are small and white; they stand at the tops of the branches and among the leaves; the seed-vessels are small and rough.

This is an excellent diuretic, safe, and yet very powerful. It is an ingredient in Mrs. Stepilens. medicine: the juice may be taken; and it is good for the jaundice, and against all inward obstructions, and against the scurvy; the leaves may also be eaten as salad, or dried and given in decoction.

\section{Cons-wort. Cruciata.}

A VERY pretty wild plant, but not very common : it grows a foot and a half high. The stalks are square, hairy, weak, and of a pale green. The leaves are broad and short; they stand four at ever, joint, star-fashioned, upon the stalk. The flowers are little and yellow; they stand in clusters zound the stalk, at the joints, rising from the insertion of the leaves. It is to be found in dry places. 
The whole plant is to be gatlicred whea beninning to flower, and dried. A strong decoction of It is a good restriagent and styptic ; it stops purgings, even when there are bloudy stools; and overflowings of the menses.

\section{Crow-rnot. Ranucillus.}

A COMMON wild plant. There are several sorts of it, but the kind used in medicine is that most common in meadows, and called the common creeping crowfuot. It grows a foot or more high ; the stalks arc firm, thick, branched, and of a pale green; but they seldom stand quite upright. The Jeares on them are lew, and divided into narrom segunents; the flowers are yellow, of the breadth of a shilling, and of a fine shining colour; they staind at the tops of all the branches; the leaves which rise from the root are large, divided in a ttisecfold manner, and oflen spotted with white.

some are su rash as to mix a few leares of this among salad, but it is very wrong; the plant is caustic and poisonous. They are cxcellent applicel externaliy in palsies and apoplexies; for they act quicker than cantharides in raising blisters, and are more felt. It is a wonder they are unt more nsed fur this purpose; but we are at present so forlt of foreign mediciues, that these things are not muided.

There are two other kinds of crow-foot distinguished as poisons; though all of them are, with some degree of justiere, branded with this rane: but the two most pernicious kinds are that called spearwort, which lias long, narrow, and unlivided leaves; and that with very small flowers, and leaves sunewhat like the divisions of those of smallage. "luese both grow in watry places. 


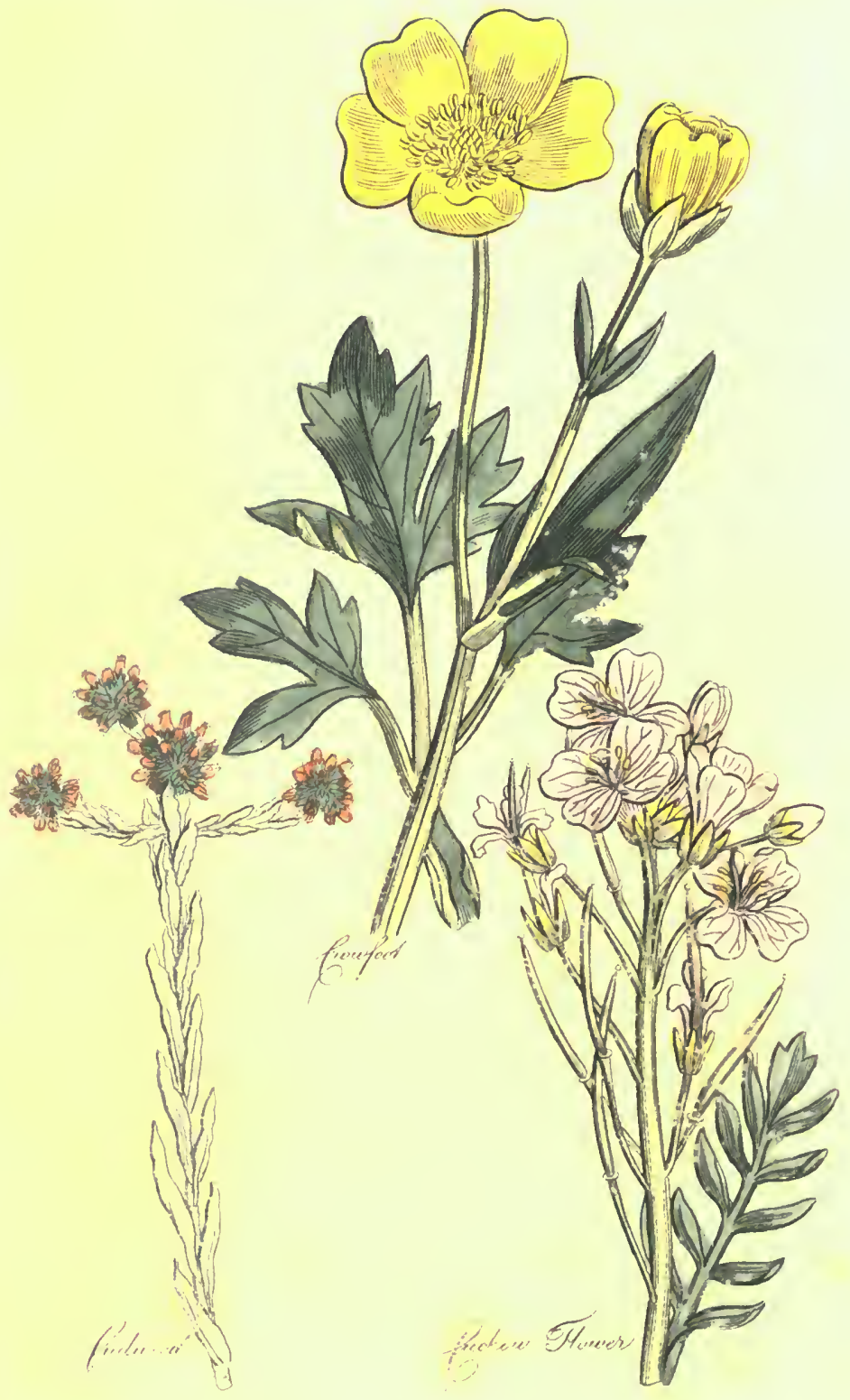





\section{Tho Cubro Plast. Cubeba.}

A CLIMBERING plant of the warm climates, but unknown in this part of the world, until described b: those who have been where it grows. 'The stalks are weak, angulated, and reddish; the leaves are b:oall and short, and the Howers small; the fruit is of the bigness of a pepper corn, but a little oblon: and grows on a long and very slender foot stalk.

This fruit is the part used ; the druggists keep it. It is a wain and pleasant spice goou against verhinesses of the stomach, in colics, aild in palsies, and all nervous disorders. But it is seliom used alone.

\section{The Cucumar PLAst. Cucilmis hortensis.}

A CREERING straggling plant suficiently known. The stalks are a yard or two long, thick, but spread upon the ground, angulated and hairy. The leaves are broad deeply indented, and very rough, and of a huish green colour; the flowers are large and yclow. The fruit is long and thick; tine ceds are used in medicine, and the fruit shoull he suliered to stand till very ripe before they are gathered. They are coolug and diuretic, good against stranguries, and all disorders of the nruary bassages; the liest way of giving them is beat up to m emulsion with barley water.

\section{The Wild Cucumer. Cucumis asininus.}

THIS, though called wild, is not a native of Fnelund. It spreads upon the erougd in the wintier of the other cucumber, and its branches frow to a consderable longth; they are thick, 
hairy, angulated, and of a pale green and tough. The leaves are broad at the base, and narrow at the point, scrated round the edges, and of a pale green above, and whitish below. The flowers are yellow, and moderatcly large; the fruit is of an oval figure, hairy, and full of juice. Care must be taken in teuching it when ripe, for the sharp juice tlies out with violence.

The juice of the fruit is pressed out, and a thick watter that subsicles from it is scparated and dried; the drugcists leep this and call it elatherium, it is a violent purgative, but little used.

Cuckow Flower, or Lady's smock. Carda. minc.

A VERY beatiful wild plant, frequent in our meadows in spring, and a great ornament to them. It grows a foot high. Tlie leaves which rise from the root, are winged very regularly and beautifully, and are spread in a circular manner, the stalk is round, thick, firm, and upright. The leaves that grow on it are smaller, finely divided, and stand singly. The flowers grow in a little cluster, on that spike on the top, and from the hottom of the leaves. They are large, of a fine white, often ringed with a blush of red.

rithe juice of the fresh leares is to be used: it is an excellent liuretic, and is good in the gravel and all suppressions of urine. It also opens obstructions, and is good in the jaundice and freen sichness; and a course of it against the seurvy.

Cudwed. Guaphalium.

A COMMON wild plont, but singular in is 
anpearance. There are many species of it. But that used in medicine is the kind called the middle cudweed, a lierb impious. It has this last name from the whinsical observation of the young flowers rising above the old ones, which is called the son's growing above the father. This cudweed, is a little low plant, it seldom rises to a foot high. Ihe stalks are tough, firm, white, slender, and upright; they are very thick, set with leaves, which are small, oblong, white, and pointed at the ends, and seldom lie very even. The flowers are a kiud of brown or yollowish heads, standing at the tops, and in the dirisions of the stalks.

The herb bruised, and applied to a fresh wound, stops the bleeding; it may be also dried and given in decoction, in which form it is good against the whites, and will often stop violent purgings.

\section{Cumms. Cuminum.}

A PLANT of the umbelliferous kind, cultivated in every part of the East, for the value of the seed. It grows a lont and a half high. The stalk is round, striated, green, and hollow. The leaves are large, and very finely divided in the manner of those of tennel. The flowers stand in large clusters, at the tops of the branches, and they are small and white, with a blush of red. The seeds are long and striated.

The seeds are used. Our druggists keep them. They are of a very disagreeable flavour, but of cxcellent virtues; they are good against the colic and wind in the stomash, and, applied outwardly, they will often remore pains in the side. They must Le bruised, and a large quantity laid on. 


\section{The Brack Curkant. Ribesia migrci,}

THIS is a little shrub, of late brought very universally into our gardens. It grows three or fi) ur foothigh. "Whe branches are weak, and the bark is smooth. The leaves are large and broad, and diviked in the maner of those of the common currants; but they hase a strong smell. The flowers are greenish and hollow. The fruit is a large and round berry, black, and of a somewhat disagrceable taste, growing in the manner of the currants.

The juice of black currants boild up with supar to a jelly, is ail excellent remedy against sore throats.

\section{Long Cyperus. Cyperus longus.}

A VILD plant in our warshes, fens, antother damp places. It is a foot and half lighti. The leaves are a foot loug or nore, narrow, grassy, aud of a bight wen colonr, flat, and sharp at the cuds. Whe stalk is trimgular and green : there are no leaves on it, except tyo or three smald ones at the top, fiom which there rises a number of small tufts or spikes of flowers. These are brown, light, chaliy, and in all respects like those of the other vater grasses.

me ront is used. It is loner and brown, and when drich, is of a pleasal riscll, ard aromatic warm taste. It shoth be talden p in suring. If it mod against patils in the head, and hi pronotes urlitc.

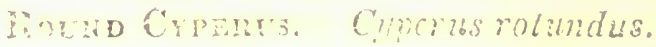

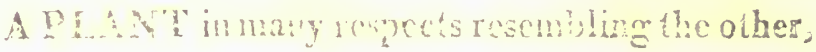


but a native of the warmer countries. It grows two feet high. The leaves are very numerous, a foot and a half long, narrow, of a pale green colour sharp at the point, and ribbed all along like those of grass. The stalk is triangular, and the edges are sharp; it is firm, upright, and often minplish, especially towards the bottom. The flowers are chaffy, and they grow from the top of the stalk, with several small and short leaves set under them; they are brown and light. 'The ront is composed of a great quantity of black fibres, to which there grows at certain distances roundish lumps. These are the only parts used in medicine, Our druggists keep them. They are light, and of a pleasant smell, and warm spicy taste.

They are good in all nervous disorders. They are best taken in infusion, but as the virtues are much the same with the other, that is best, because it may be had fresher.

\section{The Cypress Tree. Cupressus.}

A TREE kept in our gardens, an evergrern, and singular in the manner of its growth. It rises to twenty or t?irty foot high, and is all the way thick beset with branches. These are largest towards the brittom, and smaller ail the way up: so that the tree appears naturally of a conie fiware. The bark is of a reddish brown. The leaves are small and short, they cover all the twigs like scalcs, and are of a beautiful decp green. The flowers are amall and inconsiderable. wile fint is a kind of nut, of the bigness of a small walnut, and of a brown colour and firm substance. lithen ripe, it divides into several parts. and the eceets fall nut.

The fruit is the mily part used. It is to has 
gathered before it bursts, and carcfully dried and given in powder; five and twenty grains is the dose. It is an excellent halsamic and styptic. It stops the blecting of the nose, and is grood against spitting of blood, bloody-flux, and overflowing of the menses. We are not aware low powerful a remedy it is ; few things are equal to it.

\section{I).}

\section{Common Daffodill. Aarcissus.}

A WILD English plant, with narrow leaves and great yellow flowers, common in our gardens in its own form, and in a great variety of shapes that culture has given it. In its wild state, it is about at foot light. The leaves are long, narrow, grassy, and of a decp green, and they are nearly as tall as the stalk. The stalk is roundish, but somewhat flatied and elged. The flower is large and single; it stands at the top of the stalk, and by its weight presses it down a little. The root is round and white.

The fresh root is to be used, and tis very easy to have it always in readiness in a garden; and very uscful, for it has great virtues. Giveninternally, in a sinall quantity, it acts as a vomil, and afterwards purges a little; and it is excellent agaust all obstructions. The best way of giving it is in form of the juice pressed ont with some white wine, but its principal uses are externally. The eastern nations have a peculiar way of drying the thick roots of plants, especially if they are full of a slimy juice as this is: They put them to soak in water, and then hang them over the steam of a pot in which rice is boiling; after this they string them up, and they become in some 
degree transparent and horny. It would be worth while to try the method upon this root and some others of our own growth; which, because of this slimy juice, we cannot well dry any other way; probably this would lose its romiting quality when dried, and would act only as an opener of obstructions, in which case, it might be given in repeated doses; for at present no body will be prevailed upon to take it often.

The fresh root bruised and applied to fresh wounds heals them very suddenly. Applied to strains and bruises, it is also excellent, taking away the swelling and pain.

The Great Darsy. 'Bellis major.

A BEAU'TIFUL and stately wild plant, which, if it were not frequent in our fields, would donhtless be estremed in gardens. It grows to a foot high. The stalks are angulated slender, but firm and upright: the leaves are oblong, narrow, dented ronnd the edges, and of a beautiful deep green. The flowers stand on the tops of the branches. They are white, and an inch hroarl: verv like the white china starwort so much coterned in onr gardens. The root is slender.

'The flowers are the part used. They are to be githered when newly opened, and dried, and may atterwards be given in powder or infusion. They are good against coughs and shortness of hreatli, and in all disorlers of the lungs. 'They are balsamic and strengthening.

\section{The Latece Dissy. Bellis minor.}

A PRETTY wild plant, too common to need s....h he heription, but too much neylected for its 
virtucs. The leaves are oblong, broad, and obtuse. The stalks are three or four inches high, and have no leaves. The flowers grow une on each stalk, and are of the breadth of a shilling, and whitish or reddish. The root is composed of a rest quantity of fibrew.

The roots fresh gathered and given in a strong decoction, are excellent against the scurvy; the use of thein must be continued some time, but the event will nake amends for the trouble. People give these roots boiled in milk to keep puppies from rrowing, but they have no such effects.

\section{Danderion. Jens leonis.}

ANOTHER of our wild plants too common to need much description. The leaves are very long, somew hat broad, and deeply indented at the edges. 'The stalks are naked, hollow, green, upright, and six, cight, or ten inches high; nne flower stands on each, which is large, ycllow, and composed of a great quantity of leaves, and seeds which follow this, have a downy matter aflixed to them. The whole head of them appears globular. The root is long, large, and white. 'The whole plant is full of a milky juice, the root most of all. This runs from it when broken, and is bitterish but not disagresable.

The root fresh gathered and boiled, makes an excellent decoction to promote urine, and bring away' gravel. 'The leaves may be eaten as salad when very young, and if taken this way in sufifcient quantity, they are good agrinst the scurvy.

Red Darsele. Loliumb mbrum.

A (WIL) grase, very common about way-sides, 
and distinguished by its stubborn stalks and low growth. It is not above a fout high, often much less. The leaves are narrow, short, and of a dusky grcen. The stalk is thick, reddich, somewhat flatted, and upright. 'The ear is flat; and is composed of a double row of short spikes: this, as well as the stalk, is often of a purplish colour. The root is composed of a great quantity of whitinh fibres.

The rnotsare to be used ; and they are best dried and given in powder. They are a very excellent astringent ; good agrainst purging, overflowing of the menses, and all other fluxes, and bleeding ; but the last operation is slow, and ther must be continned. 'Tis a medicine fitter, therefore, for lobitual complaints of this kind, than sudden illness.

There is an old npinion that the sneds of darnell, when by chance mixed with coris, and made into bread, which may happen, when it grows in cornfields, occasions dizziness of the head, sickness of the stomarh, and all the bad effects of drunkenness : they are said also to hurt the eres; but we have very little assurance of these effects; nor are they rery probable. 'They properly belong to another kind of darnell, distinguished by the name of white darucll; which is a taller plant, and more common in com-fields than the red; but this is rery much 10 be suspected upon the face of the accomnt. Tlie antients make frequent mearion of this lind of darnell, growing, to their great distress, among the wheat; but by the accidental hints some have given about its height, and the shape of its ear, they secm to have meant the common dog 's grass or couch grass, under that vame ; though others have semed to understand the distinction. In this nncertainte, however, remains the matter abont which particular kind of grass was rea!ly accused 
of possessing these bad qualities: but it is $m$ ost jorobable that they belong to neither; and that fancy, rather than any thing really known, gare birth to the opinion.

\section{The Date Trese. Palma daetyliferu.}

A IREF of the warmer countries, very unlike ethose of owr part of the world. 'The trunk is thick and tall, and is all the way up of the same bigness; it has no bark, but is corered with the rudinents of leaves, and the inner part of the trunk when it is young is eatable. At the rop of the trunk stand a rast quantity of leaves, some erect and some droopsing, and fiom the bosoms of these grow the flowers and the fruit; but it is remarkable that the flowers grow upon the trees only, and the fruit on sorne othery. Il there be not a tree of the male kind, that is a fnwering tree near the fruit of the female, it will never nalurally ripen. In this case tley cut off bunches of the flowers, and shake them over the lesed of the female trce, and this answers the purpose

All plants have what may be called male and fe. male parts in their flowers. 'The male parts are certain dusty particles: the female parts are the rudiments of the fruits. In soine plants these are in the same flowers as in the tulip. 'llose black wrains which dust the hands are the male part, and thr green thing in the middle of them is the female: it beromes afterwards the fruit or seed ressel. In other plants, as melous, aud many inore, the male parts grow in some flowers, and the female parts in others, on the same plant: and in ofluers, the male flowers and the female grow upon absolutely dif. ferent plants, but of the skme kind. 'This is the ase in the date tree as we see, and it is same though 



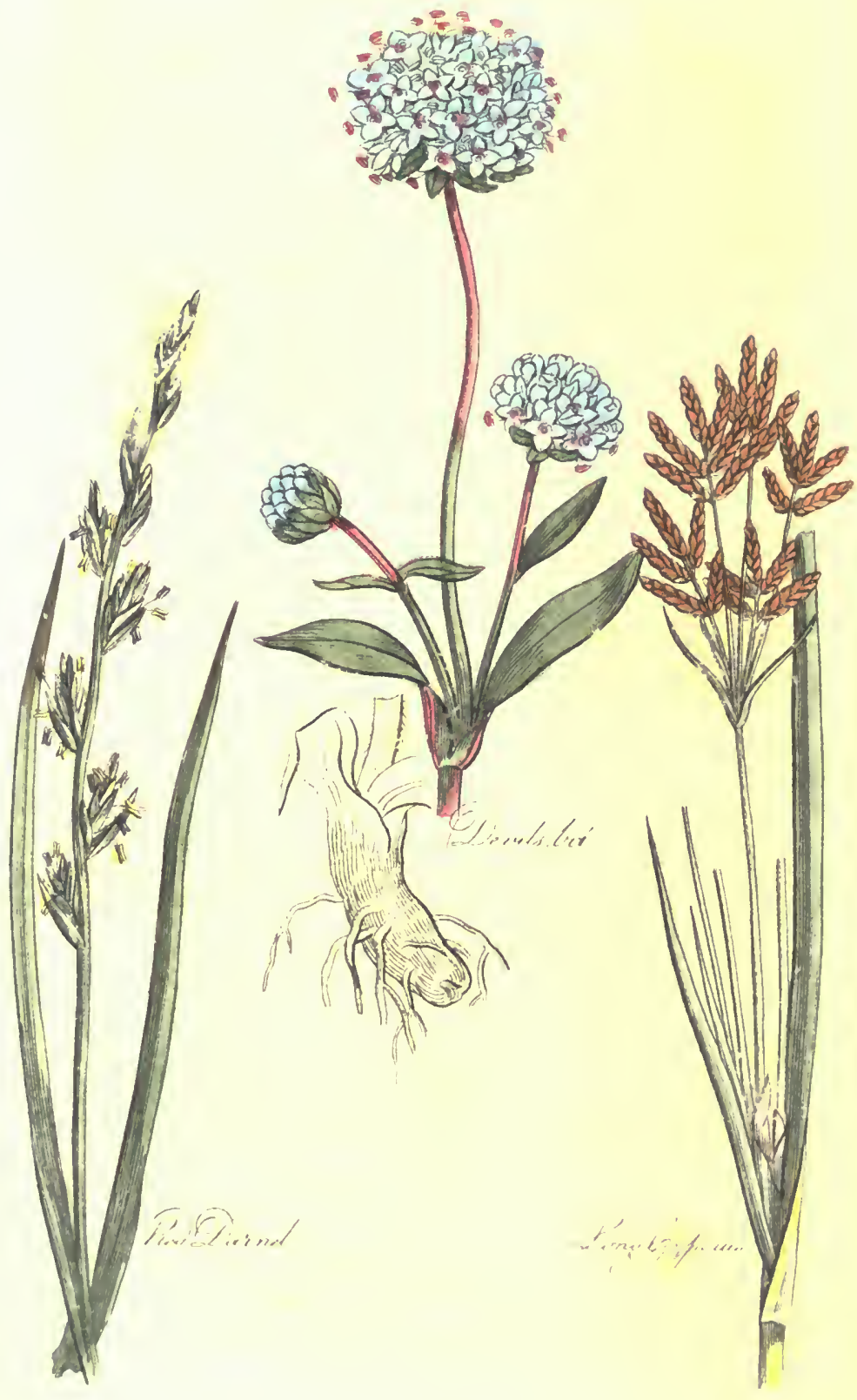


we do not much regard it, in hemp, spinage, and many others.

'The fruit of the date is the only part used. It is as thick as a man's thumb and nearly as long, of a sweet taste, and composed of a juicy pulp, in a tender skin, with a stone within it. They are strongthening and somewhat astringent, but we do not much use them.

\section{Devil's Bit. Succisu.}

A WILD plant in our meadows, with slender stalks, and globolis flowers. It grows two feet high. The stalks are rousd, firm, and upriont, and divided into several branches: they have two little leaves at eacl joint. 'The flowers are as big as a small walnut, and composed of many little ones; their colour is very strong and beautifin. The leaves which grow fiom the root are fon inches long, an inch broad, obtuse, of a dark green, and a little hairy, not at all divided, or so much, as indented at the edges. 'The roots are white, and compoined of a thick head, which terminates abruptly as if it had bcen bitten or brokes. off, and of a multitude of fibres. The Devil, as old women say, bit it away, enrring mankind its virtucs.

The leaves are to be gathered before the stalks appear. They are good against coughs, and the disorders of the lungs, given in decoction. The rot dried and given in powder, promotes sweat, and is a grood medicine in fevers, but we neglect it.

\section{Dir.t. Ancthum.}

An umbelliferous plant, licpt in our gardens, principally for the use of the kitchen. The stalk is round. striated, hollow, upright, three feet high. 
and divided intc a great nany branches. The leaves are diviod into numerous, narrow, and long parts, in the manner of fomel; but they are not so large. 'Tlie flowers are small and vellow; they stand in clusters on the tops of the branches. "The root is Innge. The sceds of dill arc good against the colic; and they are said to be a specific against the hiccough, but $I$ have known them tried withont success.

Dittander. Lepidium.

1 T\LL plant, with broad leaves and little white fiowers; wild in some places, and frequent in our gardens. It grews a yard ligh. The stalis are round, fim, of a pale green, and very much branched. The leaves are large towards the bottom, smaller upwaids; and the flowers stand in a lind of loose spikes; the lower leaves are beantifully indonted, the others scarce at all: the seeds are contained in little rombiish capsules, and are of a hot and pungent taste.

the leares of dittander fresh, gathered and boilfil in water, matic a decoction that works by urine, and promotes the menses: they are alao guod to pronate the necessary discharges after delivery.

Dhtaxy of Chete. Dictamuns Creticus.

A ThP pretty litts plant, natise of the East, and bet in some of our curiems preple's grindens.

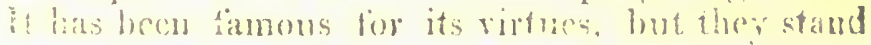
mare upon the eredit of seport th:tn experience. It is six or right buches high, the stalks are square, slember, hard, wouly, aud branclied. The leaves ancelurt, broat, and romdinh; they stand two at every joint, abd are corered with a white wolly 
matter. The flowers are small and purple: they grow in oblong and slender scaly heads, in the manner of those of origanum; and these heads are themselvcs very beatutiful, being variegated with green and purple. The whole plant has a fragrant sincll.

The leaves are used, our druggists keep them dried. The old writcrs attribute miracles to it in the cure of wounds; at present it is seldom used alone; but it is good in nervous disorders, and it promotes the menses, and strengthens the stomach.

\section{White Ditrany. Fraxinella.}

A VERY beautifil plant, native of many of the sa armer parts of Lurope; but with us kept only in gardens. It is three foot high, yery much branched and very beantiful. The stalks are round, thick, firm, and of a green or purplish colour. The leaves stand irregularly on them, and are like those of the ash tree, only smaller. The flowers are large and elegant: they are of a pale red, white, or striped; and they stand in a kind of spikes at the anp of the branches. The whole plant is covered in the summer months with a kird of halsam, which is glutions to the touch, and of a rery fragrant smell. This is so iufammahle, that if a cand! 3)e brought near any part of the plant, it takes fire and goes of in a tash all over the plant. This soes it no harm, and may be repeated after three or four days, a new quantity of the balsam being produced in that time. The ronts of this plant ar. the culy part used, and theg are laept dry by the drugmists. They are commended in evers, and in xerrous and hysteric cases, but their virtues are not great. Ihape foled and in fosion of the togs of 
the plant, a rery pleasant and excellent medicine in the gravel; it works powerfully by urine, and gives ease in those colicy yains which frequently attend upon the disorder.

Sharp-pointed Dock. Lapathum folio acuto.

A COMMON plant, like the ordinary dock, but somewhat handsomer, and distinguished by the figure of its leaves, which are sharp-pointed, not obtuse as in that, and are also somewhat narrower and longer. The plant grows three foot high. The stalks are erect, green, round, striated and branched. The leaves are of a fine green, smooth, neither crumpled on the surface, nor curled at the edges, and have large ribs. 'The flowers are small, at first greenish, then paler, and lastly, they dry and become brown. The root is long, thick, and of a tawny colour.

The root is the part used. It is excellent as gainst the scurvy, and is nne of the best things we know, for what is called sweetening the blood. It is best given in diet drinks and decoctions. Used outwardly, it cures the itch, and other foulness of the skin; it should be beat up with lard for thiz purpose.

Great Water Dock. Hycórolapathum maximum.

TIIIS is the largest of all the dock kinds; they have a general resemblance of one anotier, but this is mont of all like to the last described, in its mau. ine of errowth, though vastly larerer. It is frequont about vaters, and is five or six fect high. The sial's are round, striated, thich and very upright, braw hed a little and hollow. 'The leaves sre varly isige ; of a pale green colour, sulootb. 


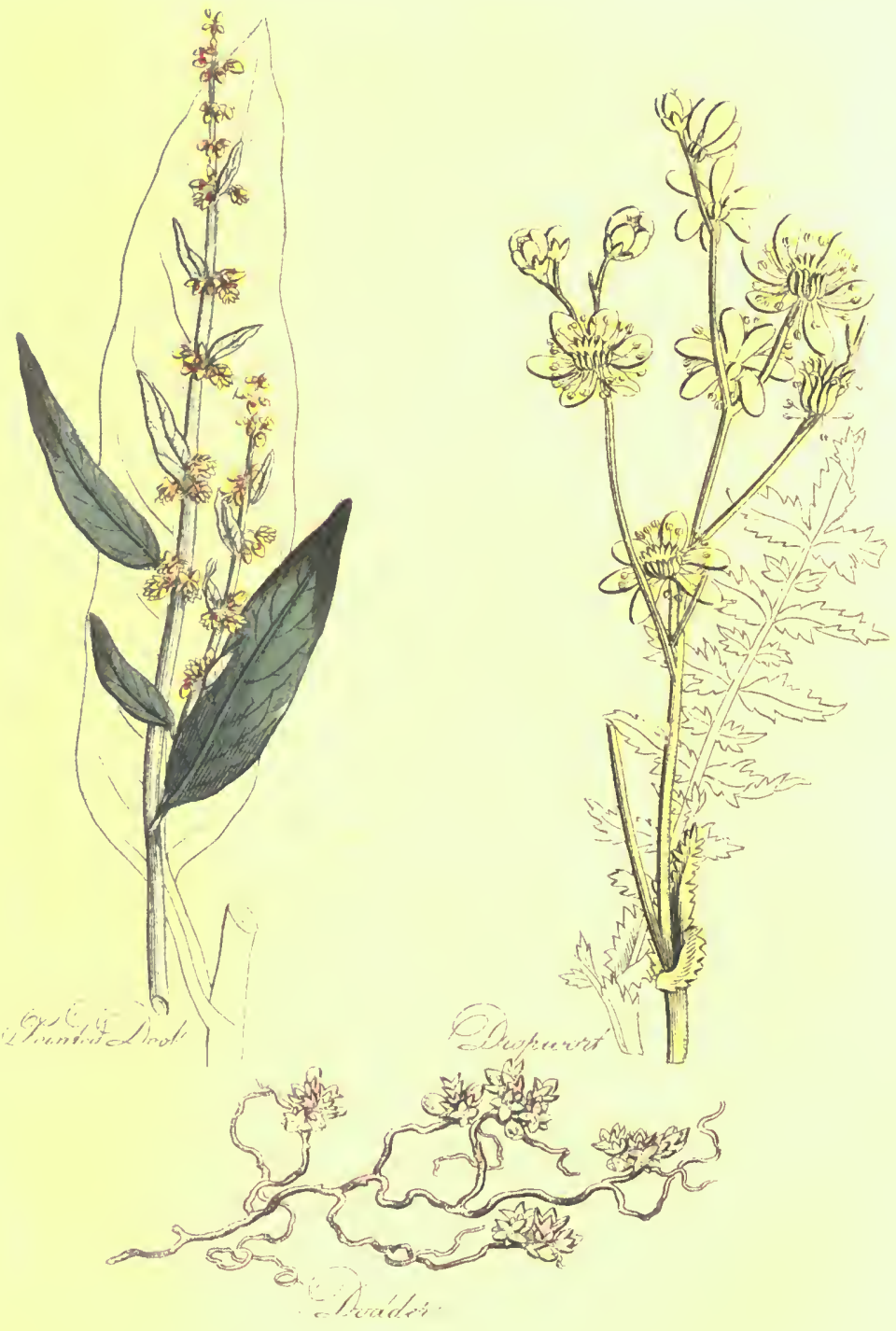



snd sharp at the point. The flowers are smail, and of a greenish colour with some white threads, and they afterwards become brown. The ront is large, long, and of a reddish brown.

it is a good remedy in the scurvy. The root contains the greatest virtues, and it is to be given in diet drinks. The seeds of this, and all other docks, are astringent, and good against purgings.

Garden Dock, cailed Monks'Rutrakb. Lapathum sativum, patientia.

A TALL plant of the dock kind, a native of Italy, and kept in our gardens for its virtues. It grows six or seven feet high. The stalk is round, striated, thick, upright, and firm. The leaves are very large, long, and are pointed at the extremity: they stand upon thick hollowed foot stalks; and the main stalk of the plant is also frequently red. The flowers are like those of the other ducks, greenish and white at first, but afterwards brown; but they are larger than in almost any other kind. The root is very large, loug, and divided; the outer coat is of a brownish yellow; within, it is yellow uixed with red. This is the part used; it has been called monks' rhubarb, from its possessing some of the virtues of the true rhubarb; but it possesses them only in a slight degree, it is very little purgative, and less astringent: It works by urine as well as stool, and is good in the jaundice, and other disorders arising from obstructions.

There is another plant of the dock kind, called bastard rhubarb, kept in sorae gardens, and mistaken for this. The leaves of it are roundish. It bas the same virtnes with the monks' rhubarb, but in a much less degree, so that it is very wrong to use is in its place. 


\section{Dodder. Cuscuta.}

A VERY strange and singular plant, but not rncommon with us. It consigts of only stalks and flowers, for therc are no leaves, nor the least reseniblance of any. The stalks are a foot or two in length, and they fasten themselves to other plants; they are of a purplish colour, as thick as a small pack-thread, and considerably tough and firm. These find themselves about the branches of the plants, and entangle themselves also witl one another in such a manner, that there is no end of the perplexity of tracing and unfolding them. The flowers grow in little heads, and are small and reddish, four little seeds succeed to each of them.

Dodder is best fresh gathered; it is to be boiled in water with a little ginger and allspice, and the decoction works by stool briskly ; it also opens obstructions of the liver, and is good in the jaundice, and many other disorders arising from the like caure.

The dodder which grows upon the gardon thyme, las been used to be preferred to the otlers, and has been supposed to possess peculiar virtues, from the plant on which it grows; but this is imaginary: experience shews it to be only a purge as the other, and weaker. The common dodder is preferable to it with us, because we can gather it fresh, the other is imported, and we only have it dry : and it often loses a great deal of its virtue in the hands of the druggeist.

\section{Dog Mencukr. Cŷnncrambe.}

A COMMON and poisonous plant named here. aot as a medicine but that peiple who gather lerks, for whatever use, may gubre againet it. It is 
common under hedges; and in the earlier part of the year makes a pretty appearance. People might very naturally be tempted to eat of it among other spring herbs, for there is nothing forbidding in its aspect; and what is much worse, the authors most likely to be consulted on such an occasion, might lead those into it, whom they ought to lave guarded agrainst it.

It is about a foot high, and has but few leaves, but they are large. The stalk is round, thick, whitish, pointed, and a little hairy; the leaves atand principally toward the top, four, five, or six, seldon more: they are long and considerabiy brosd, sliarp-pointed, notched about the edges, and a little hairy. The flowers are inconsiderable: they stand in a kind of spikes at the tops of the stalks; and the seeds are on separate plants, they are double and roundish. The herb has been from this divided into two kinds, male and female, but they liave in earlier time given the distinctions of the sex wrong. Those which bear the spikes of fiowers, are the male plants; the oihers, notwithstanding any accidental resemblance, female.

There is uot a more fatal plant, native of our country, than this; many have been known to die by eating it boiled with their food ; and probably many also, whom we have not lieard of: ret the writers of English Herbals, say nothing of this. Gerard, an honest and plain writer, but ignorant as dirt, says, it is thought they agree with the other mercuries in nature. These other mercurics are eatable; therefore, who would scruple on this account, to eat also this. Jolnson, who put forth another edition of this book, and called it Gerar.l Emaculated, from the amending the faults of the wriginal author, savs nothing to contradict it : but after some idle observations upen other lierbs of the 
same name, hut very different qualitics, which yet he seems to suppose of the same nature, leaves his rearler to suppose, that he meant equally any of the Finds of mercury, for the purposes he names; and, like his predecessor Gerard, supposed them all to he alike: those safe, and those poisonous. It is true, Mr. Ray, in his Sinopsis of the British plants, grives an account of it as a poison, aud must sufficiGutly warn all who read him, from the herb: hut whoreads him? Ilis book in which this is mentioned, is written in Latin; and those who want the information, cannot read it.

This is nent only the case in one or two particulars, it is so il: al!. To speak generally, the hooks which contain real knowledge, are written in Latin, through an ostentation of their authors, to shew their learning, or a pride in having them read in other nations as well as here; and those we have in English are ignorant; despised by the persous of judgment, and fit only to mislead. If they onumerate virtues, they give them at random, or give tho many false anong the true, that tlac reacier wnows not what to choose; or their roal ignorarice mingles poisous with salads, as we sec in the present instance: Nor is any more regard to be paid to what thev say of herbs, finm certain great names they minte. Dioscorides and Galcn were indeed great phrricians; but nen like these are not qualified te profit from their labnurs. The names of plants have been changed so often since their time, that ve do not know what they mean by several : and it is easy for such sad proficieuts as these, to record at onc plant, what the y polic of amother : besides, even in their best writung, there is a great deal of error and folly, an andy be seen in a quotation of this fohments from them, added to Gerard in this rerr chajes. Where, speaking of ont of the kinds of 
mercury, distinguished like this poisonous kind, unto male and female, he says, "that the male linds "conduces to the generation of boys, and the female 'of girls.' Sucli is the matter, that a superiority in we of these althors over the other, qualificd him to add to his book: such are the English books that are extant upon this subject; and such the direction offered to the charitable, confounding catajle herbs with poisons. This has heen one srreat reuson of writing the present book, that there inay be rne guide and direction at least, to be deperded upnn; and this its anthor has thought proper to say at large upon the inmediate occasion, rather than in a prefice; because there it must hate been accompanicd with a needless repetition, and perhaps would not have been observed by mans. who may have recourse to the book.

\section{Deg Toors. Dens caninus.}

A VERY prety litle plant, with two broal leaves and a lace drophing flower; common ia Italy and Gemany, asd frequent in our garden. It is five or six melies high. The stalk is roumd. slender, weak, and greeuish towards the top; ofters white at the botton. Whe leaves stand a litile leight abose the gyound: they are oblong, sumewhat broad, of a beautioil green, not at all dented at the edges, and blunt at the end: tiney inclose the stalk at the base. r'he lower is large and while. but with a tinge of rediin; it langs down, and is lone, hollow, and very elegant. Whe root is roumdish, and has some fitres growing frosn its botom ; it is full of a slimy juice.

The fich gathered roots are used for they dry veryill, and generally lowe their virtucs entirely

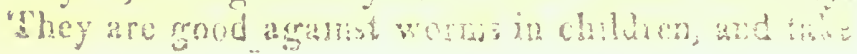


a surprising and speedy effect against those violent pains in the belly, which are owing to those creatures. The best way of giving them is in the expressed juice; or if children will not take that, they may be boiled in milk, to which they give very little taste. It is a powerful remedy; and a small dose will take effect, especially of the juice; so that it is best to begin with very little, and as that is well borne, to increase the quantity.

\section{Dragons. Dracontium.}

A FINE, tall, and beautiful plant; kept in gardens for its use in medicine, as well as for its appearance. It is four feet high. The stalk is thick, round, and firm; perfectly smooth, and painted on the surface with several colours; purple, white, green, and others. The leaves are very large, and stand on long foot-stalks : they are of a rleep and strong grcen; and each is divided into scveral portions in the manner of fingers. 'The flower is like that of the common arum or cuckno pint: it is contained in a hollow green case, of a deep purple within, and the pistil is also of a deep purple; after this is fallen, appear as in the arum, large red berries in a cluster. The whole plant is of an acrid and insupportable taste.

The whole plant is to be gathered when in flower, and dried; it may afterwards be given in decoction. powder, or otherwise. It was vastly estecmed for malignant fevers, and in the small pox ; hut it has of late lost much of its credit: at present it is only ryed in snme compositions. 


\section{The Dragon"s Blood Tree, Sanguis draconis arbor.}

A IERY beautiful tree, native of the Canaries, 7. I sme other places. It is of the palm kind, and wic of the liandsomest of them, The trunk is naLuth all the way to the top, and there stand on its smumit a great quantity of leaves, long, narrow, arit pointed at the ends; of a bluish green colour, and not unlike the leaves of our flags. The fruit is round, and is of the higness of a walnut with the green rind upon it.

'The drargon's blood is a red friable resin. Our druggists keep it: the best is in small lumps; there is an inferior kind in cakes or masses. It is prom cured by cutting the trunk of this tree in the great leats. There are also two other kinds of palm, that afford the same resin. It is a very excellent astringent. It is useful in purgings and in the overforving of the menses, in spitting of blood, and all other occasions of that kind. It may be given in powder.

\section{Dropwort. Filipendul̈a.}

A V ERY pretty wild plant, with tufts of whitish nowers, and leaves finely divided. It grows two fect highl. 'The staik is round, striated, upright, sirm, and branched. 'The leaves are large and sivided into a great number of firm sermons, they rise principally from the root, and stand on slonder foot-stalis. There are few leawes on the stalks, and they are small. The fowers are litsle, bit they stand in reat tuftsat the toys of the branches: they are white on the ingide, and often redbish on the outside. The seeds are flattish and grow several angathes. The root is composci of a gaeat rumbry 
of smull lumps, fastened together hy filaments. This root is the part most used; it is good in fits of the gravel, for it promotes urine greatly and safely. For this purpose the juice should be griven, or a strong decoction of the fresh root. Whes dried it may be given in powder to sto the whites and purgirgs, it is a gentle and safe astringent.

There are several other plants called in Englis? dropworts, which are very different in their qualities, and one of them is poisonous in a terrible degree; this last is called bemlock dropwort; care must therefore be taken that the right kind is used, but this is sufficiently different from all the others. The flower is composed of six little leaves, and is full of yellow threads in the middle; the flowers of all the others arc composed only of five leares each. They are all umbelliferous plants, hut this is not; the flowers grow in clusters, but not in umbels: they grow like those of the ulmaria or meadow sweet.

\section{DUCK-Weed. Lenticula.}

A SMALL green herb, consisting of single, little roundish leaves, which float upon the surface of the water, and send their roots into it for nourishment, without sticking them into the mul. It is the small green herb that covers almost all our standing waters in summer. There are two other kinds of it, one with smaller leaves and many fibres frow each, another with only once fibre from each leaf" : botls these are grcen all over; and a third kind with larger leaves, which are purple underneath, hut all these laase the sane virtue, and it is no matter which is taluen. The juice is to be syiven; and it is to be continued for several days.

It works powerfully by usime, and opens cbstrue. 



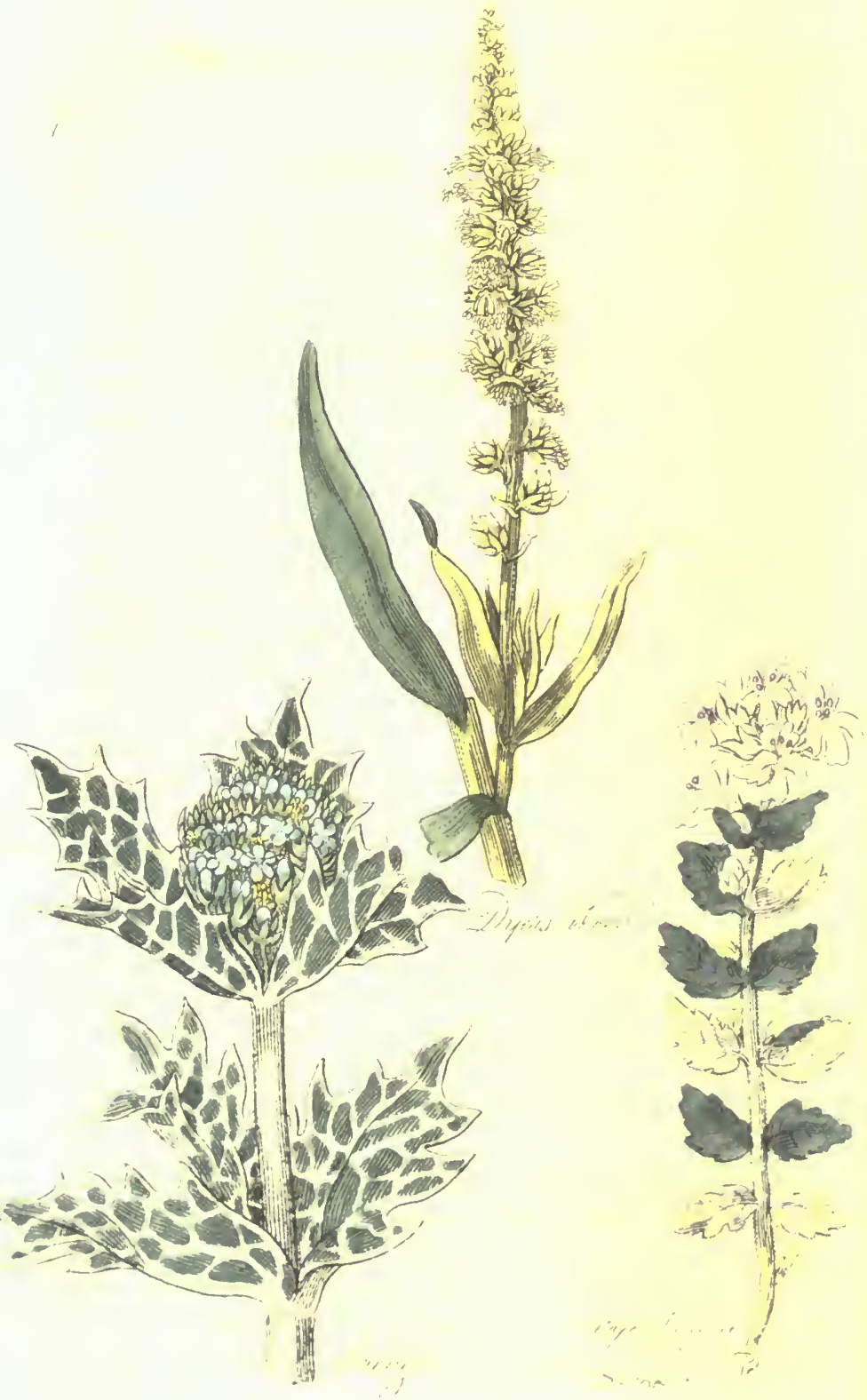


fions of the liver: jaundices have been cured by it singly.

\section{Dwarf Elder. Ebuliks.}

A PLAN'T so much resembling the common elder-tree, that it may be easily mistaken for it till examined. It grows four or five feet high. The stalks are green, round, tender, and upright; and they lave very much the appearance of the young shoots of clder; but there is no woody part from whence they rise. The leaves are large, and composed of several pairs of others, as those of elder, with an old one at the end; but these are longer than in the elder, and they are serrated round the edges. The fowers are small and white; but they stand in very large clusters or umbels, just as those of the elder; and they are succeeded by herries which are black when ripe; but that is a condition in which we seldom see them; for the birds are so fond of them, they eat them as they come to madurity. The root is white and creeping; and the whole plant dies down every year to the gound.

It is wild in Fngland, but not common; a great quantity of it grows at the back of Cuper's gardens. It may be dried : but the best way of giving it is in the juice. 'This works strongly hoth by stool and urine, and has often cured dropsies.

\section{Dyer's WeEd. Luteola.}

A VERY singular and pretty wild plant; it grows on dry banks and upon walls, and is known at sight by its upright stalks, and very long spikes of greenish yellow flowers. It grows to four feet or more in height. The stalk is thick, firm, channalled, and in a manner covered with leaves: they 
are snall in proportion to the bigness of the plant, oblong, narrow, and pointed at the ends, of a ye! . lowish green colour, and not serrated at the elycs; a tuft of the same kind of lcaves, hut somewhat larger, surrounis the bottom of the stalk. The ront is long and white. The flowers are small, but very numerous.

The flowery tops of this plant dricd, and given in decoction, are said to be a remedy for the evil, but the report is not established by any known experience.

\section{E}

Elder. Sambucus.

A COMMON wild shrub ; it grows irregularly. The stem or trunk is covered whth a rough whitish bark, and the wood is firm, but there is a hollow within ; this is smallest in the largest parts of the shrub, but it is never quite obliterated. The young sloots are thick, loug, and green; the $y$ grow quick, and are often a yard long before they begin to change colour, or grow woody. These contain a large quantity of pith; and their bark as they stand hecomes brownish, and their undersurface woorly. 'The leaves are composed of several pairs of others, with an orld one at the end : the Howers stan! in vast clusters, or umbels, and are small and white ; they are succeeded by berries, which are black when ripe, and are full of a purple juice. There is another kind of elder, with berries white when they are ripe, and another with jagged leaves, but the conmon elder is the sort to be used.

The innerhark of the elder is a strong purge; and it las heen known to cure dropsies when taken in time, and often repeated. The flowers are made 
into an ointment, by boiling them in lard, till they are almost crisp, and then pouring it off, this is cooling; the juice of the berries is boiled down with a little sugar, or by some wholly witluut, and tiris, when it comes to the consistence of honey. is the famous rob of elder, good in colds and sore throats. A wine is made of the elder-berries, which has the Hayour of Frontignac.

\section{Elecampane. Enula campano.}

A TALL and robust plant, wild in some parts of Engiand, but kept in gardens for the uses of medicine; it grows five feet high, and the lower is yellow, and very large. The stalk is round, thick, upright, very robust, and reddish: the leaves are long, large, and rough, and they are pointed at the ends; of a pale green colour. The flowers grow at the tops of the branches, and have something like the appearance of a double sun flower. They are two inches in diameter, yellow, and very beautiful. The root is long and thick, and is brown on the outside, and white within.

The root is the part used; we have it dried from Germany, but it is for most purposes better to take that fresh nut of the garden, which we have here. Harily any plant has more virtues. It is good in all disorders of the breast and lungs, and it opens obstructions: It operates by urine powerfully, and also by sweat: and the juice of it will cure the itch, applied externally. Its greatest virtue, however, is against coughs, and for this purpose it is best taken candied, provided that be well done. A little of it may in this way be held almost contimually in the mouth, and swalloyed gently, so that 
it will take cfect much better than by a larger dose swallowed at once.

\section{Erm. Ulmus.}

A TALL tree native of our own country, and sufficiently common in our hedges. It grows to a great bigness. The bark is brownish, rough, and irregular; the twigs are also brown, and very tough. Thesleaves are small, broad, short, rough to the touch, and finely indented about the edges, and they terminate in a point. The flowers are not regarded; they appear before the leaves, and principally about the tops of the tree, and they are only thready; the seeds are flat.

The inner bark of the elm boiled in water, makes one of the hest gargles for a sore throat that can be supplied by the whole list of medicines. It should be sweetened with honey of roses; it is extremcly sofit and healing, and yet at the same time very clansing.

There are two or three other kinds of elms common in garden liedges; they are brought from other countries, but the bark of the English rough elm is preferable to them all as a medicine.

\section{Endre. Findiria.}

A COMMION garden plant kept for salads. It grows two feet high, and the flowers are blue, but we see it a thousand times with only the leaves for once in a llower, and these the gardeners have the art of twisting and curling, and whitening in surh a manner, that they are scarce to be known, as betonging to the plant. Naturally they are long and tarrow, blunt at the end, and desply notched 
sit the cdges, and of a yellowish green colour; the atalk are round and firm, and the leaves that grow o. them arelike thoce from the root, hut smaller: the fluisers stand at the tops of the staks and branche' they are blue, and in shape and structure like those of dandelion: they are very bcautiful.

The juice of endive may be taken with great adrantages as medicine; it cools the stomach, and operates by arine very powerfully; it also opens obstructions of the viscera. It is good agalust the jaundice, and constantly taken for some tine, against the scurry.

\section{ERyggo. Eryngizm.}

A TiLD plant, which grows with us by the sea side, and is liept also in tardens, because of its virtues. It is prickly like a thistle, and the whole plant appears not green, but whitish. The stalk is finm, woods, round, striated, and thick, sot very upright, branched, and spread irregularly about. The leaves are small, and of a pale bluish grcen, approaching to white; they are broad, oblong, and jarged and prickly. The flowers grow in little heads at the tops of the stalts, and there stands a circle of small leaves under them. The flowers, separately takn, are small, and of a pale greenish white, but the had of them is tolerably large. The root is long and s!ender, and of at icasant taste.

This is the part used; the best $w a$ is to take them candied; they are good aganst coughts, and weahuese of all linds. They hay also caused noble vintucs, as in diuretio, and are good against the jaunice; fo: thi lest vorose a decoction made from the fresh aonts is be abe we bal-

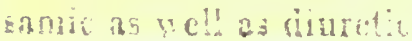


The Eurhorbug Plant. Euphomizimo

A VER $Y$ strange plant, native of the hot coun. tries, and unlike every thing that is known in this part of the world. It is ten or twelve feet highly, and is of a solid thick body, of a trianguIar or else a square figure, as thick as a. man's leg, and is divided by knots placeri at distances, so as to seem made up of several joints. The edges of the borly are all beset with very sharp prickles; the plant itself is composed only of a pulpy snft matter, covered with a thick rind, of a green colour; it abounds with a milky juice, but so acrid that there is no bearing a drop of it a moment on the tongue. The plant often consists of one single stem, such as is just described, but frequently it sends out several branches; these are naked in the same nimanner as the main stem. All that have heside the prickles, are a kind of thin fims or membranes, small and growing from their bascs, but the plant is altogether without Inayes. 'Tue flowers prow three together anong the thoms, and the fruit is a ressel containing three sectín.

line gum whiçis sweats nut from this plant, is und in medicine ; it is yeilowish and cones forth in suall drope, its taste is starp and insupportabie : it is a vivlent purge, and is recominconded anainst dropise, but we scarce ever prescribe it, it is re very rengh; it is sometimes used outwardly among obtur thing applied to tie feet in violent ferers.

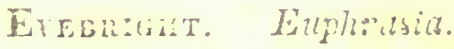

A Vind pretty low herb common in nur meadus, vith wondy stalli, and bright and little 
pariegated flowers. It grows six or eight inches high. The stalks are round, thick, firm, and very hard; the leaves are flat, broad, and very deeply indented at the edges; and they are of a bright shining green. The flowers are little, and they are very bright ; their ground colour is white, and they are streaked and spotted with black and some other dark colours.

This plant has been always famous for dimness of sight, but whether experience warrants the character that is given of it is uncertain. The juices is very diuretic.

\section{F.}

Fenvel. Fonicubum.

A commos garden plant, kept for its use in the kitchen, rather than its medicinal virtues. It grows six or eight feet high. The stalk is round, hollow, and of a deep green colour; the leaves are large, and divided into a vast number of fine slender segments, and they are also of a deep or bluish green colour. The flowers stand at the tops of the branches, and are small and yellow; but there grow large clusters of them together; the seed is small, dark coloured, and striated, and is, of a sharp acrid taste; the root is long and white.

The root is the part most used; a decoction made of it with common water, and given in large quantities, works by urine, and is good against the gravel and in the jaundice.

Sweet Fenned. Foniculum dulce.

A Garofe plant very like the common kitid 
but of a palei colour. It grows four feet high; the stalk is round, hollow, striated, upright, and brasched; and the leaves are large and divided into a great number of fine segments, in the manner of those of common fennel, bat both these and the stalks are of a pale yellowish green colour, not so dark as in the othes' kind. 'T'he flowers are yelowish, and stand in small clusters or umbels; the seeds follow, two after each flower; and they are quite difierent from those of the common fennel, in size, shape, colour, and taste. 'They are lorig, slender, of a pale colour, a little crooked, and deeply striated. Their taste is sweetish and a little acrid.

As the ronts are the part most used of the common fenncl, the seeds are the only part used of this. They are excellent in the colic, and are used externally with success in pultices to swellings. 'The seeds of the common fennel are used by some, but they are very hot and acrid. These are preferable for internal use.

\section{Feniel Fower. Nigella.}

A singular and pretty plant kept in gardeng. It grows a foot and a half high. 'The stalk is tirm, round, striated, and upright and hollow. 'The leaves are divided into a multitude of fine slender parts like those of fennel, only very small in comparison, and thence it lad the Einglish name of fennel Hower; they stand irregularly on the stalks, and are of a pale green. The flowers stand at the top of the branches: they are singular and pretty; the colour is whitish, and they are moderately large. the erren leaves about them give them a very par. ticular grace.

The juice of the plant frech sathered. is gond 



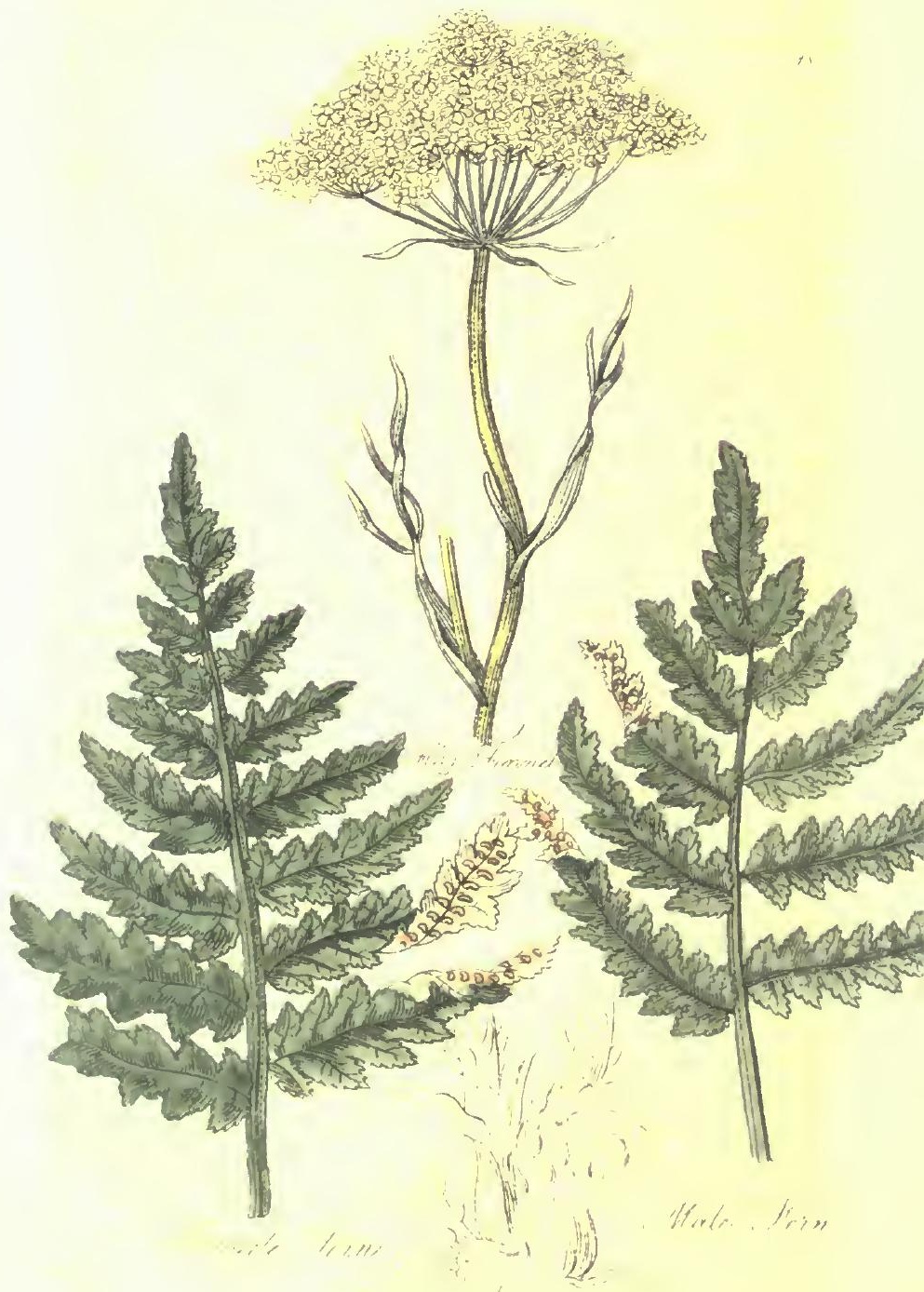


for the liead-ache; it is to be smuffed up the nose, and it will occasion sneezing; inwardly taken it works by urine, and is good in the jaundice.

\section{Hog's Fenser. Peuccdanum.}

A wiub plant with divided leaves and umbels of yellow flowers, and thence bearing a remote resemblance to fennel. It grows two feet high: the stalk is round, striated, hollow, upright, and branched. The leaves are like those of femnel, but the divisions are much broader, and they run in threes. The flowers are little and yellow, but the clusters of them are large, and the seed is oblong and flat. At the top of the root, there is always found a tuft of liairy matter. This is made up of the fibres of decayed leaves, but it has a singular appearance. The root is large, long, and brown, and this is the part used as a medicine. It is to be boiled in water, and the decoction drank night and morning; it dissolves tough phlegm, and helps asthmatic people; it also works by urine, and promotes the menses, and is good in all obstructions.

\section{Fongareck Thmum Gracum.}

A pLant of the trefoil kind, but singular in its manner of growth, cultivated in fields in many places for the sake of the seed. It is emollient. It srows a foot and a half high; the stalks are round, striated, and branched. The leaves are short and broad: they stand three upon every stalk as in the common trefoils: and are indented about the crges. The flowers are white and small, and they resemble a pea-blossom; the pods are flat, and in them is contained a quantity of yollow sceds, of an irregular figure, and disagreeable smell 


\section{Male Fers. Filix mas.}

A common weed growing at the roots of trees, and in dry ditches. It has no stalk for bearing of flowers, but several leaves rise together from the root, and each of these is in itself a distinct plant. It is two fect high, and near a foot in breadth; the stalk is naked for six or eight inches, and thence is set on cach side with a row of ribs or smaller stalks, every one of which carries a double row of smaller leaves, with an old one at the end; the whole together making up one great leaf, as in many of the umbelliferous plants.

On the hacks of these smaller leaves stand the seeds in round clnsters; they look brown and dusty. The root is long and thick, and the whole plant has a disagreeable smell. The root is greatly recommended for curing the rickets in children; with what success it would be hard to say.

\section{Female Fern. Filix fomina.}

A TALx and spreading plant, common on our heaths, and called by the country people brakes. It grows four feet high. The stalks are round, green, and smooth : the leaves are sct on each side, and are subdivided. The whole may indeed be properly called only one leaf as in the male fern; but it has more the appearance of a number because it is so ramons. The small leaves or pinnules which go to make up the large nue, are oblong, firm, hard, and of a deep green colour, and they are so spread that the whole plant is often three feet wide. On the edges of these little leaves stand the seeds in small dusty clusters. But they are not so frequent on this as on the male fern, for nature has s" well provided for the propagation of this plant 
hy the roots, that the seeds are less necessary; and where it is so, they are always produced more sparingly. A certain quantity of every species is to be kept up, but the carth is not to be over-run with any.

The roots of female fern fresh gathered, and made into a decoction, are a remedy against that long and flat worm in the bowels, called the tapeworm; no medicine destroys them so effectually.

\section{Flowering Fern. Osmunda regalis.}

Thene is something that at first sight appears singular in the manner of this fern's flowering, but when particularly examined, it is not different in any thing material from the other. It grows three feet high, and the leaves are very regularly constructed, and very beautiful; they are composed in the manner of the other ferns, each of scveral small ones, and these are broader and bigger than in any of the other kinds, not at all indented on the edges; and of a bluish green colour, and afterwards yellowish. Many leaves arise from the same root, but only some few of them bear seeds. These principally rise about the middle, and the seeds stand only on the upper part: they cover the whole surface of the leaf, or nearly so in this part, and the little pinnules turn round inwards, and shew their backs rounded up. These are brown from being covered with the seeds, and they have so different an appearance from all the rest of the plant, that they are called flowers. The root is long and covered with fibres. The plant grows in boggy places, but it is not very common wild in England.

A decoction of the fresh roots promotes urine, and opens obstructions of the liver and spleen; it is 
not much used, but I have known a jaundice cured by it, taken in the besming.

\section{Feverfew. Matricaria.}

A commos wild plant, with divided leaves, and a multitude of small flowers like daisies; it grows about farmers' yards. The stalk is round, hollow, upright, branched, and striated, and grows two feet high. The leares are large, div ded into many small ones, and those roundish and indented; they are of a yellowish green colour, and particular smell. The flowers stand about the tops of the stalks; they are small, white round the edges, and yellowish in the middle. 'The root is white, little, and inconsiderable.

The whole plant is to be used; it is hest fresh, but it preserves some virtue dried; it is to be given in tea, and it is excellent against hysteric disorders; it piomotes the menses.

\section{Fig-tree. Ficus.}

A shreb sufficiently known in our gardens. The trunk is thick, but irregular, and the branches, which are very numerous, grow without any sort of order. The leaves are very large, and of a deep blackish green, broad, divicted deeply at the edges, and full of a milly juice. The flowers are contamed within the fruit. "The fig-tree produces fruit twice in the year; the first set in spring, the second towards September, but these last never ripen with us. The dried figs of the crocers are the fruit of the same tree in spain and Portugal, but they grow larger there, and ripen better.

Our own figs are wholesome fruit, and they are 
applied outwardly to swellings with success. they soften and give ease while the matter is formung within.

\section{Figwort. Scropilularia.}

A TALL and regular growing wild plant, with small deep purple flowers. It grows four feet high, and is common in our woods and ditches, where there is little water ; there is another kind of it in wet places, called also water betony, which is to be disinguished from it by the round indentings of the leaves: it also grows in water, or just by it: the right figwort only loves shade and dampness, but not absolute wet. The stalk is square, upright, hollow, and very firm ; the leaves stand two at each joint, opposite one to the other; they are large, broad at the bese, narrom at the point, and sharply indented; they stand on long. foot-stalks, and they have the shape of the nettle leaf, but they are perfectly smooth, and of a shining colour; they are sometimes green, but often brown, as is also the whole plant. The flowers are very small and gaping, their colour is a blackish purple. The root is long, white, and full of little tubercles, it spreads a great way under the surface.

The juice of the fresh gathered root is an excellent sweetener of the blood taken in small doses, and for a long time together. The fresh ruots bruised and applicd externally, are said also to be excellent for the evil. They cool and give ease in the piles, applied as a pultice.

\section{Mir Tree. Abies.}

A wud tree in Germany, and many nther parts 
of Europe, but with us only kept in gardens. We have no kind of the fir native: wilat is called the Scotch fir, is not a fir, but a pine.

The fir-tree grows to a considerable height, and with great regularity. The trunk is covered with a rough and cracked bark, of a resinous smell; the leaves are numerous, and stand very beautifully on the branches. They stand in two rows, one opposite to the other, and are oblong, but somewhat broard and flat. They are of a pale green, and of a whitish hue underneath. The tree is hence called the silver fir, and, from the disposition of the leaves, the yew-leaved fir, for they grow as in the yewtree. The fruit or cones stand upright; in this kind, they are long, thick, and brown.

The tops of this kind are great sweeteners of the blood, and they work powertully by urine. They are best given in diet drinks, or brewed in the beer, which is commonly drank.

\section{Red fir Tree, or Prtch Tree. Picea.}

A tall tree, but not so regular in its growth, or in the disposition of its leaves, as the other. The trunk is thick, the bark reddish, and the wood soft. The branches are numerous, and they stand irregularly. The leaves are oblong, narrow, and sharp-pointed; and they do not grow in two even rows, as in the other, but stand irregularly on the twigs. The cones are long, slender, and hang downwards. The whole tree has a strong resinous smell.

The tops of this are boiled in diet drinks against the scurvy as the other, but they make the liquor inuch more nauseous; and not at all better for the intended purposes.

pitcls and tar are the produce of the fir-tree, as 



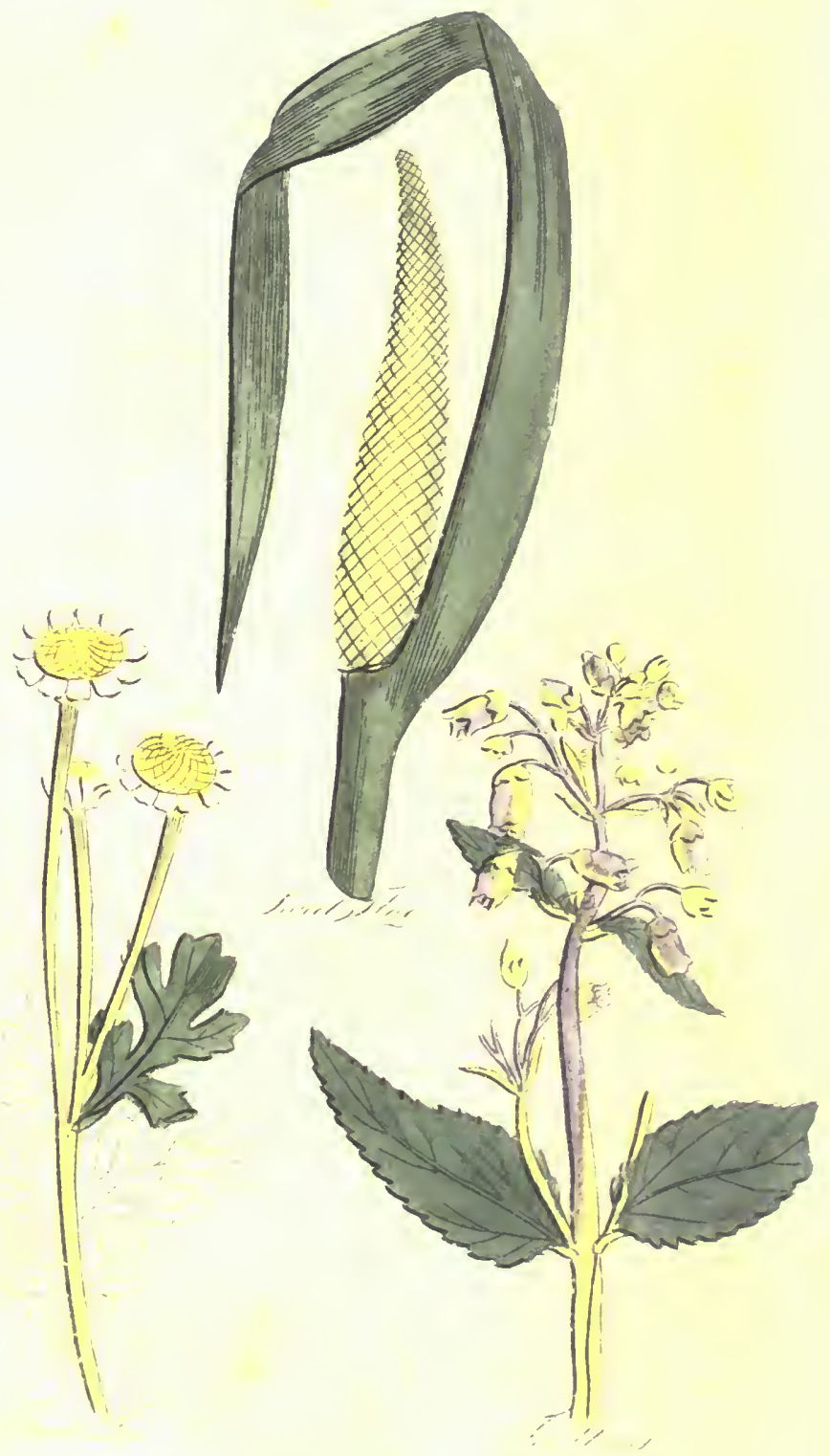




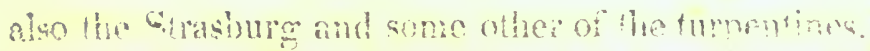

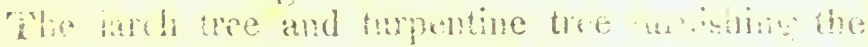

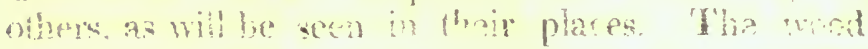

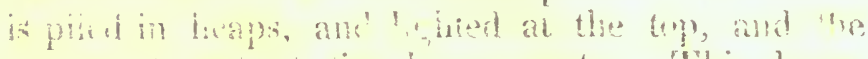

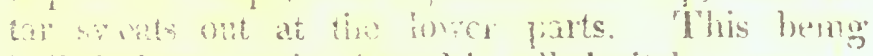
bolled, becomes land, and is calied pitch.

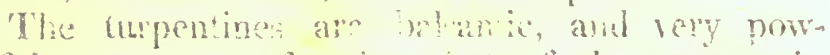
erful promoters of urin but of these more in their places: the tar has bern of ate rendered famons by the water made from it; bit it was a hathionable remedy, and is now out of repute sigetin.

Swner race Acornis calomes uromaticus dictus.

A con:10x wild plant that grows undistinguished smong the flays and rouldes, by our ditch sides. The old physicians neant another thing by calnow ansmaticus : they gave this name to the dried stolks of a prant, but at piesent it is used as the name of the poot of this. The sweet flang grows three feet high, but consists only of leaves without a stalk. They are long narow, and of a pale green colour. Among these there are commonly three or four in all rospects like the rest, but that they have a cluster of lowers breaking ont at one side, within five or wis inches of the top. This is long, brown, and thick, and resembles a catkin of a sibert tree, only it is longer and thicker. The root is lomer, fattish, and creeping : it is of a strong and rather umpleasant smell viben fresh, but it becomes very fragrant, and ammat: in drying. Oar own has its mhe, because. we can have it fresh, but the dried root is brtter had of the drugaists; they have it from warmex countries, where it is more fragrant.

The juis of tha eresh rent of acorus is sxcelImpt to pronote the imenses, it works liv nuriae 
moderately, and nives no oflence to the stomach. The dricel root is condial and sudorific, it warms the stonach, and is good against indigestions and fevels.

Commos Aronte, or Yerrow Irags. Acorus adulterinus.

A comnos phint in our ditches, and by river sides, distinguished hy its hlue-green flag like leaves, and its larae yellow flowers, which in shape resemble those of the iris, or flower de luce. It grows four feet high: the strlk is roundish, but a little flatted, of a paie green, very erect, firm, and not branched. It only sends out tiro or three shoots upwards from the bosinn of the leaves. The leaves are a foot and a halt long, narrow, flat, and sharp at the edges; the flowers stand at the tops of the stalks, and are large and beautiful. The seedis are numernus, and are contained in larye triangular ressels. The dout coreps.

The rent of this is the mily pat ned? some have confomoled them with the the acoms loot. but they are called. by waj at distunction, false or bastard acoms; they are not at all like them in shape, colour, or quinlities: ther are of a redulish

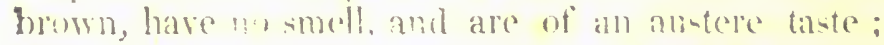
they are an excollent astringent. "They shombl be talicil up in suing and dried, and atterwarels quiren

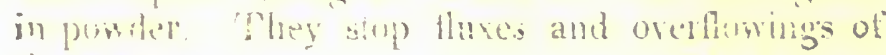
lic iitenote

$$
\text { ilix Jivitut. }
$$

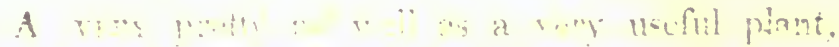

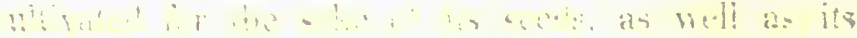

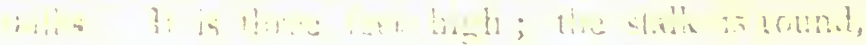




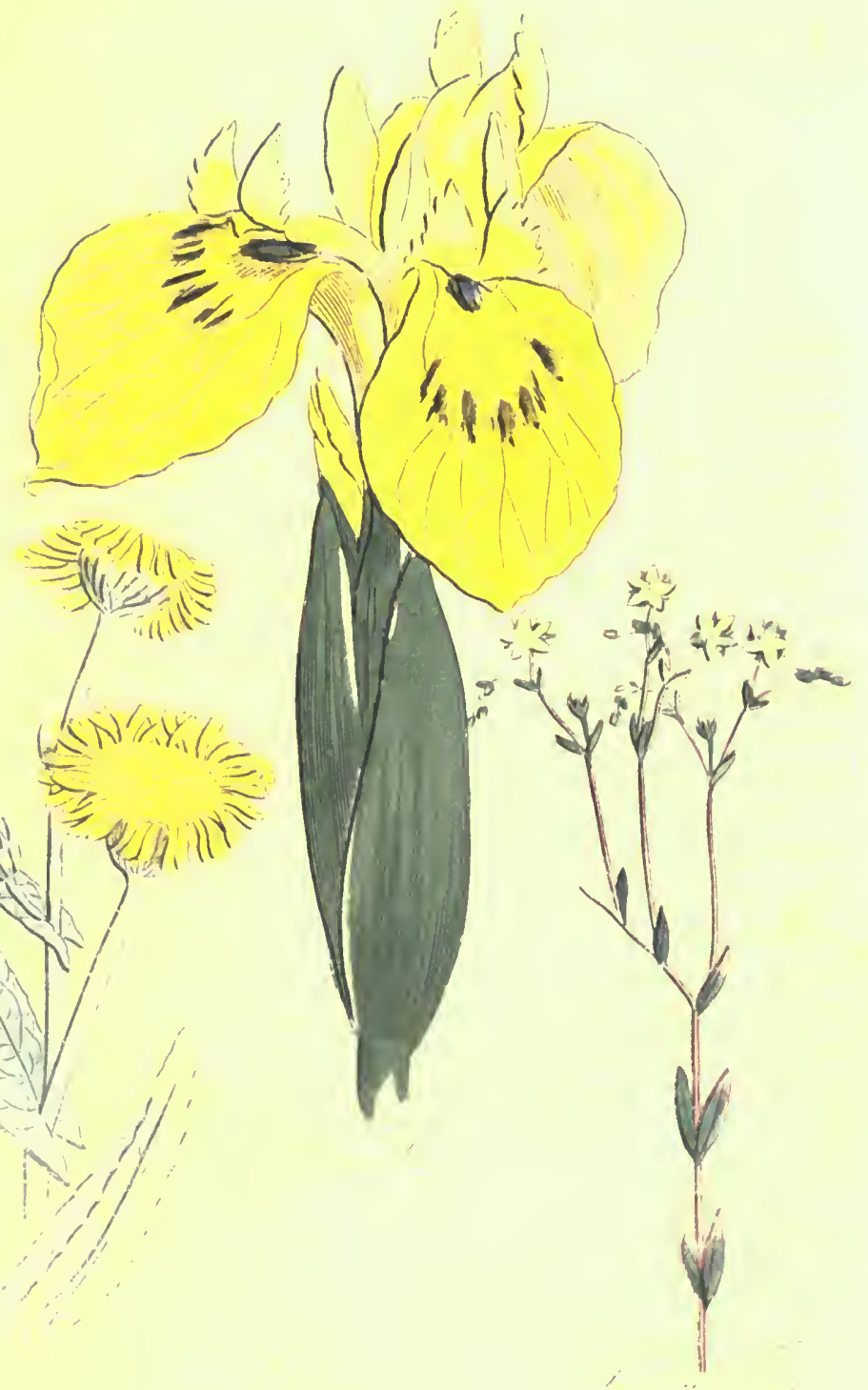



chner, firm, and upright. The leaves are small, nhong, and narrow; and they stand irrecrularly, but in mat numbers on it. Foward the tep the "talk divides into three or four short branches; and on threstant the flowers; they are large and of at beantin blue Fach of these is succeeded by a rountim weteresol; in which are a number uineds.

This apen in what is called linecel. A tea made of it is cropllent in conghes and discriders of the brenst and lungers and the seed bruised is also gond in rataphome and fomentations tor swelings. The

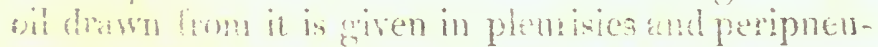

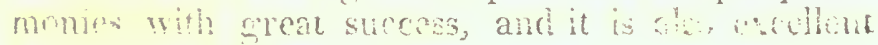
in the erand and stome.

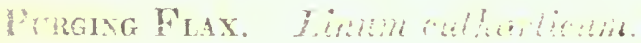

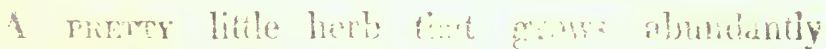

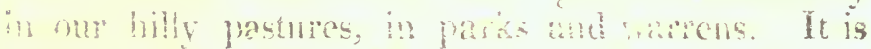
shit inche high. The ralk is rusud, firm, and whe top divided into small bronchs. The leaves are lithe, blong, and obtuse, and they stand two at each joint. The liswers are small and white, und the whole plant has very much the aspect of mome kind of chickweed, but the secd-rescel being exmined, it apperis to be altogether of the flax kind. The roxt is snall and throwdy.

This little plant is a strough but une pune; tho country people boil it in ale, and cure themselves of rhemmatic pains, and a prest many uner chstinate disurdere by it. They talk of it nis a remedy for cropses. Doubtless it is useul in all cases where a strome and brisk phigative is ra quired. 


\section{Hegabare. Comyza.}

A PRET wild plant, frequent about damp places, with whitmh leaves an! lare vellow lowers in

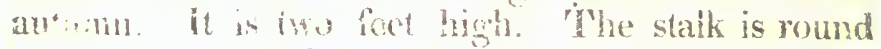

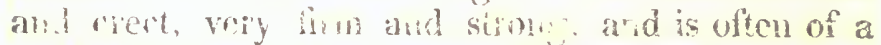

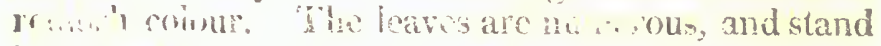

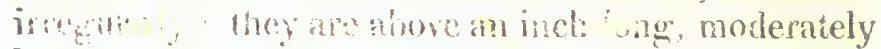

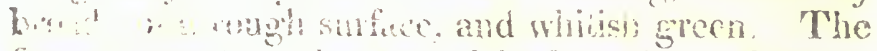
frowers and at the ing of the manches; they are

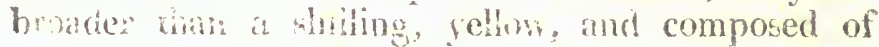
many nawe petalis. The whice piant has a diesprecable suevil.

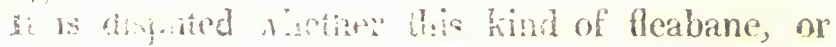
anther which is smaller, and has ghotons flowers, lines the greater virne; lont most give it for this. The juce of the whole plant ches the itch, applied sxtrially : and the rery sinel! of the herb is said to testroy thas.

\section{Fleawort Psyllim.}

As herb of 110 great beauty, natice of Finnce, but kept in gardens here. It has narrow leaves, and inconsiderable flowers. It is a foos high. The stalks are weak, greenish, and a little hawy. 'Tise leaves stand two or mone at every joint, for the is un thin; they are long, vey narrow, and alow smewiai inary: there rise from the bosoms si litese leaves, long natud stalks, on which stand

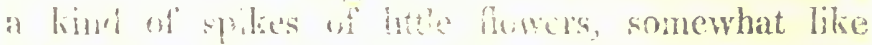

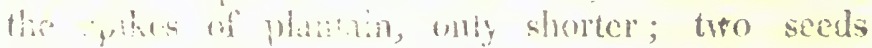

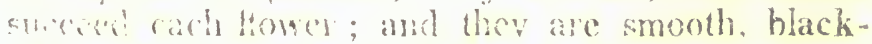

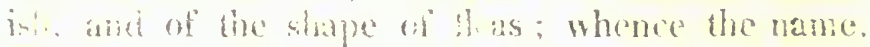

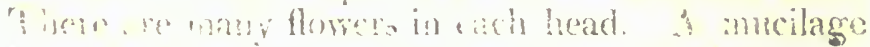

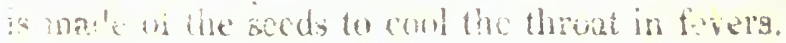




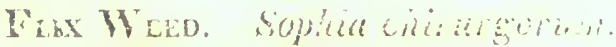

A rretry wild plant, about our vaste places and farm-lards; conspicuous for its leaves, if not so for its Hower. It grows two feet high; and the stalk is round, erect, very firm and stronis, and not much branched. The leares are muderately large, and most beatifully divided inio numerous smal! segments, long and narew ; they stand irregliarly upon the stalis. The flowers are snad and ycilow; they stand in a kind of spikes at the tors os the stalks. They are followed by short pods. The whole plant is of a dark green

The seeds are the part used: they are to be collected when just ripe, and boiled whole. The decoction! cures the bloody flux, and is good against the overflowing of the menses.

\section{Flower Gevtle, Amainthus.}

A Gamber flower. There are many kinds of it; but thint used in medirine is ta large one with the drooping purple spike. It grows to four feet high. The stalk is firm, wund, and channclled, green sometinus, but often red. The leares are oblong and broad even at the edges, and pointed at the ends: they are very large, ant ars ofiten tinged with red. The flowers are pionle, and they grow in long beantiful fpikes hanging downwards.

The flowers are the part uach. 'They are to be grathered when not quite ful blown, and dried. They are good against purring and overluwis of the menses in powder or deccetion. 


\section{Flover de Llee. Itis.}

A oommos flower in our gardens. The plant grows three fect high. The leares are a foot and a half lome, nawow, flat, and in al! reapects like the leaves of thass, and of a bluinh grien. The stalks are round, or a litue flatted; thich, lirm, upright, and of a greener colour. 'i he flowers are larese, and of a deep blue. The root spread about the surfice, and is thick and of a browinish colour, and marked wi!h rings.

Whe juice of the fiech roots of this plant bruised with white wine is a strong prarge: it will sometimes also romit; but that is not hartfu?; it is at cure for dropsies. Gordon, an od phyce writer, says if a dropsy can be cured by the hand of man, this root will effect it. I have found it true in practice.

Florentive Flower ne Lece. Iris Florentina.

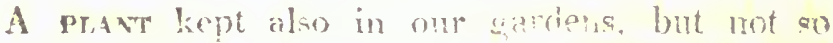

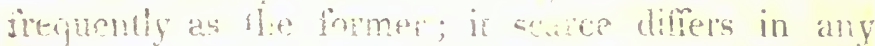

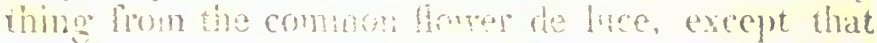
lic fiomers are white. 'Ihe mot spreads in the snow nanner, and lite faves are liamy. The

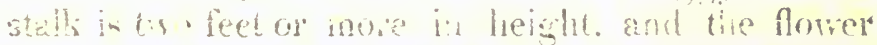
is as linge i.s that of the blue kind, and pertectly of the antc form

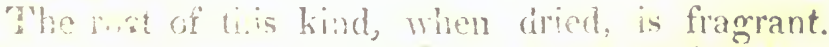

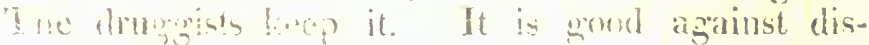

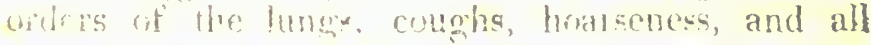
tat latir of :"

$$
\text { Ficuldx Elatine. }
$$

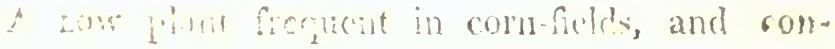



*ircuous for its preity, though small, flower. The stalins are five or six inclies long, round, hairy, weak, and trailing upon the ground. 'The leaves are little, hairy, rounded, and placed irregularly. The fowers are very small, but they are variegated with purple and yellow, both colours very bright; they have a heel behind, and each stands upon a little Iniry foot-stalk, arising from the bosom of the leat.

There is another kind, the leaves of which have two etzrs at thoir bise; in other respects they are the sane, and they have the same virtues. The juice of either is cooling and astringent. It is fiven by the comtry people in the bloody flux and arenowing of the menses.

\section{Fool's SToxs. Satyrium sive orchis.}

A bentryer wild plant in our meadows and pastures in Jume. re leaves are long and spotted, and the flumer are pupple. It grows ten inches high. The leaves are sis inches long, and three quartera of an inch broad, of a very deep green, with large and irregnlar blotches of black in different parts. The stalk is round, thick, upright, single, and flem ; it his two or three smaller leaves of the same figtire, and at the top stand the Howers, in a spike of an inch and it half long; they are not very large, and of a shape different from the generality of hlovers; their colour is a deep and glossy purple; bit sometires thay are white. The whole plant is juicy the ron consists of two round hulbs or two rond lumps, like a pair of testicles, and is white thith of a simy juice.

The row is the only part used. It is supposed to be a strenthener of the parts of greneration, and 
a promoter of vencreal desires; but with what truth one cannot say. Externally applied in cataplasms, it is excellent in hard swcllings. There are a great many other kinds of orchis in our meadows, but only this is used. The root, called salep by our druggists, is brought from Turkey, and is the root of a plant of this kind. It is strengthening and restorative, good in consumptions and all decays.

\section{Fox-glove. Digitalis.}

A VERY beantiful wild plant in our pastures, and about wood-sides. The leaves are whitish, and the flowers large and red. It is three feet high. The leaves are large, long, rough on the surface, pointed at the ends, and serrated round the edges. The stalks are round, thick, firm, an upright, and of a white colour. The flower. hang down from the stalk in a kind of spike: they are hollow, red, large, and a little spotted with white; they are shaped like the end of the fingor of a glove.

The plant boiled in ale, is taken by penple of robust constitutions, for the rheumatism and other stubborn complaints; it works violently upwards and downwards ; and cures also quartan agues, and, as is said, the falling-sickncis In ointment made of the flowers of for-glore lesiled in May butter, has been long famons in scrophulous sores.

\section{Frankmones: Tres. Albor thurifera.}

A rance tree as is said, a native of the warmer combros, bit wo know rery little of it. Those who decribe it mot, only saly that the trumk is thick, the woud spungy, and the bark rough. 


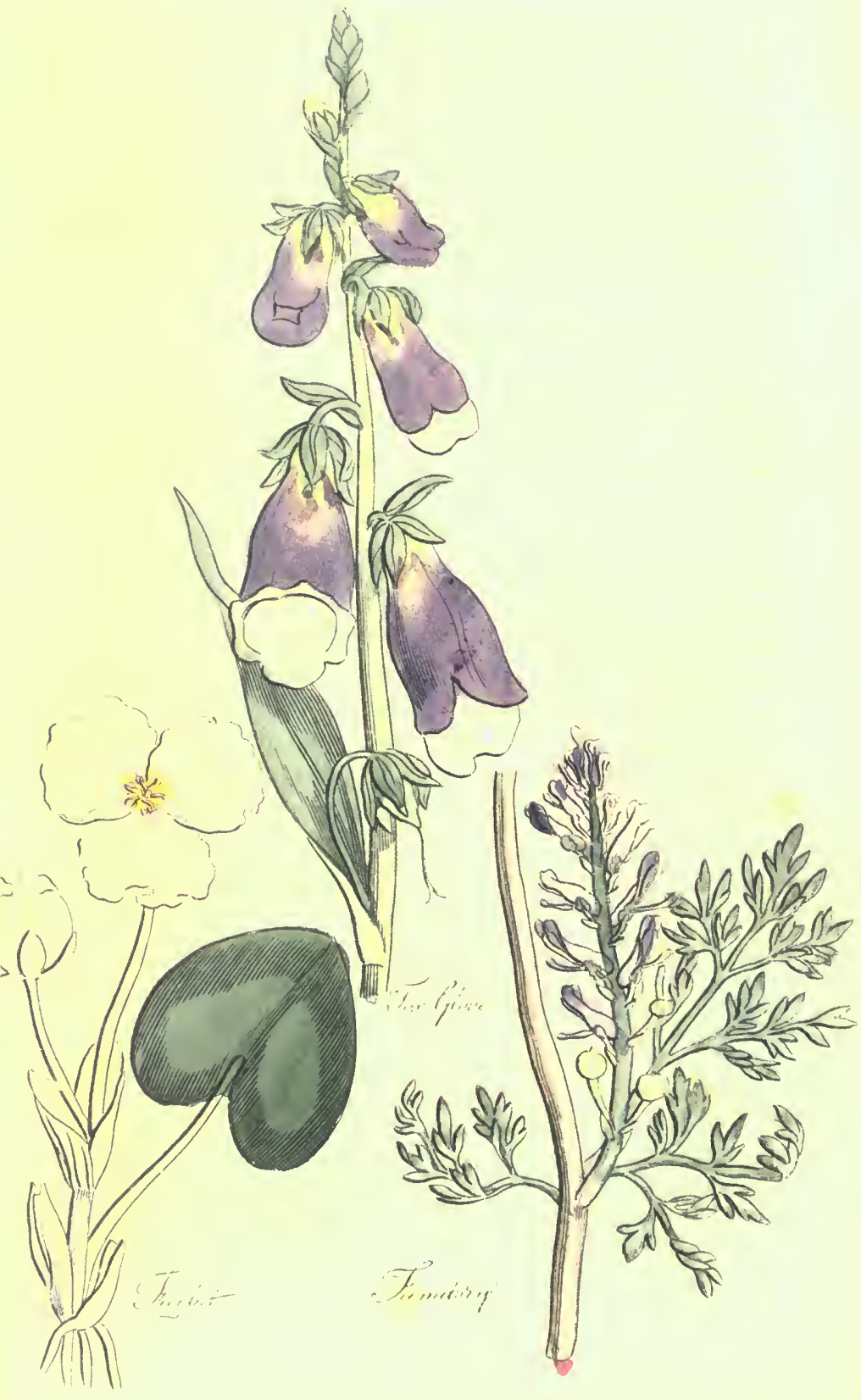



I'he leares, they say, are narrow, and of a pale ereen: but as to the flower and fruit, they are silent. Some say it is thorny.

IIl that we use is the dry resin, which is of a yollowish white colour, and bitterish resinous taste, aud strong smell. Our drugerists keep this. Whatever tree produces this, it is a nohle balsam; dissolved in the yolk of an egg, and matie into an emulsion with barley-water, it will do good in conwmptions, when almost all other things fail It were well if the common trifling practice in that fital disorder would give way to the use of this sreat medicine.

\section{Freven Mncers. Mereuriulis mas et fomina.}

A wru plant, but not very frequent in Ting land, conspicuous for little else than that it has the male flowers on some plants, and the female flowers on others, in the manner of spinage, hemp, and some others, as has been explained already under the article date-tree. It grows ten inches high 'The stalks are angular, green, thick, but not fir'm, and stand but moderately upright. The leaves are oblong, broadest in the middle, sharp at the point, serrated at the edges, and of a deep green colour. The female plants produce two seeds growing together at the top of a little spike. The male produce only one spike of dusty flowers, without any seeds or fruit at all. But people commonly mistake the matter, and call the female the male.

A decoction of the fresh gathered plant purges a little, and works by urine; it is cooling, and good for hot constitutions and over fulness. The dried herb is used in decortions for clysters. 


\section{Frog Brt. Morsus rance.}

A Litrue plant, not uncommon on waters, with round leaves and small white fluwers. It has been by the common writers called a kind of water lily, because its leaves are round, and it floats upon the water, but it is as distinct as any thing can be, when we regard the flower. Duckweed has round leaves, and floats upon the water, and it might be called water lily for that reason, if that were sufficient. The leaves are of a roundish figure, and a dusky dark green colour: they are of the breadth of a crown piece, and they rise many together in tufts, from the same part of the stalk. This stalk runs along at a little distance under the surface of the water, and from it descend the roots, but they do not reach down into the mud, but play loose like the fibres of duck-weed in the water. The flowers stand singly upon slender foot-stalks; they are white, and composed of three leaves apiece, which give them a singular appearance.

The fresh leaves are used in outward applications, and are very cooling.

\section{Fumtory. Fumaria.}

A PreTry wild plant, with bluish divided leaves, and spikes of little purple flowers, conmon in our corn-fields in June and July. It grows ten inches high. The stalk is round, striated, of a pale green, thick enough, but not very firm or perfectly erect. The leaves are large, but they are divided into a vast nimber of little parts, which are blunt and rounded at the ends; their colour is a faint green. The flowers are small and purfols: they have a heel behind, and a number of 
them staisd together in a kind of spike. The whole plent has little taste.

The juice cxpressed from this plant is excellent agianst the screry. It nons obstructions of the viscera, and is good ogainst the jaundice, and all other diseases arising fin obstructions.

\section{Funze Busir. Genista sninosa.}

A wrLd bush, upon our heaths and by road sides, ton common to need much description. The stem is thick, tough, and of a whitish colour, covered with fragments of an irregular kind. The branches are extremely numerous, and spread in such a manner, that when the plant is left to itself, it forms a kind of globular or semi-globular tuft upon the ground. The thorns are very numerous and very sharp; they stand, as it were, one upon another. The leaves are little, and of a pale green, and they fall off so quickly, that for a great part of the year we see the shrub without any. The flowers are yellow and beantiful, and the sceds are contained in pods. The root spreads a great way, and is not easily got up, when the shrub has once thoroughlyly fixed itseli. Every piece of it left in will send ip a new plant.

The root and the seeds are used, but neither much. The seeds llied and powdered are astringent, and a proper ingredient in electuaries, among other things of that intention. The bark of the ront is used fresh taken up, and is to be given in infusion: It works by urime, and is good against the gravel; but we have so many better things of our crin srowth for the same prirpose, that it is scarce worth while to medidle with it; it loses its virtuces by erying. 


\section{G. \\ Galangal Plant. Galanga.}

A wird plant in the East, which grows by waters, and has some resemblance of the generality of our water plants in its leaves, and manner of growth. It is two feet and a half high, and has white flowers. The roots spread about the surface, and are of an irregular shape. The leaves are a foot long, not half an inch broad, sharp at the point. and at the edges. 'The stalk is firm, thick, round, and of a purplish green; the flowers are small, and of a snow white; they consist of a larger upper lip, and a smaller tender one, each divided into three parts. The seed-vessels are oblong, and have each thrce dirisions, containing many seeds. The roots have a very acrid taste, and are reddish: as we have two sorts of galangal roots at the druggists, it might be expected there should be found two galangal plants, but they are both the roots of the same.

The lesser galangal is most used : it is a warm and fine stomachic, we put it in all bitter tinctures. Head-aches which arise from disorders in the stomach, are greatly relieved by this root. What is called English galangal, is the root of the long cyperus, described already in its place.

\section{Garlic. Allizim.}

A pravt kept in our gardens for its uses in medirine, and in the kitchen. It sorns two fert and a half high. 'The leaves are broad, hong, and ut a strong green. 'The stalk is round, smooth. a' inm, upright, and of a pale whitish or huich 
colour The Howers are white and small, but they srow in a large tuft at the top of the stalk. The ront is white, or a little reddish; it is composed of a great number of bulls, or, as we call them, cloves, joined together, and covered with a common skin, and with fibres at the bottom. 'The whole plant has an extremely strong smeli, and an acrid and pungent taste.

The root is to be boiled in water, and the decoction made into syrup with honey; this is excellent in asthmas, hoarseness, and coughs, and in all difficultice of breathing.

\section{Gextax. Gentiana.}

I Roexs ath handsome plant, native of Germany, and hept with us in gardens. It grows two feet and a half high. The leaves that rise from the rant, are oblong; broad, of a rellowish frcen colomr, and pointed at the ends. The stalk is thick, firm, upright, and brownish or yellowish. It every joint there stand two leaves like the others, only siritien; and towards the tops at every joint, also, there stand a number of flowers: these are small, yclow, with a great lump in the middle, which is the rudiment of the sced-ressed, and $a$ great quantity of yellow thresids about it. The root is laige. long, and often divided. It is of a brownish colmir on the outside, and yellow within, and is of a very hitter taste.

The root is used; our drugrists leep it dry: it is the great bitter and stomachic of the modern practice. Gentian ruot, and the peet of Seville manges, make thr common bitter tinctures and infusions: beside strengthening the stomach, and creating an appetite, threr open obstructions, and 
are good in most chronic disorders. "The powdel of gentian will cure agues.

\section{Germander. Chanucelrugs.}

A crrote plant, native of many partz of Europe. but with us kept in gardens. It grows a foot or more in height, but rarely stands quite upright. The stalks are square, green, and a little hairy. The leaves stand two at each joint. They are oblong, deeply indented at the edges, of a firm substance, green on the upper side, but hairy underneath. The flowers are small and purple, like the flowers of the little dead nettle. They stand in clusters about the upper joints of the stalks, and appear in $\downarrow u l y$.

Germander is an herb celebrated for many virtues. "Tis said to be excellent against the gout and rheumatism: however that be, it promotes urine and the menses, and is good in all obstructions of the viscera. The juice is the best way of givings it, but the infusion is more fiequent.

Water Germander. Scordium.

A LITTLE mean looking plant, wild in some parts of England, but kept in grardens also for its virtues. The stalks are square, hairy, of a dusky green, and so weak, that they seldom stand much up. 'They are eight or ten inches long.'. The leaves are short, broad, and indented about the edgres, but not sharply or deep as those of the other germander: they are of a sort of woolly soft appearance and touch, and of a dusky deep green colour. 'The flowers are very small and red, and 
they stand at the upper joints of the stalks, in little parects together. The whole plant has a strong and disarreeable smell.

The whole plant is to he used fresh or dried. It has been celebrated greatly as a sudorific, and for its virtues against pestilential ferers, but it is now little ised.

\section{Givare. Zinzijer.}

Is East India plant, found also in other places, and very singular in its manner of growtle. It produces two kinds of staiks, the one bearing the leaves, and the other only the flowers. The first grow two or three feet high, and are themselves composed in a manner of the lower parts of leaves; so that they seem to be only bundles of leaves rolled together at the bottom. These are long, narrow, and in some degree resemble the leaves of our common flags. The other stalks are tender, soft, and abont a foot high: they have no leaves on them, but only a kind of films, and at the tops they produce the flowers, in a spike: these are small, in shape like those of our orchis, and of a mixed colour, purple, white, and yellow. The root spreads irregularly inder the surface.

The root is the only part used: we have it dry at the grocers; but the best way of taking it, is as it comes orer preserved fiom the East Indies. It is a warm and fine stomachic, and dispeller of wiral. It assists digestion, and prevents or cures cholics. It is also an excellent addition to the ough purges, to prevent their griping in the giviration.

Guadry. Ayris sive spatula fatida.

A wiso plant of the iris kind, of no great 
beanty, but not without its virtues. 'The root creeps about the surface, like that of the common flower de luce. The leares are a foot long, narrow, and sharp-pointed, and of a strong and very peculiar smell. The stails are round, firm, upright, and of a bluish green. The flowers are like those of the common tlower de luce, but smaller. and of a very dull colour. "There is a little purple. in the mper part of the flower. and there are some reins and streaks in the lower ; but the rest is of a dull dead hue, between grey and brown, and they have a faint and bad smell.

The juice of the rout piomotes urine, and the menses. The dried root, in powder or infusion, is good against all byoteric disorders, faintings, and pains. Outwardly, the fresh root is said to be an excellent remedy for scrophulous swellings ; but this we must take upon trust.

\section{Guaswort. Käli.}

A comor wild plant, on the sea coasts of many parts of Europe, but not a native of our country. It is called cochleated kali, from the form of its seed-ressels, which are trinted in the manner of a snail's shell. It grows to a foot and a half in height. The stalk is round, thick, fleshy, and brittle. The leaves are few, and they stand irregularly; they are oblong, and blunted at the ends, and of a bluish green colour. 'The flowers are small, inconsiderable, and yellow.

The juice of the fresh plant is said to be an exrellent diuretic; but we have no opportunities of knowing its virtues here. Some say the seedressels have the same virtue, and give them in infusion, but we have better remedies of the same kind, of our own growth. The whole plant is 


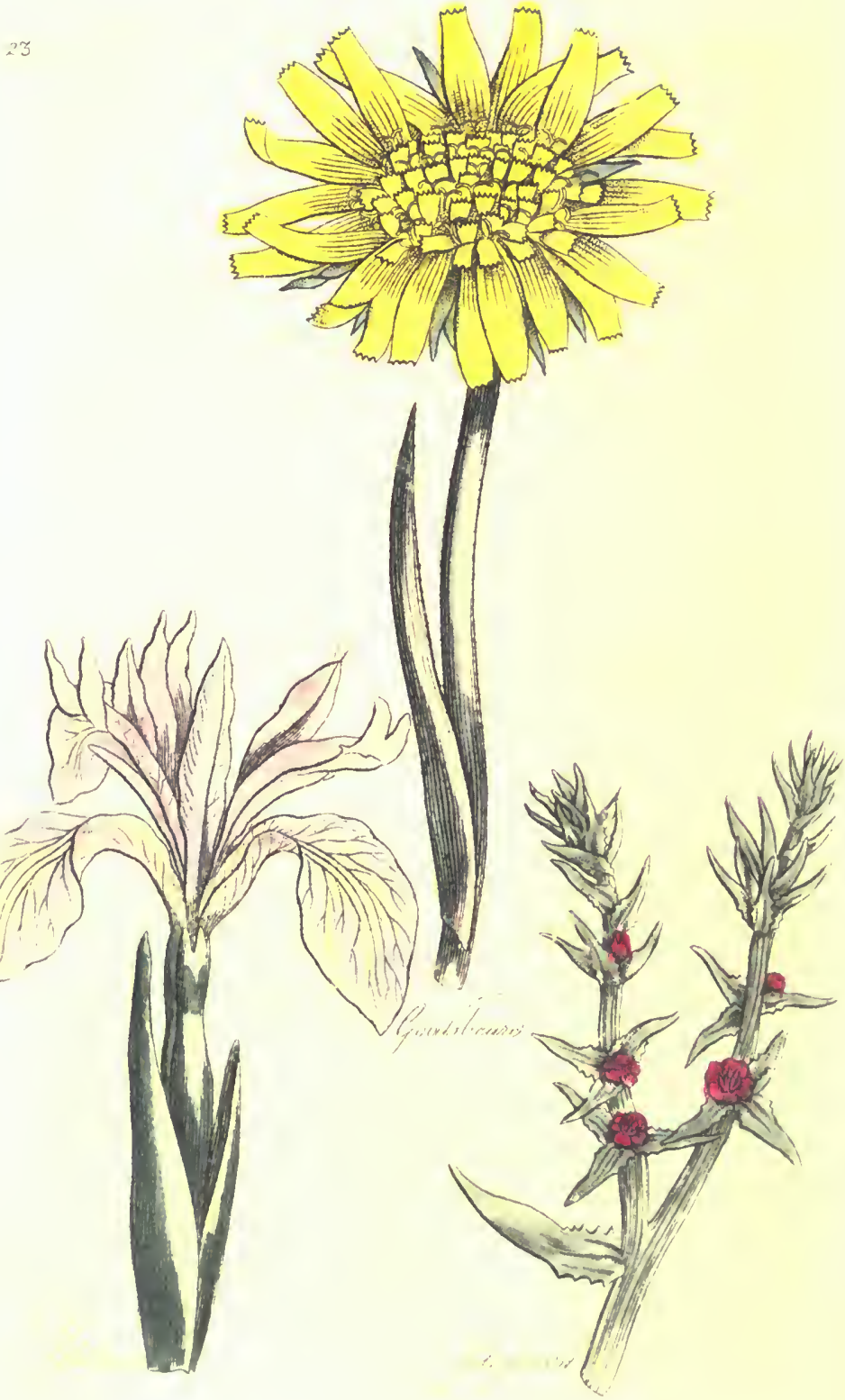
burnt for its fixed salt, which is used in making glass.

\section{Goat's Beind. 'Tragoporm.}

A romuos wild plant, disinguished in our meatows by its narrow and fresh green leaves, and the kng lenves of the cup, abont its yellow flowers. It grows to a foot and a half in heiglit. The leaves are rery narrow; they are broadest at the base, and smaller all the way to the point. The stalk is mond, thick, firin, very upright, and towards the top divided into two or thrce bianches. The flowers stand at the extremities of the staliss; they are of a teantiful pale yellow, very large and surrounded by a cup, composed of long and namrow green leaves, which, for the greatest fart of the flay, are closed over it, so that it seems only in bud. The sects are winged with a fine white down, in the manner of those of dandelion, and, when ripe, they stand upon the tops of the branches, in a round licad, in the same manner. Thie root is long and white; and the whole plant is full of a milky juice. which, after it has been a little time exposed to the air, becones yellow, sud thick like croam.

The root is used. It is sr plesent in taste, that it may 1. caten in the manner of carrots, and other ronts at table, but it exceeds them a!l in its qualitics. It is an excellent restorative, and will do great service to people after long illness: the best way of giving it for this purpose, is to boil it first in water, and then, cutting it to pieces, boil it again m milk, which is to be rmidered palatable in the usual way; it becomes thus a most excellent medi. fine in the form of food. 


\section{Gont's Rue. Gelega.}

A TALL plant, native of ltaly, but kept with us in gardens. It grows a yard high. The stalks are round, striated, hollow, not very firm, or strong, and of a pale green colour: they are very much branched, and not altogether upright. The leaves are long and large, each is composed of several pairs of smaller leares, with an odd one at the end of the rib; these are oblong, narrow, and of a yellowish green colour, thin, and not at all indented at the edges. The flowers are small, and of a bluish and whitish colour; they stand a great many upon the same pedicle, in a drooping posture.

The whole plant is used. It is to be gathered when just come to flower, and dried, and afterwards given in infusion: this gently promotes sweat, and is good in fevers; so much is true of the virtues of this plant, but much more has been sant of it.

\section{Goldex Rop. I irga aurea.}

A venY pretty wild plant, with tufts of rellow flowers, frequent on our haths in autumn. It is two feet high. The stalk is firm, erect, round. and hairy. The leaves are long, broadest in the middle, indented at the edges, romgh on the surface. hairy, and of a strong green colour. The floweres are small, and of at bright yellow, but they grmi together in a sort of thick and short spikes, wo that they are rey complowms. The ront is long. brown, and of ani ansere taste, as is also the while ylant.

The rock, tiken up in spring and died, is an excellent medicine given in powder for purgines, and fire overflowing of the menses, bloody stocks, or any 
onher hemorrhage whatsocver. The whole plant has becu at all times famous as a vulnerary or wound herb, given in decoctions.

\section{Gold of Pleascre. Miyagrum.}

A vERY pretty plant, common in many parts of England, and kinown at sight by the rast quantity of seed-resucts. it is two feet high: the stalk is round, thick, fim, $\left.u_{1}\right)$ ght. and toward the top lass a great ma! branches, all standing upright. The leaves stand irregularly, air are not numernus, the are lome rot sery broad, amb of a pale green; the are indented about the edees, and surround Alic stilli al the base; the flower's are le and white; the seed-resels are short and round he and they stand in vast quantities, forming a kind of spitse all the way up the tops of the branches, with ferw thowers at the cummit.

The fresh tops of the plant are to be ueed before it is run to sed. An infusion of them sweencmet with honey, is excellent for sore throats, and werations of the month. The sceds yield a grent gliantity of oil on presing, and they are so plentifinl. that it might seem worth while to $\mathrm{cu}$ '. vate the plant for them; the oil is pleasant and well tated.

\section{Gotrd. Cucurbita.}

A targe plant, of the melnu or cucumber kind, kept in gardens. The stalks are ten or twelve feet Inng; thick, angular, rongls, and hairy, hut mable to support themselves upright: they trail upon the ground or climb upon other things. The leaves are very large and broad, indented Letply, rough, of a blakkish green. 'The flowers 
are large, and bell-fashioned, white and downy on the inside, and not altogether smooth on the vuter surface.

The fruit is large, and has a hard, firm shell on the outside, and is fleshy and juicy with?. "ith sceds in the manner of the melons; these are flat, of ais oblotig shape, and hard.

These seedis are the only part uned: they are

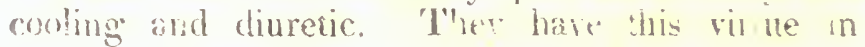
mach the same degren with uncumber and melon seeds, and are given witi them in emulsions.

\section{Brter Gockn, called Bittre Apple.} colocynthis.

A sative of the Fast, and of some other warm countries, kept in our curiois gardens, and atlording the famous drug called coluguintide. It is a snall plant of the geure kind. The stalks are thick, angular, hairy, and of a pale wreen. They camot support theiselves, but have a namber of tendrils growing from them, by which they kay hold of every thing they come near. The leases are large, broad, and rery deeply divided at the edges. The flowers are of a pale yellow, large, and not unlike the flowers of melons. The fruit is a round sourd, of the bigness of the largest orange. The bark is hard, and the inner part spungy, with seeds among it: these are flat, hard, and of an owal figure.

'The foult is the part used; they take off the onter shell, and send the dried pulp, with the seeds among it: but these are to be separated afterwards, and the pulp used alone. It is a very violent purge. lus it may be given vith proper caution; and it is exrallent againal the rheumatism, and violent

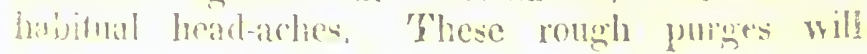





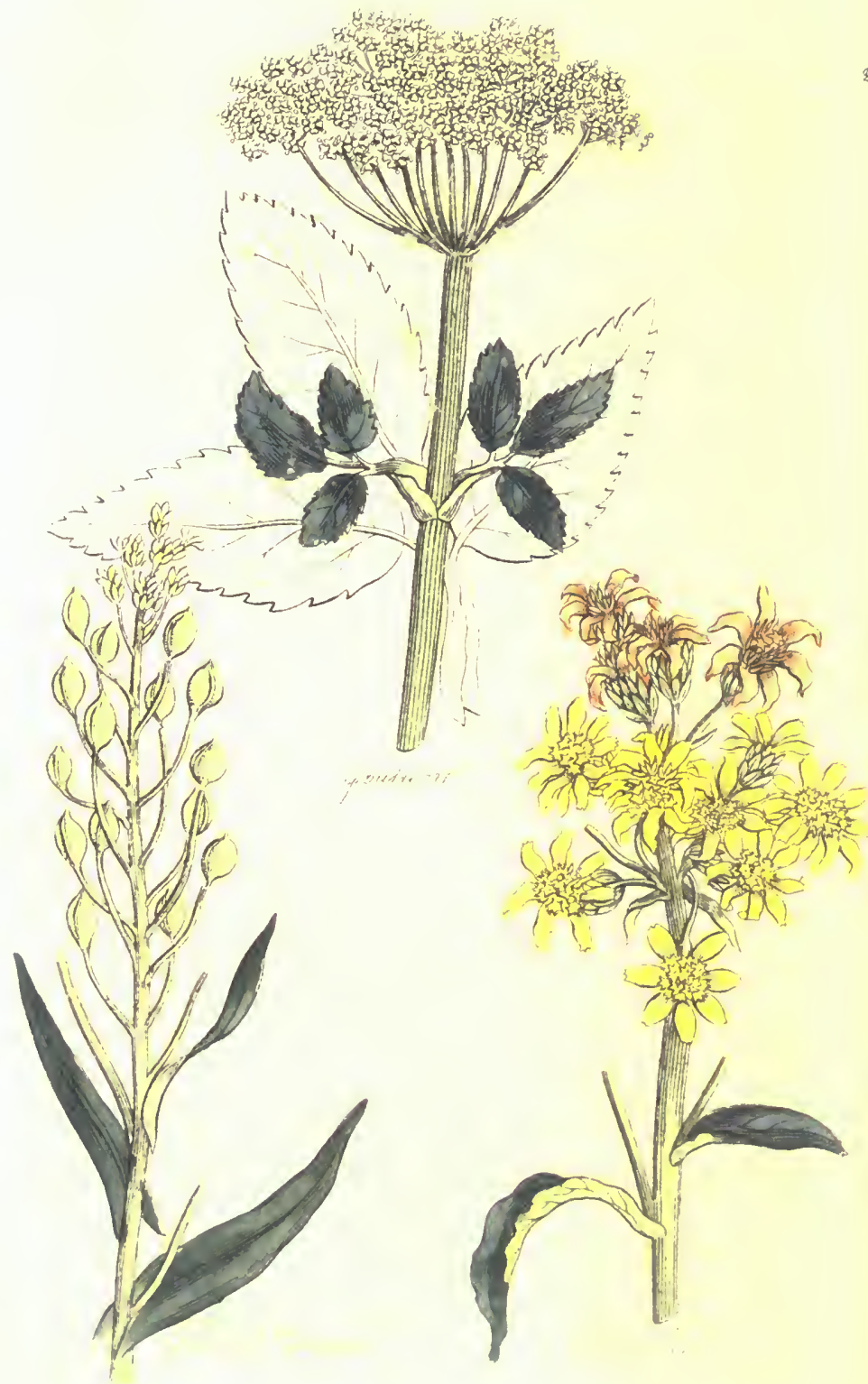


reach the canse of disorders, that the common genthe ones would not tonch; and the present practice denies the use of many of the best medicines we hikut:

\section{Gout Wont. Palugrara herba gerrardi.}

A commox wild plant over-pumning our gardens, and when once it has taken root very diffi("in" to be got out again; it grows two feet high. The leaves which rise from the ronts are large, and they are composed ench of screral smaller, set on a divided rib, in the manner of those of angelica, of which they have some resemblance. They are of a pale green colour, and are oblong and indinted at the edges. The stalks are rombl, upright, and a little branched, they are slender, striatod, and green; the leaves on these are smaller, and consist of fewer parts than those that rise from the ront. The flowers are little and white, and they stand in small round clusters; each is succecided by two flat secds. The root creeps.

The root and fresh buds of the leaves are both nsed, but only extervally; they are excellent in fomeritations, and pultices for pains ; and the plant has obtained its name from their singular eflicacy against the pain of the gout : but it is not advisewhle to do any thing in that disorder; the warm applications of this kind are of all others the least. dingerous. I have known a quantity of the roots and leaves boiled soft together, and applied to the hip in the sciatica, keeping a fresh quantity hot to renew the other, as it grew cold, and I have seen great good effect from it. Its use should not be confined to this pain alone, it will succeed in others. 


\section{Gromvel. Lithospermon.}

A wisp piant of no great beauty, but distingnished by its seeds, which are hard, glossy, and resemble so many pearls, as they stand in the opon husk. 'The plaint grows a yard high. 'The stalk is round, thick, firm, very upright, and branched. The leaves are oblong, not very broad, rough, and hairy, of a deep blackish green colour, and placed irregularly; the flower's are small and white: when they are fitlen off, the cups remain, and contain these shining, and, as it were, stony seeds. The plant is fiequent about hedges.

The seeds are the only part used; they work powerfully by urine, and are of great service in the gravel and all other obstructions ; they are best siven in powder, with a great deal of barley-rater at the same lime.

\section{Growd-Pive. Chamapitys.}

A venr singular little wild plant, of a mossy appearance, and resinous smell: it grows four inches high; the stalks are hairy, and scldom stand upright; the leaves are very close set, and the young shoots which wrow from their bosoms perfectly obscure the stall; ; it seems a thick round tuft. 'These leaves are short, narrow, and divided into three parts at their ends, and they stand two at every joint of the stalk: they are rongh and hairy like the stalk. The Howers ale little and yellow, and they stand at the joints.

The whole plant is used, and it has great vir1112: it is to be need dry in powder or infusion. It works stroingly by mine, and promotes the menses. It "pens also all obstructions of the liver and 


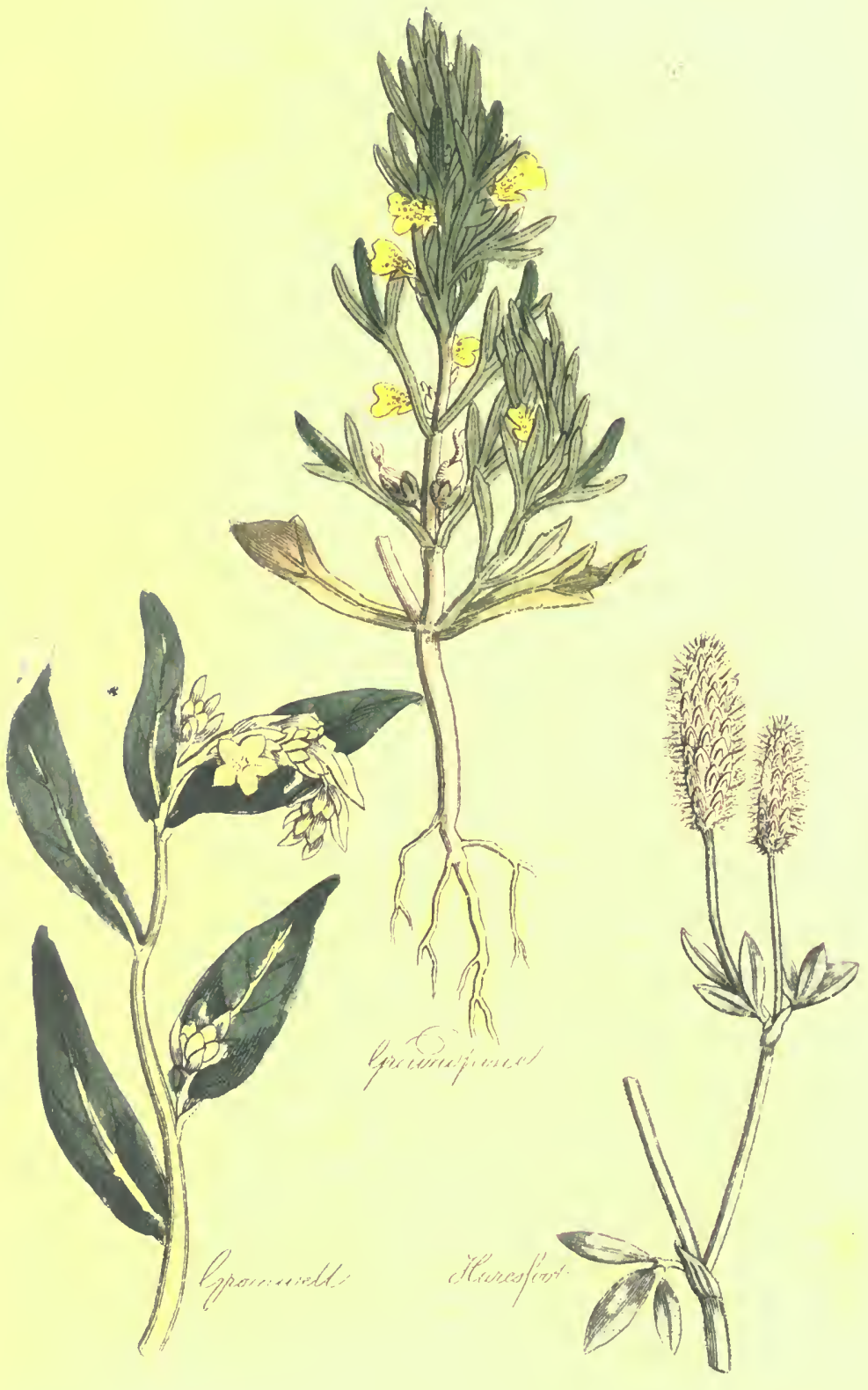



spleen, and is good in faumdice, the rheumation, and most of the chronic disorders.

Gronsomet. Erigeron siac seilecio.

A comsox weed in our gardens, and upon walls, with litto veilow flowers, and downy seeds: it grows eight inches high: the stalk i= romd, flesiy,

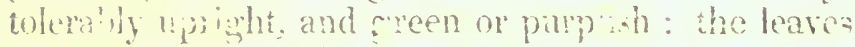
are oblong, broad, bhint, and divided at the extges. The flowers are small and yellow: they grow in a sort of long cups at the tops of the staiks and branches.

The juice of this herb is a gentle and very gnod emetic: It cantses romiting withont any great irritation or pain : and it is also good for cutaneous foulnesses applied outwardly.

\section{Genacry Tref. Guancum.}

A GREAT trea, native of the West Indies, and to be seen in some of ru: crisus gardeus. The fruit in rery large, and the branches are numerous ; the leares ane small, each is composed of two or three para of emallere ones, with no old leaf at the end of the rib. These are short, broad, roundish, and of a dumb nureen colour. The flowers are small and rellow, but they grow in large clusters together, so that the tree when in blom makes a very pretts atpentance.

The baik and wood are the only parta of the trec nsed; they gro given in decoction, to provinote ' neat,

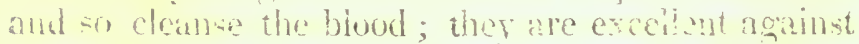
the themmation, -cirrt, and all other di urdere,

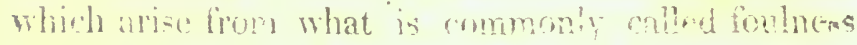

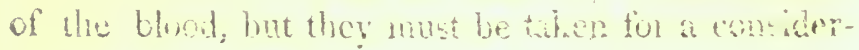


able time; for these effects camnot be produced at once.

What is called gum guaiacum, is the resin poured firm this tree; it is very acrid and pungent, and in the rhemuatism and many other cases is to be preferred to the wood itself.

\section{II.}

\section{Ihne's Exars. Bupleuron latifolium.}

A comsos wild plant in some parts of Europe, nut kept here in warlens. It is two feet or more in height. 'The leaves are long and broad, of a stiff substance, and somewhat hollowed, which gives them the appearance of a long and hollow car. firm whence they are named; they are of a whethereen colour, and the ribe on them are high. There is a sort with narrow leaves, but the broad leaved kind in a be mon in sicine. The sta!ks are ronid, npright, srlatert, and towand the (op) bramched. 'the flowers are little and yellow, and they tesul at the fops of the branches in small mubels. The root is long and hick, and has many diis ine.

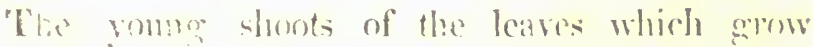

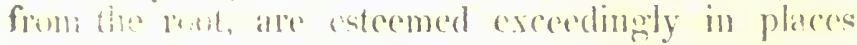
where the y ale molive, for the ruse of fresh wounds.

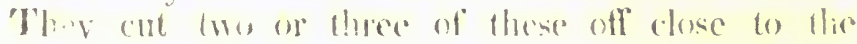

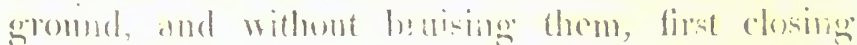
the lips of the wombl. they lay them on ane overe the wher, making a kind of compress: ther then hind them on with linen rases, and newer take off the dressing for there dose at the end of whele

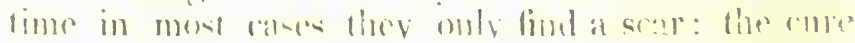
becing perfected. 'flits is the substance of a posin- 
bus account sent lately to a person of distinction with some leaves of the herb. There is no doubt of the truth, and the surreons will very well understand the nature of the cure; the discovery however is not new, for the herb has always been reckoned among the vulnerary plants; and some have pretended that it will singly cure the king's evil, but that is not to be expected; at the same time it may be proper to observe, that we do not want plants for the same use in Fingland; we have the tutsan which is to be applied in the same manner, and has the sarre effect; clown's all-heal, and many others, named in their places.

\section{HARE'S FoOT. Tagopus.}

A comov litle plant, singular in the tuft, which contains its seeds, and whence it has its name, but not so much regrarded as it ought to be for its virtues. The stalks are numerous, round, slender, and spread upon the ground, each is divided into a number of lesser branches: The leaves are small, oblong, narrow, of a pa's green colour, and hairy; and they stand three togrther, in the manner of trefoils. The flowers are small and of a faint red, they stand several together in a short spike, and the cups which receive them at the base, are downy; this gives the singular aspect of hairiness to these hearls, and their sofiness to the touch.

The whole plant is to be used dried. It is an excellent astringent. It stops the orerflowings of the menses and the whites, and is good against blondy fluxes, and purgings of all kinds. The best way of taking it is in a strong decoction, which must be contirued some time. 


\section{Hart's Tongue. Phyllitis. Lingua cervina}

A wiLn plant of the fern kind, that is, consisting only of leaves, without a stalk, the flowers and seeds being borne on the backs of them. But it has no resmblance to the ordinary ferns in its aspect. Each leaf of hart's tongue is a separate plant, but there rise many from the same ront. The foot-stalk is five inches long, the leaf an inch and a quarter broad, largest at the bottom, and smaller to the top, usually simple, but sometines divided into two or more parts at the end. It is of a beauti. $\mathrm{ll}$ green at the upper side, somewhat paler underneath, and the foot-stalk runs all along its n: ddle in the form of a very large rib. The seed-vessi, s are disposed in long brown streaks on each side of this rib, on the under part of the leaf, and they are more conspicuous than in most of the fern kinil. The plant grows in old wells, and in dark ditches, and is green all the year.

It is not much used, but deserves to be more known. It is an excellent astringent; the juice of the plant, taken in small quantities, and for a continnance of time, opens obstructions of the liver and spleen, and will cure many of the most obstinate chronic distempers.

\section{Hartworz. Seseli.}

A TALL, robust, and handsome plant, native of the Alps, but kept in our gardens. It grows live or six feet in height: the stalk is round, thick, striated, and hollow, very firm and upright, and lout little branched. The leaves are very large, and they are divided into a sireat number of parts, by fives and by threes; they are of a yellowish green. The flowers are small and white, but they 


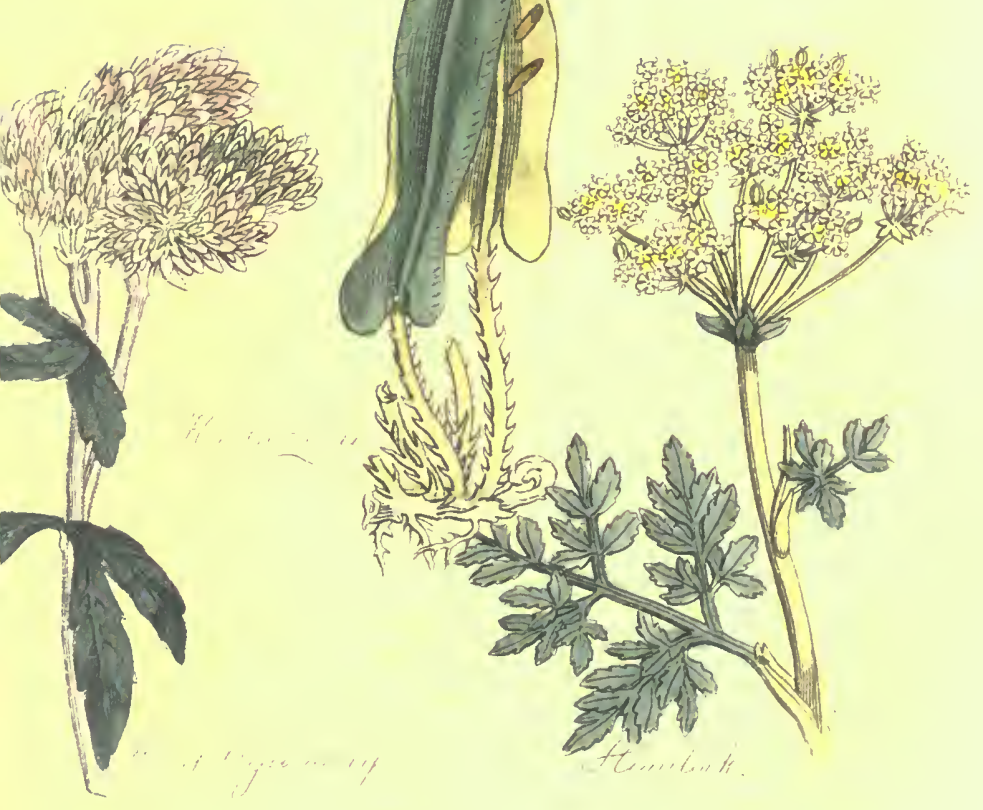



stand in great tufts or umbels at the tops of the stalks: the seeds follow, two after each llower, and they are oblong, broad, and edged with a leafy border; they are of a dark colour, a strung. smetl, and acrid taste.

The sceds are the only part used; they promote the merises, and the necessary discharges after delivery, and are an excellent warm and cordial medicine; they work also gently by urine, and cure colicy pains; they are to be given in powder or infusion.

\section{Hawthors. Spina alba.}

A suker too common in our hedges to need much description. The trunk is irregular, and seldom straight; the branches are strong, tough, and thorny ; and the leaves of a glossy green and beautifully divided. The fowers are white and beautiful, the fruit is small.

The flowers and the dried fruit are used in medifine; they have the same virtue; they work by urine, and are good in the gravel, and all complaints of that kind; but there are so many better thiugs for the sane purpose at hand, that these are not much regarded.

\section{Hedge, Mrstand. Erisimum.}

A VERY common wild plant, and of no greal beanty; it is freqrent about old walls, and in farm varck, and is distinguished by its long spikes of pods, which are lodged close upon the stalk. It grows two fect in height; the stalk is round, firm, upright, but not always quite straight, and a littie branched. The leaves are of a pale green colous, hairy, oblong, and deeply indented at the edges. 
The flowers are smail and yollow, and they commonly stand at the tops of long spikes of pods, which have been fiowers before them.

The whole plant is used, an infusion of it fresh is the best way of taking it. This dissolves tough phlegm, and is excellent in asthmas, hoarsenesses, and other complaints of the breast. This simple infusion, made into a syrup with hone'y, also answers the same purpose, and keeps all the year.

\section{Hemlock. Cicuta.}

A LARGE, tall, and liandsome umpelliferous plant, frequent in our hedges. It grows to six feet in height; the staik is round, firm, hollow, and upright; it is of a dark green, and often stained with purple and yellow. The leaves are very large, and divided into very fine and numerous partitions. The flowers are small and white, and stand in large clusters on the topus of the stalks. The seeds are roundish. The whole plant has a strong disagreeable smell, and has been called poisonous.

The roots are excellent in pultices for hard swellings.

\section{Henp. Cannabis.}

IIEMP is a tall plant, of a coarse aspect, cultirated in fields for its stalk. It grows five feet high, and is a robust plant; the stalk is thick and rigid; the leaves are numerous, they are large, and rach composed of six or seven smaller; these are disposed in the manner of fingers, and are of a deep green criour, mugh, narrow, and serrated at the elges. The flowers in hemp srow in some plants, and the 



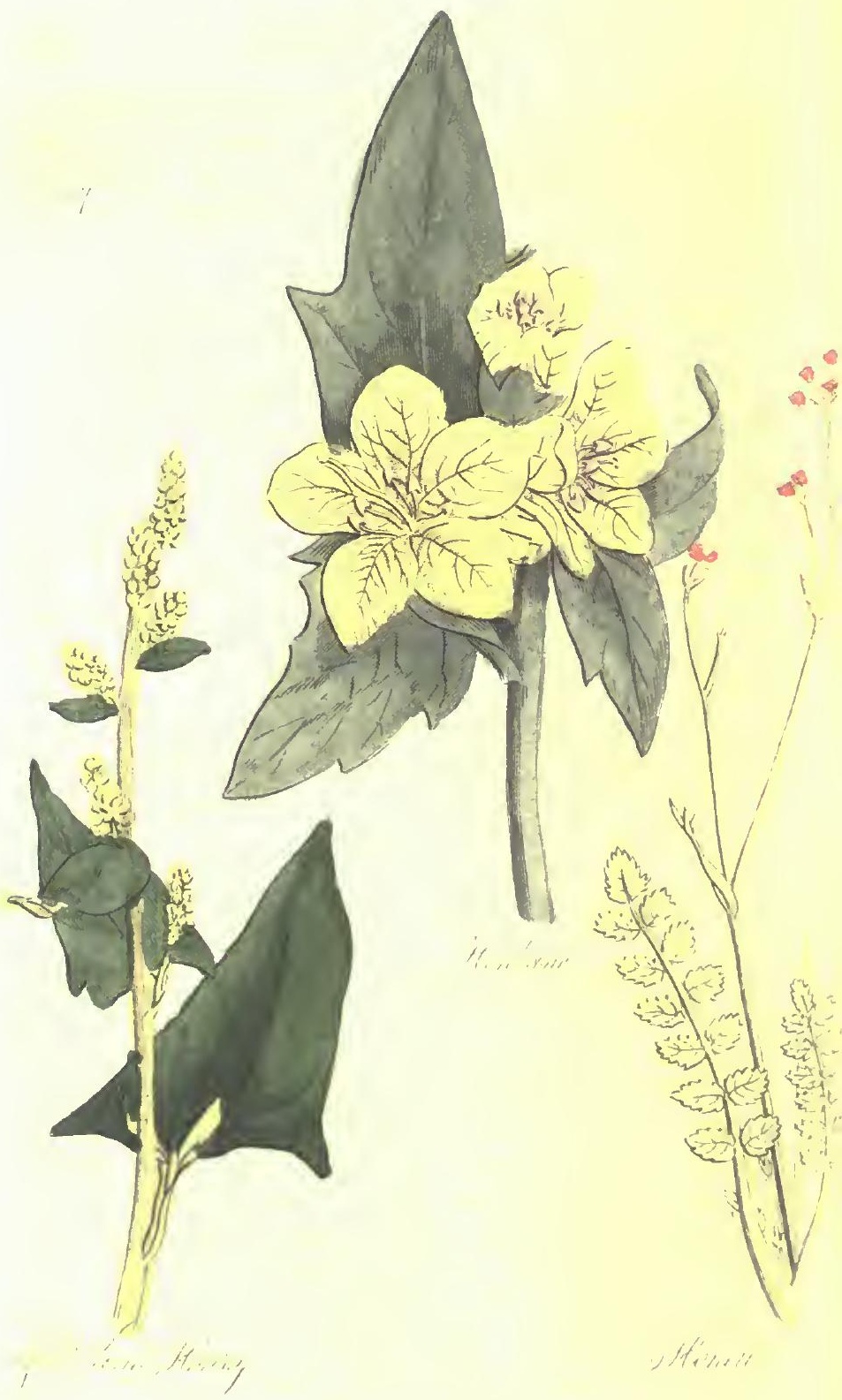


seeds on others. The flowers are inconsiderable, and whitish; the seeds are large, roundish, grey, and have a white pulp within. The root is fibrous. The seeds are used in medicine; an emulsion made of them cures the jaundice.

\section{Hemp Agrmory. Eupatorium cannabinum.}

A TALL plant growing by waters, with tufts of red flowers and leaves, divided in the manner of those of hemp. It grows five feet high; the stalk is round, thick, reddish, and very upright. The leaves are large, of a pale green and fingered; they stand two at each joint; the flowers grow in bunches as big as a man's fist, on the tops of the branches, and are of a bright red.

The root fresh gathered and boiled in ale is used in some places as a purge; it operates strong. ly, but without any ill effect, and dropsies are said to have been cured by it singly.

\section{Buck Hendane. Hyoscyamus niger.}

A comor wild plant, of a dismal aspect and disagreeable smell. The farm yards and ditch banks in most places are full of it. It grows two feet ligh. The stalk is thick, round, hairy, and clammy to the touch; but not very upright. The lcaves are large, long, and broad, deeply serrated at the erlges, of a bluish green colour, hairy, and clammy to the tonch, and leaving a disagreeable smell upon the hands. The slowers are large, and stand in rows on the tops of the branches, which often bend down; they are of a strange yellowish brown colour, with p) urple veins. The seeds are numerous and brown. 
The seeds are used; the rest of the plant is esteemed poisonous. They are given in small doses against the bloody flux, and it is said with great success ; I have not known it tried.

\section{White ilexbane. Hyoscyamus albus.}

A Native of Italy and Germany, kept in our gardens. It is a foot high, and has something of the aspect of the black henbane, but not so dismal. The stalk is round, thick, and of a pale green; the leaves are large, broad, but short, and a little indented at the edges; they are of a yellowish green, and somewhat hairy; the flowers are small and yellow, and the seeds are whitish.

The seeds of this kind are preferred to those of the others, as less strong. in their effects ; but if any harm wonld happen from the internal use of the other, we should have known it, for they are gene. za!ly sold for them.

\section{Good Kra llexry. Bonus Henwicus.}

A connox wild plant, called also by some English mercury, by way of distinction from the vther, which is ealled French mercury, and has been described already. This grows a foot high; the stalk is round and thick, but rarely stands quite upright; it is greenish and purplish, and is corered with a lind of grey powder unctuous to the touch. The leaves are large, broad, and of the shape of an arrow-head, they stand on loner stalks, and are of a pale green above, and greyish moderneath, being there covered with this grey powder. The flowers are inconsiderable, and are of a greenish rellow, and they stand in lone spikes at the tops of the branches; the plant is common in farm yark 
The young shoots are eaten as spinare, the juice of the whole plant works gently, and well by urine; and the dried herb is used in decoctions for glister..

\section{Hermódacty Plant. Hermodactylus.}

A Beactifle plant, having more the aspect of a garden flower, but it is common wild in the East. The root is roundish, but flatted, and indented at the bottom, and smaller at top. The leaves are small and broad; they are sharp at the point, and of a deep green colour. The flowers are large and of a whitish colour, reined and striped with purple; this is the best account we have received of the plant, but part of it comes with less authority than one would wish to things of this kind. The root is dried and sent to us.

It is a gentle purgative, but it is less used at this time than many others. It has been in more repute, perhaps with reason.

\section{Helioak. Malza arborea}

A comos garden flower. It grows cight feet high, and the stalk is round, firm, hairy, and upright. The leaves are large and roundish, of a deep green, hairy, and cut in at the edges; the flower's are very large, red, whito, or purple, anú stand in a kind of long spike. The root is white, long, and thick, and is of a slimy nature, and not disagreeable taste.

This is the part used; a decoction of it operates by urine, and is good in the grarel; it has the same virtue with the mallow and marshmallow, but in a middle degree between them; more than the mallow, and not so much as the otier, nor is it so plesant. 


\section{Honewort. Selinum sii foliis.}

A common plant in corn-fields and dry places, with extremely beautiful leaves from the root, and little umbels of white flowers. It has its English name from its virtues. Painful swellings are in some parts of the kingdom called hones, and the herb, from its singular effect in curing them, has received the name of honewort, that is, honenerb.

The root is long and white; there rise from it, early in the spring, half a dozen or more leaves, which lie spread upon the ground, in an elegant manner, and are all that is menerally observed of the plant. The stalks do not rise till the end of summer, and these leaves decay by that time, so that they are not known to belong to it. These leaves are eight inches long, and an inch and a half in breadth : they are composed each of a double row of smaller leaves, set on a common rib, with an odd leaf at the end; these are oblong, tolerably broal, and indented in a beautiful manner. They are of a fresh green colour; they are the part of the plant most seen, and the part to be used; and they are not easily confounded with those of any other plant, for there is scarce any that has what tre nearly so handsome. The stalk is two feet high, round, hollow, upright, but not very firm, and branched toward the top. The leaves on it are somewhat like those from the root, but they have not the singularity of those beantiful and numerous small ones; the flowers are little and white, and the secks are small, flatted, striated, and two of them follow every flower.

The leaves are to be used; they are to be fresh gathered and beat in a murble mortar into a kind of paste. They are to be laid on a swelling that is 
red, painful, and threatens to have bad consequences, and they disperse it. The application must be frequently renewed, and there are those who speak of its suring the evil.

\section{HoNey-Suchle. Pcriclymenum.}

A beactifur wilt shrub. The trunk is seldom more than an inch thick; the branches are very long and slender, of a reddish colour, brittle, and all of the same bigness. The leaves stand in pairs, they are broad, short, blint, of a dark dead green colour. The flowers grow in little clusters; they are long, slender, tubular, and very fragrant; the berries are red.

The fresh leaves of honey-suckle given in decoction, are good against obstructions of the liver and spleen; they work by urine, and they are also a good gargle for a sore throat.

\section{Honeriwort. Cerinthe.}

A Juicy plant frequently wild in many parts of Europe, but with us kept in gardens. It has its name from the sweet taste of the flowers. Almost all flowers have a drop of honey juice in their bottom: this is indeed the real substance of honey, for the bees only pick it out and get it together: the hollow flowers in general have more of it, or it is better preserved in them than others, but scarce any in so great a degree as this plant named from it. It is two feet high, when kept erect, but if left to itself, is very apt to lean upon the ground. The stalk is round, thick, juicy, and tender; the leares are large, oblong, broad, they surround and inclose the stalk at their base; they are of a bluish greer 
colou;, spotted or clouded irregularly with white, and they are full of a sort of prickles. The flowers grow at the tops of the stalks, several together, among the clusters of leares; they are hollow, oblong, and very wide open at the mouth; their colour is yellow, variegated with purple in the midale, and they have a very preity appearance.

The fiesh gathered tops of the plant are to be used; an infusion of them is cooling, and works by urine. It is good against scorbutic complaints, and in the jaundice.

\section{IIor Plaxt. Lupulus.}

A chimbrog plant, with very long stalks, common in our hedges, and cultivated also in many places. The stalks are roundish, rough to the touch, and of a purplish colour often, sometimes only grcen. The leaves are very large, of a roundish figure, deeply indented, of a dark erreen colour, and very rongh also to the touch. The fruit is sufficiently known.

A decoction of fresh gathered hops is good against the jaundice; and the powder of hops dried in an oren has been often known to cure agues, but upon this there is no absolute dependance.

White Ilonsmocxd. Marrubium album.

A wite hoary plant, with little flowers in tufte round the stalks, frequent in dry places in many parts of the kirgdom. It grows sixteen inches hight. The stalks are square, and very robust, hairy, pale coloured, and upright. "The ketres stand two at each joint; they are short and broad, blunt at the ends, and widely indented at 


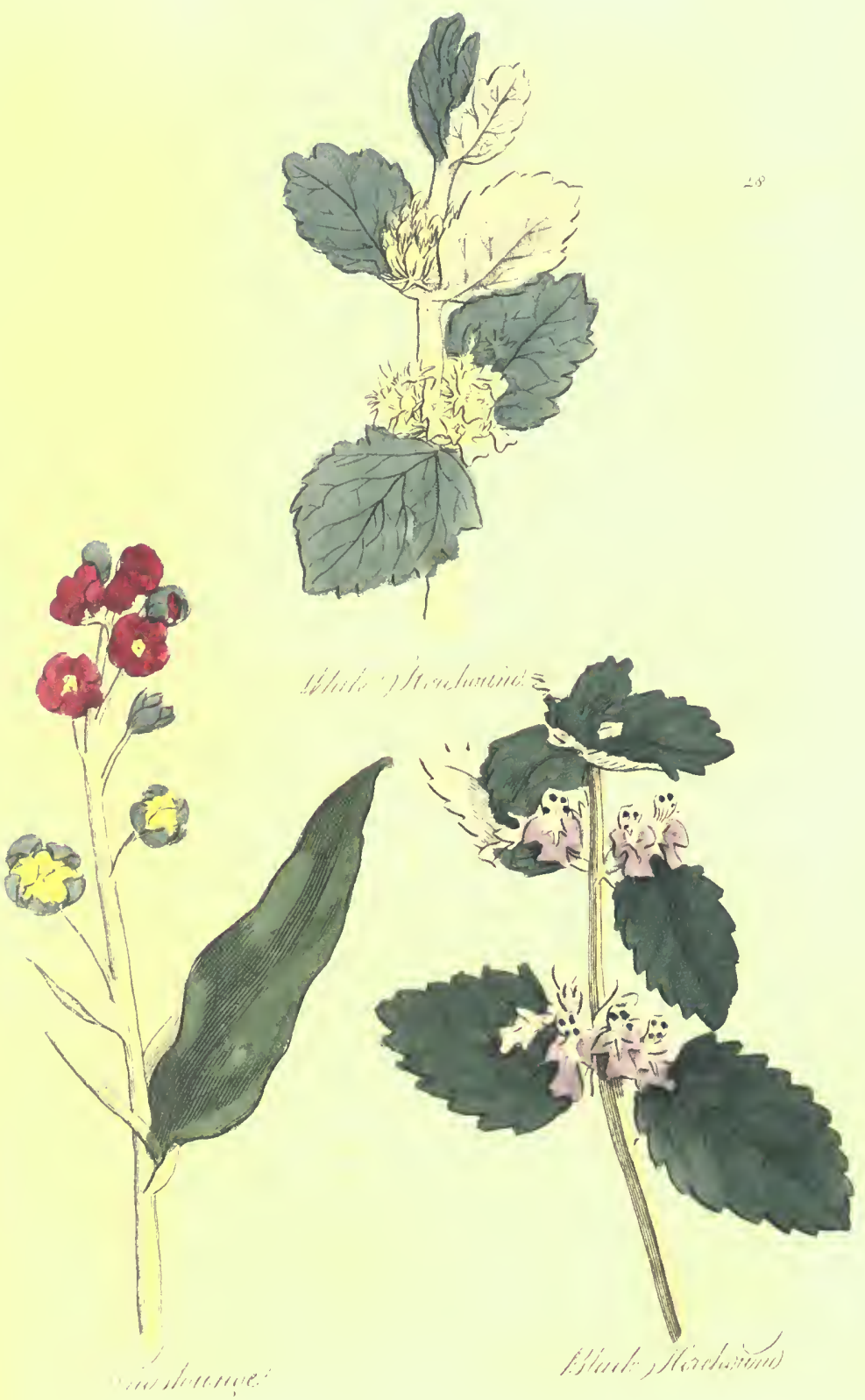



the cages, of a rough surface, and white colour. The thanes are white, and the points of their cups are privity.

"The biest part of the plant for medicinal use, is the $t^{2}$ on $)$ of the young shoot: ; a decoction of these nade rery strong, and boiled into a thin syrup with luney, is excellent against coughs, hoarsenesses of long standing, and all disorders of the lungs. The sume decoction, if laken in large doses, and for a continuance, promotes the menses, and opens all obstructions.

\section{Black Horenouxd. Ballote.}

A commox wild plant of a disagreeable smell, thence also called by sone stinking horehound. The taiks are square, the leaves grow two at every joint, and are bonad, short, and of a blackish green colonir, hut in shape not unlike those of the white lind. The flowers stand in clusters round the stalk at the joints, as in the other, but they are red. The whicle plant has a dismal aspert. The root is librons.

The plant is to he vised fresh and dried, and it has mene virtue than most imagine. It is to be given in the form of teat it promotes the menses, and is smperion to mot things as a remedy in hysteric cases, famtings, convolsions, and low-spiritedness, and all the train of those disorders.

\section{Ihorsetai. Eqquisctum segetale.}

I connos, and yet very singular wild plant, frequeith in our corn-fiells, and composed of barehe's only, without leares ; there are also many other linds of horsetail. It is a foot or more in height, and is extremely branched; the stalk is 
round, blunt, ridgeci, and angulated, and cumposed of joints. It is hollow, weak, and seldom supports jtself tolerably upright. The branches are of the same structure, and they are again branched; they grow several from every joint of the main stakk, and have others again, thongh in less number, growing from their joints. The whole plant is of a green colour, ard when bruised, not of a very agreeable smell.

The whole plant is to be usea, and it is best fresh ; though it retains a great deal of its virtue dried. Given in decoction, it stops overflowings of the menses, and bloody stoois ; and applied externaliy, it immediately stops the bleeding of wounds anc heals them.

\section{Hound's Tongue. Cynoglossum,}

A TALL and singular looking piant, frequent by our way sides, and distinguished by its large whitish leaves, and small purple flowers, as also by the particnlarity of its smell, which has been supposed to resemble that of a kennel of hounds. It is two feet and a half high. The stalk is angulated, firm, and upright: the leaves are long, considerably broad, and of a pale whitish or bluish grcen colour, sharp at the points, and not at all serrated at the edges. The flowers are small, and of a deep purple: they grow along the tops of the branches, and are followed by rough seeds.

The ront is the part used; it is long, thick, and brown, but whitish within; it is balsanic and astringent. Given in tecoction, it is excellent amainst conglis arising from a thin sharp humour. Dried and powdered, it is good against purgings, and stops the overflowing of the nienses. 


\section{Grfat Houseleex. Scdum majus.}

A plant sufficiently known as well by its particular manner of growing, as for its place of growth. It forms itself into clusters of a roundish figure, these are composed of leares, which are largest toward the bottom, and smallest at the end; they are very thick and juicy, broad at the base, sharp at the point, flat on the upper side, a little rounded on the under, and somexhat hairy at their edges. The stalk grows to ten inches high; it is very thick, round, and juicy, upright, of a reddish colour, and divided at the top into a few branches. The leaves on it are thin and narrow. The flowers are numerous; they are red and have a green head in their middle, which afterwards becomes a cluster of seed-ressels.

The leaves are the part used; they are applied externally in inflammations, and are very useful, when cooling things may be employed. The juice is also cooling and astringent taken inwardly, but it is rarely used. Some praise it greatly for the inflammations of the eyes.

There is another kind of houseleek very unlike this in form, but of the same virtues, this is called the lesser houseleek; the stalks are round, small, and reddish, and grow six inches high; the leaves are long and rounded, not flat as the other leaves; and the flowers are white, and stand in a kind of tufts, like umbels at the tops of the stalks. This grows on old walls, and the tops of houses like the other.

I.east Hocseleek, or Whal Pepper. Sedum minionum acre.

A common plant on old walle, of kin to the 
preceding, but very different both in face at virtues. The root is little; from this grow ab. of dance of stalks; they are round, weak, and unal d to support themselves; they spread erery wa, about, and are six inches in length. The greater. part of every stalk is covered with leaves, so that i appears a green substance, of the thicknesz of one $t$ little finger; these leaves are short and thick ; the re of a fine green colour, and are broad at the bast and sharp at the point. The flower's are litile, and $a$ : a bright yelkw; they grow in great numbers, from the tops of these branches, and are of the shape of inose of common houseleck, and rounded by such serd-ressels.

The juice of this lind of houseleck is excelint against the scurry and all other disenses arising fiom what is called foulness of the blood. It is said that a continued course of it will cure the kings evil: but we want experience to support this.

\section{Inrocks. Hypocistus.}

A rrny singular plant, native of the Grecian istands, and of sone of the warmer parts of Europe. It is five inches hirh, and of a singular figure. It does not crow in the earth at large as other plants, but to the root of some species of cistus; as miscletne grows to the branches of trees. The stalk is thick and fleshy, and is often twice as lar'ge toward the top, as at the bottom. It is whitish, or yellowisis, or purplish, and has a parcel of short and broad skinny tilins. by way of leares upon it. The forrers grow at the top, with leaves of the same hime among them. 'Tleey are larese and benutiful, ant are slecected by liuits of a mundish firure, 
wh is a grantity of glutinous lingor, and with e sceds, which are very small, and of a bromcolour.

We use the hardened juice of the fnit; it is aponated over the fire, to a thick consistence, and en is of a black colour, like the common hiqurice ice, called Spanish liquorice. The druggists ep it in this state; it is grood in rivlent purgings, it li bloody stools, and in orenfluning of the menses: is to be given in an electury, with conserve of red oses.

\section{Hyssop. Hyssopus.}

A FERY pretty rarden plant, kept for its virtues. It crows two feet high. The stalks are square, robust, upright, and of a pale green colour. The leaves stand two at each joint ; they are long, narrow, pointed at the ends, and of a bright green colour. The flowers are small, and they stand in long spikes, at the tops of the branches; they are of a beantiful bluc colour. The whole plant has a strong, but not ditagreeable smell.

Hyscop is to be gathered when just begimning to flower, and dried: the infusion made in the manner of tea, is not unpleasant, and is the best way of taking it: it is excellent against conghs, hoarsenesses, and obstructions in the breast. A strong infusion made into a syrup with honey, is excellent for the same purposes, mixed with an equal guanity of cil of almonds.

\section{IIEDGE HYSEop, Gratiola.}

A ImTre plant kept in our gardens. "It grows to a fon in beicht; the stalks are square,

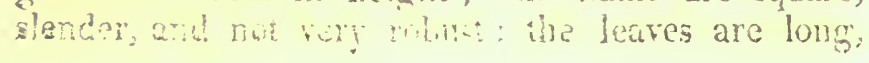


narrow, and sharp-pointed: they stand twe at every joint. 'The flowers are long, moderatriy large, and yellow; they grow from the bosoms of the leaves, and are hollow, and only a little divir sd at the ends: they are somewhat like fox-glo e flowers.

A decoction of the fresh plant is an exceller! purge, but it works roughly ; it is good against dropsies and rheumatisms; and the jaundice ha been often cured by it singly.

\section{$J$}

J.Ack ty the lledge. Allicria.

A sprise plant of a conspicuous figure, freruent in our hedges. The stalk is round, thick, firm, upright, and of a pale green, inree feet in height, and rery straight. The leares are large, broad. and short, of a figure approaching to roundish, but somewhat pointed at thie ends, and notched at the edgess; they are of a vale yellowish sicen colour, and sland on long fopt-statis. The flowers are little and white; they stand ten or a dore'n logether, at the tojs of the branches, and are tollowed by loug pods.

The frech leaves eaten as salad rork by urine powerfuly, and are recommended in dropsies. The juice of itsem boiled into a symp with honey, is gend to break trugh phlegm, and to cure coughts and lonarseneswess

Antwit, or Huacistur. Hyacinthus rulisiris.

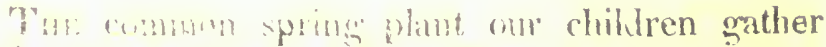
wh the in comblegs dial bidy fluners, and call blue 



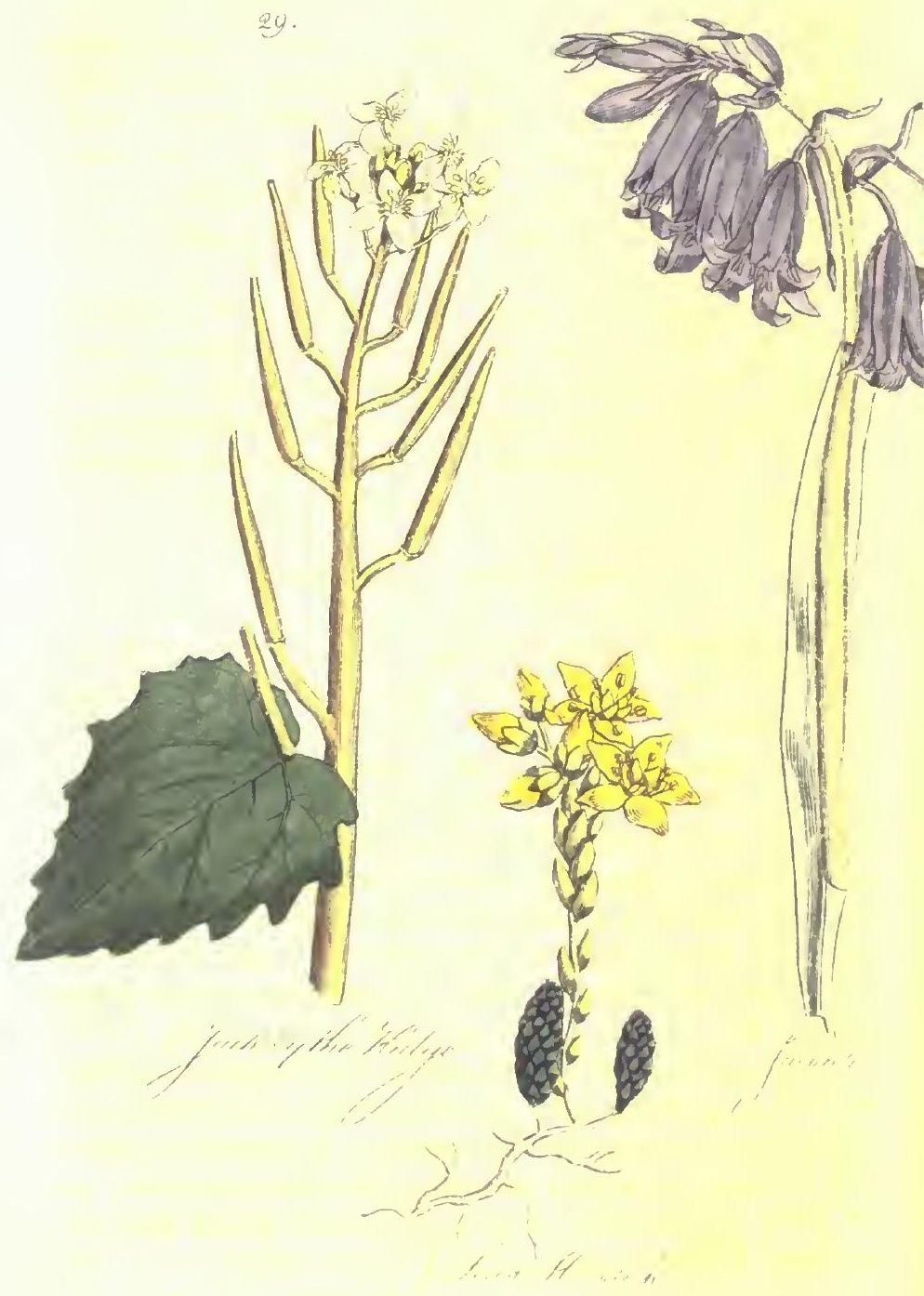




\section{FAMLY IDRBAL}

15:

Bills. The root is white and roundith; the icares are narrow and long, like grass, but of a deep green colonr, and smooth surface: the stalks are reund, upright, and smooth; they have no lentrin on them. The llowers are large, and of a beautitu? blue; they are hollow, oblong; and turn up at the rim. Who root is the piart used.

It abounds in a slimy juice, but it is to be died, and this must be done carefully; the decocition of it operates well by urine; and the powder is balsamic, and somewhat styptic. It is not enough known. There is hardly a more powerful remedy for the whites

\section{J ALAP PLiñ. Julapium.}

A climbing plant, native of America, and not yet got into our gardens. The root is long, irregularly shaped, and tinick. The stalks are round, tough, and firm, but slender and unable to support themselves. They grow to ten or twelve feet in length, and wind among the bushes. The leaves are oblong, broadest toward the base, of a dusky grreen, and not dented about the edges. The flowers are large, and of the shape of a bell, and their colour is purplish or white. The seed-vessel is large and oval.

The root is the part used; and druggists sell it. Given in powder with a little ginger, to prevent its griping, it is an excellent purge. A strong tincture of it nade in brandy answer's the same purpose; it is good in drupsies; and is in general a safe and $e x-$ collent purge.

\section{JESSAMNE Jusminum.}

A covimox shrub in our gardens, and a 
great omament to them. It does not well support itself, so that it is common'y nailed against walls. The trunk is covered with a greyish bark: the young shoots are green. The leaves stand two at each joint, and they are very beautiful; each is made up of about three pair of narrow, oblong, and pointed leaves, with a very long one at the end. 'They are of a deep green colour: the flowers are long, hollow, open at the end, and white; half a dozen or thereabout grow on each stalk, and they are of a very delicate and fragrant smell; these are succeeded by berries, which ripen in the warmer countries.

The flowers are the part used. Pour a pint of boiling vater upon six ounces of the fresh gatherea and clean picked flowers of jessamine; let it stand twelve hours, then pour it off; add honey enough to make the liquor into a thin syrup, and it is an excellent medicine in conghs.

\section{Rosf of Jumcho. Rosa Hicracontea.}

A LITTLE, woody plant, named a rose from nothing lout its size, and its inamner of folding itself up, by bending in the tops of the branches, so that it appears hollow and roundish. We are accustomed to see it dry, and in that condition it is always thus drawn together. It in of the bigness of a man's fist, and is composed of a quantity of woody hranches, interwoven with one another, and all bending inwarl. When it is put into warm water, it expands, and hecome flattish, but on drying, it acquires the old form again.

It is in reality a hiald of thlaspi, or treacle mustard, but of a peculiar woody tixture. The root is long, and pierces deep inte the ground; there grow from this eight or ten stalks, winch spread 
themselves upon the ground, in a circular manner, as we see the stalks of our bird's foot, and mally other little plants. These stalks are thick and woody, and about four inches in length: they lie upon the ground toward the base, but lay turned up a little at the tops, and each of them has a number of branches. The leaves are long, narrow, and of a pale green; they are very numerous, and they stand irregularly. 'The flowers are small, and white like those of our shepherd's purse. The seed-vessels are small, and contain several seeds like those of the common treacle mustard.

This is the appearance of the plant, as it grows very frequent in the warmer climates; and thus it has nothing singular in it, while in its perfection of growth, but after at time, the lares decay and fall off, and the stalks as they dry, in the heat, draw up more and more, till by degrees they get into this round figure, from which warm water will expand them, but they recover it again as they dry.

This is the real history of that little lind of treacle mustard, which is called the rose of Jericho, and concerning which so many idlc, as well as etrange things, have been said. Our good women have many ways of trying many experiments with it, by way of deciding future events, but nothing can be so foolish. 'The nature of the plant will make it expand, and open its branches, when put into warm water, and draw them together aginin, as it grows dry. This will always happen, and it will be more quick or more slow, according to the condition of the plant. Where it is to be had fresh, it does not want medicinal virtues. 'The young' shoots are good in infusion against sore throats, but we have the plant without its leaves, and, in reality, 
lithe more than a stick; so that it would be idle to cespect tny reood in th.

Jrent's Bark Tree. Albor Feruviana.

A sudur tree, native of South America, which has not yet got into our gardens. The trunk is as thick as a man's leg, and its bark is grey. 'The branches are numerous and irregular, and their bark is of a browner colour, but with the same tinge of grrey. 'The leaves are long and large, thiee inches in length, and hall as much in breadth, and of a pale green colour: they are pointed at the end, but not at all indented at the edges. The flowers are small, and their colour is a pale purple: they stand in great clusters together ; they are long, hollow, and open at the end, where they are a little dirided. The fruit is a diy capsule, of an oblong figure.

The bark is the part used. Besides its certain afficacy aganot andues and intermitting ferers, it is an excilent stonachic and astringent; nothing is beter ts serengthen the appetite, and in overflowinges of the menses, and all other bleedings, it is of the gresitest aficiry. It is best given in powder. The tincthes is to lie made in brandy, but it is not neaty so groot as the sulestance: when it is given for disolders of the strumeh, the best way is to pick ane preces of the batk and chew them.

Jew's Lirs, Auriculde Juda.

A KTAD of fungus, or, as the comminn phrase 14, of toal's stool, grorving upon old elder trees. It is ainut an iuch and a half tong, and reneraliy an rich broakl, and is somewhat of the shine of an 
car. It grows by a broad base to the bark of the tree, and from this it gradually spreads into a flat, hollow, substance, with several ridges in it, runuing irregularly, whence it is supposed to have the resemblance of the ear most perfectly. Its colour is a pale grey on the ontside, it is darker within, and there ruin sereral ribs along it. It is to be dried. Boiled in milk, it is recommended greatly in sore throats and quinsies. These remedies of the rulgar have come originally from physicians, and they commonly have something to support them. 'The Jew's ear is at this time out of repute, but that seems owing to sophistication. They conmonly sell, under the name of it, another fungus that grows to a great bigness, overspreading wond, in damp places. 'They get it off the water' pipes at the New River head at Islington, to supply Covent Garden market.

\section{St. Ignatics's Bean. Taba sancti Ignatii}

A plint common in the Wrest Indies, and very ill called a bean, being truly a gourd. The name bean was given to the seeds of this plant hefore it was kunwn how they were produced, and some have continued it to the plant. It grows to a sreat height, when there is a tree to support it, for it camnot support itselt. It has a stalk as thick as a man's arm, angulated, light, and not firm. The leaves are very large, oblong, and undivided, and they have the ribs very high upon them: they are broad at the base, and grow narrower to the point, and are of a deep green colonr. The flowers are vary large, and of a deep blood red; at a distance, they have the aspect of a red rose. The fruit is large and roundish; it has a woody shell, and over that a thin skin, bright and shining. 
Within there are twenty or thirty sceds; they are of the bigness of a small nutmeg, when we see then: they are roundish, and very rough upon the surface: each is of a woody substance, and, when tasted, is of the llavour of citron seeds, but extremcly bitter and nauseous. The colour is of all grey or lisownish.

These sceds aile what we use in medicine, and call the St. Irnatius's bean. It is a medicine, to be griven with great cantion, but it has many virtues: the most powerful remedies, when in ill hands, are naturally the most dangerous; the powder given in a small dose occasions vomiting and purging, and oftew, if the constitution be tender, convulsions; it is much better to give it in tincture, when no such eflects happen from it. 'T'is of an excellent cffect against nervous complaints: it will cure the fallingr-sickness, given in proper doses, and continued for a long time: the tincture is best for this purpose. Some have given the powder in very small quantities against worms, and that with success; its extreme bitter makes it very disagreeable, and the taste continues in the throat a long time, whence it occasions voniting. We neglect it very much at present, because of its roughness : but it would be better we found the way of giving it with safety. There are gentler medicine's, but none of then so eflicacious: it will do service in cases that the common nethods do not reach.

\section{Sr. Johx's Wort. Mypcricum.}

A nobess and pretty plant, frequent in our pastures, and other dry places. The height is a foot and a half. 'The stalk is romond, thick, firm, and rery upright, and divided towards the top into serval branches The leaves are short and 

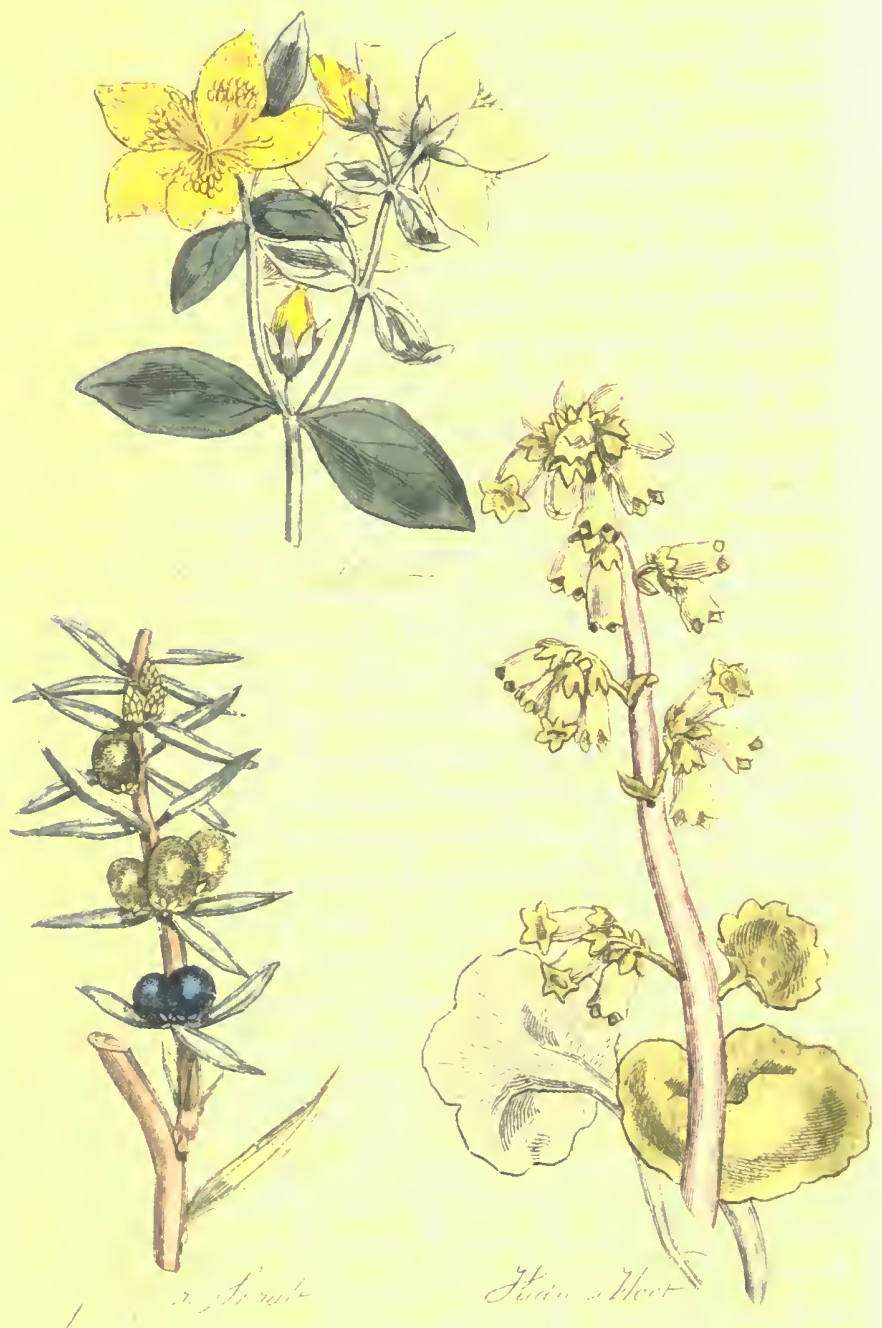

blunt at the points: they are of a bright green colour, and if held up against the light, they scem to be full of pin holes. The flowers grow in abundance on the tops of the branches: they are large, and of a bright and beautiful yellow, full of yellow threads, which, if rubbed upon the hand, stain it like blood. The fruit is a dry seedressel.

The part used is the flowery tops of the plant just as they begin to ripen. $\mathbf{A}$ decoction of these works powerfully by urine, and is excellent against the gravel, and in ulcerations of the ureters. The same tops fresh gathered and bruised are good for wounds and bruises; they stop bleeding, and serve as a balsarn for one, and take off blackness in the wher

\section{Jujue Tree. ¿izyphus.}

A TREe of the bignecs of our plum trees, and not unlike to them in shape. The bark is grey on the trunk, and brown on the branches. The leaves are moderately large, and each is composed of a number of smaller ones, set on each side of a middle rib, but not opposite to one another, and with an odd one at the end: these are oblong, obtuse, and serrated round the edges, and the odd leaf at the end is the largest and longest. The flowers are small and yellow. The fruit is oval, and of the bigness of a moderate plum ; it has a snft substance on the outside, and a stone within, which is large and long, and pointed at both ends.

The fruit is rsed. It was at one time brought over to us dried, but we see little of it now; it was esteemed balsamic, and was given to cure coughs, and to work by une. 


\section{White Stock July Flower. Leucoium album.}

A rovust garden plant, kept for its flowers, which art variegates and makes double. It grows two or three feet high. The stalk is thick, firm, round, and of a greyish colour. The leaves are long, narrow, hairy, and whitish. The stalls which bear the flowcrs are also of a whitish green, and tender. The flowers are as broad as a shilling, white, and sweet scented.

The flowers are the part used, and they are to be fresh gathered, and only just blown. A tea made of them is good to promote the menses, and it operates also by urine. An ointment is to be inale, by boiling them in hog's lard, which is excellent for sore nipples.

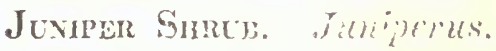

A comos shrub on our heathe. It grows to no great height in Eughtund, but in some other parts of Europe rises to a consideribly larege tree. 'The bark is of a reddish brown. The branches are tough. The leaves are longish, very narrow, and prickly at the ends. 'The flowers are of a yollowish colour, but small and inconsiderable. "The berrics are large, and when ripe blackish: they are of a strong but not disagrecable smell, and of a swcetish, but resinous taste. The leaves are of a faint bluish grreen colour.

The berries are the part most used. We have them from Gomany principally. They have two creellent qualities, they dispel wind, and work by urine, for which renson, they are excellent in those colies which arise from the eravel and stone. With these is also made the tric (ieneva, but the 
liquor our poor people drink under that name, is only malt spirits and oil of mrpentiue.

\section{Iry. IIrdera.}

A Very common shrub, crawling about old trees, or upon old walls; it sometimes runs upon the ground for rant of such support, but then it rarely bears any fruit. The trunk is thick, brown. and corered with a peculiar rongluess. The branches are munerows and britte the teares have a strange varioty of shapes, oblong, angular, conered, of dirided. The fowers siand in little round clusters, and they are smail and inconsiderable: they are succeded by large berries. The leaves upon the roung shoots that bear the flowers are always obloin; those on the trunk are angulated. They are all of a deep glossy green.

The leares and berries aie both used, but neither mu!n. A decoction of the leares destroyg rermin in children's head, and heals the soreness that attents them. The berries are purging; an infuiven of them will often work also by romit, but there is no harm in this : they are an excellent semedy in wheumatisms, and pains of all kinds, and, it is said, have cured dropsies; but this is perhaps going too far.

The iny in the varm conntries sweats ont a kind of resin, which has been used externaly at some times, on varions oreasions; but at this time, it is quite unknown in practios.

\section{K.}

Kinney Worr. Umbilicus veneris.

A rexy singular plant, which grows on old lis b 
vialls in some parts of England It is eight inches high, and is distinguished at sight by a cluster of round leaves which grow about the stalk The root is roundish, and its fibres grow from the bottom. The leaves stand on longish and thick foot-stalks, which are, except in the lowest of all, inserted not at the edges of the leaf, but in the middle: these are round, thick, fleshy, and indented about the edges. The stalk which bears the flowers is round, thick, and, towards the top, divided into two or three branches; on these grow the flowers, in a kind of spikes: threy are oblong, hollowish, and of a greenish wlrite colour.

The leaves are the part used. Externally, they are cooling, and good against pains. They are applied bruised to the piles, with great success. 'The juice of them, taken inwarily, operates by urine, and is excellent against stranguries, and good in the gravel, and inflammations of the liver and spleen.

\section{Ksap-Wren. Jacea.}

A VERY common wild piant, with dark-coloured lingish leaves, and purple thowers, like those of thistles. It is two fect high. 'The stalks are roundish, but ribbed: they are of a pale colour, very firm and strong; upright, and divided into minches. The leaves are long, and of the same brearlth: those which grow immediately from the root, are but little jagrged or cut at the elges: thuse which stand upon the stalk, are more so. 'The flowers are large; they stand in scaly heads, one of which is placed at tie toge of every branch: and at a distance, they hase something of the appearance of the flowers of thinfl's, but when exsuined nester, they are more like these of the blue 
bottle. The flowers themselves are of a bright resl, and large.

The young plant is used fresh : a decoction of it is gond against the bleeding of the piles, against loosenesses with bloody stools, and all other bleedings. A slight infusion is recommended against sore throats, to be usel by way of gargle. There are so many of these gelitie astringent plants, common in our fields, as yarrow and the like, that less respect is to be paid to one of less power in the same way. Knapweed may be rery properly adled to decoctions of the others, but it would not be so well to trust to its effects singly.

\section{KNot-grass. Polygonum.}

A uost common wild plant in our fields, pathways, and hedges: there are two or three kinds of it, but they pretty nuch resemble one another in form, and in virtues: the laresest is the best. The stalks of this are ten inches long, romol, jointed, and of a dusky green. The leaves are of an oval form, of a bluish green colonr, and not indented at the elges. 'The stalks lie upon the ground, and one of these only grows at each joint. The flowers are small and white, but with a tinge of reddish. The seed is single, black, and three-colnered.

It has been obeerver before, that Providence has in general made the most common plants the most useful. A decoction of knot-grass roots, stallis, and leaves, is an excellent astringent. It stops bloody stools, and is good against all blecdings, but, in particular, it is a remedy against the bleerling piles, and against the overflowing of the menses 


\section{l.. \\ Girm Lae Tree. Laca arbor.}

A Tnke, of the ligness of our apple tree, freginent in the East, but not yet known in Europe. The tumk is covered with a rough reddish bark. The branches are numerous and tough. 'They have a smontier rind, of a colour inclining to purple. The leares are broad, and of a whitish green on the upper side, and of a silvery white underneath. The flowess are small and yellow. The fruit is of the bigness of a phum, and has in it a large stone:" 'Whe onter or pulpy part is of an alstere, and not very auteable taste.

rhe gum lac is found upon the branches of this tree but it is preteruled by some, that a sont of flies; dipposit it three, and on other substances; and that it is a lind of wax; however, there are perasus if credit, who say they have obtained by cut-

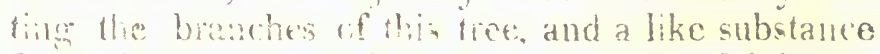
from the hranches of the seperal kinds of jujubes, to which this butongen in the hot cenntries. Probathly the flies get it wit this tree, and lodge it for heir purposes upon stichs, and other substances, as we sere it.

Our druggints have three bints of this resin, for it is ill called a mun. The one they call stick lac, beranse it is bromernt in round sticks; the other seed lac, in small lumps; ard the other shell lac, which is thing and transparent, and has been melted; of this resin the sealing wax is made with rery little alteration more than the colouring it, which is dome by means of a cinnabar or coarser materials. 'Titerm inwardly, gum lac is good agranst whetructiwns of the liver: it operates by urine and swett, 
and is mol in most chronic cases aringe liows such olsstructions.

\section{Lidnifs' Mavrue. Archimilia.}

A very pretiy little plant, natice of some pethe England, but not rery common wihl. 'The leats are numerous and rery beantiful they are brow,

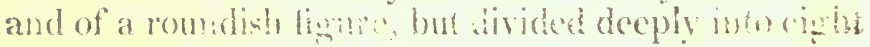

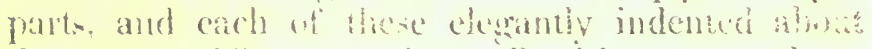
the edowes. 'Ther ane of a rellowish green colme. neary as broad in the paim of ones hand, and they stand upon fort-stalks of an inch or two in leregti: The staiks grow in the midist; they are romed, a little hairy, eight inches long, not very upright, and of a pale green colour. The flowers stand in rensiderable numbers at their tops ; they are small and of a greenish colour, but have a great many yellsw throatio in the middle. The root is Jung, thet and dark coloured.

'The root is the part most valuable; a decertion of it firesh taken up, is an excellent renerly lise the oventowings of the mentes, for blowly thises, and all oner bleedingse. Dried and powdered it answers the same purpese, and is also goont ayment

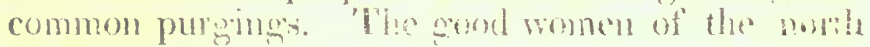

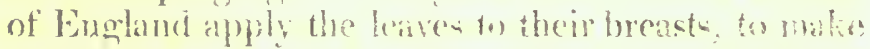

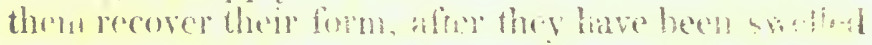

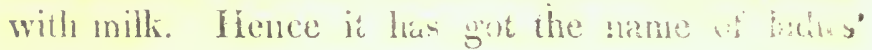
mantle.

\section{Larcí Thee. Larix.}

A monerstrey tall, and in summer a ren beantiful tree; but though one of the resinous kind, and in many respects approaching to the nation of the for and pine, it lores its leaves in winter: it is a mative 
of Italy, and is frequent in our gardens. The trunk is rugged, and the branches are covered with a rough bark, of a brownish colour, with a tinge of reddish. The leaves are an inch or more in length, extremely slender, and of a bluish green colors', and they grow in little cluster's, on different parts of the branches. 'The flowers are inconsiderable, the fruit is a cone, but very small. It is not bigger than a little walnut.

The young leaves are boiled, and the liquor is drank to promote urine, but this is an idle way of getting at the virtues of the tree. Venice turpentine is produced from it, and this liquid resin contains them all in perfection. They cut the trunk of the tree decp, in the heat of summer, and the resin flows out. This works powerfully by urine, and is a noble balsam ; it is good against the whites, and to stop the running that often remains from a clap after all the virulence is removed; but in this case it must be given cautionsly.

\section{Lanks' Sper. Delphinizm.}

A commos flower in our gardens; but not without its virtucs. It grows a yard high: the stalks are round, upright, firm, and of a pale green. The leaves are cut into a multitude of longe, narow, and very fine divisions, and are of at deep green colour, and the flowers which grow in long spikes at the tops of the branclies, are naturally blue, but often red on white. They are moderatcly large, and have a kind of spur behind.

'The leaves are used; they must be boiled fresh in water, and the deroction-is gond against the blerding piles. It atops the hemorrhage, and at the wine time one the boxk, whereas too many of the nsting-ant mencenes are heating. 


\section{LAYETDER. Lavendula.}

A commos plant in our gardens, natre of the warmer parts of Hurope; it is of a shrubby nature in the stem, but the rest is lierbaceous. It grows a yard high. The trunk, or main stem is thick, woody, firm, and covered with a whitish bark. The young shoots from this, are tender and greenish; and on these stand the leaves. They are long, narrow, and of a pale green colour, and stand two at each joint. 'The stalks which bear the flowers are square, green, and naked; the flowers stand in short spities, or ears; they are small, blue, and rerv fragrant; the cups of the flowers are whitish.

These flowers are the part used; they are good agrainst all disorders of the houd and nerves. They may be taken in the form of tea. The famous spirit of lavender called palsy drops, and the sweet latender watcr are made with them. The spirit of lavender called palsy drops is thus made best.

Put into a sinall still a pound of lavender flowers, and five ourices of the tender tops of rosemary, put to them fire quarts of common inclasses spirit, and a quart of water: distil off three quarts; put to this cinnamon anil nutmegs, of each three quarters of an onnce, red sanders wood half an ounce; let these stand together a week, and then strain off the spirit.

The lavender water is thus made. Put a pound of fresh larender flowers into a still with a gallon of molasses spirit, and draw of five pints. This is lavender water.

Layender Cotton. Abrotonum fomina.

A xamre shrubby plant, frequently wild in Italy, 


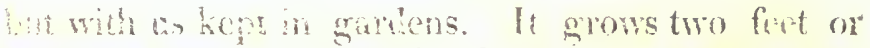

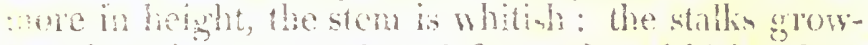

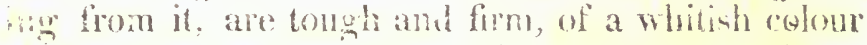
abo, and very muricious; the leaves are ohlong, s-arder, of a square shape, and indented; they are

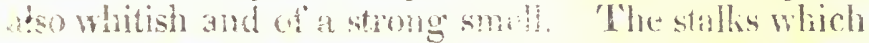

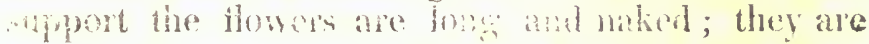

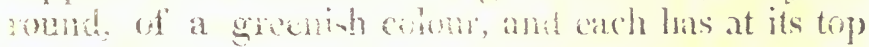
single thwrer. Which is rohoir and naked, and of

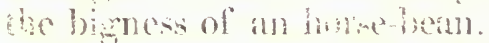

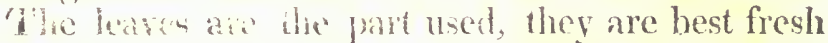
yotheras. The anc to be given infused in water Gainst woms, they are a disagreable medicine,

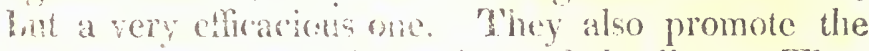
menses, and open obstrotions of the liver. They have been recommented greatly in the jaundice.

\section{Surzge Iat hes. Tarureola.}

A wro litule shrub of a singular aspect and of comsirforble virtues, it is three feet ligh, the sitem is half an inch thick, and divides into a great many brancles. The bakk is of a brombish colome, and they are not very strorg. "fire leaves stand at the fors of the branches, they are long, narrow, and of A bright and fine green; they are of a firm substance, and are not indented at the resce. The flowers are vey sanell and incomsidendhle, they are sreen with. singe yellom throvis, and have a sucet smell; the beries at:a small, roudish, and lidw.

the lears are : porertul remedy against the

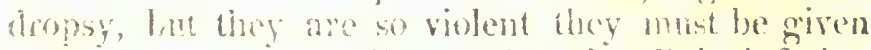

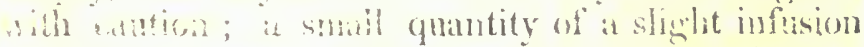

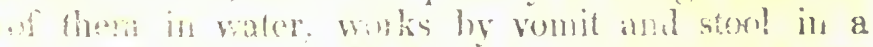

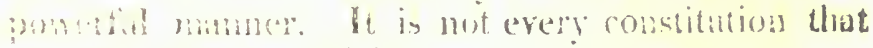

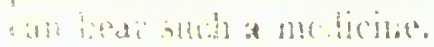


LEKK. Porrum.

A convox plart in our kitchen gardens. It grews thee feet high; the clalk is round. green, and

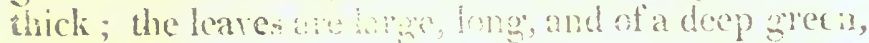
and the flowers on in! an round cluster at the top of the stalk; they ate of a mir)lish colour, with a tinge of green; the root is white, oblong, thick, and roundish, with fibres at the bottom.

An intusicn of the roots of leeks made in water, and boiled into a syrup with honey, is good against asthmas, coughs, and obstructions in the breast and lungs. It answers the same puryoses with syrup of garlic, hut it will agree with some who cannot bear that medicine.

\section{Lenos Tree. limonia malus.}

A sures, native of the warmer countries, and frecuent in onr green houses, very beautiful and fragrant. The trunk is morlerately thick, and corered with a bmwn bark; the branches are numerous, irregular, and beset with prickles. The leares ale large, and rery beautiful, of an owal fignre, and set upon a naked stalk; they are of a beautiful green, and remain on the tree all winter. The flowers are large and white; of a thick firm substance, and very fragrant smell. The fruit we are sufficiently acquainted with; its shipe is oblong, and its rind of a pale yellow colour: it has a part lite a nippie at each end. Its smell is very fragrant, and xts juice sour.

The reel and the juice of the fruit are used. The peel is stomachic and warm, it is a good ingreatient in bitier infusions. The juice made into

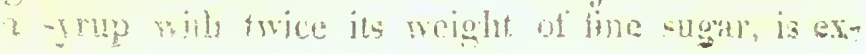
:. : 
collent for sarectening juleps and drinks in fevers, and, mixed with salt of wormwood, it stops romitings.

\section{LeidFont. Dentillaria sive plumbago.}

A cigtle plant, native of some parts of Europe, and kept in our gardens. It is two feet high ; the stalks are slender, tough, and weak, hardly able to support themselves upright. The leaves are of a pale bluish grcen colour, oblong, not very broad, and they surround the stalk at the base. The flowers are red, they are singly, very small, but they stand in thick, oblong clusters, on the tops of the stalks, and each is succeeded by a single seed, which is very rough, and stands naked.

The dried root is to be used; a piece of it put into the mouth, fill it with a great quantity of rheum, and is often an almost instantaneous cure for the head-ache. It also cures the tooth-ache in the same manner as pellitory of Spain does: it is more hot and acrid than even that fiery root.

\section{Indian Leaf Tree. Malabathrum.}

A TALL and beantiful tree of the East Indies, not unlike the cinnamon tree in its manner of growtls. The trunk is as thick as our elms, and it grows as tall, but the branches are disposed with less regularity; the wood is brittle, and the young shoots are of a pale brown. The leaves are recy large, nine inches long, and seven in breadth, and not at all indented. The flowers stand in clusters on the tops of the branches; they are small and greyinh, and the fruit is of the bigness of our ied currant. It is common in the mounlainous parts of the enat. 
These leaves are the part used, we have them dried at the drnggists, but they commonly keep them till they are decayed. It is an aromatic medicine, it strengtheris the storirach, and is grond in nervous disorders.

\section{LextiL. Lens.}

A KIND of little pulse, sown in fields in some parts of England. It grows a foot and a hall high, but dres not stand very upright. The stalk is angulated, of a pale green, and branched; the leaves are like those of the common pea : they consist each of several pairs of small ones, set on a rib, and there is a tendril in place of an odd leaf at the end. 'These small leaves are of a pale green colour, and oval shape. 'The flowers are white and small, but in shape like a pea blossom, they shand singly on long stalks. The fruit is a pod of a flattish shape, in which there generally are two sceds also a little flatted, and of the bigness of a sma!l pea.

The fruit is used; it is ground to powder to make into pultices for swellings, but it is not much regarded

\section{LetTice. Lacluca.}

A comos plant in our kitchen gardens, which we eat raw. When it rises to flower it is two feet and a half high. The stalk is round, thick, very upright, and of a pale green. The leaves are ohlong, broad, and somewhat waved at the edges: the flowers stand on the tops of the stalks, and are of a pale yellow; the seed is winged with a light white dowit.

The juice of lettice is a grood medicine to promcure sleep, or the thick stalk caten will serve the 
same parpose. It is a roor metliod to put those into who require a gente opiate, and will not take nedicines.

\section{Mind Letroc. Lachea syluestris major.}

A coinox plant in our lickges, and laving some resemblance to the guriten len in its flowers, thomph not in its manney at growth. It is six os se"en feet high. The siath is thick, romed, very upright, bianthad, and of a pals vellowish grecin cilour. The leivis at the botum are vory larre, a tout long and cise inches broad, and of a pale grcen colvur; those highel up the stalks are smaller, tiky are decply indented at the edges, and either these, the stalk, of any other part of the plant being wennded, there flows ont a milky juice, which has tice smell of opium, and its hot bitter taste: the branches are very numerous, and the flowers are alor very nuncrous, but they are small and of a pale ICllow.

rinis is a plaut rot introduced intw the common practice, but rery worting of that notice. I have known it usen in misate familics, with great suc. cess. A surue made from a strong infusion of it, is an excellent andyrae; it eases the most violerit prin in collios, and soluer disurders, and gently disposes the person to slecp. It has the good efiece of a rentle oniate, and nome of the bad ones of thet vislent medicint.

\section{Wurte Lizy. Lilikn: a' at?}

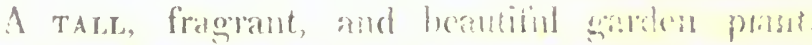

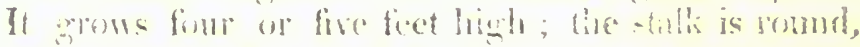

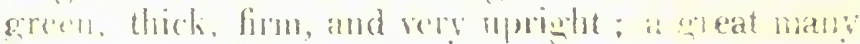

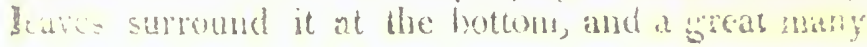


grow lypon it all the way: these are of the same shape, long, narow, and smooth, and of a pale green upon the stalk, and deeper green at the root. The flowers stand oti the divisions of the top of the sialk, they are large, white, and composed as it were of a quantity of thick scales

The roots contain the greatest virtue; liey are excellent mixed in pultices, to apply to swellings. The flowers possess tle same virtue also, being emollient and grood against pain. An oil is made of the flowers steeped in common oil of olives; but the fresh flowers are much better in the season; and the root may be had fresh at all tines, and it possesses the same viltues.

\section{Lily or ture Yalley. Tilium conzalliam.}

A veny pretty plint, but so different from the former, that one would wonder how it came to be called by any pat of the same name. It is six or eight iuches high. The leaves are large, long, and broad, of a deep green colour, and full of very thick rilss or veins. The stalks are weak, slenter, angular, and grean; they bend towards the top, and ou each there stands, or rather hangs, a rov of white flowere; they are roundish, loollow, and of a delicate and pleasing smell; these are succeeded by berries, which are red when they are ripe.

The flowers are used. A tea made of them, and rirank for a constancy, is excellent against all nersous complants; it will cone norrous head-aches, and tremblings of the limbs: a great deal 100 much has bren satd of this plant, for porplo call it a remerdy for apoplexiss and the deed palsies, but thomen an! this is not true, enough is, to give the plant a reputition, aud bring it again into use. 


\section{Water Lily, Mymphau aúua.}

A LABGi and elegant plant, the broad leaves of which we see floating upon the surface of the water in our broolis not unfrequently; and in the autumn large white flowers anong them. The root of the plant is very long, and extremely thick, and lies busci on the mud. The leaves rise singly orte on each stalk; the stalks aie round, thick, and of a spungy substance, having . White pith in thern; and tie leares ans are thick and somewhat spungy; they are of a roundish figure, and they lie flat upon the surface of the water. The flowers stand upon single foot-stalks, arising like those of the leaves separately from the root, and being like them, light, round, glossy, and full of a white pith; the flowers are large and white, and have some yellow threads in the middle; the sced-ressel is large and roundish, and the seeds are numerous.

The root is the part used, and it is best fresh, and given in a strong decoction. It is a powerful remedy in the whites, and in those weakneswess left after vencreal complaints: it is alan good andust violent pursings, especiatly where there are bloody stowls. There are other liuds of water lily in our rlithes, particulaty a lase yollww flowered one, whose ronts possess the same virtucs with the others, but in a less degrec.

\section{Lime Thee. Tilia.}

A TREE comnion eurugh in parks and gardens, ate! when in flower very heantilul and fragrant; the trunk is thick, and the branches grow with a tollerable regularity. The leaves ares short, broad, of a figure approaching to round, but terminating in a print, ind serratod about the edges. Thr 


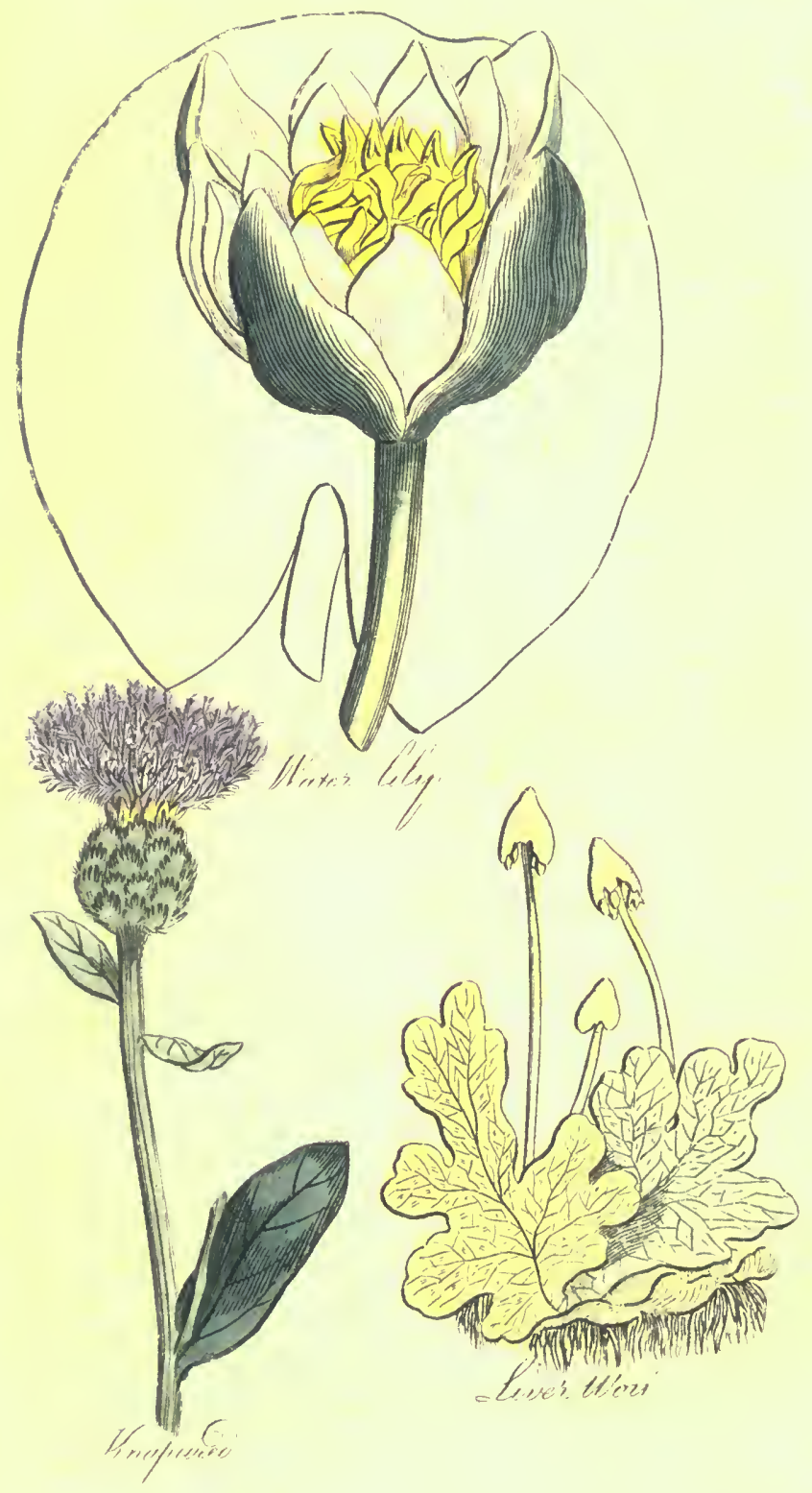



flowers grow on long yellowish stalks, with a yellow, oblong, and narrow leaf upon them. They are themselves also of a yellowish white colonr, and extremely delicate and sweet smell. The fruit is roundish and sma!t. The flowers are the only part used ; they ase good against giddiness of the head, tremblings of the limbs, and all other lighter nervous disorders. 'They are best taken as tea.

\section{Lreon Amber Tree. Liquil Ambar.}

A very beautiful tree of the Amcrican islands, which we have brought of bate into our gardens; it yrows fifty feet high, and the branches are numerms and dispesed with a tolerable regularity. The leaves are large and very beautiful ; they are b) wad, and are divied much in the manner of the leares of onl manle tree, unt much more beautifulIy; they are of a glossy green, and the tips of the bough have a fragrant smell. The flowers are grecenish and small ; the fruit is of the bigness of a sinall walnut, ronndish and rough upon the surface, with several seeds within.

ive une a resin which runs from the trunk of this tree in weat licats. It is of a reddish colour, soft, and exirmely fragrant, nearly a perfume. It is an excellent baisam, nothing exceeds it as a remedy for the whites; and for the weaknesses left after senereal disonders. It i.s also good in disorders of the lungs; and it works by urine, and dislodges gravel. There was a custom at one time of mixing it among perfumes, but of late it lias been neglected, and is grevon scarce. 


\section{Liqum STonax True. Styrax liquida arbor.}

A Liligi tree, so much we hear of it, is native of the East Indies, but rery ill described to us. We are told the leaves are large, and the flowers fragrant, but of what form they are nobody has told us, "1) what is the fruit. All that we use is a liquid resin of a very peculiar kind, which we are told is obtained by boiling the bark; and the shonts of this tree in water; the resin swims at the top, and they scum it off and strain it, but it will not all pass through. It is from hence that we see two kinds; the one finer, thinner, and purer, the other thicker and coarser ; this last kind is more common than the better sort, and it is generally used.

It is a balsam of the nature of the turpentines; and is gond against the whites, and the weaknesses that follow venereal disorders. Some have used it also in diseases of the lung's, but it has never been in sereat repute on those orcasions. It is sometimes plit into ointments intended for old ulcers ; and it is raid to lee used this way with great success.

\section{haqune. Glycyrrhiza.}

A RocGr looking plant, cultivated in many places for the sake of the root. It is a yard high or more. The stalk is round, striated, and branched: the leaves are long and large, each is composed of a great many pairs of smaller, standing on a middle rib, with an odd one at the end; these are of an owal higure, of a dirky green colour, and they are clammy to the tunch. The flowers are very small and blue, they stand in long spikes, riving fom the busims of the leaves. The seeds are cuntuined in puls. The ront is the jort used; and its virtues are vory great. It is best firesh taken 
out of the ground, the sweetness of its taste renders it agreeable, and it is excellent against coughs, hoarsenesses, and shortness of breath. It also works gently by urine, and is of service in ulcerations of the kidneys and urinary passages, acting there as in lungs at once, as a detergent and balsamic.

The best way of taking it is by sucking or chewing the fresh root: but it may be taken in infission, or in the manner of tea. 'The black substance called liquorice juice, and Spanish liquorice, is made by evaporating a strong decoction of this root. But the fresh root itself is better.

\section{Noble Liverhort, or Hepatica. Hepatica, nobilis.}

A commox garden flower, wiich makes a very pretty figure in spring, and is little regarded, except as an mament in our borders ; though it is not without considerable virtues. The leaves are supported cach on a single foot-stalk, white, slender, and recidish, they are near an inch broad, and of the same length, and divided each into three parts. The flowers rise early in the spring, before these appear ; they also stand singly on long foot-stalks, and are noderately large and bine, with a greenish liead in the midlle, the root is fibrous.

An infusion of the leaves of this plant is good against obstructions of the liver and spleen ; it works erently by urine, and is a grod medicine in the jaun. dice, taking it in time.

Greex hiverworer. Lichen vulgaris.

A commox low plant, composed wholly of feaves, which mead themselves on the ground, and D d 
are of a beatiful green colour; authors refer it to the kinds of moss. It grows on old walls, in wells, and other damp places. 'The leaves are oblong, blunt, and thin, they spreart one over another and take root wherever they touch the ground. They ofter cover the space of a foot or more in one cluster. 'This is all that is ustially sten of the plant, but in spring when the place and the weather farour, there rise up among these leaves certain long and slender stalks, on the tops of which stand imperfect flowers, as they are called, small roundish, and resembling the heads of ittle mushrooms.

The whole plant is used, and it is best green and fresh gathered. It is to be given in a strong decoctron. It opens obstructions of the liver, and works by urine. It is grood against the jaundice, and $\therefore$ in excellent medicine in the first stages of cona.? "un in be. It is also used externally for foulness of the skin.

Grex Ground Invrwont. Lichin cinerens ter restris.

A plant, very common by our dry wood-sides, and in pastures, in some degree resembling the last tescribed, but difiering in colour and in its fructification. This consists also entirely of leaves; they are of a bluish grey colour, on the outside, and of a whitish grey underneath. They are two inches long, and an inch and a halt broad; and grow in clusters together ; often they are less diatinct, and therefore appear larger. These do not send up ary stalks to bear a kind of tiowers in heads. The tips of the leaves turn up, and are reddish, and in these parts are contained the seeds T'be whole plant secms dry and sapless. 
The whole plant is used, and has been of late very famous. Its efficacy is against the bite of a mad $\mathrm{dog}$; it is mixed with pepper, and the person is at the same time to bathe in the sea. There have been instinces of its suceess, when given to dogs, but perhaps no cure was ever performed upon a human creature, when this terrible discase had arisen to any height. Bleeding and opium are the present practice.

\section{Logwood Tree. Arbor campechiana.}

A tree, native of the Southern parts of America, the wood of which has been used in dying, honger than in medicine, but is very serviceable in the latter capacity. The trec is large, and makes a beautiful appearance. The branches are numerous, and they spread with a sort of regularity. The leares are composed each of sereral pairs of smaller, set on the two sides of a common rib; with an ndd one at the end. 'The flowers are of the shape of pea blossoms, but they are yellow; the pods which succeed them are very large, and the bouglis of the tree are very thick set, with sharp thorns of a reddish colour.

We use only the heart of the wond which is of a deep red colour. It is of an anstere taste, but with something of sweetness in it at last, in this it resembles greatly what is called Japan earth, and it resembles that drue alen in its virtues. It is a a very powerfinl medicine to stop fluses of the helly, and overlowing of the menses. The best way of giving it is in form of an extract, which is to bie mate by boiling down a strong decoction of wood th thite consistence of honey. In this form it will leep a lone time, and is always ready for use. 


\section{Purfle Loosestrife. Lysimachia purpurea.}

A wiud plant, that decorates the sides of ditches and rivers, and would be an ormament to our gardens. It grows to three feet high, and is very regular; the stalk is square, hairy, and generally of a reddish colour. 'The leares stand two at each joint, and they are longr and narrow; of a dusky green, and a little rough. 'The flowers stand in ery long spikes at the inps of the stalks, and are virge, and of a strong purple colour. The spikes are orten a foot or nore in length. 'The seed is very little and brown.

'The leaves are used. They are a fine balsam for fresh wounds, and an ointment is to be made of them boiled in lard, which is also cooling and detersive. but it is not of a fine green colour.

\section{Yellow Looststure. Iysimachia lutca.}

A wild plant not uncommon in our watery places, but for its beanty, very worthy a place in our gardens. If it were bronght from Ancrica, it would be called one of the most elegrant plants in the world. It is four feet high, the stalks are rigid, firm, upright, and very regular in their growth: a little hairy; and towards the tops divided into several branches. 'The leaves are as long as onez finger. and an inch and half broad in the middle, and small at each end ; they are a little hairy, and of a yellowish green. The flowers are large and of a beatutif yellow, they grow screral together on the tops of the branches. Tile seed-ressels are full of small sieds.

The root dried and eriven in powder, is goond andut the whiter and areanst hoody fluxes, wer-

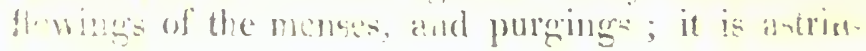


gent and balsamic. The young leaves bound about a fresh wound, stop the bleeding, and perform a curte in a short time.

\section{Lovige. Levisticum}

A tax plant of the umbelliferous kind, kept in our gardens for its uoe in medicine. 'The stalk is round, thick, hollow, and dreply striated or channelled. The leaves aie very large, and they are each composed of a number of smaller ; these are set on a divided stalk, and are short, broad, and indented at the edges. The flowers are simall and yellow, the seed is striated, the root is brown, thick, and divided, and the fibres from it are numerous; it is of a liot aromatic taste.

The ronts fresh dug woik by urine, and are good against the jaundice. rlie secds have the same effect also and they dispel wind. The dried root is a sudorific, and is good in fevers.

\section{Tree Lctigort, Muscus pulmonarius.}

A FROAD and large kind of moss, in form somewhat resembling the ercen and grey liverwort, but bigger than either. It prows on the barks of old oaks, and beech trees, but is not common. It is principally found in large woods. Each leaf, or separate plant, is eight or ten inches long, and noarly as nuch in brealth, of a yellowish colour, and of a substance resenbling leather : it is divided deeply at the edges, and is rough, and full of high veins on the surface. At the season of flowering there also appear certain small red heads, which contain the seeds for a new succession of plants.

This plant is not so much known as it deserves to be. It is an excellent astringent, a strong decoction 
of it atops the overfiowings of the menses, and all other bleedings; it is remarkable agrainst the spitting of blon. and hence it is got into general use in consump. tions, but that not so properly. It may be given in powder, but the other way is better.

\section{Lupine. Lupinus sativus albus}

There are many lupines kept in gardens, but the best kind for use is the white-flowered; it grows to a yard high, the stalk is round, thick, firm, and of a pale green. The leaves stand on long footstalks, and are each composed of seven, eight, or nine long narrow ones, disposed in the inanner of fingers; these are also of a whitish green colnur. The flowers are larere and white, of the shape of a pea-blossom. The pods are hairy. A decoction of the seeds of lupines, drank in the manner of barley water, not only works by urine, but is good to bring down the menses, and open all obstructions. It is excellent in the beginning of cousmmptions, jaundices, and dropsies; but when thore diseases are ad. ranced to a height, more powerful remedies are to be employed. A decoction made very strong is good to wash the heads of children that have breakings out upon them; they cleanse and dispose them to heal.

Golden Lungwort. Pulmomaria aurea.

A TALr, erect, and beantiful plant of the hawkweed kind, with yellow flowers, and very hairy leaves ; it is frequent in the mountainous parts of Europe, and we have it wild in some places in England, npon walls and in very dry places, but with us it is not common.

It is two feet high; the leaves are large and ob. lons; they grow half a dozen or thercabout im- 
mediately from the ront, and have thick foot-stalks; they are oblong, broad, of a deep and often a purplish colour, and are extremely hairy, the hairs being long, white, and set so thick, that they give it an aspect of woolliness. The stalk is round, slender, tolerably firm, upright, of a purplish colour, and also hairy: the leaves on it are smaller than those from the root, but like them in shape, and they are in the sanie mamner very hairy. The flowers are not very large, but they are of a beautiful yellow, and they have the more singular aspect, as the plant has so much whiteness. The seeds are winged with a white down.

The young leaves rising from the ront, are the part used. They are of the same nature with those of coltsfoot, but they possess therr virtues in a much greater degree. In many other parts oi Europe, where the plant is more common, it is a constant medicine in diseases of the lungs, in coughs, asthmas, and the first stages of consunptions; it is best given in form of a strong infusion; and I have known it tried here with more success than could be expected from so simple a remedy, in cases of such consequence. It is scarce wild, but it is easily propagated in gardens. Let but one plant of it ripen its seeds and leave them to the chance of the winds, and the garden, the walls, and the neighbouring places will never be without a sufficient supply of $1 t_{2}$ for all purposes.

\section{M}

Mace. Macis.

TuF. spice we call mace, is the covering of the stone or kernel of a fruit, within which is the nutmeg. The tree will therefore more naturally be 
described under the article nutmeg; but it may be proper to say here, that the fruit of it is large, and roundish, and has somewhat the appearance of a peach, being of nearly its bigness; the onter part is more like the green rind of a walnut, than the flesh of a peach : within is the nutmeg contained in a hard shell, and on the outsifle of that shell, is laid the mace, in a kind of thin, divided, yellowish leaves. It is of a swit and unctuous nature, and very fragrant ; more so timan the nutmeg itgelf.

Mace is a noble spice, it warms and strengthens the stomach, and is good against pains in the head, arioing from faults there: it is also good against colics; and even ontwardly applied will take ellect. The mace bruised may be used for this purpose, or its oil by explession.

\section{M.IODER. Rubia tinctorum.}

1 rovgri and unlandsome plant, cultivated for the sake of its root, which is used by the dyers, and also in medicine. It is a loot and a half ligh. The stalk is square and veak. The leaves stand six or eight at every joint, disposed star-fashoned, and they are of a cusky nreen colour, and very romgh, they fed almost prickly. The flowers are little and yellow; and they grow from the bosnms of the leaves. The row is long, slender, and of a red rolour.

A decontion of the fresl roots of madder, works erently by urine, but it very powerfully opens obstructions of the liver and splecin. It is very good agrainst lie gravel and jamndice.

Thes Nannsinar. Aliantum zerum.

A verx beautiful plant of the fern kind, but 
exceeding the ordinary ferns very much in elelicacy. The stalks are small, black, and glossy ; each divides toward the top, into a great many branches, and on these stand the smaller leaves, which make lip the complete one, or the whole plant; (for in this, as in the fern, every leaf is an entire plant : these are short, blunt, rounded, and notched very beantifully and regularly at the edges, and they are of a pale green colour. The seeds are fixed to the edges uf the linder side of the leaven, in form of a hrown powder. The whole plant is used: our druggists have it from France.

$\Lambda$ decoction of the fresh plant, is gently diuretic, and opens obstructions, esperially of the lungs; but as we cannot easily have it fresh, and it loses a great deal of the virtue in drying, the best expedient is to use the fine syrup of capellaire, which is wade of an infusion of the plant, when in its perfection, with fine Narbome honey. We suppose this a trifle, but burley water sweetened with it, is one of the best known remedies for a violent cough.

\section{English Miadomian. Trichomancs.}

A VERY pretty litíc plant, of kin to the true waidenlair, and frequently used in its place; but this is very wrong, for its virtues are no greater, and it is unpleasant. It grows eight inches, and cach leaf, as in the rest of the forn kind, is an entire plant. This leaf consists of a vast number of small ones, set on each side a middle rib, and they are very short and obtuse, of a roundish, but somewhat oblong figure. Tlie stalk is sienter, black, and shining, and the little ieaves are of a bright and strong arecn colour. The seets an lodged as 
In the rest, in form of a brown dust, on the urider part of these leares.

The plant grows frequently on the sides of old wells and on damp walls, and it is used entire. $\mathbf{A}$ syrup. made fiom an infusion of it, is the best shift we could make for the true French capellaire; but that is so casy to be had, that no such shift is neces. sary; an infusion of the dry plant may also be used.

\section{Wime Manenuan. Adiantum allum.}

A vеку little plant of the fern kind, and of the nature of the two other's just described. Some will be surprised at the calling it a very little plant, haring seen lecives a foot iong, sold in Covent Gardes, under that name; but this is an imposition: they sell a kind of water fern under this name. 'The real white maidenhair, is not above two inches high. 'The stalks are very slender, and of a whitish green, not black as in the others. The leaves are divid: into a gieat many smull parts, and at first sight th. have nome resemblance of the leaves of rue. The s.rls are contaized in brown lumps, behind the learf : orering the greatest part of the surface.

This is not uncommon in old walls : it has the sane virtnes with the ntiv : against coughs, and a decociom of it is also strongly limetic and good against the grawl, and all stoppages of urine.

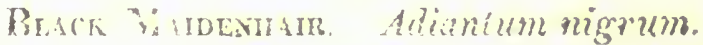

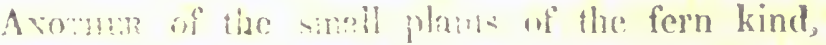
and more af the shabe null form at the common

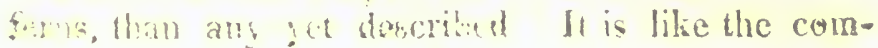


mon furn of the divided kind, only very small. It yrows to right or ten inches high. The stalks are thick, black, and glossy. The leaves are very beautifully divided into a great many parts: these are short, of a dark shining green, and deeply notcherl at the edges, and they terminate in a sharp point, not blunt as some of those already mentioned. The sceds lie on the edges of the under part of the leaves, in form of a brown dust. It is not uncommon by brood sires, and in shady lanes.

A flecoction of it works powerfully by urine, and if has the same virtue with the rest in the cure of sounhs.

Ot these four, for they possess the same virtues, the proference is given to the first described, or true kind; next to the English maidenhair ; and in refect of both these, to the black kind. The white maidenhair is preferred to any against the gravel, and in suppresion of urine; but for the conmon use in rough and hoarsuesses, it is the least estermed of all.

There is ancther plant, called by the name of maidenhair, which is yet to be described, it makes one of what are commonly called the five capellary herbs, lint it is so distinct from the others, that it is best kirpt sepaiate. They are all kinds of fern : this is a sort of moss.

\section{Goidex Mardenerar. Adiantum aureum.}

A cutree upright plant, but considered as a moss, one of the largest of the kind. It grows four or five inches high, when in perfection. The towel part of the stalk is covered for an inch or nore, with thick, short, narrow leaves, sharp at the point, and of a dusky green colour: these stand in fnch clusters, that they quite hide the stalk; from 
the top of these rise the pedicles, supporting the heads; they are uaked three or four inches hish, slemier, and of a brownish, reddish, or blachish colour: the head of the summit of these is single, square, and is covered with a woully cap, of the figuse of an exthingisher, which fall: off when the liead is intirely ripe: this hearl is full of a fire desi.

The plant is fiequent in bogrgy places, and is to be used intire. Some talk of its being good in conghs, but the more frequent use of it is externally, they boil it in water, and wash the head with it, to make the liair grow thick.

\section{Common Mallow. Matua.}

A wisp plant, every where about our hedges, fields, and gardens. It is one anong many instances, that God has made the most useful plants, the most common. The mallow rrows thee or four feet high. The stalk is romel, thick and strong. The leaves are roundish, but indented and divided at the cdges. The flowers are numerous, large, and red. 'The root is long and white, of a firm, tough substance, and not disagrceable titste.

The whole plant is used, but the root has most virtue. 'The leaves dried, or fresh, are put in deroctions for glisters; and the root may be dried, for it retains a eresen deal of virtue, but it is best fresh, and shotild be choseis when thre are only leares growngry from it, not a stalk. It is to be boiled i: watcr, and the decoctiom may be mate: rery strong. for there is notheng clisengecable in the tante: it is to be domb in ciantitics, and is ex rellest to promote mine, and to take ofl the ptranguly. It is grood also in the same mannel. 



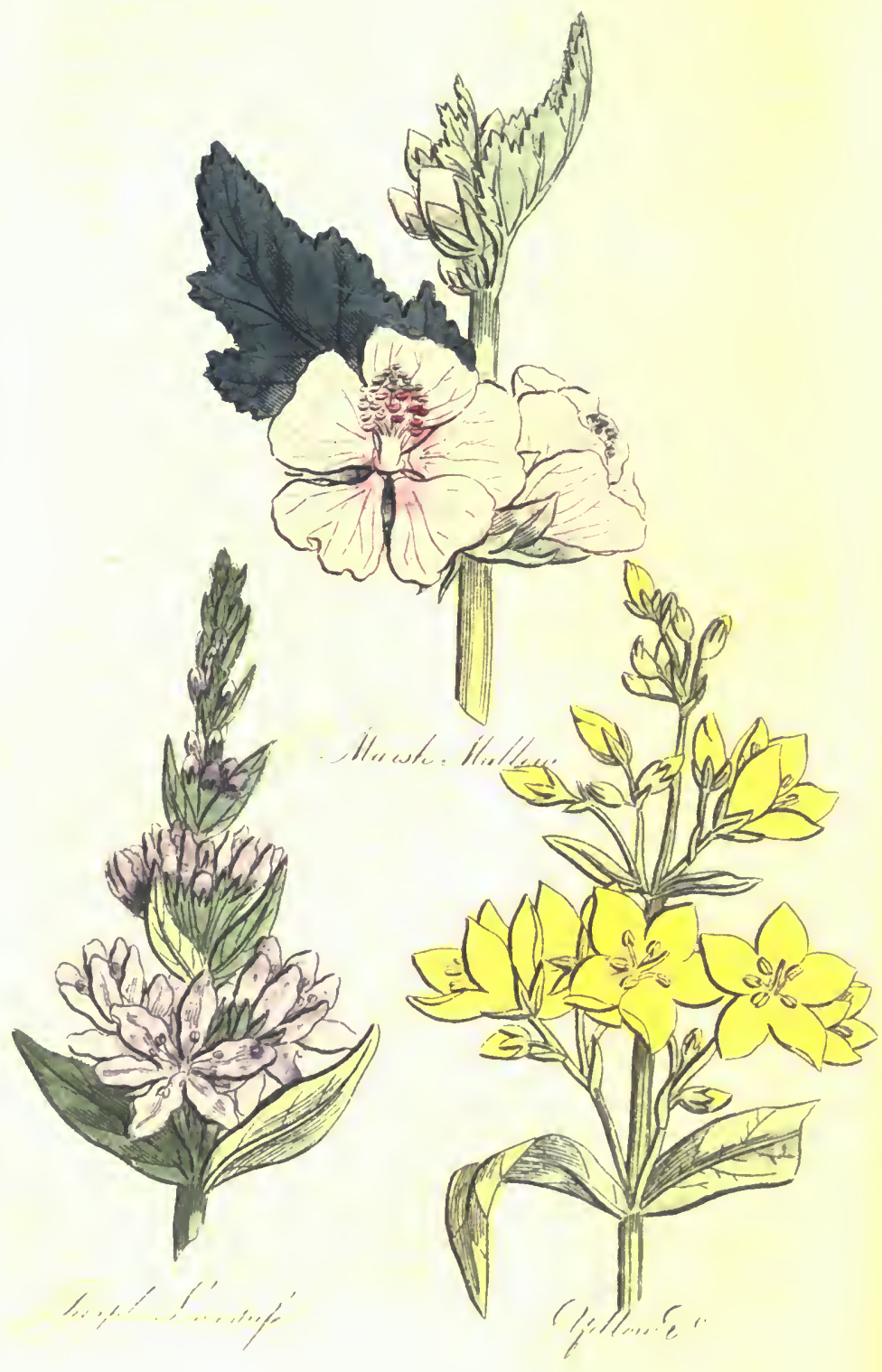


against sharp humours in the bowels, and for the gravel.

There is a little kind of mallow, that bas whitish Alower's, and lies flat upon the ground. 'This is of a more pleasant taste than the common mallow, and has the same virtues. A tea made of the roots and tops of this, is rery agrecable to the taste, and is excellent for promoting the discharges by urine.

\section{Marsi Mallow. Althea.}

A TaLe wild plant, of the mallow kind, frequent with its about salt marshes, and the sides of rivers where the tides come. It grows to four feet in height. The staik is round, upright, thick, and somewhat hairy. The leaves are large, broad at the base, small at the point, of a figure approaching to triangular, and indented round the edges: they are of a whitish green colour, and soft to the touch like velvet. 'The llowers are large and white, with sometimes a fint blush of reddish. They are of the same size and shape with those of the common mallow.

The root is most used. It is white, long, and thick, of an insipid taste, and full of a mucstiginous juice. Boiled in water, and the decuction made strong, it is excellent to prumote urine, and bring away gravel, and small stones; it also cures stranguries, and is good in coughs. Its virtues are the same with those of the common mallow, but in a greater degree.

\section{Vervain Malieiw. Alceco.}

A VERY beautiful plant, both in its flower and unanner of growth; common in pastures, and worthy to be cherished in our gardens. In grows tiro feet 
high. The stalks ale round, moderately thick, a little hairy, and very upright. The lower leaves are rounded, and divided slightly at the edges : those on the stalk are cut into very small Jarts, and in a very beautiful manner. The flowers are of a very bright red, and are three times as large as those of the common maliow, and very heautiful. The seeds are disposed in the same colnen as in the common mallow. The root is winte.

The ruot is the part used. It has the same virtue. with that of the common malow, but in a less degree The leaves also have the same virtue, and are very pleasant taken in tea.

\section{Musx Mallow. Bamia Moschata.}

A PLANT, not unlike the vervain mallow in its aspect, but a native only of the hotter countries. It is two feet high. The stalk is single, round, thick, hairy, and upright. "ihe lower leaves are roundish, only indented : little at the edges; the upper ones are divided in. ine parts, pretty deeply. The flowers are of the shape of those of the common mallow, and are large, bu: their colom is yellow. 'The seed is contained in ng husk, or case, and is of a kidney-like shape, and sweet perfumed smell.

The seed is the only part use: and that very rarely. It is sair to he good agrainst ti. head-ach, but we seldom meet with it fiesh enough to have any virtue.

\section{M.smrake. Mandragora.}

A plant, about which there have been a multitude of errors, but in which, there is, in reality, notling so singulur as pretcisded. There are pro- 

perly speaking, two kinds of mandrake; the one with round fruit, and broad leaves, called the male; the other with oblong fruit, and narrower leaves, called the female : their virtues are the same, but the male is generally preferred. They are natives of Italy, where they grow in woods, and on the banks of rivers: we keep them in gardens; but they grow there as freely as if native.

The mandrake has no stalk. The leaves rise immediately from the root, and they are very large : they are a font long, four inches broad in the midale, and of a dusky green colour, and bad smell. The flowers stand upon foot stalks, of four inches high, slender, and hairy, and rising immediately from the root: these flowers are large, of a dingy purplish colour, and of a very bad smell. The fruit which follows, is of the bigness and shape of a small apple, or like a small pear, according to the male or female kind: this is yellow when ripe, and is also of a very bad smell. The root is long and thick; it is largest at the head, and smaller all the way down; sometines it is divided into two parts, from the middle downwards, if a stone have lain in the way, or any other accident occasioned it; but usually it is single. This is the root which is pictured to be like the human form: it is when single, no more like a man than a carrot or a parsnip is, and when by some accident it is divided, 'tis no more like, than any long root, which happens to have met the same accident. Those roots which are shewn about for money and have the head, limbs, and figure, of a human form, are made so by art, and they seldom use the real mandrake rout for that purpose: they are often made of white briony rout, sometimus of angelica. The people cut then into this shape, and put them into the ground again, 
where they will be sometimes in part covered with a new bark, and so look natural. All the story that they shriek, when they are pulled up, and they use a $\log$ to draw them out of the ground, because it is fatal to any person to do it, and the like, are idlc, false, and groundless ; calculated only to surprise ignorant people, and get money by the shew : there is nothing singular in the rnot of the mandrake; and as to the terms male and female, the two kinds would be better distinguisherl, by calling the one, the broader leaved mandrake, with round fruit, and the other, the narrower leaved mandrake, with oval fruit. There are plants which are separately male and female, as hemp, spinach, the date tree, and the like: but there is nothing of this dis. tinction in the mandrakes.

The fresh root of mandrake, is a violent medicine; it operates both by vomit and stool, and few constitutions are able to bear it. The bark of the root dried works by vomit alone, but rery roughly. The fruit may be eaien, but it has a sleepy quality. thongh not strong. The leaves are used in fomentations and pultices, to allay pains in swellings, and they do very well.

Most of the illie stories concerning the mandrake, have taken their origin from its being named in scripture. And from the account there given of it, snme have inagined, it wonld make women risuitful; hut this plant does not seem to be the thing intrmicd by the word, nor las it any such virtues. What the vegratable is, which is mamed in the scripture, and translated mandrake, we do not humw.

\section{Sweet Mlizonim. Majorana.}

A comang garden plant, of no great beauty. 
but kept for the sak: of its virtues and use. It is a foot high. The stalks are firm, upright, and a little hairy. The lesves are broad, short, and somewhat haliy, of a pale green colour, and unt indented at the edges, and of a fine smell. At the tops of the branches, stand a kind of soft scaly heads, three quarters of an iuch long, and from these grow the flowers, which are small and white. 'The seed are very small; and the root is finrons. The whole plant has a fine smell.

The whole plant is to be userl firsh; and it is best taken by way of infusion. It is good against the head ach, and dizziness, and all the inferior order of nervous complaints ; but they talk idly who call it a remedy for apoplexies. It gently promotes the menses, and opens all obstructions. 'The dried herb may be given for the same purpose in powder, but it does not succeed so well.

\section{Wild Marjoray. Origanum.}

A wird plant, frequent about way-sides, in mary places, but superior to the other in beauty and in virtues. It very well deserves a place, on both accounts, in our gardens. It grows a foot and a half high. The stalk is firm, vely upright, a little hairy, and of a purplish brown colour, extremely regular in its growth. 'The leaves are iroad and short, of the bigness of one's thumb-rail, and of a dark green colour; two stand at every joint, and they have long foot stalks. The flowers giow on the tops of the branches: there stand on theie long" scaly heads, of a beautiful form, and purple colour ; from different parts of those, arise the flowers, which are little, but of a beautiful red colonr. The whole plant has a fragrant smell, and an aronatic tinte. 'The fresh tops of the herb are to be used. 'They if 
are lest then in infurion: 1.tey stranghen the stow

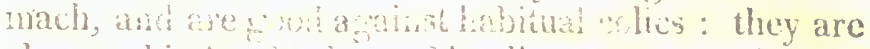

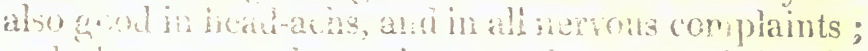

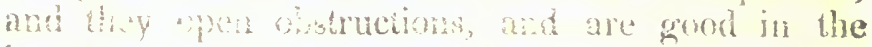
jound a ant to promote che nenses. Chymists sell what uaty ret oil of origanim, but its commonly

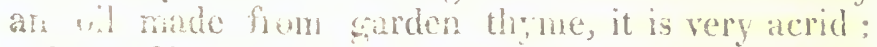
a drep, wit put upon int, and laid to atn aching tooth,

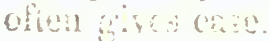

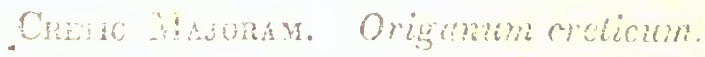

A nesteme jolnut, of the wild marjorans kind, fre. quent wid in the east, and kept in our garderis. It grows a wot high. The stalks are square, bpright, and brown. The leares are oblong and broad: they are of a whitish colour, and stand on long foot stalks: there grow scaly heads at the tops of the branches, as in the other kinds, and from these burst out the flowers, which are little and white.

The tops are the part nsed : our druggists keep them dry; but they generally have lost so much of their virtue, that the fresh tops of our own wild majoram, or the dricd ones of the last season, are better.

\section{Marigond, Calcndula.}

A rLANT to conmon in our kitchen gardens, to need much description. It is a foot high. The stallis are thick, angalated, and not very upright. The leaves are long, narrow at the base, and broader toward the end. The flowers are large and yellow, and they stand at the tops of the branches. The whole plant is of a pals: bluish green colour, and feels slammy. The root is librous.

A tea made of the fresh gathered flowers of 
marigold, pieked from the cups, is gond in levers: it geuty promotes perspiwition, and throwe cut any thing that ought to appear on the shin.

\section{Mastrc Tree. Lentiscus.}

A vatre of the warmer countries, but ind un. common in our gardens. It grows to the bigness of our apple trees, and is as irregnale in the disposition of its branches. They are covered with a greyish bark, and are brittle. The leaves are composed, each of about four pairs of small ones, without any odd leaf at the end : they are arixed to a kind of rib or pedicle, which has a film running down it, on each side. They are oblong, narow, and pointed at the erds. The flowers are little, and yellowish; and they grow in tufts. The fruit is a Uluish berry.

Wo use the resin which droys from the wounded branches of this tree. The tree itscif is common in France and Italy, but it yirids as an there; we have that from Greece: It is whinis, hard, and in little lumps. It is good tor all nerrous disorders, and acts also as a balsam. Thicre is scarce any thing better for a spitting of biond, or in the first stage of a consumption: it is also good against the whites, and in the gleets after gonorrenas. Somo have a custom of chewing it, to prearese the tectl: and sweeten the breath.

\section{Inog Mastic. Iifarum.}

A rempry little plant, native only of the warmer dimatcs, but common in om gyldens. It is a fisct light, and the stem and principal branches are sirniby or woody in their texture : the smaller shoots are whitish the leaves grow two at 
cileh joint: they are little, oblong, and pointed; of a pale colver, and tigrant smell like mastic, resinous, and very andeabis. At the tops of the

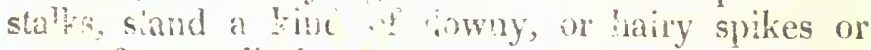
ean of a pecilian'y un aplear nce, and from ont of thest whit the lowers, which are litle and white Wisc roo is smail.

The whole plant is lined dry. It may be given in infusion, or in powder : it is a good stronghener of the stomactr, and an astringent. It ships the overflowing of the ine:ises: the powder of the tops is best given for this purpose in red wine, a scruple for a dose.

\section{Syrian Mastic Thyme. Marum siriacum}

A Beactiful little plant, native of the warm countries, but not unferenient in our gardens. It grows a foot high. The slatks are britle stender, and whitish. 'The leciten stand two at cucie jont: they are small, in shape very like those of thyme, and of a pale greer: roloni on the upper side, and white and hoary uicents 'The flowers are small and red: hey $: w$ in a hir of litte spike, or oblonger clusters at the tops of the stalks,

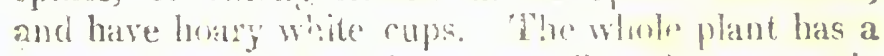

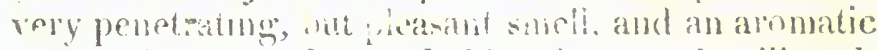
taste. (atis are fond of this phat, an!l will rub it to pisces ing therip formenes. It is subd for all disorder: of th: head and merves: it may be given in powales but the most common way is to tate it in mnutf

\section{Merenvener. Imperitoria}

A PLANT of no bisaty, kept in our gardens tor its virtue. It grows two feet high. The stalke 
are romul, striated, wollowed, npright, not very stirnar. The leaves are each composed of three smailer : they are of a dark green colour, blunt at the points, and indented about the erges. The flowers are small and white : they stand in little umbels at the tops of the branches. The roots are long, brosn, rivided, of a strongrsmell, anrl a sharp aromatic taste.

The root is the part used : it is good in fevers, disorders of the head, and of the stomach and howels. It is best taken up fresh, and given in a light infusion : it promotes sweat, and is a better medicine for that purpose, than most of the foreign roots kept by d"ugogists.

\section{Maldun. Agcratum.}

$\Lambda$ commox plant in our gardens, not without beauty, but kept more for its rirtues. It ts a foot high. The stalk is round, upright, firm, singte, and of a price sreen. The leaves are very numer-

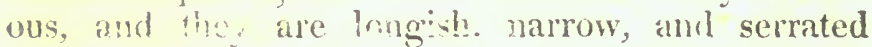
about it. res. The flowers are small and naked, comsisting only of a kind of thrums; but they stand in a large cluster together, at the top of the stialk, in the mamner of an umbel. 'The whole plant has a pleasant smell.

The whole is used, fresh or dried; but it is hest fresh gathered. In infusion ot it taken for a continu. ance of timk, is good against obstructions of the kiver: it opcrates ly mine.

\section{Stringaga Marwed. Cotula fatida.}

A common wild plant in com fields, and waste grounds, with fmely rivided leaves and whice tloness like daizies, The stalk is round and stria- 
bed. The herb wows a foubligh. Wha leaves are ille those uf canumile, onty of a biacher green, and larger. The Howers stand ten or a duzen nar one another, at the tops of the branches; but they grow separate, not in a cluster. The whole plant has a strong smeil.

The infusion of the fresh plant is good in all hysteric complaints, and it promotes the menses. The herb boiled soft, is an excellent rutice for the piles.

\section{Mesdow Swrer. Ulmaria.}

A mino plant, frecingt about the sides of rivers, with divided leaves, and icautiful tufts of white flowers. It is four fect whe The stalk is round, striaterl, upight, firm, and of a pale green, or sometimes of a purple colour. The leaves are each composed of about three pain of smaller, set on a thick rib, with an odd leaf at the cnd: they are of a fine green on the upper side, and whitivh underneath, and the are romgh to ihe tourdi, The flowers are small and white, but lise y stand so che , that the whole cluster looks like onc lowe flumer. The seeds are set in atristod orter.

An infusion of the fiesh topes of meadow sweet, is an excollent sweat, and it is a little astringent. It is a good nedicine in fevers, attended with purgings. It is to be given in a basou once in two hours.

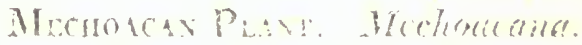

A compras jo!nt. native of the Mest Indice. It is rapable of rmmong to a grout legght, when it (an be supported : it will climis to the tops of all trees. The salks alc anculated, slender, 
green, and brittle; and when broken, they yind a vast quantity of an acrid, milky juice. The leares stand vingly; they are bread, and not very long, and of a beantiful slape, terminating in a point. The fowers are larege and of the chepe of a bell : they are of a dway muph a inside, and of a pale red witurt; and the seed-reconls are large, as are wiso the seeds. "Le root is whitish, and very" thick.

The root is the part used: our drugrgists keep it dry. It is in slices, and is whitish and brittle. It is an excellent pu"ge, but there requires a large dose to work tolerably ; this has orcasioned its being much less used than worse medicines, that operate more strongly, and can be taken with less disgust; but it is to be lamented, that so litt: use is made of it.

\section{Menlar Tree. Mespieus.}

A commor tree in our giardens. It is of the big. ness of an apple tree, and grows in the same irregular manner : the branches liave thorns on them. "The leaves are longer and narrower than in the apple tree, and they terminate in a point. The blossoms are large and white. The fruit is roundish, and open at the bottom : and till very much nellowed, is of an austere taste.

A strong decoction of unripe medlars, is good to stop violent purgings. The seeds work by wine, and are good against the gravel; but the"re are so many more powerful things at hand, they are seldom used.

Mernot. Melilotus.

A commor wild plant, with three leares at 
a joint, and long straggling spikes of yellow flow. crs. It is a fout an? a half high, or more. The stalk is weak, slender, green, and striated. The feaves are oblong, and blunt at the ends: they are serrated round the edges, and of a bright green colour. The flowels are small, and of the shape of the flowers of tares, but little ; and there follows each a roundish pod, rough and green. The whole plant has as singuiar, but not disagreeable smell ; and the leaves are the food of so many insects, that they are commonly gnawn to pieces.

The firsh plant is excellent to mix in pultices, to be applied to swellings. It was once famous in a plaister, used for dressing of blisters, but the apothecaries used to play so many bad tricks, to imitate the green colour it was expected to give, that the plaister is now made without it.

\section{Merov. Melo.}

A tramixg herh, with yellow flowers, and large fruit; well known at our tables. 'The plant grows to eight or ten feet lon are angulater, thick, and of a pale green. 'The leaves are larend broad, somewhat roundish, and not deeply divider., as in most of the creeping plants of this sort. There are tendrils on the stalk for its laying hold of any thrigg. The flowers are very large, and open at ihe mouth. The fruit is oblong and rough, more er lese on the surface, containing seerls, with a juicy inatter within.

The sceds are the part used : they are cooling, and wok by urine. They are best griscin in an emmlsion, beat up with barley water: this is a good drink in ferers given warm. 


\section{FAMIIY IIERBAL.}

\section{Mercreon Shrte. Menereum.}

A TeRY prefty slirub, ustive of many parts of Europe, and frequent in our gardens. It is four feet high, and very much branched. The branches stand irregularly, and they are rery rongh and firm. The leaves are oblong and narrow : they grow in clusters from certain little swellings on the bark. The flowers are small and red; they are hollow, and ar: suciceded by oblong berries, which are black when rince. Thic root is woody and creeping; and the plant is not easily destroyed, when once well established.

The bark of the root, or the inner bark of the branches is to be used; but it is a violent medicine, and must be given with great caution, in small doses, and only to those who have strong constitutions. It will cause vomiting, and bloody stools to people that are tender, or to any, in a lirge dose; but to robust perple, it only acts as a brisk purge. It is excellent in dropsies, and other stubborn disorders; and the best way of giving it, is in a light infusion.

\section{Mirlet. Millium.}

A PIAXT of the grass kind, large, upright, and not without its beanty. It is four feet high. The stalk is round, hollow, jointed, thick, and firm. The leares are long and broad, of a pale green, and hairy. The flowers and soeds grow at the top of the stalk. in a vast cluster, so heavy that the head usually hanga down : they are altoguther of the grass kind. The flowers are inconsiderable, and the seeds small, hard, and white.

The: secds are used sometimes in the mainney of

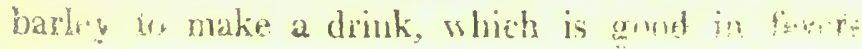


and against heat of urine; it is also a little astringent. The yrim is eaten also as borley.

\section{Nunworr, Polygala.}

A covisox litte plant upen our heaths, and en diry pastures, with numerous leaves and blue or white thow'the the this is a variety and caused by arcidents, dispored in luose spikes. The root is long, and divided into several parts, the stalks are very mumerus, and very much branched, they are a fender and weak, and they spread thenselves upon the compund, forming a litic green tult. There is sreat variely in the appearance of the plant, beside what has been already named in the colom of the luwer; nor is that inded tise mly variation thers: so that it has been divided intu tivo an thee kinds by some writers, but as all there will rise from the sime seed, and on? are minn bn the wil and exposure, the plent is withot dombe the sume in

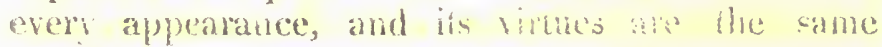
in wish exer state it is ahen. When it erons

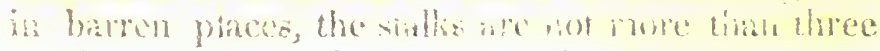

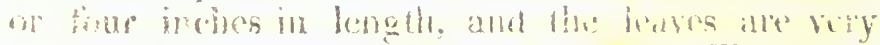
momerous, shert, and if an snat ingre. The How-

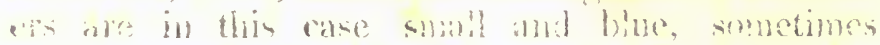
rifiests strated with bine, and smmetimes insirely shite. Whon the flant wrows in sone-

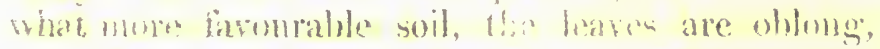
mo namess, printed at the ante and of a beantiful

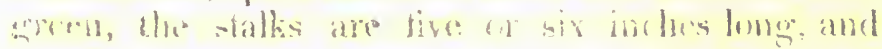

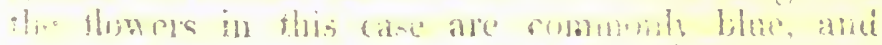

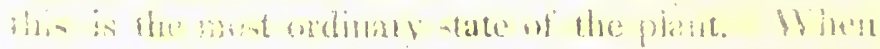

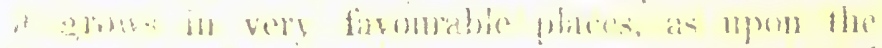

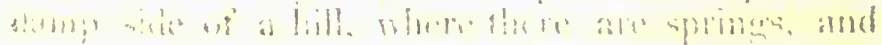

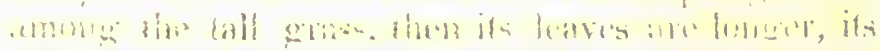

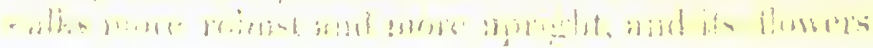




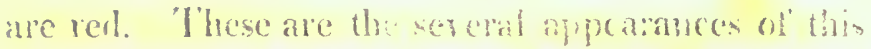
little plant, and it is all one in which of tiem it

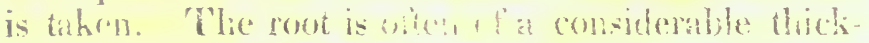
ures, and single, but it is mone ustatly diricked and smaller; it is whitish, and of a disagireable acrita taste.

This plant had passed miconarder as to any mesticinal use, till Dr. 'A'cmant brought into Fingland the senekla root. famous in America against the eflects of the bite of the rattle-snalie, and found here to be of service in pleurisies: but when it was found, that this was the root of a kind of milkwort, not very different from our own, we tried the roots of our own kind, and found them effectual in the same cases: as to the poisonons bites of a serpent, they are so moommon here, that we need not regard that part of the qualitios, but we fund it groot in the other disorder, and in all diseases in which the blood is thick and sizy. 'The fresh root is best, but it has not its full virtue except in spring, when the stalks are just shouting out of the ground. for this reason it is most promer to take it up at that tine, and dry it for the service of the year. When fresh, it is heat given in infision : but when dried, it is kept in powder.

\section{Sorik Mrve. Wentha vulgaris.}

A convos phant in our gardens, and of frequent

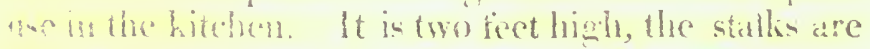

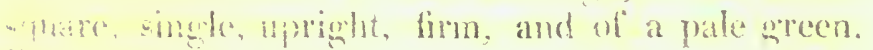
"he lowes stand tuo at a joint; thes are long,

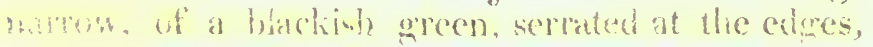

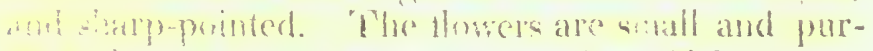

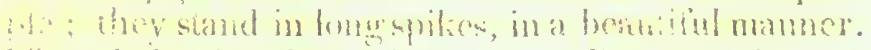

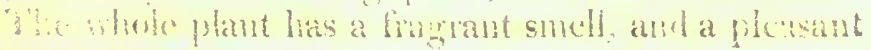
arominte tate. 
The whole plant is used, fresh or dried, and is excellent against disorders of the stomach. It will stop vomiting, and create an appetite; it is best given in the simple distriled water, well made, or else in the form of tea. The fresh herb bruised, and applied outwardly to the stomach, will stop vornitings.

\section{Water Mint. Mintha aquatica.}

A common wild plant of the mint kind, not so much regarded as it deserves. It is frequent by ditch sides. It is a frot and haif high. 'The stalks are square, upright, firm, and strong, and generally of a brown colour ; the leaves are broad and shoit ; they stand two at a joint, and are of a brownish or deep green colour, somewhat hairy, and serrated about the edges. The flowers are lesger than those of common mint, and are of a pate red colour; they stand in round thick clusters at the tops of the statks, and round the upper joints. The whole plant has a strong smell, not disagreeahle, hut of a mixed kind between thit of inint, and penny royal: and the taste is strong and acrid, but it is not to be called disagreeable.

A distilled water of this plant is excellent against colies, pains in the stonnach and bowels, and it will bring down the menses. A single dose of it often cures the coilc. 'The use of peppermint has exrluded thin kind from the present practice, but all tiree ought to be ned. There a simple weaknewe of the stomach is the couplaint, the common mint strosist be used ; when colicy pains alone, the feppernint; and where supressions of the nom, all an the caste this wild water mint: they $\because$ aty all be given in the way of tea, but a simple 
water distilicu from them, and made sufficiently strong, is by much the most efficacious.

\section{Pepperunt. Mentha pipcrata.}

A puse kept in om gardens, but much more resembling the wild mint last described, than the spear mint, both in form and qualities. It grows two fect and a half high. The stalk is square and firm, upright, and of a pale sereen; the leaves stand two at each joint: they are broad, not very long, of a dark green, and serrated deeply at the ediges. The floners orow in thick spities, but not very long ones, they are large, and of a pale red. The whole plant has an agrecable quick smell, and a hot taste like peppere, but not disagrecable.

'The whole plant is used fiesh or dried; but the best way is to give the distilled water. It cures the colic, often almost instantaneously, and it is good angainst the gravel.

\section{Lovg Leaved Wild Mint. Menthrastrum.}

A singutar wild plant, of the mint kind, but not without its beauty; it is two feet high, and grows with great regularity. The stalk is square, firm, and of a pale green, very upright, and at the top finl of yomg shoots. Thin leares are long and narrow; they are of a whitish green, dereply indented about the edges, and pointed at the ends: the Howers stand in spites, at the tops of the yome shoots; they are male, red, and larese, and very mumerous. The whole plant has a strong smell.

The whole plant is used fresh or dried, and is to be given in the way of tea, for the distilled water 
is disarrecu?l. It strenghlyens the stomach, and

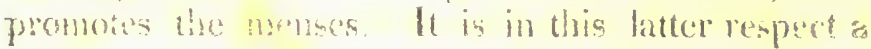

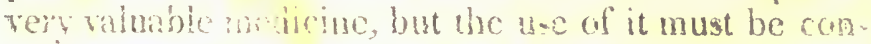
tinued someline.

\section{Hister, Myrtus}

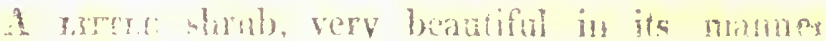

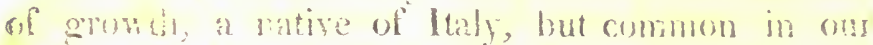

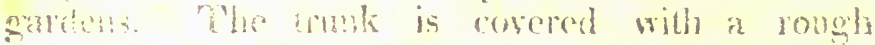

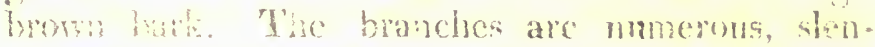

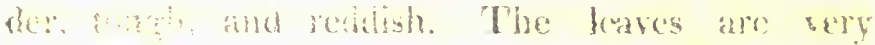

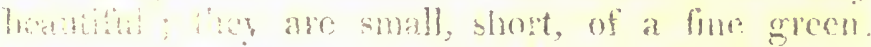

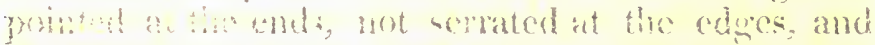

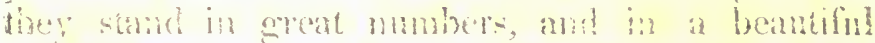

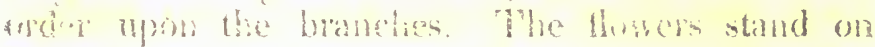

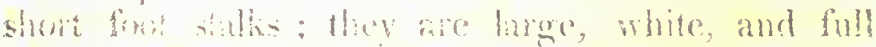

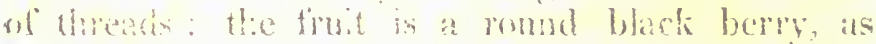

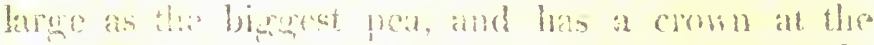

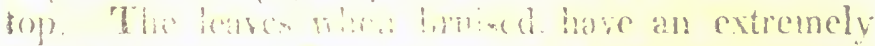

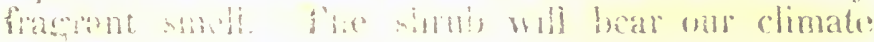

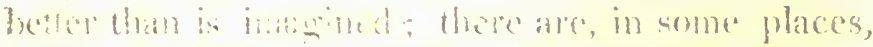

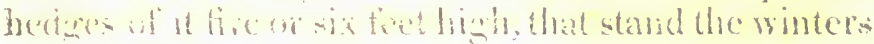

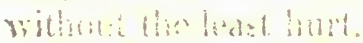

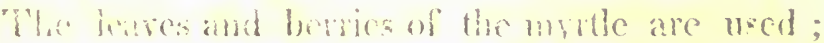

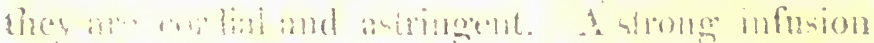

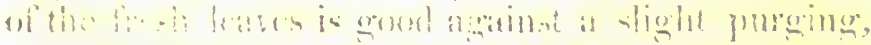

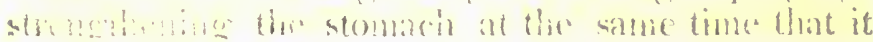

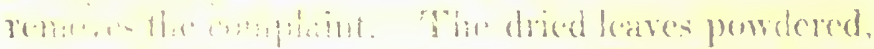

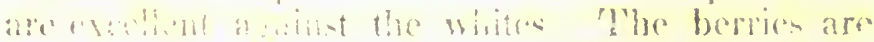

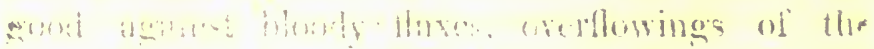

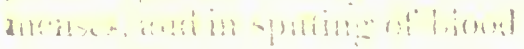

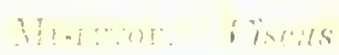

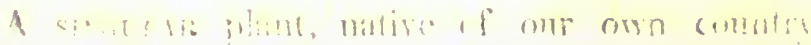

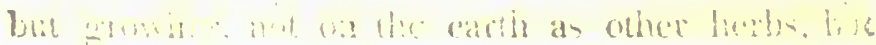




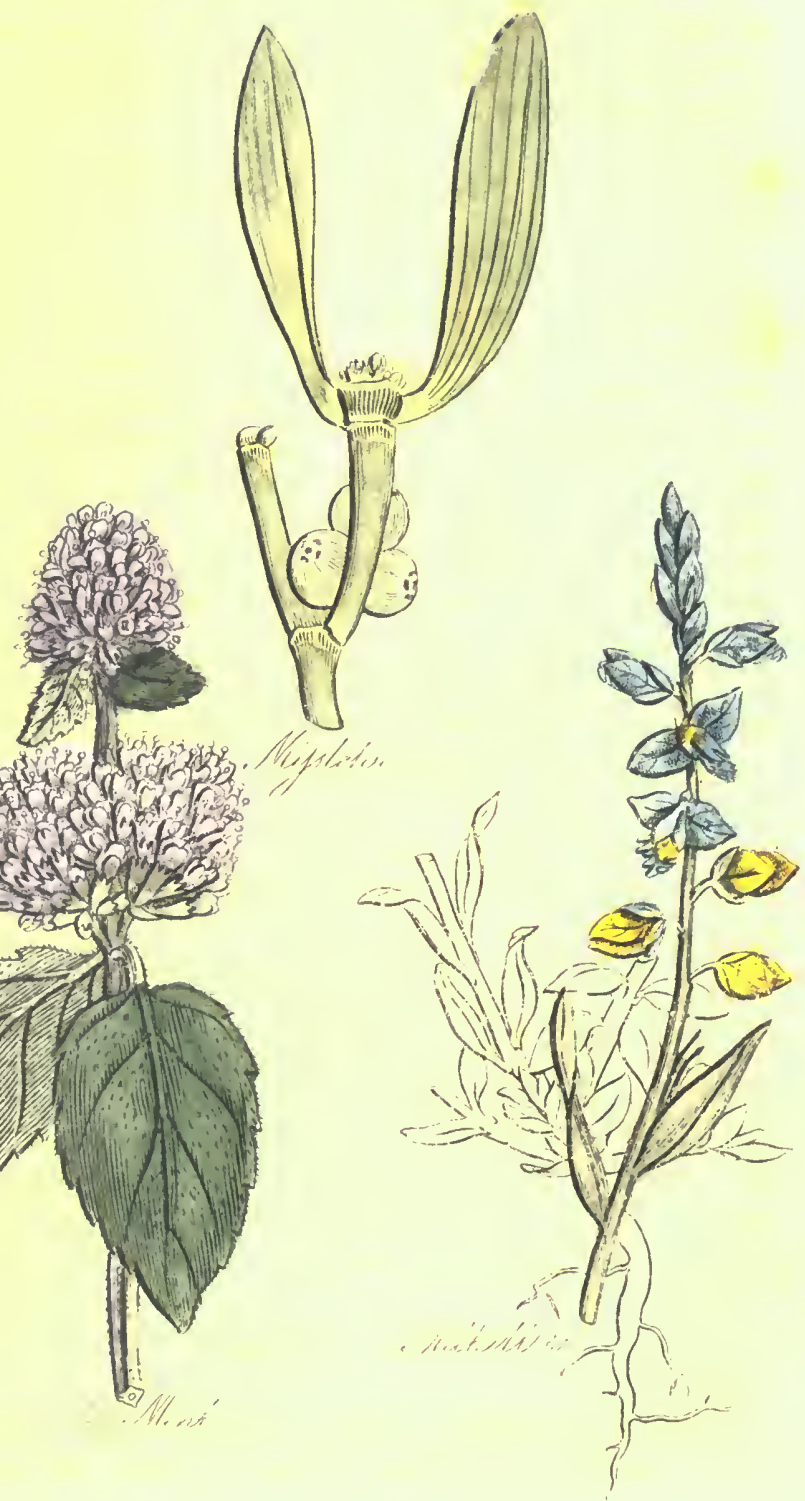



was given as a purge, but at present none regard it. There are also four other's of the same kind, the names of which we see in books of medicine, but the fruits are not to be met with, nor is it much loss, for we have better thing; to answer their purposes. They were called the citrine, chebule, belleric, and imblec mirubalanus; they are all nised as purges, but common semna is worth then all.

\section{Mooswort. Lunaria.}

A reny singular, and very pretty plant, fre. quent in some prarts of the kingiom, but in most very scarce. It grows six inches high ; and consists of the stalk, one leat, and the flowers. 'The stalk is round, firm, and thick. It is naked to the middle, and there grows the leaf, which is composed as it were of several pairs of small ones, or rather is a whole and single leal divided deeply, so as to resemble a number of smaller ; these are rounded and hollowed, and thence came its name of moonwort; from the base of this loaf, the stalk is continued up an inch or two, and then rise the cluxters of tlowers and seeds; these are very small, and like dust, and of a brown colour. 'The leaves of moonwort dried and given in powder, stop plirgings, and the overllowing of the menses. The fresh plant bruised and laid to a cut, stops the biceding, and heals it in a day or two.

\section{Mlire 'lime Moss. Usnea.}

A rus singular plant of the moss kind, fre-

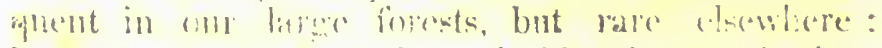

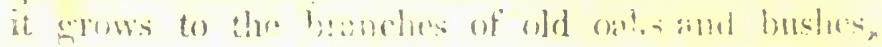

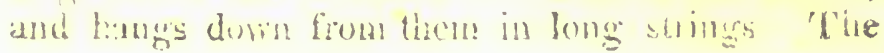




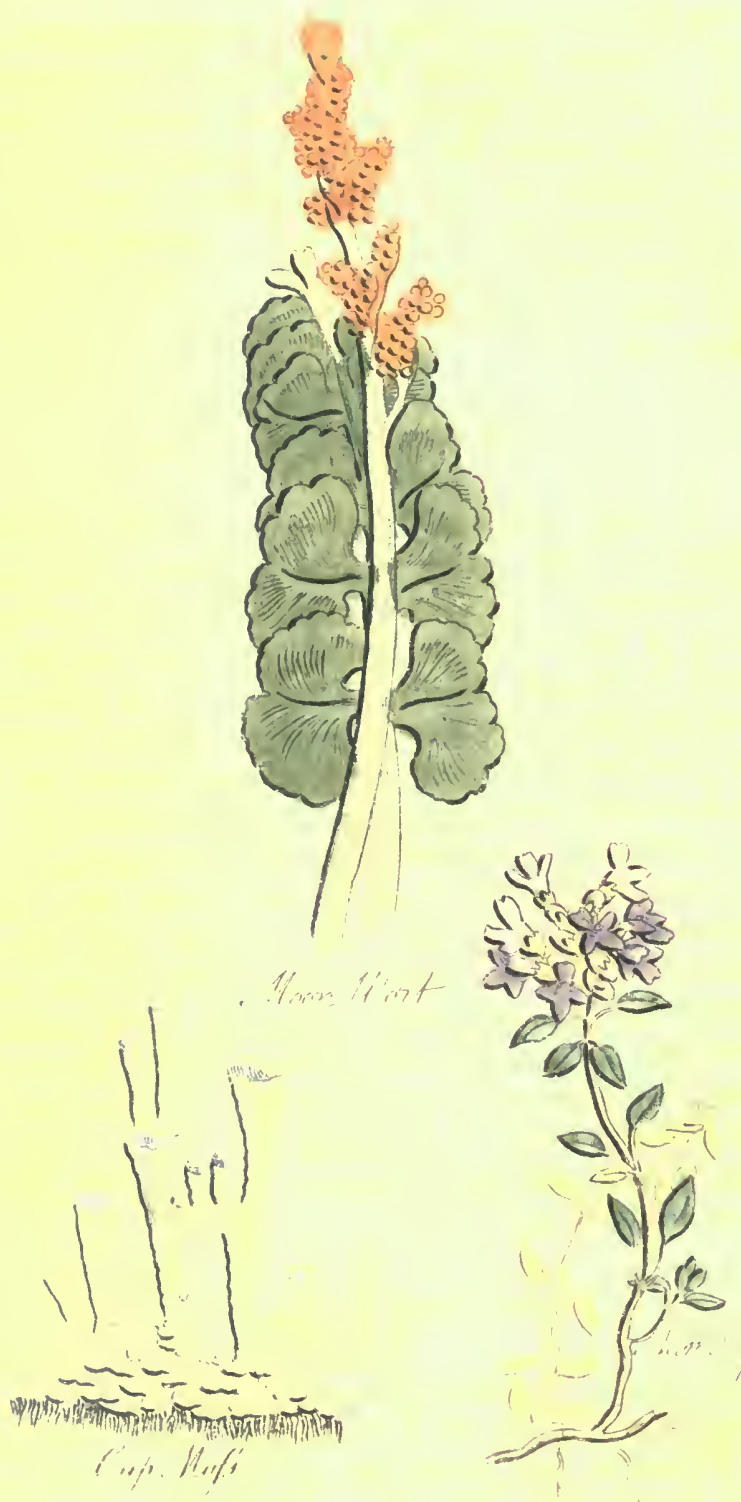



tufts of it are often a font long, and in the whole two or three inches thick; they are composed of a great quantity of statks and branches, the largest not bigrger than a large packthread; these are of a srey colour, and are composed of a soft bark, and a firm white fibre within : this bark is often cracked, and the fihres appear jointed; the small tibres of the plant resemble hairs: on the larger grow, at cerain seasons, little hollow brown bodies. Thewe contain the sceds, but they are too minute to be distngnished singly. 'The whole plant is dry, and sapleas as it grows, and has not the least appearance of leaves upon it.

'The powder of this moss is an excellent astringent; it is to be dried in an oven, and bent in a morar: the white fibres will remain, when the soft part has gone through the sieve; they are of no use, the wher has all the virtur. it is good against the whites, against overflowing of the menses, and blondy lluxes, and against spitting of blood: it deserves to be much more renarded than it is in the present practice. The dose is lialf a dram.

\section{Cip Mosq. MInscus pyxidatus.}

A connos little plant on ditch banks, by wood sides, and in dry barren places. It consists of a thin cont of a leafy matter, spread upon the surface of the ground, and of a kind of a little cups rising from it. 'The leafy part is dry and without juice, divided into serral portions, and these irregularly notcied; it is grey or greenish on the upper side, and whitish mdcrneath. The cups are haif an inch high. They have each a thick stem, ard an open mouth, and lather resemble a clumsy drinking slass, than a cup. They are of a grey colour, often with some old mixture of II h 
green, of a dusty surface; sometimes they grow one from the edge of another, up to the third or fourth stage: they have also many other accidental varieties; and sometimes they bear little brown lumps, which are supposed to contain the seeds.

The whole plant is to be used; it is to be taken fresh from the grround, shook clean, and boiled in water, t!ll the decoction be very strong; then there is to be adiled as much milk as there is of the lignor, and it is to be swectened with honey. It is an excellent mediciue for children's coughs: it is recommended particularly in that called the chincoughti.

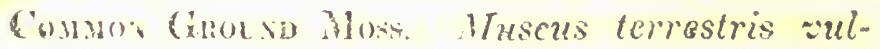
geris.

A rnezry, but very small plant. It creeps on the ground, or rises in tufts two or three inclies high, acording to the place. The stalks are very slender, but they are thick, concred with leavos. and their branches are disposed in such a mamer that they in some degree resemble tern. The leaves are very small, of a triangular shape, and of a bright green : they stand loosely on the lower part of the stalka, bit on the upper, they lie close and cover them. It very marely produces its seerls; but when it does, thare rise naked and rery slender pedicles an inch long from the hosoms of the laves, and at the top of ach of these stands a little oblong head, of a brownish red colour, corered with a cap like an extingrisher in shape, and finll of a fine green dist.

The whole plitnt is used ; it is to be dried and nowdered, and is given with surecess against overflownow of the mense's, and all blecelings ; it is also good gainst the whites. 


\section{Moss of an Human Skith. Muscus ex cranio humano.}

There is rot any particular kind of moss that grows upon the human skull, nor does any moss by growing upon it acquire any particular virtues, whatever fanciful people may have imagined. In England, we comnionly use the moss just described, when it happens to run orer an human skull, that has been laid by accillent, or has been laid! on purpose in its way: in other plares, they use the sort of white moss, that grows npon our old apple trees. Both these are in their own nature astringents, but they are as good if take: from trees, or off the gromud, as if found upon these bones. They have besen supposed goed against disorders of the lisad, whe: gathered from the skull, hut this is atl funcy.

\section{Mothic of enyie. sipyllum.}

$x$ conmon wild little piant, but very pretty, very fagrant, and of great virtues. It grows in little tufts hy way sides, and on dry hillocks; the stalks are round stender, reddish, and six or eight inches Inng, but they lo not stand upright. The leaves are very small, and of an oval figne; they grow two at each joint, and they are smooth, and of a bright green. The flowers are of a pale red, and stand in little tufts at the tops of the stalks, the whole plant has a very fiagrant smell, and an aromatic and agreeahle taste.

It is a butter medicine in nervous cases than most that are used; the fresh plant or dried, may he drank as tea; it is very agreable to the raste, and by a continuance, will cure the common nervous disorders. The night mare is a very trouble. 
some disease, and ofien puzzles the physician, but it will be perfectly cured by $a$ tea made of this plant.

\section{Motnerwozt. Cardiaca.}

$\Lambda$ TALL, and not unhandsome wild plant. It grows wild about farm-yards and in diy places. It is a yard high ; the stalk is square, thick, upright, and firm. The leaves stand o' long foot stalks, two at each joint. 'They are divided into three parts, the middle one being the longest, and are deeply indented at the edres ; of a lark grecu colour, and bad smell. The flowers are of a pale red : they grow in a kind of prickly cups, from the bosoms of the leaves, smrrounding the staiks. The root creeps, and is whitish.

The whole plant may be used dried, but the tops fresh cut are best; they are to be given in a strong infuion or decotion. It is grood anainst hysteric commlanina, and it promotes the menses. It is famesis for corring the palpitation of the heart, when that a ises from an hysteric cause : for there are palpitations, which nothing can cure.

\section{Morse-ear. Pilosella.}

Ax exceeding preffy litle plant, with whitish leaves, and lawer bright yellow flowers, frequent on our ditch banks. "îhe loaves wow in little chuters, and ane lomeich and brovil, of a dark

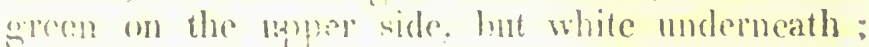
and so much of the under part is risualiy seen. that the whole lowis whitinh. The stalks twat

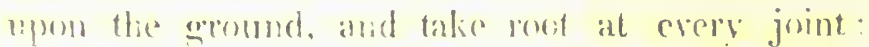
the hases have bong hairs npon them. The stalks

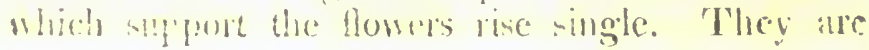




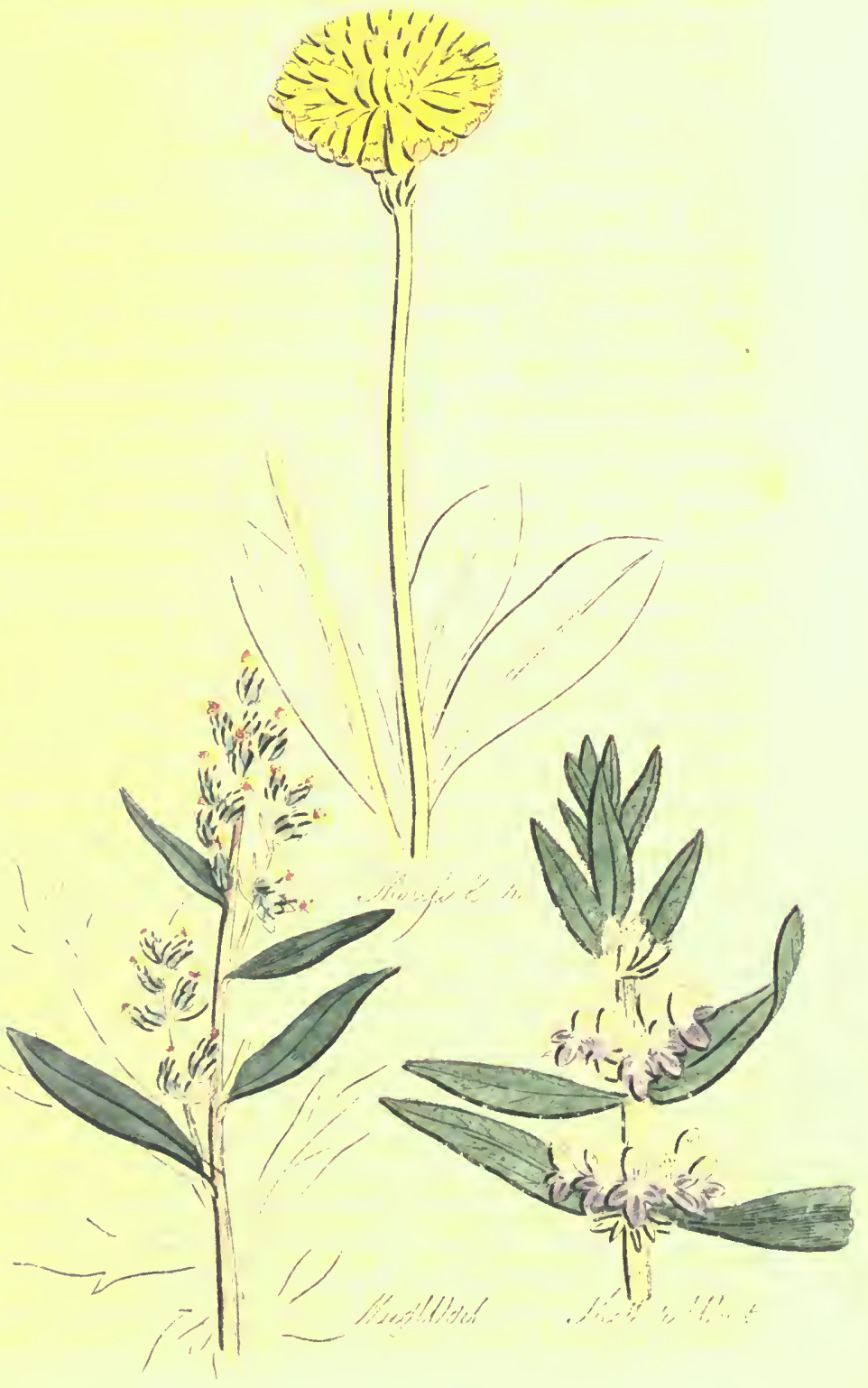



hairy, they have no leaves, and each hears only one Hower, this stands on the top, and is large, somewhat of the form of the dandelion flower, but of a beautiful pale yellow.

The seeds are winged with down, and the stalks when broken yield a milky juice, but in no great quantity. The plant has scarce any smell, bit an austere bitterisin ta: e.

A decoction of the fresh gathered herb is excellent against the blecding of the piles: and the leaves boled in wilk may be applied externally. It is good also in the overflowing of the menses, and in all other bleedings, and in the whites.

\section{Nugwort. Artomisia.}

A TiLL, and sot mhandsome plant, frequent on ditch banks, having divided leaves, and flowers like those of wormond. It is a yard high or more: the stalk is round, striated, often purplish, firm, mipight, and branched. The leaves stand irregularly upon it ; they are large, and composed of a number of small parts, which are sharply indented and pointed. They are of a dusky green on the upper side and white muderneath. The flowers are little and brownish, they stand in small tufts all along the upper parts of the branches, but they stand upright, whereas those of womwood hang down. They often have a tinge of purple before they are quite opened, which adds greatly to the berity of the plant.

The leaves of numgwort are to be used fresh or dried; they are best given in intusion, and they are excellent to promote the menses, and against all the common ligsteric complaints. 


\section{Mulberry Tree. Morus.}

A LARGE and irregular growing tree, common in our gandens. The branclies are numerous and spreading; the leaves are very beautiful, large, broad, of a bright green, pointed at the end, and delicately serrater sound the edges. The flowers are small, and inconsiderable: the fruit is sufficiently known; it is largere, oblong, juicy, and composed of a creat number of small granules : it is usually black when ripe. But there is a kind with white fruit.

The bark of the root of the mulberry tree fresh taken off and boiled in water, makes an excellent slecoction arainst the jamblice ; it opens obstructions of the liver, and works by une. A very pleasant syrup is made trom the juice of the ripe fruit, with twice the fuantity of sugerr. It is cooling, and is good for sore months, and to quench thirst in fevers.

\section{White Menles. Tipbascim album.}

A TAL. and statcly wild plant, singular for its white leaves, and long spike of yellow hlowers; and frequent on our ditch banks, and on dry places. It grows six feet high; the leaves rising from the root, are a foot long, as broad an oness hand, slarp-pointed, serrated about the edges, and concered with a white downy or woolly matter. 'The. - walk is thick, firm, and very upright, and is coserof wih smaller leaves of the same kind: the flowens are yollow and large : they stand in spilies. of

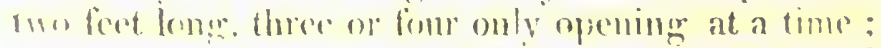

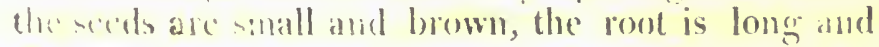
thases

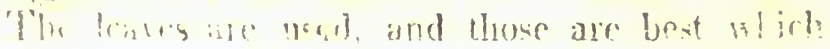


grow from the ront, when there is no stalk. T'hey are to be given in decostion against the overlowing of the menses, the hloorly flnx, the heeding of the piles. and spitting of blood ; boiled in milk, they are also excellent by way of pultice to the piles, and other painful swellings.

\section{Mustand. Sinapi.}

A comuos roigh looking plant, wild in many places, but kept also in gardens, for the sake of the seed. It wrows a yard high. The stalk is round, smonth, thick, and of a pale green ; the leaves are large, and of a coarse green, deeply indented, and placed irregularly; they hang down, and have a disagrepable aspect. The flower's are small and yellow ; they grow in great numbers on the tops of the tranches, and the pods of the seed follow them. The whole plant is of an acrid pungent taste. 'The root is white.

The seeds are the part used; what we call mus. tard is made of them, and it is very wholesome; it strengthens the stomach, and procures an appetite. The seed bruised and taken in large quantities, works by urine, and is excellent against rlieumatisms, and the scurzy. It also promotes the menses. Laid spon the tongue it will sometimes restore speech in alsices.

\section{Treache Mistard. Thlaspi discordis.}

- trrte wild plant with broad leaves, white flowers, and flat pods, crmmon in dry places. It is eight inches high; the stalk is round and striated. The lenves are ublong. and hroad, of a pale green colour, and dentated rind the edges. 
They grow irregularly on the stalks, and liave no foot stallis. The flowers are very sinall, a little tuft of them stands at the top of the stalk, and the pods forlow them; so that the usual appearance, when the plant is in flower, is a short spike of the pods, with a little chister of llowers on the top ; the pods are larege, flat, roundish, and edged with a leaty border. The seeds are small, brown, and of a hot taste. The sced is the part used; but our drumgists generally sell the seeds of the garden cress, in the place of it. It is not much regardert.

\section{Mitumide Mistard. Thlaspi incano folio.}

1 urTte wild plant, common in corn-ficlis. It is of a foot high ; the stalks are round, firm, upright, and not much branched; the leaves are long, narrow, a little hairy, and of a dusky green. 'The flowers are small and white, and the ports which folinw them ane roundish and little, not flatted as in the former kind, nor surromed with a fo-

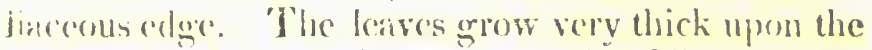
stalk. and rarh has as it were a couple of little ones at the rase.

The soend of this is used also, at least in name, for the cresesenes serves for both: the matter is not

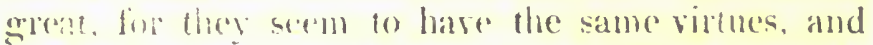
noither is minded, execpt as ingredients in comp)ostertis.

\section{Mrum Tare. Nyma.}

A Tree concerning whish we have but vere imperfect areonnts. and those not well wartanted for genumine. III that we hares of it is, that the banches are numerous, and hive thorns on them; 
that the leaves are oblong, broad, and of a strong smell, and that the hark of the trunk is rough, and of a greyish colour.

The gum resin called myrrh, is certainly pro. cured from some tree in the liot countrics, but whether this be a true description of that tree, there is no certainty. The gum itself is a very great medicine; it opens all obstructions of the viscera; is gond in consumptions, jaundices, and dropsies ; and is excellent for promoting the menses, and assisting: in the natural and necessary discharges after delivery: it is to be given in powder ; the tincture dissolves it but imperfectly; hut this is exenllent again tisorders of the teeth and gums.

\section{N \\ Siwet Naver. Napus.}

A plast kept in some gardens, and not unlike the common turnip in its aspect and appearance. It grows a yard high. The staik is round, smonth, and of a piale green. The leaves stand irregularly on it, and they are oblong, broad at the base, where they surround the stalk, and narrower all the way to the point. The leaves, which grow from the root, are much larger and deeply cut in at the cides; and they are all of a pale or binish green colour. The Howers are smail and yollow, and the porls are long. The seed is round and black. Whe root is white and large, and has the taste, but not the romd shape of the turnip, for it is rather lik a prorsnip.

The seeds are inged, but not much. A decoction of them is said to promote swcat, and to drive nuy thing ont to the skin ; but it does not seem to de. snroes an great regard. 


\section{Wud Navew. Bunias}

Wus plant which produces what we call rapesered, and in some places cole-seed. 'Thonght wild on our ditch banks; it sown in some places for the sake of its seed, from which an oil is made for mechanical purposes. The plant is two or three lect high; the stalk is round, upright, smooth, thick, firm, and of a pale green, the lower leaves are ling and narrow, very deeply divided at the edgers, and of a pale or bhish green colour. Those on the stalk are of the same colour, but small, narrow, and a little divided: the flowers are small, nund of a bright yellow. The porls are long, and the secols are rominl, large, and black; they are of a somewhat hot and sharp taste. The seeds are used for the same purposes as the other, and are supposed to have more virtue, but probably neither have much.

\section{Colic Nard. Nardus cellica.}

A urTrue plant of the valerian kind, frequent in 'many parts of Europe, but not a native of Eng. land. It is six or eight inches in height; the stalks are round, striated, and areenish: the leares at the bottom are oblong, narrow at the base, and romnded at the end, and of a yoliowish green colour. Those (itt the stalls stond in pairs: they are small and deeply rut ; the flowers stand in a little cluster at the top of the stalls; they are small and white: the root is long, condere, and creepins:

"hio mot is the part resed; our druggists leep it dy. It is best taken in infusion. It operates by whe, and in sume degree by sweat, but that very murerately it is commended in fevers and in the bistidínt 


\section{FAMILY HERBAl.}

\section{Netrus, Urtica.}

A prant ton common to need much description. It is three feet high ; the stalls are angulated and rough ; the leaves are large, and of a beamifin shape, regularly from a broal base diminishing to a sharp point, and nicely serrated round the relges: the colour of these and of the stanks is a dusky green, and they are hoth covered with a kind ot prickles, which easily make thir way into the skin, and have at their base, a hollow hag of sharp juice, which grets into the womml, oceasioning thet swelling, inflammation, and pain that foilows. The naked eye may distingugh thee bagn at the bottom of the priclies on the stalk of a fir!l grown nettle. but a nicroscopestews them ail orer. The flowers of the rettle, are yellowish, little, and incomiderable, the sects are small, and reund, tine root is long and creeping.

The juice of the nettle is grond against oremowings of the menses. The root is to be given in infusion, and it works powerfuly by unine, and is excetInt against the jaundice.

\section{Romax Nettee. Urlica Romana.}

A wimp plant of the nettle kind, but not conmon. It is two fect high, the stalks are round, and of a deep green colour. The leaves are larger. and of a deep green also; broat at the base, marrow to the point, and decply serrated. The flown!s are small and inconsidereble, the fruit is a round ball, as big as a large pea, it stands on a long foot-stalk, and is of a deep green colour, and fill of small browu seeds. All the plant is corered with the same sort of prickles as the common nettle, but they are shorter and finer; they are silyery, white at the 
tips, and hare the same bag of liquor at the base, and they sting very terribly; more a great deal than the common nettle.

The seeds are the part used; they are good against coughs, shortness of breath, and hoarsenesses; the sceds of the common nettle are commended for this purpose, but these are greatly preferable. The best way of giving them is in tho manner of tea, swectened with honey.

\section{Comaox Nicutemade. Solanum vulgare.}

A wre plant, that overruris gardens, and all other cultivated yaces, if rot continmally weeded ont. It gruws two fee high; the staiks are roundish, thick, but not very ereci or strong, and of a duslis green. The leaves are broad and roundish, but they terminate in a point. They are of a dark green colour, and stand on foot stalks. The llowers grow in little rlusters, ten or a dozc! in a bunch ; thry are white, with a yellowish centre, and they are succeeded by round biack berries.

The leaves are userl fiesh, and only externally. 'They are very cooling, and applied bruised to infanimations, scalds, burns, and troublesome erup: tions on the skit.

\section{DFadly Nightstade. Solanum lethale.}

Ir may seem strange to mix a poison among medicines, but a part of this herb has its uses. This is a wild plant of a dulf and dismal aspert. It srows five feet high. The stalks ate angulated, and of a reep green. 'The leaves are very' large. troad, and fat, and they aky are of a clull dead rever. The flowers stand singly on long forttalks, niving from the bosen of the leaves, and 
they also have the same dismal aspert; they are large, hollow, and hang down. On the cutside they are of a dusky colour, between brown aind green, and within they are of a very deep purple. These are succeded by berries of the bigness of cherries, black and shining when ripe, and ful! of a pulpy matter, of a swcetish and nawkish taste. The root is lone. The berries are tatal ; chidem have often cat them, and perished by it. Whe laves externally applieu are cooling and stftening ; ther are good agamst the ringwom and tetters, and against hard swellinss. 'lhey heve very great virtue is this respect, but the plant should be linpt out of the way of children, or never suffered to grow to fruit, as the leaves only are wanted.

\section{Nutregr Trae. Nure nioschete.}

A ThLL, spreading iree, native only of the warm climates ; the trunk is large, and the branches are numerous and irregular; the bark is of a grevish colour, and the wood light and soft. The leaves are large, long, and somicuhat broad: they are not unlike those of the bay tree, but bigger, and are of a beantiful green on the npper side, and whitish mnderneath. They stand irregnlarly, but often so nearly opposite, that they scem in pairs, as we sce in the leaves of sonse of our willows. The blossom is of the shape and bigness of that of our cherry tree, but its colour is vellow. The fruit which snccecos this, is of the himness of a sma!l peach, and not unlike it in thr feneral form ; when cut open there appears firt the the hiy onat, which is a finger thick, and of a sumin tate. when the mace spread ower a wooly siell, in which io the nutmeg. We often have the utinte frest sent aver preserved 
The nutmer; is an excellent spice, it strengthens the stomach, and assists digestion. It will stop vomitings, and is good against the colic. When roasted before the fire, and mized with a small quantity of rhubar, it is the best of all remedies against purgings.

\section{D.}

OAK. Quercus.

$\Lambda$ NOFEE and statcly tree, native of our coun. try, and no where growing to so great perfection. it is very tall, and though irregular in the disposition of its branches, that very incegularity has its beanty; the trunk is very thick; the branches are also thick, and often civoked : the bark is brown and rough: the leaves are large, oblong, broad, and deeply cut in at the eilges, and thay are of a shining gecen. The flowers art: incousided able. The fruit is the arom, well known. Galis are proluced upon the oak, sut as fruit, but from the wounds made by an insect.

Ilic bark of the oak is a very porrerful astrinrest; it stops purgings, and overflowings of the menses, riven in prwiler; a decoction of it is excellent for the falling lown of the uvula, or as it is called the falling down of the palate of the mouth. Whenever a very powerful astringent is required, oak bark demands the preference over every thing: if it were brought from the East Indies, it would be leld inestimable.

\section{Scarlet OAK. Ilex.}

$\Lambda$ smici not much regarded on its own account, lout from the insect called kermes, which 
is found upon it; and las at sometimes been supposed a fruit of it: the shrub thence obtained its name of the scarlet oak. It grows only six or eight feet high. The branches are tough, and covered with a smootl greyish bark. The leaves are an inch long, three quarters of an inch broad, of a figure approacling to oval, serrated about the erlges, and a little prickly. The flowers are small and inconsiderable; the fruit is an acorn, like that of the common oak, but smaller, standing in its cup. The kermes, or scarlet grain, is a small round substance of the bigness of a pea, of a fine red colour within, and of a purplish blue without, covered with a fine hoary dust, like a bloom upon a plum. It is an insert at that time full of young. When they intend to preserve it in its own form, they find ways of destroying the principle of life within, else the young come forth, and it is spoiled. When they express the juice, they bruise the whole grains, and squeeze it through a hair cloth; they then add an equal weight of fine sugar to it, and send it over to us under the name of juice of kermes ; this is used in medicine much more than the grain itself.

It is a cordial, good against faintings, and to drive out the small pox; and for women in childbed. It supports the spirits, and at the same time promotes the necessary discharges.

\section{Oak of Jerusarm. Botrys.}

A uITTE piant, native of the warmer countries, and lieve in oill gardens, with leaves which have been sippoed to resemble those of the ark rece, wherese it wot its mom, and small yelowish flowers. 'The staitk is a front and hall ligh, roundish angulated a liture on deenly striated, and of a 
paic green; the leaves are of a yellowish green, and of a rough suriace; thicy are oblong, somewhat hroad pointed at the ends, and reeply cut in on the sides. The flowers stand in abundance of long spikes on the tops of the hranches; they are very small and inconsiderable. The whole plant has a pleasant smell, particulariy the young shonts, which are to bear the flowers.

The fresh plant is to be used, and it is best taken in the manner of tea, or in infusion. It is good in asthmas, harseness, and coughs, and it promotes the inenses and lischarges after delivery.

\section{Olive 'Tres. Olea.}

A r.spos: tree, native of the warmer parts of Europe and the East. The trunk is thick and rough. The branches are numerous, and stand irregularly; their hark is grey and smooth. The leaves are longish and broad, and of a deep green on the upper side, and whitish underneath, and of a firm texture; the flowers are small and yollow; the fruit is of the bigness of a small plum, but of longer shape, and has a irey large stone within.

1 The ril is the only produce of this tree used in medicine, it is pressed out of the fruit, and is excellent in disorders of the lungs, and against colies, and stopparges of urine. But in the latter cases the oil of sweet almonds fresh pressed is preferable, and for the first linseed oil ; so that oil of olives, or as it called sallad oil is scldom used in medicine, unless these others cannot be had.

\section{Orion. Cegla.}

1 roxuov plant in our gartans. known at

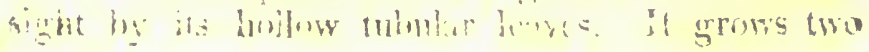


feet and a half high. The leaves are long, roundex, of the thickness of a man's finger, and hollow. 'T'he stalk is round also, and has at the top a round cluster of little flowers, these are of a mixed purplish and greenish colour; and of a strong smell, as has the whole plant.

The rnot is the part used ; it is rotindish, and com. posed of a great multitude of coats laid one orer another. A syrup made of the juice of onions and honey, is excellent for an asthma.

\section{- Opoponax Plant. Opoponax.}

A LARGE and robust plant, of which we have but imperfect descriptions: it is a native of the East, and has not been brought into Europe. It is said to be eleven or twelve feet light : the stalk is round, thick, and hollow. The leaves very large, and each composed of a vast number of smaller set npon a divided stalk. The flowers we are informed stand in very large round clusters at the tops of the stalks, and that the seeds are broad, brown, and of a strongry smell; striated on the surface and flattish. The root is said to be long and large, and full of an acrid and milky juice.

We vae a kind of resin, whirh is and to be collected from this root, after it has been wounded to make it flow in sufficient quantity; but the whole account comes to us very imperfect, and inon no very sound authority; however it seems probable.

The resin is brownish or yellowish, and in small pieces. It is an excellent medicine against nerr. ous complaints; and particularly against disorders of the head. It works by urine and promotes the menses; and has a tendency to operate, though very gently, by stool. It is not so much used as a $k$ 
it descres to be. I have experienced excellent ef." fects from it.

\section{Orange Tree. Auranía ma'us.}

A Benriffu and valuable tree, native of Spain, Italy, and the Wast. It grows to a considerable hignews and its branclies spread irregularly. The bark of the trunk is hrown and rough, that of the bromess is smooth and grey ish. The leaves are knse, and very beantiful; they are oblong, aud

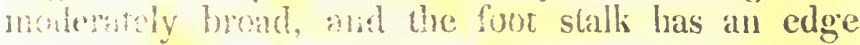
of a leafy maticr on cach side, sining it a heartlike aplearance. 'ille flowers are white, large, frasernt, and very beatiful. The truit is enough hiown.

The sour, or Scrille orange, is the kind used in medicine, but the peel of this more than the juice or mipy part. A ploamint surup is made of seville monge juice, by moling; in thire its weight of the finest sugal : and a syup equally pleasant, viough of another hind, is nade of an infusion of the peel: but the great use of the peel is in tincture, or infusion as a stomachic. It is for this purpuse to be pared off rery thin, only the yellow part beivg usefil, and to be put into brandy or wine, or to have boiling water poured on it fresh or dry. If a litle gentian and a fer cardamon seeds be added to this tincture or inlinsion, it is as good a bitte: as cam be made: it prevents sickiness of the stomach and romitings, and is excellent to anend the splectite.

\section{Ormse. Telephizit.}

A rins beautiful wild plant, of a font bigh or more, with fresh green leaves, and tufts of 


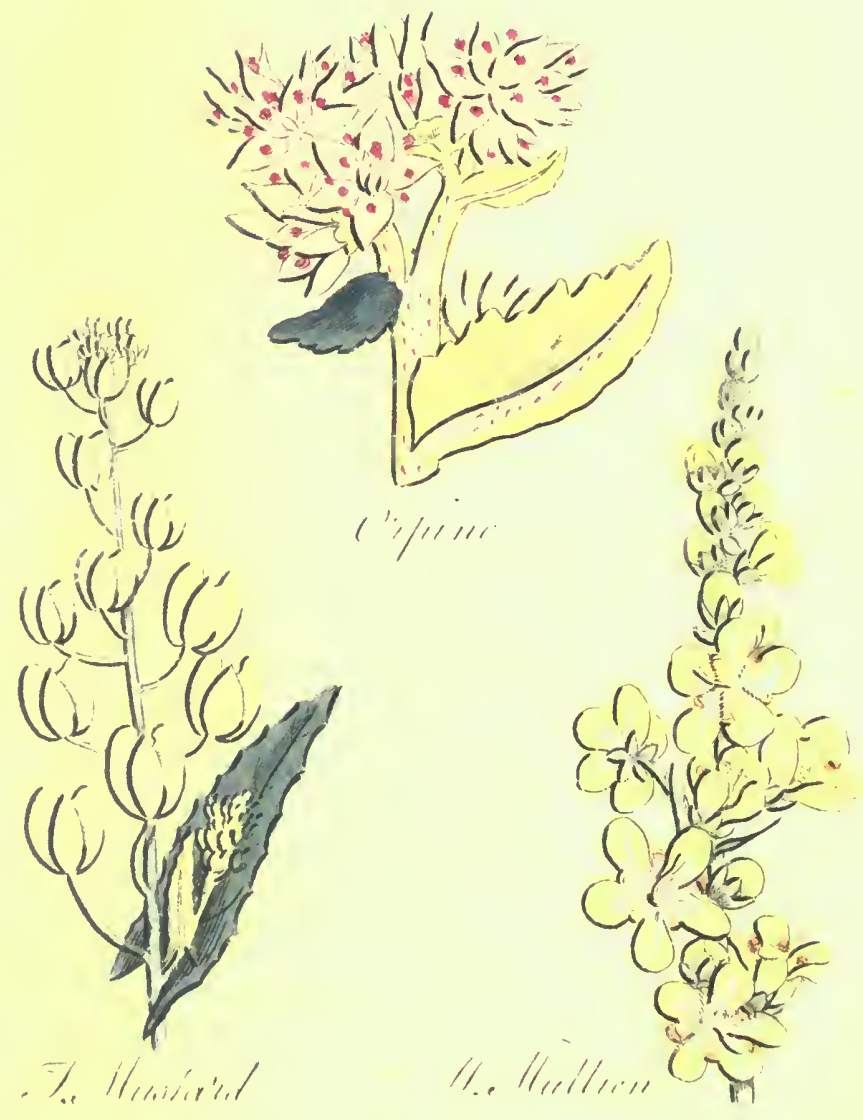






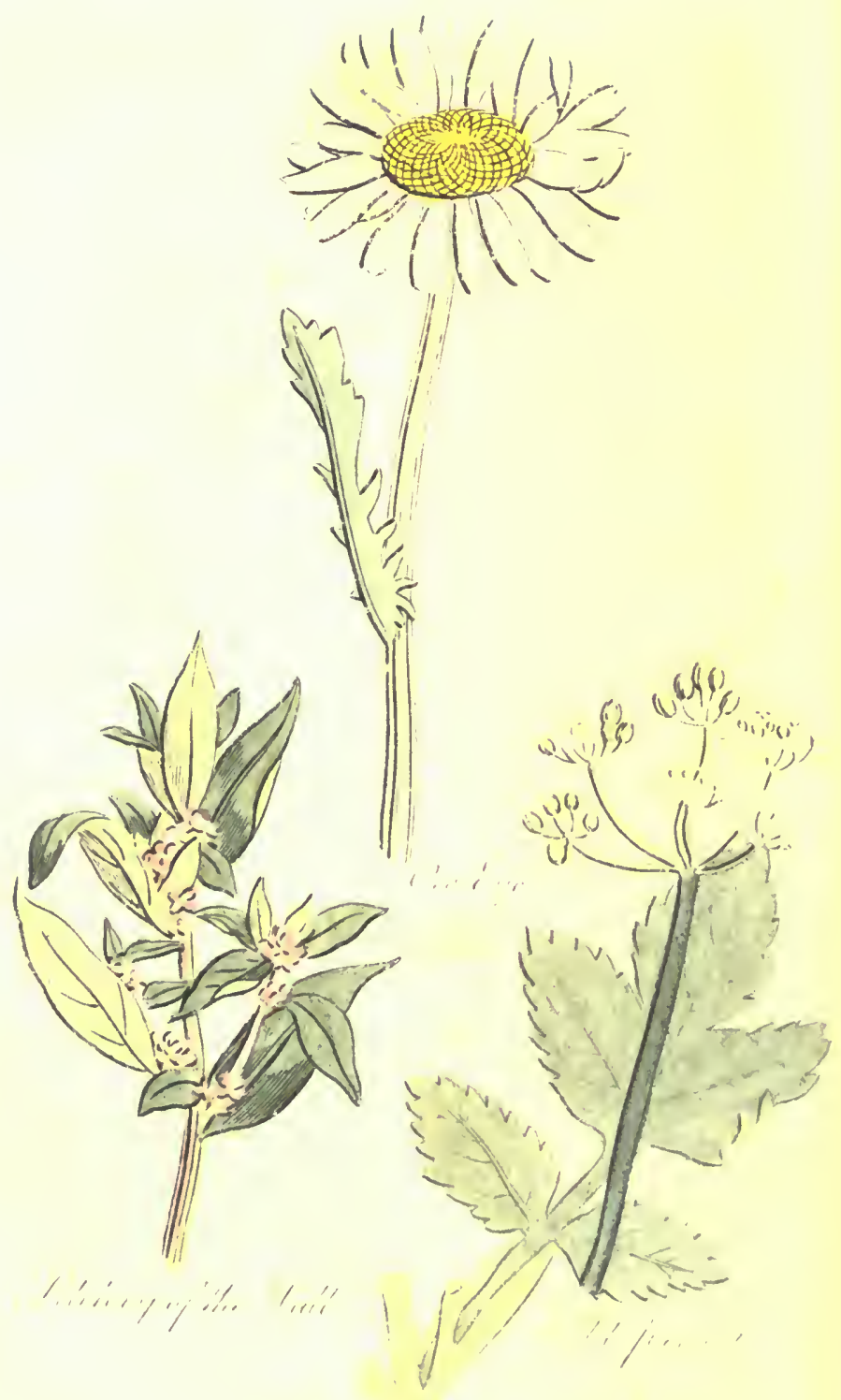


bright red flowers; common in cur ledges in autumn in many parts of Eughnd. The stalk is zound and fleshy; the leaves are oblong, brond, and indented round the edges, and their colour is a bluish green. The flowers are small, but they are very beantiful; the root is witise rnd thick. The whole plant has a fleshy appearandes and it will grow out of the ground, a long the taling its nourishment from the air.

'The juice of oipine is good against the bioody flux : the best way of giving it is male into a thin syrup, with the finest sugar, and with the adrition of some cinnamon.

\section{Oxere. Buphthalmum.}

A very beautiful wild plant, common in the North of England, but not in other parts of the kingdom. It grows a foot and a half high. The stalk is round, firm, and branched; the leaves are numerous; they are divirled each into a multitude of fine segments, so that at a distance they somers hat resemble the leaves of yarrow, but they are whitish. The flowers are large and yellow; they somewhat resemble a marigold in form, aud they stand at the tops of the bramines.

The fresh herb is rack ; they boil it in ale, and give it as a remedy for the jamalice : it wots by urine.

\section{$\mathrm{P}$

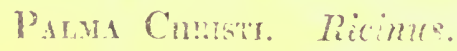

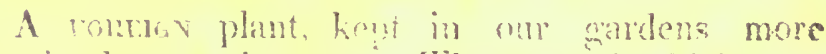
for is beanty than now. The stem is thick, and looks roudy toward the botom. It wrows sid 
feet high, and on the upper part is covered wilh a sort of inealy powder, of a bluish colour. 'The Jeaves are large, and very beautiful. They are somewhat like those of the vine, but they are divided decply into seven or more parts, which are also sharply serrated at the edges, and they stand upon long foot stalks, which are not inserted at the edge, but in the middle of the leaf. The Howers are small: they grow in bunches toward the top of the plant. The secols grow upon the trunk of the plaut in different places: three are contained in husks, and they have over them severally a hard shell.

'The kernels of these seeds are the part used, but they are very little regarded at present. There nsed to be three or four linds of them kept by the drugerists, under different names, hut nobody now minds them: they are very violent in their uperasion, which is both upwards and downwards, and hare been given in dropies and rheumatisms.

\section{Oily Paly Thied. Palma oleosa.}

A Very beantiful tree, natwe of Africa and America. It grows moleratcly high. The trunk is naked all the way to the top, where the leaves grow in vast quntities: they are long and narrow, and the fortstalks on which they stand are prickly. The flowers are small and mossy. The linit is of the bigress of a plumb, oblong, and flattish, and is corered orer with a tough and fibrous coat. From this fruit the natives express what they all palm oil: it is a substance of the consistence of hutter, and of a pleasant, though very little taste.

'The wil is the only produce of the tree nsed: 'Ihey eat it upon the spot, but ve apply it exter- 
nally against cramps, strains, pains in the limbs, and weaknesses : but we seldom meet with it fresh enough, to be fit for use ; and at present, it has given place to the famous opodeldoc, and to several other things, which have the same qualities in a much greater degree.

\section{Pavic. Panicum.}

A VERY singular and pretty plant of the grass kind, cultivated in some parts of Europe. 'The stalk is rery thick and firm, round, jointed, and a yard high. The leaves are grassy, but they are large and broad. The flowers and seeds are conlained in a long ear, which is broad and flat; it is composed of several smaller ears, arranged on the two sides of the stalk; these spikes are hairy. The seed is round, and is much like nillet, only smaller.

The seed is the only part used. It is good against sharp purgings, bloody fuxes, and spitting ol blood.

\section{Phemen Brave. Parcirabrava.}

A cummer slmub of South America, the root of which has lately been introduced into medicine It grows to twelve or fourtecn feet in height, if there be trees or bushes to support it, else it lies upon the ground, and is shorter. The stalks are woody, light, and covered with a rough bark, which is continually coming off in small flakes. 'The leaves are large and broal. The flowers are small, and of a greenish colour ; and the berries are round, and when ripe, blitel. The root is large, woody, and very long and creeping. 
The root is used. It is of a brownish columr, rough on the surface, and woody, but loose in its texture. It is to be given in infusion. It is an excellent medicine in the gravel, and in suppressions of urine, as also in the quinzy, and in pleurisies, and peripneumonics. It works the most powerfully, and the most suddenly, by urine of any medicine : and is so excellent in forcing away gravel and small stones, that some have pretended it a remedy for the stone, and said it would dissolve and break it. This is groing too far; no medicine has been found that has that effect, nor can it be supposed that any can. Great good has been done by those medicines which the parhiament purchased of Mrs. Stephers, more than perhaps, by aliy other whatsocver, in this terrible complaint ; but they never dissolved a lawe and hard stone. Indeed there necds no more to be assured of this, than to examine one of those stones; it will not be suprosed, any thing that the bladder can beal, will be able to discolve so firm and solid a substance.

\section{Parsiy. Petroselinum.}

A rens common plant in our gardens, uscful in the kitclen, and in medicine. It grows to two fect in height. The leaves are composed of miny small parts: they are divided into tnree, and then into a multitude of sub-divisions : they are of a bright green, and indented. The stalks are round, angurlated, or deeply striated, slender, upright, and branched. 'The flowers are small and white; and they stand in larese tuft at the tops of the branches. The serens are rombish and striated. The root is lomen and white.

The route atre the nert used in medicino A 
strong decoction of them is good against the jaundice. It operates powerfailly by urine, and opens ob. structions.

\section{Parsir Piert. Percicier.}

A irTrte wild plant, common among our corn, and in other dry places, with small pale leares, and hairy drooping stalks. It loes not grow to more than three or four inches in length, and seldom stands well upright. The stalks are round and whitish. The leaves stand insegularly : they are narrow at the base, and broad at the end, where they are dificled into three romded parts. The flowers are very small : they grow in clusters at the joints, and are of a precnibh colcur. The seed is smail and rount. The root is fibrous.

The whole plant is uscd; and it is best fresh. An infusion of it is rers berichert against the sravel. It operates volentls, but sately, by urine, and it opens cbetrations of the liver" whence it is good also in the janumice. There is an opinion in many places, $c$ it hering a power of dissolv. ing the stone in the buther ins idle: there is, however, a frest den aroud to be done in nephritic cases, $6 y$ medetus inch have not this power.

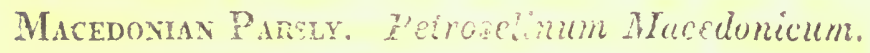

A plant kept in eme of orir gardens. It is two feet high The widk is -lender, bunched, and hairy. The leaven are composed of many parts, and those are small and rounded: those on the upper part of the stalk are more fincly divided. The flowers are small and white, like those of common parsly; and they stand like them, in clusters 
on the tops of the stalks. The seeds are small, somes what hairy, and of a clusky colour.

The seed is used; and it is besi given in powder. It operates powerfully by urine, and it is good against stoppages of the menses, and in the gravel and colics, arising from that cause. It is also recommended against the dropsy and jaundice.

Wind Parsnep. Pastinaca syliestris.

A wild plant, common about our road sides. It is three feet high. The stalk is straight, upright, round, striated, and yellowish. The leaves are composed of many broad divisions, and resenble those of the garden parsnep, but they are smaller. The flowers are little and yellow : they grow at the tops of the stalks, in large, romded tutts, and the secds are flat, and of an oval figure. 'The root is long, white, and well tasted.

The root is to be used. A strong decoction of it works by urine, and opens all obstructions. It is grood against the gravel and the jaundice, and will bring dewn the menses.

\section{Piring Sinter. Paíana}

A sunmer plant of the East Indies, of a beatiful, as rell as singular aspect. It is six or seven feet ligh. The stem is woody, firm, and nalied almost to the top. The leaves grow upon long foot stalls, and they all rise nearly together, at the upper part of the stem : they are larga, of a romadiel finwe and divided at the edges pretty derply into several parts: their colour is a decep stren. The flowers are small, and of a greenish collour. 'The frut is of the bignese of a harks 
nut. The wood is not very firm, and when cut, yields a wilks juice, of a very disagrecabie sizell.

The wond and the serds are tased; and they have be thinc same violent operation by vomit and stool; but the wood given in infusion, and in a moderute lose, rnly purges, and that, though briskIy, without any lianger. It is crood in dropsies, and in other stubboru disurders: and it is excellent aga. rheumalic paiss. Sume recommend it as a specific against the sciatica. The sceds are what are called grana tiglia; but though much spukn of by some uriters, they are at this time very little used in the shops.

\section{The Prich Tree, Persica malus.}

A TREE ver frequent against our garden walls. The truk is civered with a brown oark. The branches grow irregularly. The leaves are beatiful : they are long, narrow, and elemantly serrated at the edges. The blossoms are large, and of a pale red. The fruit is too well known to need much description: it consists of a snft pulpy matter, covered by a hairy skin, and inclosing a lard stone, in which is a kernel of a pleasant bitter taste.

The flowers are to be used. A pint of water is to he poured boiling hot on a pound weight of peach blossoms; when it has stood four and twenty hours, it is to be poured off, through a sieve, withont squeezing, and two pounds of loaf sucrar is to be dissolved in it, over the fire: this mates an excellent syrup for children. It purges gently, and sometimes will make them puise a litile. They have so frequent occasion for this, that people who have children, have continual uae for it.

$$
\text { a! }
$$




\section{Pellitory of the Wall. Paricturia.}

A WILD plant frequent on old walls, with weat branches, and pale gretn leaves. It grows a fou high, but seldom altogether erect. The stalks are round, tender, a little hairy, jointed, and oftei, purplish. The leaves stand irregularly on them and are an inch long, broad in the middle, ant smaller at cach end. The flowers stand close upon the stalks, and are small and inconsiderable, of a whitish green colour when open, but reddish in the bun.

The whole plant is used, and it is best frosh. An infusion of it works well by urine. It is very serviccable in the jaundice, and is often found a present remedy in fits of the gravel, the infusion being taken largely.

\section{Pellitory of Spare. Pyrethrum.}

A VERY pretty little plant kept in our gardens It is cight inches high. The stalk is round and thick. 'The leaves are very finely divided, so that they resemble those of the camomile, but they are of a pale green, thick, and fleshy, and the stalk is purple. The flowers stand at the tops of the branches, and are vers pretty : they are of the shape and size of the great daisy or ox-ere, white at the vlges, yellow in the middle, and red on the back or underside. The root is long, and somew hat thick, of a very hot taste.

Tlye root is used: we have it at the druggists. Its great acridness fills the mouth with rheum on shewing, and it is good agranst the tooth-ach. It is also groud to he put into the mouth in palsies, for it will sonetimes alone, by ity atimulation, restor itic uice, 


\section{FAPITY IBEMBAE。 \\ Penimy-Royal. Pultgiltho}

A WILD plant, creeping about on marshy places, with little leaves, and tufts of red fonwers at the juints. The stallis are a foot long, round, and often of a reddish colour. The leaves are suall, broar', and pointed at the ends, and of a rale green colonr. The flowers stand round the joints in thick clusters: they are like those of mint, and of a pale red, and the cups in which they stand are green, and a little hairy. The whole plant has a strong penetrating smell, and an acrid but not disagreeable taste.

The whole plant is used, fresh or dried; but that whicin grows wild, is much stronger than the larere kind, which is cultivated in gardens. 'The eimple water is the best way of takilig it, though it will do very well in infusion, or by way of tea. It is excellent against stoppages of the menses.

\section{Blách Pepper. Piper nigrum.}

AN eastern plant, of a very singular lind. It grows six or eight feet in length, but the stalks are not able to support themselves upright : they are round, green, jointed, and thick, and when they trail upon the gromul, roots are sent forth from these inints. The leaves are large, of an oval figure, it a firm substance, and ribbed highly: they stand an short pedicles, one at each joint. The flowers ares small and inconsiderable: they grow to the atalk. The fruit sucreeds, which is what we call p pper: they hang upon a long stalk, wenty or urty together: they are green at first, hut when line they are red: ther erow black and wrinkled 1:1 drying. The farcest and least wribled on the ana, arg the beat graine. 
The fruit is used, and it is excellent against all coldnesses and crudities upon the stomich. It gives appetite in these cases, and assiots digestion. It is also good against dizzinesses of the heat, and aggainst obstructions of the liver aur spleen, and against colics. We are apt to negrect things as medicines, that we take will food; tut there is hardly a more powerful sinple of its kind than pepper, when given singly, aid on an empty stomach.

\section{White Pepper. Piper Album.}

THE common white pepper we meet with, is made from the black, by soking it in sea water till it swells, and the dark wainkled coat falls off; but this though the common, is not the true white pepper : there is anotler kind, which is natural, and las no assistance from art. The white pepper n! !ant, las round, thick, and whitish stalks: they lie upon the ground, and have large joints: at each joint stands a single leaf, which is Iong, and narrow, sharp at the end, and ribbed. The flowers grow on little stalks, banging down from the joints: they are small and rellow. The fruit is round; at first green, and when ripe white, which is gathered and dried for use.

This fruit is used. The common white pepper is milder than the black; that is, it is black pepper, which has lost a part of its virtue : this possesses all the qualities of the other, and yet it has not so sharp a taste.

\section{The Long Pepper Plant. Piper lonsum.}

AN American plant, in some degree resembling the other peppers in its general growth, but not 


\section{FAMILT IIERBAL.}

at all in its fruit. The stalk is round, thick, jointch, and of a reey green colour : it is not able to support itselt, but l limbs upon bushes. The leäts are low and narow : they stand one at each joint, lipen hong firt stalls. The lowers grow upontie entive : the frut: they are small and inconsiduble. The fruit, which is what we call long pepper, is an int and a half long, and as thick as a large quill, marlict with spiral tines, and dirioed ince celts within, in each of which is a single sied.

This lias the same virtues with the commnn black peprorer, lint in a less degree ; it is not so hot and acrid, and therefore will be borne upon the stomach wher that cannot. It is excellent to assist digention, andi prevent colics.

The Jamaica Pepper Tree. Piper Jamaicense.

$A N$ American tree, in all respects different from the plants which produce the other kinds of pepper, as is also the fruit altogether different. It shomid wat be called pepper: the round shape of it was the only thing that'led people to give it such a wame. The Jamaica pepper tree is large and beatiful. The trunk is covered with a smooth brown bark. The branches are numerous; and they are well covered with leaves. The tree is as big and high as our pear trees. Thie leaves are chlong and broad, of a shining green colour: they grow in pairs, and they stand on long pedicles. 'The fiowers grow only at the extremities of the branches: they stand a great many together, and are snall. The fruit which succedis is a berry, yrer'n at first, and afterwards becoming of a red. Hicl, brown, and in the cnd, black. They are, waen rige, full of a pulpy matter, surroundisig 
the seeds; but they are dried when unripe for our use.

The fruit, thus gathered and dried in the sun, is what we call Jamaica pepper, piamenta, or allspice. It is an excellent spice : it strengthens the stomach, and is good against the colic. The best way to take it is in powder, mixed with a little sugar. It will prevent vomiting, and sickness after meals, and is one of the best known remedies for habitual colics.

\section{Guinen Pepper. Capsicum.}

A COMMON plant in our gardens, distinguished by its large scarlet pods. It grows a foot and a half high. The stalk is angulated, thick, and green, tolerably erect, and branched. The leaves stand irregularly, and are longish, pretty broad, and of a deep green colour. The flowers are moderately large ano white, with a yellow head in the middle: they grow at the divisions of the branches. The fruit follows, and is an inch and a half long, an inch thick, and biggest at the base, whence it grows smaller to the point : the colour is a fine red, and its surface is 80 smooth, that it looks like polished coral: it is a skin contaiuing a quantity of sceds.

The fruit is the part used. Held in the mouth it cures the tooth-ach ; for its heat and acrimony are greater than in pellitory of Spain, and it fills the inouth with water. Applied extcrually, bruised and mixed with honey and crumbled bread it is good fur a quinsy.

Peniwinke. Tinca pervinca.

A VERY pretty cresping plant, wild in some 
places, but kept in gardens also. The stalks are numeruus, and a foot or more in length, but they do bot stand upright: they are round, green, and tough, and generally trail upon the ground. The leaves are oblong, broad of a shining green colour, smooth on the surface and placed two at each joint. The flowers are large and blue: they are bell-fashioned, and stand on long foot stalks: the fruit succeeding. Each is composed of two longish pods; each containing several seeds.

The whole plant is used fresh. It is to be boiled in water, and the decoction drank with a little red wine in it. It stops the overflowing of the menses, and the bleeding of the piles.

\section{Spelt, or St. Peter's Corn. Zen.}

A PLANT of the corn kind, resembling barley; sown in some parts of Europe, but not wulnh known in England. It grows a foot and a lials high. The stalk is round, hollow, jointed, and green; the leaves are grassy, but broad. At the tops of the stalk stands an ear like that of barley, but smaller and thinner, though with long beards; the grain is not unlike barley in shape, or between that and wheat, only much smaller than either.

The seed or grain is the part used; it is supposed to be strengthening and in some degree astringent, but we know very little of its qualities, nor are they considerable enough to encourage us to inquire after them.

\section{Pimperiel. Aingallis flore rubro.}

A PRETTY little plant common in corn fields and garden borders. The stalks are square, smooth, sreen, but unt very upright: they are five or sin 
inches longr. The leaves stand two at each joint, and they are of an oblong figure, considerably broad in the middle, and pointer at the end. The flowers stand singly on long slender foot-stalks; they are small, but of a most bright scarlet colour.

The whole plant is used, and the bost method of giving it, is in an iufusion, mate by pouring boiling water upon it fresh gathered: this is an cxcellent drink in fevers; it promotes s.weict, and thiows out the small pox, measles, or any oflur eruptions: the dried leaves may be given in powder or a tea made of the whole dried plant, but nothing is so well as the infusion of it fresh, those "hw have not seen it tried this way do not know how valuable a medicine it is.

There is another lind of pimpernel, perfectly like this, but that the flowers are blue; this is called the female, and the other the male pimpernel, but the red flowered hind has most virtue.

\section{'The Pine Tree. Pinus.}

A LARGE and beautiful tree, native of Italy, but kept in our gardens. We have a wild kind of pine in the North, called Scotch fir, but it is not the same tree. 'The trunk of the true pine is covered with a rough brown bark, the hranches with a sinnother, and inore reddish. The leaves are long and slender, and they grow always two from the same base, or out of the same sheath, they are of a bluish green colour, and are a little hollowed on the inside: the flowers are smull and inconsiderable; they stand in a kind of tufts on the branclics: the fruit are cones of a brown colour, large, longe. and hlunt at the top). These contain between the scalcs certain white keruels of a swect taste, aud covered with a thin shell,

'Whesc kernels are tno part used, and they are cx- 
relle it in conaumptions, an! after long illuess, given by way of misorative. An emulsion may be inade by batigg then up with harley water, and this will leot the saise service with common emulsions for hesit of urive.

\section{The Wild PINe Tree. Pinus syluestris.}

A TREE mative of many parts of Germany, very much resembling what is called the manured pinc, or simply the pine before described. It grows to be a laree and tall tree; the truik is covered with a rough brown bark, that of the branches is paler and smother. The leaves are very narrow, and short; they grow two out of a case or hisk, as in the other, and are of a biuish green colour. They diller principally in being shorter. The nowers are yellowish, and like the other very smalt and inconsiderable, the cones are small, brown, and hatd, and sharp at the tops, they contain kervels in their shells, among the scales as the other; but they are smaller.

The kermels have the same rirtucs as those of the other pines, but being little, they are not regarded. 'The resin which fows from this tree, either naturaily, or when it is cut for that purpose, is whet we soll commonturpentine. It is a thick substance, like honey, of a brownish colowr, and siry strong and disagrceable smell.

When this turpentine has been distilled to make oil of turpentine, the resin which remains, is what we call common resin; if they put ont the fire in lime, it is rellow resin; if they continue it, foneer, it is black re:in. They often beil the tur-peritic in water withont distilling it for the commor iesin; and when they take it out helf boiled for this proppose: it is what we call Burgund.

$$
\text { it is }
$$


pitel. And the whitish resin which is called thus; or frankincense, and is a thing quite different from olibanum, or the fine incense, is the natural resin llowing from the branches of this tree, and hardening into drops upon them. It does not differ much from the common turpentime in its nature, but is less offensive in smell.

The several kinds of pitch, tar, and resin, are principally used in plaisters and ointments. The turpentine produced from this tree also, and called common turpentine, is principally used in the same manner, the finer turpentines being given inwardly. 'These are procured from the turpentine tree, the larch tree, and the silver fir. The yellow resin and the black are sometimes taken inwardly in pills, and they are very good against the whites, and the runnings after gonorrhaas : but for this purpuse it is better to boil some better sort of turgentue to the consistence and give it,

\section{Prony. Pronia.}

A FIOYER common in our gartens, but of wate lise as well as ornament. The eommon dunte piony is not the kind used in medicine; flis is called fur temale piony; the single flowered one called the male piony, is the right kind. This rows two or the feet high. 'The stalk is round, striated. and branclicd : the leaves are of a decp ateil, and eacis composed of several others: the llewere are very large, and of a deep purple, with a grembad in the middle. When they are limavel, this head swells ont into two or more $\therefore$ ref ressele, which are whitish and hairy on the mfsid:, and roit whin, and full of black serds. ilu row is compliund of a number of lomgish or

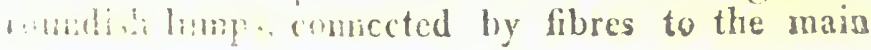


sotarce of the stalk; these are brown on the outside. and whitish within.

The roots are used; an infusion of them promotes the menses. The powder of them dried is rood against hysteric and nervous complaints. It is particularly recommended against the falling sickness.

\section{The Pistachin Tree. Pistuchil.}

A TPEE common in the East. The trunk is covered with a brown rough bark, the branches grow irregularly, and their bark is reddish. The leaves are cach composed of several pairs of small ones; these are oblong, broad, and of a beautiful green colour, and firm texture. The flowers grow in tufts; they are white and snall ; the fruit which sncceeds is what we call the pistuchia 11 at ; it is as big as a filbert but long and sharp-nointed, and it is covered with a tomgh wrikled bark. The shell within this is woody and tough, but it easily enough divides into two parts, and the hernel within is of a greenish colour, but corered with a red skin. It is of a sweet taste.

The fruit is eaten, but it may be considered as a medicine; it opens obstructions of the liver, and it works by urine. It is an excellent restorative to be giren to people wasted by consumptions. or other long and tedious illnesses.

\section{Pitch Tree. Picea.}

A TREE of the fir kind, and commonly called the red fir. It is a tall tree of regular growth; the bark of the trunk is of a reddish brown, and it is paler on the branches; the leaves are very nunerous, short, narrow, and of a strong grem : 
they stand very thick, and are sharp, or almost prickly at the cxtrenities. The flowers are velJowish and inconsiderable; and the fruit is a long and large cone, whish liangs down; whereas that of the true fir tree, or the yew-leaved fir, stanls upright.

The tops of the branches and yourg shoots are ured: they abound with a resin of the turpentine kind. They are best given in decoction, or brewed with beer. They are good against the rheumatism and scurvy; they work by urine, and heal ulcers of the urinary parts.

Pitch and tar are produced from the wood of this tree, the tar sweats out of the wood in burning, and the pitch is only tar boiled to that consistance. To obain the tar, they pile up great haps of the woud, and net fire to them at top, and the tar sweats ont of the ends of the lower, and is catched as it runs from them.

Burgunty pitch is made of the resin of the wild pine tree, wheh is common turpentine boiled in vater to a certain consistence, if they boil it longer, it would be resin, for the common resin is only this surpentine boiled to a hardness.

\section{The Angracum Plaxt. Ammoniacum.}

A TALS plant, native of the East, and very im perfectly described to us. What we hear of it is, that at grows on the side's of hills, and is five or six feet him ; the stalk is hollow and striated, and painter with various enlours like that of orer hemloc. The flowers, we are told, are small and white, and stand in great round clusters at the tops of the stalk, the leaves are very larere and componed of a maltitude of small divisions : onc circumstance wc can adl from our own 'snowledge to this description, 
and it gives sat proof of the authenticity of the rest; this is, that the sects are broad, flat, striated. and have a folienous rim, as those of dili. We conld know by tive witich are found very frequently anmus the mum, that it was a plant of this kind which proxisced it: so that there is great probability that the est of the description, which has been eren us by tho who did not know rie had this confination: at lome, is true. Thuse seeds often sobewrerr fair and sound. I bave causcd a great mumb of them to be sown, but they have never grown. Though one of the sagapenum seeds grew up a litlle when snwil among them: it would he worth while to repeat the experiment, for some times it mights succed.

We use a rum or rather gurn resin, for it is of a mixed nature betwen both, which is precuied from thisplant, but from what part of it, or in what mumer we arenot informed; it is whitish, of an acrid taste, with some biterness, and is an excollent medicine. It is superior to all other drugs iil an asthma, and is grood to promote the menses, and to open obstructions of ali kinds. The best way of griving it is dissolved in hyssop water. It makes a milky solution. It is used exteritally also in plaisters for hard swellings, and pains in the joints.

\section{Viriolo Leaved Plantaix. Plantagomajor.}

A COMMON plant by our way-sides, with biond short leaves, and long slemerter pikes of brown soedis. The leaves rise all from the root, for there arenone upon the stalk. They are of a somewhit oval ligure, and irregularly indented at the efere, sonctimes scarce at all. Thev have several larger rha, but these do not grow side-ways from 
the middle one, but all run length-ways, like that from the base of the leaf toward the point. The stalls grow a fnothigh, their lower half is naked, and their upner part thick set, first with small and inconsiderable flowers, of a greenish white colour, and afterwards with seeds which are brown and small.

This is one of those common plants, which have so much virtue, that nature scems to have made them commoa for universal benefit. The whule plant is to be used, and it is best fresh. A decoction of it in water is excellent against overflowings of the menses, violent purgings with bloody stools and vomiting of blood, the bleeding of the piles, and all other such disorders. The seeds beaten to a powder, are good against the whites.

rhere is a broad leaved plantain with short flowery spikes, and hairy leaves, this has full as much virive as the kind already described: the narrow loaved plantain las less, but of the same kind.

Plow Man's Sorenard. Paccharis monspelicnsium.

A TALL robuat wild plant with broad roug:" leaves, and numerous small rellowish flowe frequent by road-sides, and in dry pastures. 'T plant gions three fret high. The stalks are ron thick, night, and a little hairy. The leaves larese, broad from the root, and narrower on chalk; they are blunt at the prints, and a little (icutcl at the edges. The flowers grow on $t$. tojis of the branckes, sproading ont into a large fead from a single ntem : thry are little and yellow: the sects have down fixed th them. The root is brown and woody; the whole plant has a fragrant aral aromatic sme!l.

The leaps and tong gुiven in decoction, are gont 
achingt inward bledings. The root, dried and powdercd, is a remedy for purgings, and is good again:t the whites.

\section{Poleymountain. Polizm montanuri.}

A PRETTY plant, native of the warmer parts of Europe, and kept in our gardens. It is ten inches high. The stalks are square and whitish : the leaves are oblong and nurrow, of a white colour, and woolly surface; they stand two at a joint, and they are indented at the edges. The tlowers are small and whitc. They grow in a kind of woolly tufts at the tops of the branches.

'lle whole plant is used; it is best dried ; civen in infusion, it promotes the menses, and remeres obstructions of the liver, hence it is recomnended ereatly in the jamdice. It onerates by urine.

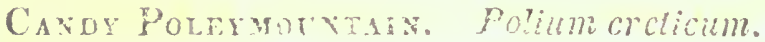

A LITTIE plant a woily spearance, native "the Grecian Islame, and hept in some gardens.

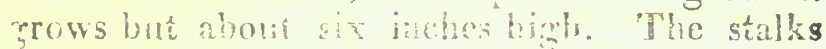
square, white, wesk, and selom upright. leaves stand two at each joint: they are naroblong, and not at all indented at the s. They are of a white woolly ancet, and of asant smenl The flowers are small and whice, they grow in turts at the tops of the stalks: or cun are very white.

The whole plant is to be uscl diried. It operates very powernil!y by mine, and is good against all hysteric complaints, but is is not to be given to women with child, tor it has so much sferacy in

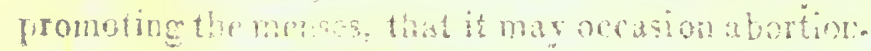




\section{PAHLE IISRBA. \\ Ponpory. Polmodizm.}

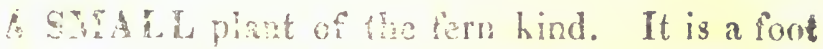

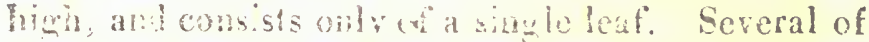
these commonly ane from the same root, but each is a separate and entire plant. The stalk is naked for ine inches, and from thence to the top stand on each side, a row of small, vilone, and narrow stogncuts, resembling so mary small le res, with an odd one at the end. The vilue plant is of a bricht green consen but the hacks of these divisions of the leat, aro at a certain scason, inyard autumn, ormanented whit a great number of romel brown spots, these are lio sceds: those of all lems are cillried in the sane maner. The root is long, situder, and creeps mon the surface of old stumpi of trees among the moss. The ront is used, and it is best fiesh; it is a sale and unentic purge; the west way of giving it is in decoction, in which form if always operates also by urine. It is good in the jaundice and dropsies, and is ancexcellent ingredicat in liet-drinks anganst the scury ; but heside tiese considerations, it is a sale and good purche, on all crumon occasions.

\section{The Ponegrinate 'Tree, Cirincilus.}

A COMMOON wild tree in Spain and Ita? kept with us in gardens. It grows to the bigne of our apple-treas. 'Tho hranches spread irrege larly; the have a red!ish hrown batk, and hat here and there a few thorms. The learea are be merous; on the extrenities of the branches the are small, oblonge, narrow, and of a fine erees The thwers atre large, and of a beatibldece red the froit is as bien as a larece apple, and has as brow wasty coscring ; it contains within a great qu 
tity of seeds, with a sweet and tart juice about them.

The rind of the fruit is used, it is to be dried and given in decoction; it is a powerful astringent : it stops purgings and bleedings of all kinds, and is good against the whites.

\section{Wild Ponegranate Tree. Balaustia.'}

A smaller tree than the former, but like it in its namner of growth; except that the branches are innre crooked and irregular, and are more thorny. The leaves are oblong, small, and of a bright green, and thay are set in clusters towards the end of the branes. The fowers are beautiful, they are dousie like a rose, and of a fine purple.

The flowers are the part of the wild pomegranate userl in medicine; our druggists keep tiren ariu ca!! them balaustines. They are given in powder or decoction to stop purgings, bioody stools, and orcrilowings of the menses. $A$ strong infusion of them cures ulcers in the moutli and throat, and is a good thing to wash the mouth for fastening the teeth.

\section{Ромркеи. Dеро.}

A very large and straggling plant, cultivated by our poor people. The stalks are very long and thick, hut they lie upon the ground; they are angulated and rough. The leaves are extrencely arge, and of a roundish figure, but cornered and angulated, and they are of a deep irreen colour, and rough to the touch. The flowers are very large, and yellow, of a bell-like shape, but angulated at the mouth, and the fruit is of the melon find, only bigger and round; of a decp green. 
when unripe, but yellow at last: in this, under the

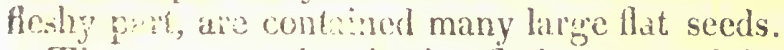

The pow people nix the fleshy part of the fruit with apples, and bake them in pies. The seeds are excelient in medicine; they are cooling and diuretic; the best way of taing them is in emulsions, mace with harley water. They make an emulsion as milky as clmovds, and are preferable to them,

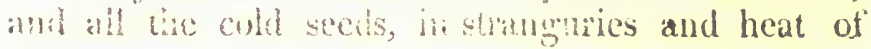
arme.

\section{Brack l'oplar. lopulus nigra.}

A tracr tree, frequent about waters, and of a wery beantitul anjert. The trumk is covered with a smooth pale but: the branches are mumerous, and grow wh a sort of rewhing. The leaves are short and hroaci, roundish at the base, hut ending in a point ; they are of a glosey shimiug wreen, and stand on long fort stalks. Hilie flowein and seeds are incmiderable; they appear in spring, and are little regarded.

'I'he young leaves of the black poytar are eacellent mixed in pultices, to be applied to hard painfu. sirelititgs.

\section{Whre Popry. Papaver album.}

A ralu and beantiful plant, liept in our gardens, a native of the warmer clinates. It grown a vard and half high: the stalk is roumd, smooth, mpright, and of a bluish preen ; the leaves are sery long, considerably broad, and dreply and irrerularly cut in at the rolges; they are also of a bush green colonr, and stand irregnarly on the stalk. The fuwers are very larere and white, one stands at the fon u! "arit division of the stalt: 
when they are fallen, thic sere-resecl, or poppy head. srows to the bigness of a large apple, and contains within it a very great quantity of swall whitish seeds, with several skinny divisions.

When any pait of the plont is brokm, there flows out a thick milky juce, of a strong, bitter, and hot taste, very like that of opimn, and full as disagreeable.

The heads are used with ns, and sometimes the sceds. Of the heats boiled in water, is mate the syrup of diacodium. The heats are to be dried for this parpose, and the decoction is to the made as strong as possible, anc then boiled ii w with sugar. The seels are beaten up into emilsions with barley water, and they are good agains stranguries, and hest of urine: they have nothing of the sleepy virtue of the syrups, nor of the other fats or preparations of the poppy. Syrmp of diacodinn, puts people to fleep, but genty, and is sater than opiun or lavdanum.

Opinm is nothing more than the miliy juice of this yhant concreted; it is obtained from the heads: they cut them while upon the plant in the warmer comintries, and the juice which flows ont of the wound, hardens and becones opium: they make. an inferior kind also, by bruizing and speezing the heads. Laudanum is a tinctuare of this opium made in wine. Either one or the ather is given to compose people to sleep, and to abate the sense of pain ; they are also cordial aud promote sweat; but they are to be given with great care and calltion, for they are very powerful, and therefore they may be vely dangerous medicines. It is grood to stop violent purgings and romiting, hos this must be effected by small cuses carciully given. The present practice depents mon opiun and bleeding for the cure of the hite of a mad dogi: 
but it is not easy to sily that any person ever was curcd, who became thoroughly distempered from that bite. One of the strongest instances we have known, was in a person at St. George's hospital, under the cure of Dr. Hoally, there was an appearance of the symptoms, and the cure was effected by this method.

\section{Black Poppy. Papazer nigrum.}

A TALL and fine plant, but not so clegant as the former. It is a yard high. The stalk is round, upright, firm, and smooth, and toward the top divides into some branches. The leaves are lons" and broad, of a bluish green colour, and deeply and irregularly cut in at the (tress. The flowers are large and singie: they are of a dead purple colour, with a black hotom. The heads or sced-ressels are romal, and of the bigners of a walint. The seed is black.

A syrup of the heads of thin noppy is a stronger sudorific than alle common diacótimm, but it is unt used. The genteness of that medicine is its merit: when something more powerful is used, it is better to have recourse to opium, or laudaumm.

\section{Red Porry, Paparer crraticum.}

A commos wild flant in our com fields, distinguished by its groat scarlet flowers. It is a foot highl. The stalk is round, slender, hairy, of a pale irreen, and branched. The leaves are longr arid narrow, of a dusky green, haity, and rery deeply, but very renularly indented. 'The flowers are rery large, and of an extremoly bright and fine scarlet colour, a litile hlackish toward the 
bottom. The head is small, not larger than a horse bean. and the seeds are small, and of a dark colour. The whole plant is full of a bitter yellowish juice, which runs out when it is any where broken, and has something of the sincll of opiun.

The llowers are used. $\Lambda$ syrup is made from then by pouring as much boiling water on them as will just wet them, and after a night's standing, straining it off and adding twice its weight of sugar: this is the famour syrup of red poppies. It gently promotes sleep). It is a much weaker medicine than the diacodiun. It is greatly recommended in pleurisies and fevers; but this upon no grood foundation. It is very wrong to depend upon such medicines: it prevents having recourse to better.

\section{Phnnose. Primula zcris.}

A rrny pletty, and very common spring plant The leaves are lono, considerably broad, of a pale green, and wrinkled on the surface : they grow immediately from the root in consicicable numbers. The stalks which support the flowers are single, stender, four or five inches high, a little hairy, and have no leaves on them: one flower stands at the top of each, and is larese, white, and beautiful, with a yellow spot in the nidcle. The root is fibrous and whitish.

The root is used. The juice of it snuffed up the nose occasions sneezing, and is a good remedy against the head-ach. The dried root powdered, has the sane effect, but not so powerfúlly.

\section{Priver. Ligustrum.}

A nTrie wild shrub in our hedges. It 
grows four feet high. The stalks ate slender, tough, and covered with a smooth hrown bark. The leaves are oblong and narrow: they are small, of a dusky green colour, broadest in the niddle, and placed in pairs opposite to one another, and they are of a somewhat firm substance, and have ne indenting at the edges. The flowers are white and little, but they stand in tufts at the ends of the brancliss, and by that make a good appcarance. 'The fruit is a black berry: one succecds to every flower in the cluster.

The tops are used; and they are best when the flowers are just beginning to burl. A strong infusion of them in water, with the adrition of a little honey and rerl wine, is excellent to wash the mouth and throat when there are little sores in them, and when the grums are apt to bleed.

\section{Punslaiv. Portulace}

A comor plant in our gardens, and of a very singular aspect: we lave few so succulent. It g!oins a font long, but trails on the ground. The statis are round, thick, ard fleshy, of a resldish colour, and very hrittle. The leaves are shot and broad. they are of a gand green, thick, fleshy, and broad, and blunt at the end. The flowers are little and ycllow: they stand among the leaves foward the tops of the stalks. The roat is small, fibrons, and whitish.

Purslain is a plcasant herh in sallads, and so wholesome, that 'tis a pity more of' it is not caten : it is cxcellent against the scurry: 'The juice fiesh pressed out with a little white winc, works by urine, and is excellent against stranguries and violent heats, and also against the seury. 
Q

\section{Qrince Tree. Cydonia.}

A common tree in our gardens, of irregular growth. The trunk is thick, and has a brown bark. The branches are numerous, straggling, and spreading. The leaves are roundish, of a dusky green on the upper side, and whitish underneath. The flowers or blussoms are large and beautiful, of a pale flesh colour. The fruit is of the shape of a pear, and has a large crown : it is yelow when ripe, and of a pleasent smell : its taste is austere, but agreeable. The seeds are soft and mucilaginous.

The fruit and seeds are used. The juice of the ripe quirce made into a syrup with sugar, is excellent to stop vomiting, and to strengthen the stomach. The seed, hoiled in water, gives it a softness, and mucilaginous quality; and it is an excellent medicine for sore mouths, and may be used to soften and moisten the mouth and throat ir. fevers.

\section{R}

Radish. Raphanus.

A common plant in our gardens, the root of which is caten abundantly in spring. In this state we only see a long and slender root, of a purple or scarlet colour, (for there are these varieties) mingled with white; from which grow a quantity of large rough leaves, of a deep green colour, and irregularly divided: amidst these in summer rises the stalk, which is a yard ligh, round, and very much branched. The leaves on it are much smaller 
then thaze from the root. The flowers are vely nu. merous, small, and white, with some spots of red. 'The pods are thick, long, and spungy.

The juice of the radish roots fresh mathered, with a little white wine, is an excellent remedy against the gravel. Scarce any thing operates more speedily by urine, or hings away little stones more successfully.

\section{Honse Radisir. Raphanus rusticanus}

A ruant as well known in our gardens as the other, and wild also in many places. The root is very long, and of an exceedingly acrid taste, so that it cannot be caten as the other. The leaves are two feet long, and half a foot broad, of a deep green colour, blunt at the point, and a little indented at the edges: sometimes there are leaves deeply cut and divided, but that is an accidental variety. The stallis are a yard high : The leaves on them are rery small and harrow, and at the tops stand little white flowers, in long spikes: these are foidowed by little scert-iessels. The plant seldom flowers, and when it does, the seeds scarce. ever ripen. It is propagated sufficiently by the root, and wherever this is the case, nature is less careful about seeds.

The juice of horse mdish root operates very powerfully by wrine, and is good against the jaundice and dropsy. The root whole, or cut to pieces, is put intu diet drink, to sweeten the blood; and the rating frequently and in cumutities, at table, is gond agains the theumitisn.

\section{Ricwort. Jurobar.}

A "rep flant, rely anmmon in our pastures. 


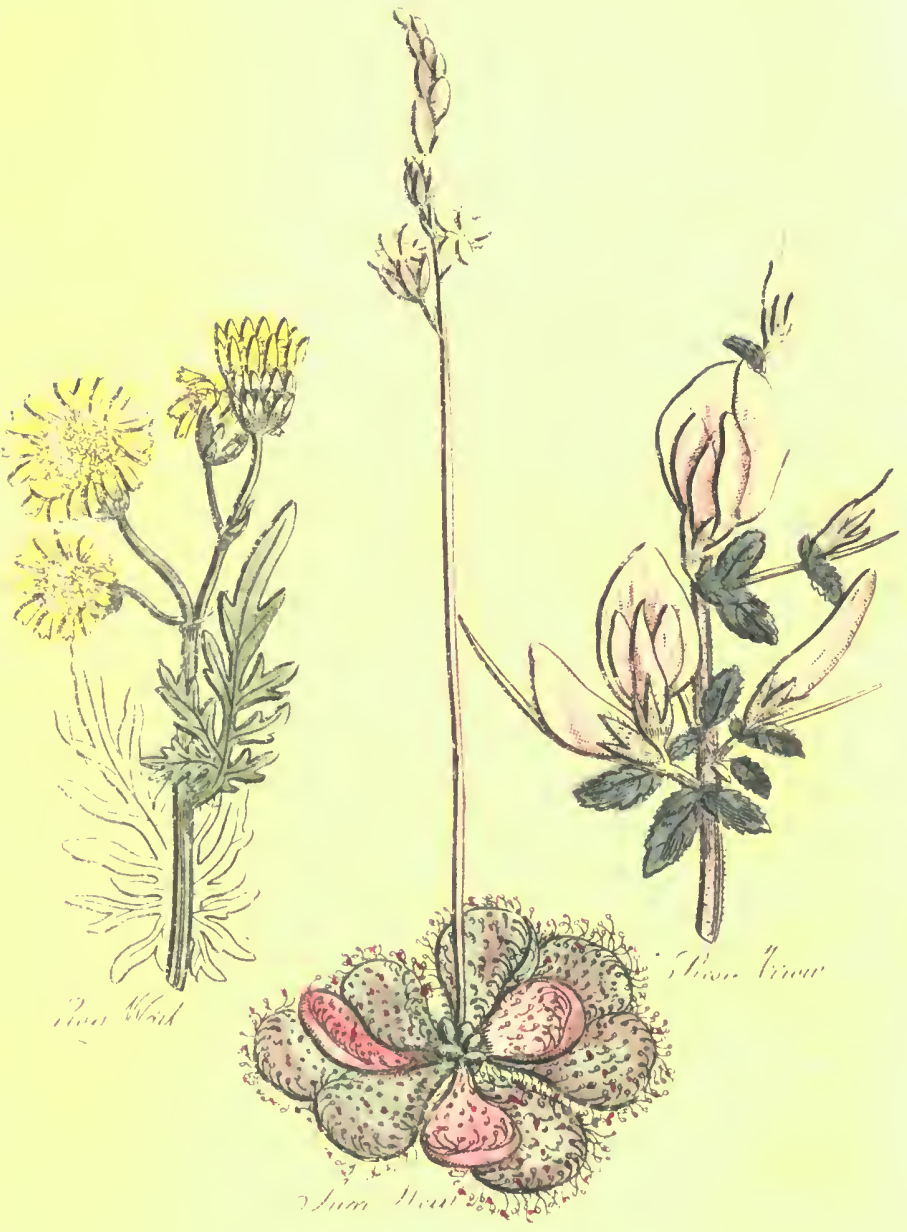



and distinguished $\mathrm{by}^{\mathrm{n}}$ its ragged leaves, and clusters of yellow Howers. It is two feet high. The stalk is robust, colurl, striated, and often purplish. The leaves are divided in an odd manner, into several parts, so that they look tom or ragged ; their colour is a dark dusky green, and they grow to the stalk without any toot-stalk, and are broad and rounded at the end. The flowers are moderately large and yellow, and the tons of the hranches are $\therefore$ covered with them, that they often spread together to the breadth of a plate. "The whole plant has a disagreable smell. The root is finrous, and the seeds are downy.

The frewh leaves are uscd: but it is best to take Unse that rise inmediately from the ront, for they are Jarger and more juicy thain those on the stalk: they are to be mixed in pultices, and applied outwardly as a remedy aghanst pains in the joints : they have a surprining eflect. It is said that two or three times applier, they will cure the sciatica, or hip grout, when erier so violent.

\section{Rupzergy Pen. Rubus idcus.}

A imtre slimb, common in nur gardens, but wild istor in some parts of the kingdon. The stalks are round, wak, tenler, of a pale brown, and prickly. The leaves are each composed of five others: they are large, of a pale green, indented about the ederes, and hairy. The flowers are little, and of a whitish colour, with a great ruantity of threarls in the middle. The fruit is the common rasploery, composed like the blackberry of several grains : it is soft to the souch, and of a delicate taste. The colour varies, for white olies are common.

The juice of rije rasplerries, boiled up with sngar, makes an excellent syrup. It is pleasant, and 
asrecuble to the stomach, good against sicknesses atd reacinges.

\section{Rathesesake hoot Plaxt. Sencea.}

A smot plant, native of Imerica, with weak stalks, little leares, and white flowers. It grows a foot high. The stalks are numerous, weak, and round, lew of them stand quite upright, some genebilly lic upon the ground. The leaves stand irregulnry : they are oblong and somewhat broad, and of a pale green. The flowers are little and white : they stond in a kind of loose spikes, at the tops of the stalks, and perectly resemble those of the common plant we call milkwort, of which it is indecl a linit: the whole plant has very much the atpect of the taller hind of our English milkwort. The root is of a singular form: it is long, irregular, shender, and divided into many parts, and these have on each sidle, a kind of memblanoms margin banging from them, which makes it distunct in its appenance, from all the other roots used in the sinops.

We owe the knowledge of this medicine, origimally to the fullians: they sive it as a remedy against thas poing of the rattle-smake, but it lias been watkil, is possecsing ereat virtues. Dr. 'T'ennant

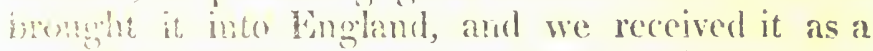
menen! rmedy agranst pleurisies, quinzies, and

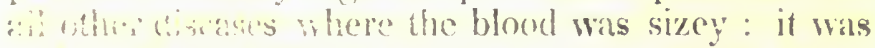

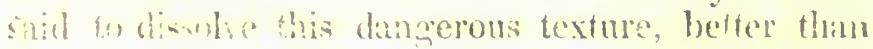
s!l ofler known medicine; but experience does

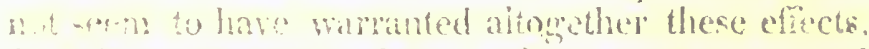

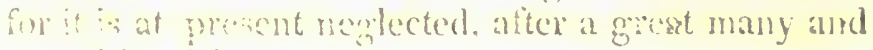

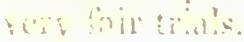

bithe thin renedy was discosered to he the

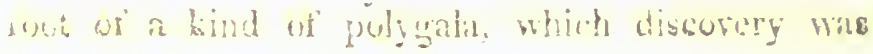


owing to the gentleman who brought it over, and with it some of the plant, for the inspection of the curions. 'The roots of the linglish polygala were tried; those of the common blue or white flowered milkwort, (for that varicty is purely accidental,) and they were found to have the sme cilects: they were wiven by sone in plenisies, with great success. It was said at that time they had less virties thas the serreca root, though of the same kind: but it mut be remembered, the virtues of the seneca root were then supposed to be inuch gieater than they really were. The novelty adding to the praise.

\section{Commox Reen. Amundo.}

A Tile water plant sufficiently known. The stalks are round, hard, jointed, and six or cight feet high. The leaves are long and broad, but otherwise like those of grass, of a pale green colour, and highly ribbed. 'The flowers are brown and chafly, and stand in prodigious numbers at the tops of the stallis, in a kind of panicle. The roots are knotiy and jointed and spread vastly.

The juice of the fresh roots of reeds prometes the menses powerfully, but not violently. It is an exrellent medicine: it works by urine also; and is grood against stranguries and the gravel.

Prickly Restumrow. Anonis spinosa.

A ritcte, tomgh, and almost shrublyy plant, common in our dry ficlds, and by road sides. It is a foot high. The stalks are round, redish, tough, and almost woody. The leaves are numerous: they stand thee on erery foot sta!k, and grumg 
pretty close to the staik. There are several shore and sharp prickles about the stalks, principally at the inscrtions the leaves. Whe laves are of a dusky green, and serrated about the edres. The flowers are small and pupple : they stand among the leares towards the tops of the stalks, and are in shape like pea blossoms, but flatted : each is followed by a small porl. The root is white, very loug, tongh, and woody.

The root is to be taken up fresh for use, and the bark separated for that purpose. It is to be boiled in water, and the decoction given in large quantities It is grood against the gravel, and in all obstructions by urine; and it is also good in the dropsy and jundice.

\section{Rompoxre. Fharanticum sire tha.}

A This robust blant, native of Scytlia, but kept in many of on. garrems. It grows four feet high. rybe stolk is rond, strated, sto inch thick. sometimes holkw, and rey uprighth. The leaves are larise and bronel: thexe from the ront are abont a foot and a salf howg. pend a font bread; of a deep green colctr, with larese rils, and blunt at the fulls. Whe fowers whe snall and white: they stand in cinsters at the tons of the stithis, they are succected by triangrihr seeds.

rive ront is the part raed, and this is what the antients llised under the name of riat. It is of the nature of rhubarb, bat clifterent in this, that it is Jess purgative, and more astringent; for this reason, there are many purposes which it would answer much better. We hawe it at the drugerists, but the ene no

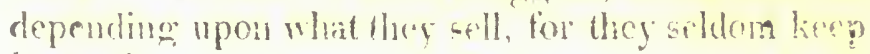
it genuine. 


\section{FAMLY MERER. \\ Rerce. Or,}

A very common plant in the East, sown in the fields for the sake of the seed or grain. It grows four feet high; the stalk is round, hollow, and jointed; the leaves are long and grassy, and of a pale green colour, but they are broader than those of any of our kinds of corn. The flowers are inconsiderable; the seeds or grains are contained in bushes of a brown colour, each having a long beard to it, usually cuiled at the bottom, and divided at the top into two parts.

We eat rice as a food rather than medicine; but it is excellent for those who have habitual purgings or loosenesses ; it is to be eaten any way for this purpose, only it must be continned, and it will do more than all the medicines in the world. The rice-milk is excellent for this purpose.

\section{Garden Rocket. Eructe sutivit.}

A commor plant in our gardens, two feet high. and very erect. The stalk is round and et a deep green ; the lase are oblong, considerably

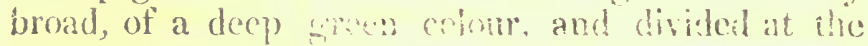

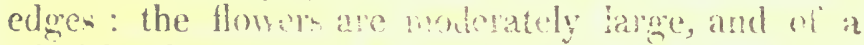
whitish colour, vened with muls. and they stant? in a long spike at the kny whe taik. The ports are long and slende".

Some poople arc fom? riforet as a sallast heab, but it is mot very pleanant. It works by mine", and is grood againet the scurry. A strong intingen of the leaven made into a syrup is good agmmst congts, it causes expectoration, and cases the lungs 
Dog Rose, on WiLs Rose. Cynosbalus, sive
yosa syliestris.

A connow bush in our hedges. The stalks or stems are romd, wooly, and very prickly. The leaves are composed each of several smaller; these stand in pairs on a rib, with an odd one at the end; and they are small, oblong, of a bright glossy green colour, and regularly indented at the edges. The finwers are singie, large, and very beautiful : there is something simple and elecrant in their aspect that f)leases many, more than all the double roses raised by culture. 'They are white, but with a blush of red, and very beaniful. The fruit that follows there is the conmon hip, red, oblong, and containing a great qlantity of hairy seeds.

The fruit is the only part nsed; the pulp is scpaJated from the skins and seeds, and beat up into a consorve with sugar ; this is a pluasant medicine, and is of some effieacy against coughis.

Thmagh this is the only part that is used, it is not the only that deserves to be. The flowers, sathered in the bud and dried, are an excellent astringent, made more powerful than the red roses that are commonily dried for this purpose. A tea, made strong of these dried huds, and sonse of them griven with it twies a 1,; in powher, is an exeellent medicine for overting of of the menses; it seldom fails to

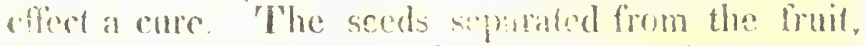
dricel and powdired. work ly wine, and are grood agame the grand, hut tisy do not work very meniming

Ypon the branches of this shuth, there grow it

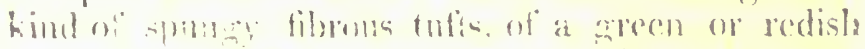

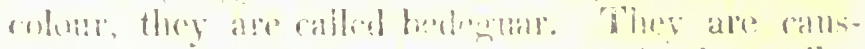

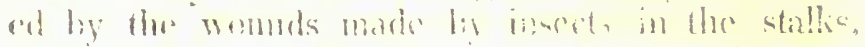

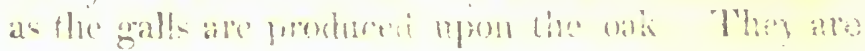


astringent, and may he given in powder against fluxes. They are said to work by urine, but exierience does not warrant this.

\section{Dhmask Rose. Rosa damascona.}

A commos shrub in our gardens, very wuch resembling that in our hedges last nientioned. It grows five or siv feet high, but the stalls are not very strong, or able to support themselves. They are round, and beset with sharp prickles. The leaves are each composed of two or three pairs of smaller ones, with an odd one at the end : they ere whitish, hairy, and broad, and are indented at the edges. The flowers are white and sery beritiful, of a pale red colour, fuil of leaves, nod of an extremely sweet smell; the fruit is like the common hip.

The flowers are used. The best way of giving them is in a syrup thus male. Pom boiling water upon a quantity of fresh gathered damak roses, just enough to cover them; let then stand four and twenty homrs, then press off the liguor, and add to it twire the quantity of sugar ; melt this, and the syrup is completed : it is an excellent purge for children and there is not a better medicine for grown people, who are sulyect to be costive. A little of it taken every night wiil keep the bouly open continmally; medicines that purge struagly, bind afterwards. Rose water is distilled from this kind.

\section{Whate Rose. Rosil elba.}

a comos slirub also in sur gardens. It grons ten or twelve feet ligh, but is not wary alle to support itseif upright. 'The stallis auc rount. 
pricisly, and rery much branched. The leaves are of a rluky grcen, each composed of several pairs of smaller, with an odd one at the end. The flower's are sonewhat smaller than those of the damask rose, but of the same form: and their colour is whits, and they have less fragrance than the domask.

The flowers are used. They are to be gathered in the bud, and used liresh or dry. A strong infusion of them is good against overflowings of the menes, and the blecting of the pilos.

\section{Prop Rose. Rosa rubra.}

Anomirn shus, common in our gardens, and the least and twrest of the three kinds of roses. The stallis ar fomkl, woody, weak, and prickly, but they haw fewer prichles than those of the damask rose: the law are large : they are composed each of three or four pair of smaller, which are oval, of a dusky grecn, and serrated round the edges. The flowers are of the s!rpe and size of those of the ramank roes, lint they are not so double, and they have a great ginatity of yellow threads in the middle. They are of an exreding fine drep and red colour, and ilicy bave very litte smell : the fruit is like the ommoni lip.

The fomos are used. They are to be grathered when in bitel, and cut from the hurks without the white bottoms and dried. The conserve of red roses is mate of these buds prepared as for the dirying : they are beaten up with three times their weight of sligar. When dried, they have more virtue ; they are ciren in infusimn. and sometimes in pmoder against overtlowings of the menses, and all other heedings. Ilalf an ounce of these dried buds are to be put into an earthen pan, and a plint of 
boing water poured upon them after they lave stood a few minutes, fifteen drops of oil of vitriol ste to be dropped in upon them, and three drachms of the finest sugar, in powder, is to be added at the same time, then the whole is to be well stirred about and covered up, that it may cool leisurely : wher cold it is to be poured clear off. It is called tinciure of roses; it is clear, and of a fine red colour. it strengthens the stomach, and prevents romitings, and is a powerful as well as a pleasant remedy aigainst all lluxes.

\section{Rose-trood Tres. Riadium.}

THERE are two kinds of nood known under the name of rose-rood, the one from the liast, which, when fresh brought over, has a very fraprant smell, excecuingly like that of the damask rose, and from the wood is listilled the oil, which is sold undre the name of cesence of damas roae; we have no account of the tree which afords this. The other rose-nod is the produce of Jamaice, and has very much of the frogrant smell of the eastzin lind, but it is not the same : the tree which moduces this is fully described by thet great natumalint si" llans Sloane, in his listory of the Island wi Jamaica. The tree srows trenty feet or more in height, and to frunk is very thick in proportion. The lares are cach compesed of three or four pairs of surbller: these stand at a distance from one anothe nn the common stalk; the flowers are little and white, and they grow in clusters, so that at a distance, they look like the bunches of elder flowx's. The fruit is a round berry, often each of the bignes of a tare. The wood of this tree is lighter, paler coloured, and of the looser grain than the sastern rosc-wood. 
The woud is said to be good in nerrous disorders, but we seldom make any use of it.

\section{Rosehiar. Roscmarinus.}

A FRerry shrub, wild in Spain and France, and kept in our gardens. It is five or six feet high, but weak, and not well able to support itself. The trunk is covered with a rough bark. 'The leaves stand very thick on the branches, which are brittle and slender: they are narrow, " an inch long and thick, and they are of a deep green on tho upper side, and whitish underneath. The flowers stand at the tops of the branches among the leaves; they are large and very beautiful, of a greyish colour, with a somewhat reddish tinge, and of a very fragrant smell. Rosemaly, when in flower, makes a very beautiful appearance.

The flowery tops of rosemary, fresh gathereri, contain its greatest virtue. If they are user in the manner of tea, for a continuance of time, they are exccllent against head-achs, tremblings of the limbs, and all other nervous disorders. A conserve is maric of them also, which very well answers this purpose : but when the conserve is made only of the picked flowers, it has less virtue. The conserve is best made by beating up the fresh gathered tops with three times their weight of sngar. The famous Hungary water is made also of these flowery tops of rosemary. Put two pound of these into a common still, with two gallons of melasses pipirit, and distil off one grallon and a piut. This is IImgary water.

Rosd Sous. on Suxnew. Ros solis.

A VERY singular and very pretty little plant, 
common in boggy places on our lieaths. It grows six or seren inches high. The leares all rise im. mediately from the root: they are roundish and hollow, of the breadth of a silver two-pence, and placed on foot-stalks of an inch long; they are covered in a very extraordinary manner with long red hairs, and in the midst of the hottest days they have a drop of clear liquour standing on them. The stalks are slender and naked: at their tops stand litt'e white flowers, which are succeeded by seedressels, of an oblong form, containing a multitude of small sceds. The root is fibrous.

The whole plant is used fresh gathered. It is esteemed a great cordial, and good against convulsicus, hysterie disorders, and tremblings of the limbs; but? is is nat mon reguted.

\section{Rnumes Rhabarbarum.}

A Taze, robust, and not unhandsome plant, a native of many parts of the East, and of late got into our girdens, after we had received many others falsely called by its name.

It grows to three feet in height. The stalk is round, thick, striated, and of a greenish colour, frepuently stained with purple. The leaves are very large, and of a figure approaching to triangular: they are broad at the base, smill at the point, and waved all along the edges. 'These stand on thick hollowed foot-stalks, which are fiecpuently also reddish. The flowers are whitish, small and inconsiderable: they stand at the tops of the stalks in the manner of dock-flowers, and make little more figure; the seed is triangulated. The root is thick, long, and often divided toward the bottom; of a yellow colon veined with purple, but the pirple 
appears much more plainly in the dry, than in the fresh root.

The root is used : its virtues are sufficiently known; it is a gentle purge, and has an after astringency. It is excellent to strengthen the stomach and bowels, to prevent vomitings, and carry off the cause of colics; in the jaundice also it is extrencly useful. Rhubarb and nutmerg toaster together before the fire, make an excellent remedy against purgings. There is scarce any chrouic discase in which rhubab is not serviceable.

The Rhapontic monks rhubarb, and false monks" rhubarl, all approach to the nature of the true shubarb; they have becn described already in their several places.

\section{Rive. Ruta}

1 prettry little slurub, frequent in nur gardens. It grows three or four teet high. The stem is firm, upright, and wondy ; very tough, and covered with a whitish bark. The branches are rumerous, and the young shoots are round, green, and smooth; the leaves are composed of many emalier divisions; they are of a blue green colour and feety substance; and each division is short, obtuse, and roumdish. The flowers are yellow, not larene but very conspicuous ; they have a guantity (f) throds in the center, and they are succected by

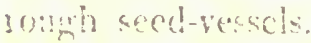

Rue is to be wad frech frathered, and the tops of the young showe contain its greatest virtuc. "They are to be given in infusion: or they may be buasu un into a rouserve with thec times their wcisht of sunar, and taknn in that form. The iafur inn is art excellent meclicine in fevers; it raises the spirits, and promenes cremt, drimos any thing 


\section{FAMILY HERBAL.}

out, and is good against head-aches, and all other nervous disorders which attend certain ferers. The coinserve is good against weatnesses of the stomach, and pains in the bowels. It is pleasant, and may be taken frequently by people subject to histeris dis. orders with great adiantage.

\section{Rertun-wort. Herniciat.}

A urterle low plant, wild in some parts of the kingdom, but not common, and kept in the gardens of the curious. It grows the or war inches long, but the stalks lie on the pround: many grow fron the same root, and they spread inte a kind of circular figure. They are slude:, rouid, jointed, arsi of a pale green. "The dives are very small, and nearly of an orat finule; they stunt two at cach joint, and are also a pale green. The leaves are very small; the rou is rery hong, but not thick.

The juice of the fresh gathered herb, externally applied, has been much colcbrated against ruptures; perhaps without any great foundation. An in: fusion of it, taken imwardly, whs by urine, and is very good agrainst the gravel, and in the jaundice.

\section{$S$ \\ Sarros: Croculis.}

A reRY pretty plint, of the same hind with what are called crocuses in our gardens. It is planted in fields, in some prarts of England, and yields a very profitable hind of produce. The flowers of this plant appear in autumn, but the leaves not till sometime after they are fallen. 'These fow. ers have, properly speaking, no stalli : they rice ime 
mediateiy from the root, which is roundish, and as bigr as a large nutmers, and they stand a little way abure the surfice of the ground ; they are of a purplish blue, and rery large; the lower part is covered with as simmy listi. In the centre of these stand three stamina, or threads, with yellow tops, Fhich are useless, but in the midst between these rists ip what is called the pistil of the flower. "Whis is the rudiment of the futme secol-vessel; it is oblong and whitish, and at its top separates into three filaments; these are long, and of an orange scarlet colour; these three filaments are the only part of the plant that is used; they are what we call sathron. Thicy are carefully takcn out of the flower and presserl into cakes, which cakes we sec under the name of Winglish saffrom, and which is allowed to be the best in the world.

The leaves are long and erassy, of a dark green colour, and very marrow. They are of no use.

bitron is a nohle corital.

\section{Bastard Sarfron. Carthomus.}

A Puario in its whok appect as unlike to that whirh proberes the ente sation, as one herb can bo to andust ; but catid by this name, because at the yellow theats whish grow from the flow cr. It is af the thistle kind, two feet and a half high, aint rery nupight. 'T!u stalk is romd, anglated, and branded, but it is not pridily. ring leares are oblong, broad, yound at the points, and prickly about the colges. The fowers stand wh the tops of the brancless: they romsiat of round-

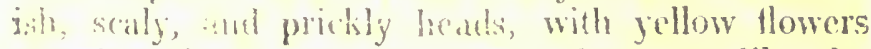

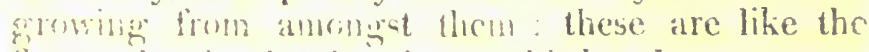
flowers in the leads of on litistles, but narrower and longer. 
These flowers are used by the dyers in some parts of Europe. The seed is the part taken into the shops: it is longish, covered, and white with a hard covering ; it is to be given in infusion, which works both by vomit and stool, but not violently. It is good against rheumatisms and the paundice.

\section{Sagapenca Plant. Sagapenum.}

A taRge plant, native of Persia in the Fast Indies, and described but imperfectly to us; however, so that we have confirmation that the descrintion is anthentic, if not on finished in all its parts as we could wish. It crows upon the mountains, and is eight feet high ; the leaves are very large, and are composed of a rrent multitude of little parts, which are fixel to a divited rib, and are of a bluish green colour, and when briged, of a strong smell. 'The stilk is thick, striated, round, hollow, and upright, purplish towerds the botom, but green upwards. "ilic leaves which stand ors it are like those which rise from the ront, nily smaller. The flowers are little and yellowish ; they stand in very large umbeis at the tops of the stalks, and each of them is surcerded by two seeds; these are ilat, large, brown, and striated. The root is long, thick, of a yellowish colour, and of a disagreeable smell. This is the account vie have from those who have been of late in the East: and there is a great deal to confirm it. WC find among resin which is broight ner to we, pieces of the stalk and many seerls of the plant: these agree with the description. I procured some of the seeds picked out of some samaponum, by zoung Mr. Sisson, to be soved witil all puper cave at the lord l'atre's, whose princiga! gardener 
was an exclient person at his business, and with them sonie setils of the ammoniacum plant, picked also out ne arge quantity of that gum. Those of the ammouacum plant all perished; from the wagapenum seeds, thugh more than an hundred were sown, we had ouly one plant, and that perished by some accident very folno; but what we saw of the leaves gave crerlit t: the account given of the plant by Mr. Willians, who told us he had seen it in Persia. These are rurions parts of knowledge, and they are worth prosecuting by bose who have leisure: the success of this experi. ment shews the possihility of raising some of those plants at home, which we never have been able to set truly and fully described to us.

$1 \mathrm{c}$ use a gum resin ohtained from the roots of this plant, iy cutting them and catching the juice; we call this, wireil concreted into lumps, sagapentim. Ire have it either finer in small piecrs, or conser in masses; it is hrownish, wilh a cast of red, and wil grow soft with the heat of the hand: it is divegrecahle both in smell and taste, but it is an excellent medicine. It is grood for all disonters of the lunes arising form a tough plifegm, and also in nervons cases. It lias been found a remedy in inveterate hear-aches, alter many nther medicines hare failed. It is me of those drings, ino much negiected by the present practice, which encourages the use of others that have not ladf their virtue: but there are fashoms in plipsic, as there are in all other things.

\section{Ren Suge, Salvil hortorsis.}

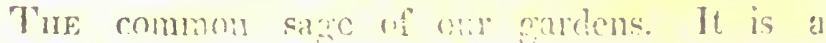

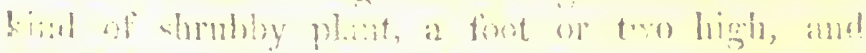

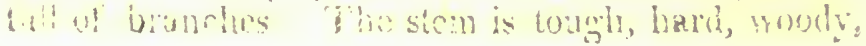




\section{FAMILY HERBAL:}

and covered with a brown rough bark; the smaller branclies are reddish, the leaves are oblong and broad; they stand on long foot stalks, and are of a singular rough surface, and of a reddish colour. The Howers grow on stalks that rise only at that season of the year, and stand up a great deal above the rest of the surface of the plant ; they are large and blue, and are of the figure of the dead nettle fowers, only they grape vastly more. The whole plant has a pleasant smell. The leaves and tops are ised, and they are best fresh; the common way of taking them is in infusion, or in formin of what is called sage tea, is better than any other : they are a cordial, aud good against all discases of the nerves: they promote perspiration, and throw ang thing out which nught to appcar upon the skin. The juice of sage works by urine, and promotes the menses.

\section{Sage of Virtce. Salvia mincr.}

Asother shrubby plant, very like the former in its manner of growth, but wanting its red colour. It is a foot or two in height, and very bushy. The stem is wondy. The branches are numerous. The leares ne ohlong, narrower than in common sage, and of a whitish green colour : there is often a prair of small leaves at the base of cach larger. The flowers grow in the same manner as in the red sage, but they are smalier. The whole plant has a pleasant smell.

Thic green tops are used; and their virtue are much the same with those of the former, but they are Jess. It got into use from an opinion that the other was too hot, but this was idle. 


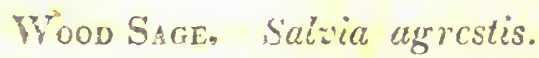

A wybd plant, conmon in woods and hedges, with leares like sage, and spilies of small flewers. It grows two feet and a latt high. 'The stalk is square, frrm, slender, and upright. The lenves stand two at each joint: they are somewhat shorter and broaler thian those of sage, of a green colour, and serrated abont the edges. The flowers are numerous, and rery small: they stand in long spikes, and are of a greenish yollow colour, with some red threads in them. The plant has a singular smell, with something, of the garlic flavour, but that not strong.

The tops are to be used fresh. Nade into an infussion, they promote mine and the nonses: the juice of them drank for a continuance, is excellent againsibinuatic pains.

\section{Salep phant. Orchis orientalis.}

A VERY pretty plant, of the nature of our cornmon orchis, mative of the East, but growing to a greater height and producing larger roots than with is, though it scerns very nearly allied to what wo call the tail female orchis, with large flowers, which is frequent in our mearlows. It grows in diunp whound, and is a foot high. 'The stalk is ronul. Jay, and tender. The leaves are eight turhes long, and wut an inch broad, of a dark green coloner, and also juicy. The flowers stand at the tops of the stalk, in a spitie of two inches loner: they are moderately large, and of a pale red coluur. The root is composed of two roundish bodies, of the limene of a pridgeon'segg, and of a white colour. with some fibres.

We use the rnot, which we receive dry from 


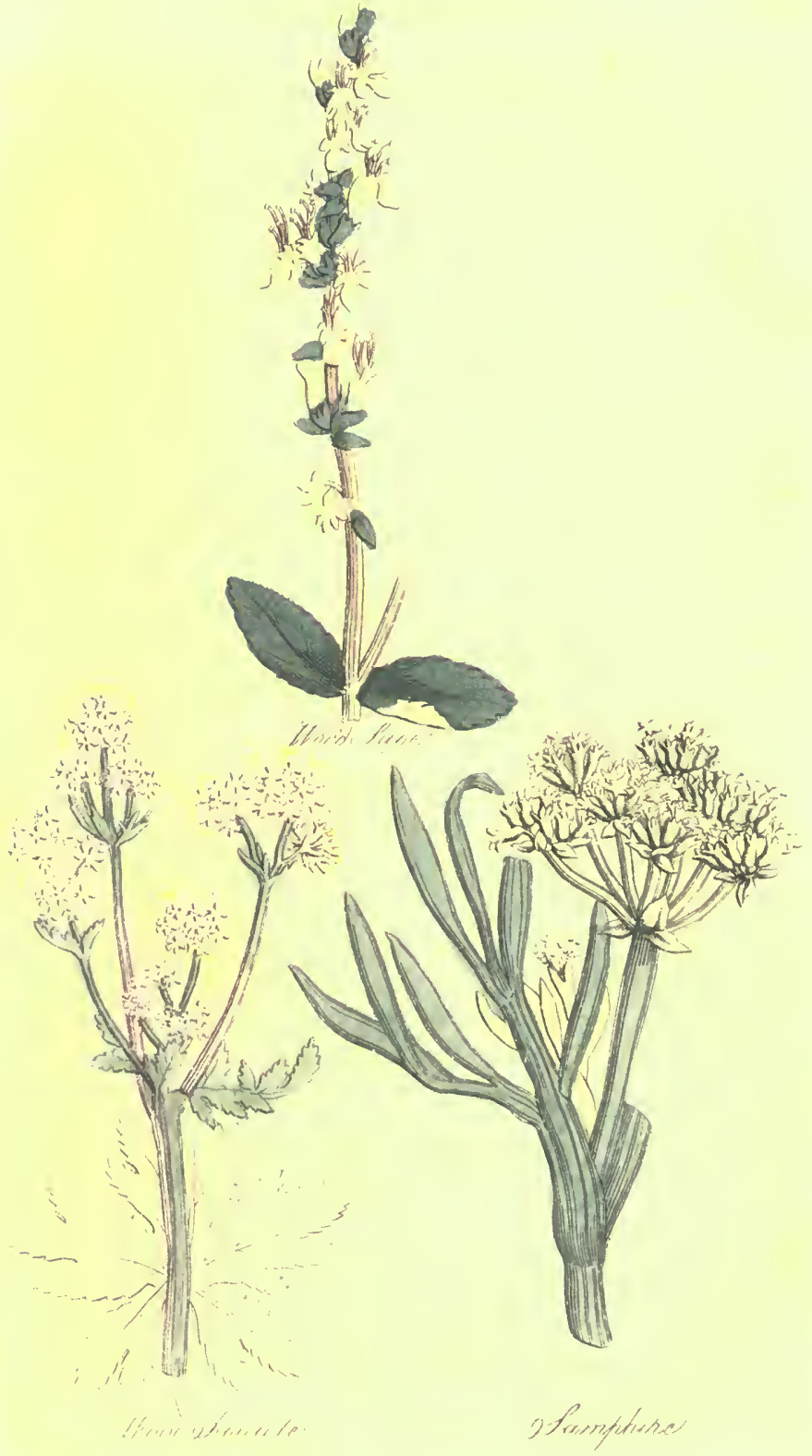



Turkey. They have a peculiar method of curing it; they make it clean and then soak it four and twenty hours in water; after this, they hang a quantity of it in a coarse cloth, over the steam of a pot in which rice is boiling; this softens it, but it gives it a sort of transparence, and qualifies it for drying; these juicy ronts, otherwise growing montdy. When they have thus far prepared it, they string it upon a thread, and hang it in an airy place to dry ; it becomes tough as horn, and transparent. This is a practice common in the East with the roots they dry for use, and it would be well if we would practise it here ; the fine transparent kind of ginseng, which we have from China, is dried in this manner. It is highly probable, nay it is nearly a certainty, that the roots of our common orchis have all the qualities and effects of this salep, but we do not know how to dry them. If we tried this method, it might succeed; and in the same manner, our own fields and meadows might aftord us many medicines, what at present we purchase at a great price, from the farthest parts of the earth.

The dried root is the part used; and it is an cxcellent restorative, to be given to persons wasted with long illnesses: the best way is to put a small quantity of it in powder, into a bason of warm vater, which it instantly turns into a jelly, and a little wine and sugar are to be added. The 'l'uris use it as a provocative to venery: they take it dissolved in water, with ginger and honey.

\section{Sanpsine, Crithmum marilimum.}

A PLANT not uncommon about sea coasts, witic much of the appearauce of fennel, only not so tall: some have called it sea fennel. It is two fert high. rhe leaves are large, and divided in the manner of 
those of rennel, into slender and small parts, bu they are thick and fleshy. The stalk is round, hollow, striated, and a little branched. The flowers are small and yellow, and they stand at the tops of the stalks in great clusters or umbels, in the manner of those of fennel. The whole plant has a warm and agrecable taste, and a good smell.

The leaves are used fresh; but those which grow immediately from the roo, where there is no stalk, are best; they are pickled, and brought to our tables; but they arc often adulterated, and other things pickled in their place. The juice of the fresh leaves operates very powerfully by urine, and is good against the gravel and stone, against suppressions of the menses, and the jaundice.

\section{Sinicle. Sanicula.}

A pretry wild plant common in our woods. and distinguished by its regular leaves, and small umbels of flowers. It grows a foot and a half ling. The leaves are numerous, and they all rise inmediately from the ront : they stand on long footstalks, and are very conspicuous : they are of $x$ roundish shape, but cut in so, as to appear five cornered, serrated about the rolges, and of a very decp glosiy green colour, and shining surface. The stak is striated, upright, naked: on its top grows a little round cluster of flowers: they are small and white, and each is succeeded by two little rough feds. The root is tibrous.

The leaves are used. A strong decoction of thems is good against the overfowing of the menses, and the bleeding of the piles. It has been vastly crlebrated for the cure of runtures, but that ij idlo. 


\section{Sarsaparilua Puayt. Sareaparilla.}

A ruant of the climing kind, native of the warmer countries. 'I'he stalks run to ten or twelte fect in length, but are weak, and support themselves among the bushes: they are whitish, angular, and striated, and are fill of small prickles. The leaves are an incl long; or more, and above half an inch broad, of an oval figure, of a deep green on the uppe'i sude, and white underneath, firm in their texture, and very glossy. The flow ers are little and yeliowish. Whe berries are black, round, and of the bigness of a small pea. The root is very large and siender.

The ront is used. On druggists keep it : they split it in two. It is brown on the outside, and white within; and its taste is insipid. It is sup. posed to have great virtues, but they are not perfectly established. They have been at times disputed, and at times supperted. Given in decoction, it promotes sweat and urine. It has been esteemed good against the scurvy, and famous in the cure of the veneral disease. It is, in general, accounted a sweatener of the blood.

\section{Sassafras Tree. Sassafras.}

A esiutifur tree, native of America, and to be met with in some of our gardens. It grows twenty five or thirty feet high. The trunk is naked till it comes near the top. The branches grow near together, and spread irregularly. The leares are of two kinds: those on the older parts of the twigs are oblong and pointed, somewhat like bay leaves; and those on the tops of the beanches are larger, hroader, and divided into three parts, like the leaves of manle, or they carry 
some resemblance of the smaller leaves of the fig. tree. The flowers are small and yellow. Thic fruit are berries like bay berries. The wood is of a reddish colour and perímed smell.

The rood is ved. Our druggists receive it 'in logs, and cut it out into shavings. The wood of the root is best, and its bark contains most virtue of all. It is best taken in infusion, by way of tea for it is very picasant: it promotes sweat, and is grood against the scurvy, and all other foul. nesses of the blond. It is a constant ingredient in diet drinks against the venereal disease.

\section{SArise. Sabina.}

A LTTE garden "shub, green all the winter. The trunk is covered with a reddish brown lrark. The branches are numerours, and stand confusedly. The leaves are small, narrow, of a dark greer colonr, and prickly. The flowers are very small, and of a yellowish colone; and the fortit is ar

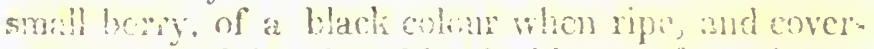

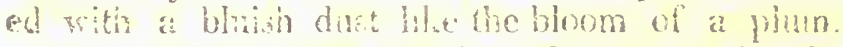

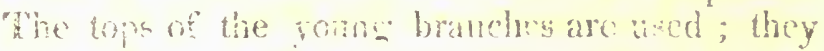

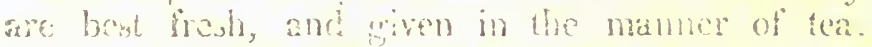

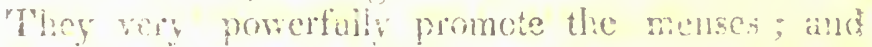
if siven bis woren with child, will freyuently ratise a nibraminge. The comntry people give tive juice mixed with will to childien, as a renizely against worns: it generally works by stoml, and brings worms away with it.

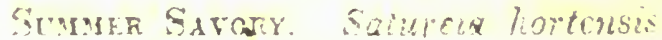

1 cougox libic plant in our kitchen gardens It is ten inchis of is foot high. The stalks are nis merous, and very land, and woorly toward the ho:- 
fom. The leaves are oblong and narrow: they stand two at each joint, with a quantity of young ones on their bosons. The flowe's grow on the upper parts of the stalls among the leaves: they are white with a tinge of bluish or reddisis. The whole plant has a pleasant smell, and au agreeable taste.

The whole plant is used. sn infusion of it; drank in the manner of teat, is good agrainst colicy pains, and it opens obstructions, and piromotes the menses.

There is another kind of savory, with more woody stalks, called winter savory; this has nuch the sanic virtues.

\section{Red Salvofrs Tree. Sartalum ruburar.}

A TrEe, native of the IVcst Iudies, but of which we have seen nothing but the wood, and have received very imperfect descriptions. They say it grows forty feet high; that the leaves are small, but many, set near togrether: their colour is a dusky green; and their substance thick and fleshy. The flowers are like pea blossonts, and the fruit is a pol, containing three or four seeds. This is all we have been informed concerning the tree, and part of this by hear-say only.

The wood is used. It is of a deep red colour It is astringent, and is good against violent purgings and overflowings of the menses: for the former purpose, it is best given in powder, in small doses; and for the latter, it is given in decoction. But it is not much used.

Yeezow and White Saundegs Tree.

Santalum flavum et album.

A Banturux tree, native of the East Indies 
It grows forty or fifty feet high, and is very much branched. The leaves stand two or three pairs upon a stalk, in the manner of those of the lentisk, and are not unlike those of that tree in shape; they are of a dark green colour, small, oblong, and fleshy. The flowers are moderately large, and of a deen dusky blue; the fruit is a berry, of the big ness of a large red cherry, which is black when ripr The wood is white in the outcr part, and yellow the heart, and these two parts are kept separat. and were long supposed the woods of two differes trees. They have the same smell and taste, onl that the yellow has them both in the greatest perfec tion: and in the same manner, their virtues are the stme; but the yellow is so much superior, that the white deserves no notice.

The rellow saunders is best taken in the man. ree of tea, it is this way not unpleasant, and is condial, goor against disorders of the rierves, and hysteric conplaints, and opens obstructions, it also gently promotes perspiriation, and works by urine.

\section{White Sumprige. Saxifraga alba}

A verr pretty plant in our mendows, distinguished by the regular shape of its leaves, and its white snowy flowers. It grows ten inches high: the stalk is round, thick, furm, upright, and a little hairy. 'The leaves are of a pale green colour, and fleshy substance: they are of a roundish figure, and indented about the edges; and they stand upon long fool-atalks. The flowers are large and white; they grow in considerable numbers on the tops of the stalks. The rnot is comprosed of a parcel of small white or reddish grranin!es.

The rent is used ; and these small parts of which it consists have been nsed to be called by ignorant 



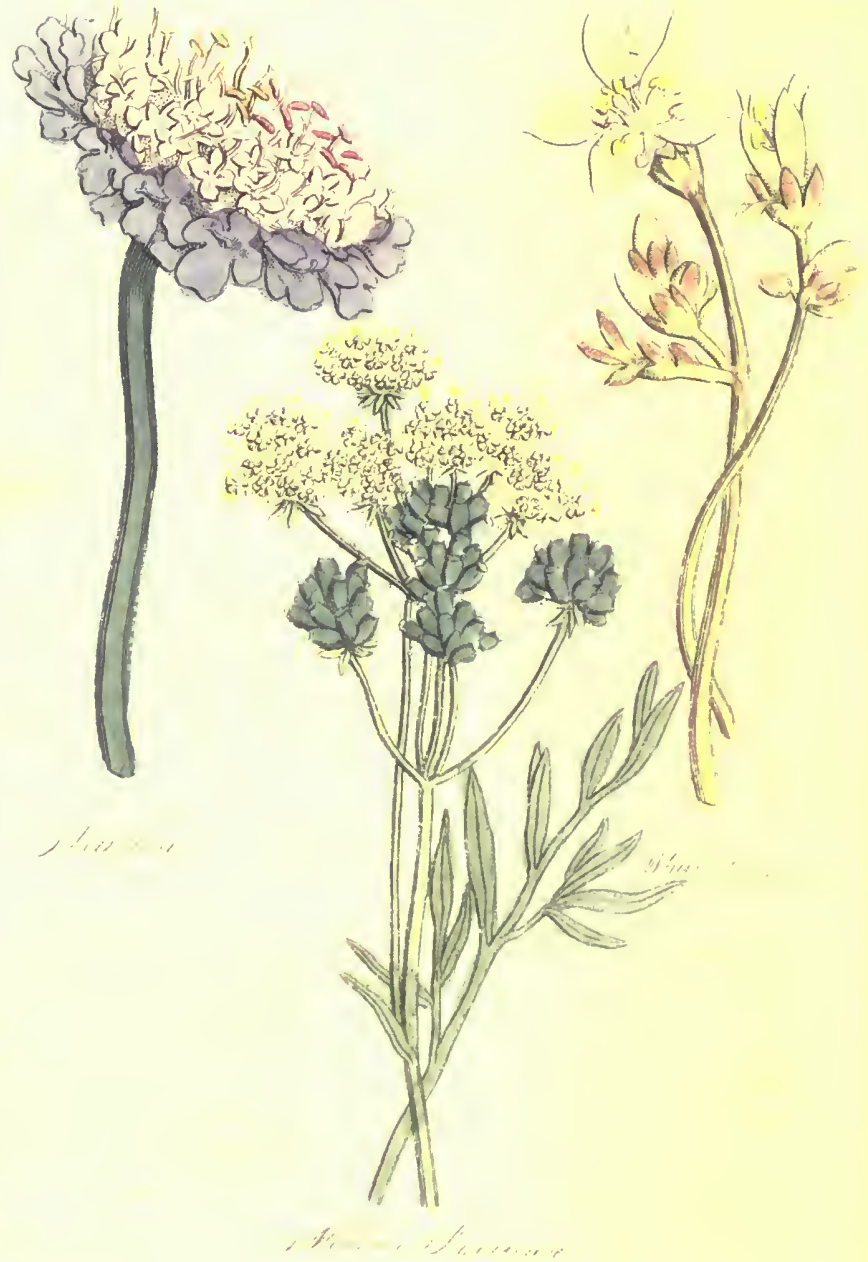




\section{FAMILY HERBAL.}

apothecaries saxifrage seed. It is diuretic, and good against the gravel. The roots are best fresh, and the best way of giving them is in decoction.

\section{Mendow Stxifragr. Scseli pratciuse}

I who plant also, but thongh known by the same Einglint name with the other, very different in form and flower. It grows to more than two feet in lacight. The stalks ane mund, deeply striated of a dork reen colour, and conoiderably houched. The leares are larege, but they are divided into a muluturie of fise narrow sements. The flowers stancin at the tops of the salks in little umbels or ronnd clisters, and they are amall and yellow. The root is brown, long, und sleticis, and is of an aromatic and acrid taste.

The root is used: it is best fiesh taken up. Given in a strong infusion, it works powerfully by urine, and brings away gravel. It alor eascs those colics, which are orwing to the same cause.

\section{Scumocs. Scaúosa.}

I convox wild plant in onr com-fithlo, distingnished by its tall round stalks, and rotmol blue floncir. It grows to three fiet in height. The leases rise principally from the root, and they lie s. reat upon the ground. They are obloing, and imentarly divided at the edges; they are of a pate green, hairy, and rongh to the touch. The stalls are round, uprigtht, hairy, of the same pale swen, cokmur, and they late a few leaves on them, flaced two at a joint; these are nirne deeply divided than those on the ground. The flowers stand at the rops of the branches, they are of 
dcep blue colour, and each is composed of a number of smaller flosucles, collected into a head. The root is long and brown.

The leaves growing from the root are to be gathered for use before the stalks appear. They are best fresh. A strong infusion of them is good against asthmas, and difficulty of breathing, and the same infusion made into syrup, is good against conghs. The flower's are said to be cordial, and an infusion of them to promote sweat, and cany ofi fevers, but this is less anthentic; the juice externally applied is good againsi founesses of the skin.

\section{Sicannoxy Plant. Scammonia}

I crums plant, native of the castern forts of the world. Whe stalls are numerous, green, slender, and angulated ; they are tive or six feet long, but unable to support themselves without the help of bushes. The leaves stand irregularIy, and not very close to one another; they are of a triangular ligure, and bright green colour, and they stand upon homg foot-stallis. The flowers are large and bell-fishoned; they resemble very mach those of our common little bind-weed being whitish but they oftener have a yellowish than a reddish tinge. The rout is a fort and a half long, and as thick as a man's arm, full of a milky juice. 'They wound the roots and catch the milky juice as it rung mut in shells; and this when it is concreted into a hard mass is the scammony we use.

It is a rough punge, but a very powerful and useful one. It is good against the rhumatic pains, and with reach the seat of many disonders that a wimmon purge docs not elfect. However, it is stldom given alone: and a great misfortme is, that the compositions made with it are never to be 



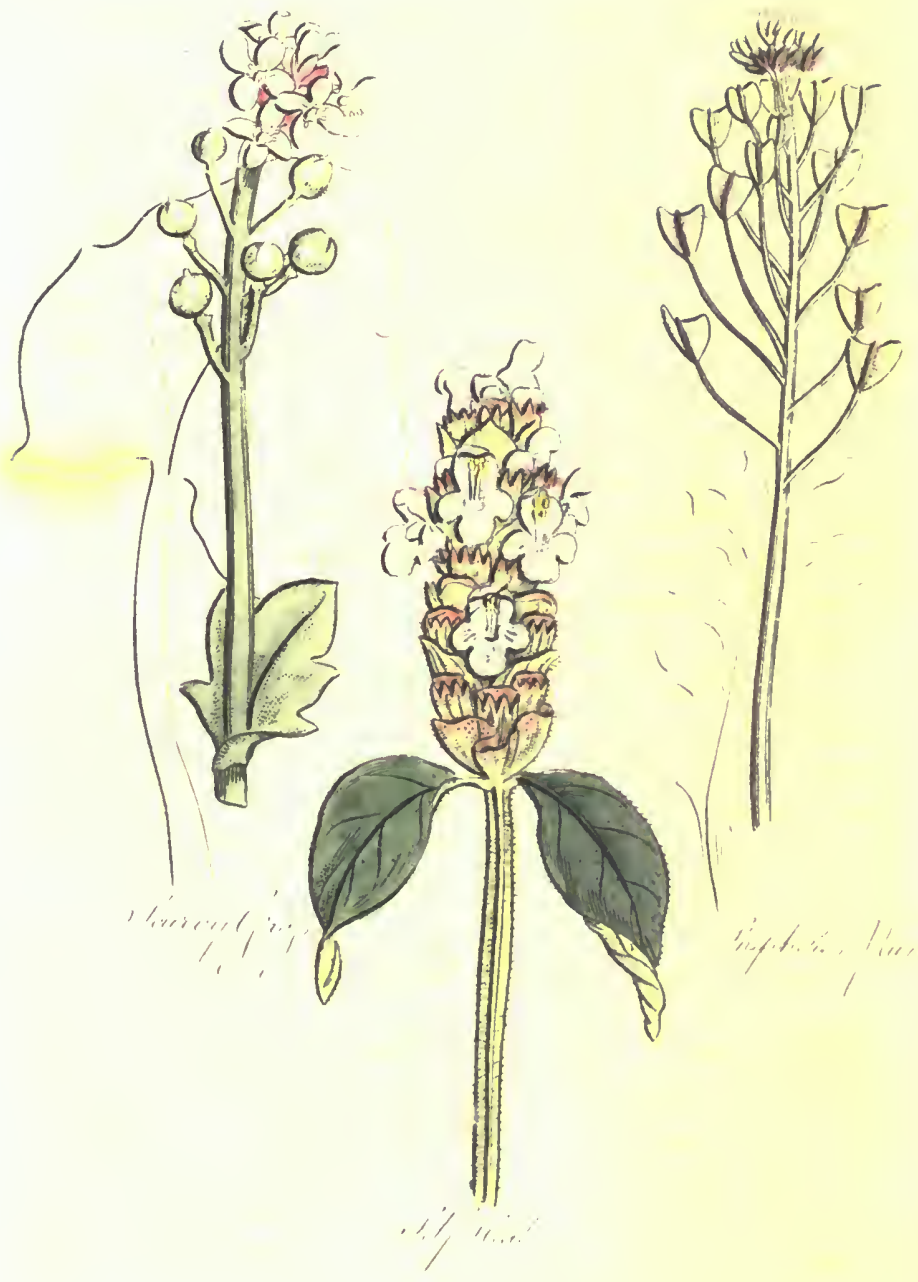




\section{FAMILY MERBAT.}

perfectly depended upon, because there is so much difference in scveral parcels of scammoniy, that they seem hardly the same medicine, some are so very strong, and some so weak.

\section{Gandex Scubvy Grass. Cochlearia hortensis.}

A comuos wild plant about our sea coasts, but kept also in gardens for its virtues; it is a foot high : the stalks are round, weak, and green ; the leaves that rise from the root mane the most considerable appearance; they stand in a large tuft, and are of a roundish figure, and a bright green colour, tender, juicy. and supported on Iong and slender foot-stalks. There are but few leaves on the stakks, and they are not so round as those from the root, but are a little angrolar and pointed. The flowers stand at the tops of the stalks, in little clusters; they are white. small, and bright; they are succeeded by short roundish seed-iessels.

The fresh leaves are used, and the best way of all is to drink the pressed juice of them; this is excellent against the scurry, and ail other foulnesses of the blood. It may be mixed with Seville orange juice to make it pleasant, and silould he taken every day for six weeks or two months together in spring.

\section{Sea Scervy Grass. Cochlcaria marina.}

A commox plant also about our sea coasis, and by the sides of rivers, where the tide comes The leaves are not so numerous as those of the other ; and they are oblong, of a reddish green colour, pointed at the ends, and indented at the edges in aa irrcenlar manner they are considerably larger than those of garden scurvy grass, and mol: fleshy. The 
stalks are eight or ten inches high ; they are teir der, round and striated; they have few leaves on them, but the flowers are sinall and white, and stand in clusters at the tops of the staiks, as in the other. The leaves ate to be used fresh wathered, or their juice is to be taken. Their virtues are the same as those of the other. But it is the general opinion that they are greater, though the taste be not so agrceable.

\section{Sebestex Tree. Myja siue sebesten.}

A tree of the bigness and form of our common plum tree, and producing a fruit not altogether unilike it. 'The trunk is coverof with a rongin bark, the branches grow irregularly and crooked, and are generally so slender toward the ends, and so full of Icaves that they bend downward; the leaves are hroad and short; the flowers are white, small, and sweet scented; they stand in turts or clusters, and the cup in which they stind remains, and encloses the fruit. This is somewhat like a plum, and has a kernel in the same manner : its shape is oblong ; and the pulpy part of it is so tough and clamy, that being beat up with water it makis's good bird lime.

This frut is the part used; it is sent over to ma dried in the manner of a prune. It waed to be a constant ingredient in decoctions for mughs, and diserders of the lungrs, but it is now disregarded.

\section{SeLrime frumblla.}

A IfTTre wild plant common abont way sides, with dark green leaves, and stonit tufts of blue flowers. It groms six inches high; the stalk is 


\section{FAMHY LFRBAL.}

square, and a littlc hairy; the loaves ctand in pairs sumen 1t, but there are stom nore than two or thro pair, the great yathity of then rise imme-

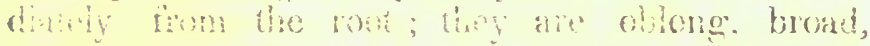
blat at the pont an not al indented at the

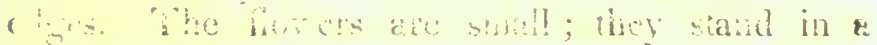
hina of short spities or hearis: tlie cups of them are often purplish. The root is sutall and creeping, and fuli of fibres. The juce of seli hien is astringent ; it is good against purgings, with very shaip or bloody tools, and against overflowings of the menses. 'The dried herb made into ail infusion and wentence with honey, is good

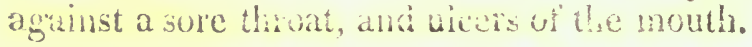

\section{Sexi Smen. Sena.}

A Imtruf shrub, three or four feet high, native of the East. The trunk is covered with a whitish and rough bark; the leaves are composed each of three prit of smaller, disposed on a common rib, with ais oid one at the end: they are oblong, narrow, and sharp pointed, of a smooth strfice, a thich stibstance, of a pale green-colour, and me bidenter at the edigne The flowers are liki a par blocom in shape, bit they are yellow, matied with preple vins. The pods are short and that. and the seces ane small and brown.

We have the dried le from the last, the druggists keep them. Tley are griven in infusion, and are an excellent pure, but as thy are apt to sripe in the working, the common ripelod is to throw in a few cardanom sculs, or sume other warm medicine into the water. 


\section{Bampard Sena. Colutea}

A commos shrub kepi for ornament in our gardens. The trunk is not very robust, but it kceps upright, and is covered with a whitish rough bark. The leaves are composed each of several pairs of smaller, set on a common rib, with an odd loaf at the end; but they are rounder and broader in proportion to their leugth than those of the true sena. The flowers are yellow: they are but small, but they hang in long branches, and are succeeded by pods, which look like bladders of a greenish colour.

The leares are used; some give an infusion of them as a purge, but they are very rough : they work both nipwards and downwards, and are only fit for very robust constitutions. For such as can bear them, they are good against rheumatic pains.

\section{Seveg Thee. Serica.}

$A$ rase firequent in the East, and named from a gum which it affords, and which is brought in great quantities into liurope. 'The tree is large and spreading; its trunk is corered with a rough bark, its branches with a smoother, of a pale hrown, and they are very full of thorus.

The leaves are large, and they are composed of many smaller, set in pairs, very beatufiully and erenly about a common rib, with an odd one at the end of each rib): they are oblong. and of a beautiful green. The flowers are white, and of the shape of a pea blossom; the fruil is a large and flat pod, jointed or divided inte sereral parts, with seeds in them ; the tree is of the acacia kind, in many things rery like that which prosinces the 
gum mabic, and the gum which is obtained from it is in the same manner very like that.

This of in medicine, and this is not much. It is brought over, however, in great quantities, for the dyers ase a great doal of it. It is in large iumps, of the bigness at an eggr, rough on the surface, but glosiy and smooth when broken, and of a pale brown coleur. It is as easily and entirely dissolved in water ats gum arabic, and has the same virtucs. It is very seldom called for by name in medicine, but it is nevertheless often used, for the drugrists have a way of breaking the lumps to pieces, anci putting them among the gum alabic : they may be distinguished by their brown colour, the irue gum arabic being white, or yellowish, if coloured at all, and never having any brown in it: some pick these brown pieces out; but, upon a separate trial, they are found to be so periectly of the same nature, that it is a needless irnuble.

\section{Right Servare 'l'ree. Sorbus legitima.}

A TREF wild in some parts of this lingdom, thit wat knorn in others, nor even in many of our sardens. It grows twenty feet high or more, and the banches stand rery irregutarly. The leaves art cech composed of several pairs of smaller. set on a common rib, with an odd onc at the end these are long, nurrow, and serrated, so that they have some ressmblance of the anh tree. The flowers are not larer ; they are white, and stend in chisters. Each is succeedrd by a fruit of the shape of a pear, and of the bigness of sume pears of the smatler kind; these are green, excegt where 
they have been exposed to the sun, where they are sometimes reddish; the tasie is rey pleasant when they are ripe.

Tise unripe fout is used ; they press the juice? and give it aganst purgings, bat is little hrown.

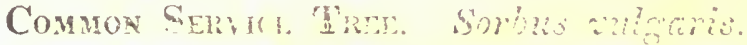

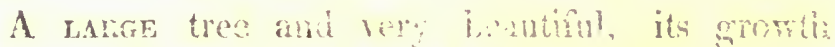
being regular, and the jerice of an elegant shape; the bark of the tmik is merisin, and nolerably smooth; on the branches it is butwm: the leaves are single, large, and of a rounder figmre, bet divided into five, wix, or seven parts, pretiy diegly, and scrated round the edges; they are of a bright green on the uper part and whitish undemeath. The flowers are little and yellowish, and they grow in clusters; the fruit is small and brown wheil rine. It grows in bunches.

The unripe fruit of this service is excellent anginst purgings, but it can only be had reconse to when in season, ton there is no way of preserving the virtue in thein all the year.

\section{Shapuen's Pegse. Bursa Pastopis.}

Thin most common almost of all vild plants, over-ruming our garden-beds, and cont-yards. The laves spread upon the ground, and ane long somewhat broad, and more or less intented at the edres, for in this there is great variation: the stalks ale romd, upright, and right or ten irches high, they have few leaves on them. The fowcrs stand at the topse in littic clusters, and they are small and white: below there is commonly a kind of spike of the seed-vessels: these are short, brond and of 
he figure of a bag, or pouch, and are divided a little at the end. The seeds are small and yellowish, and the roots white.

The juice of Shepherd's purae is conling and astringent; it is good aganst purgings, with sharp and blondy stooh ; aganst the bleeding of the piles, and the orerlowng of the menses.

\section{Sumer. Sisarum.}

A privt kept in our kitchen gardens. It grows three or four teet high. Whe stalk is round, hollow, striatod, and somewhat bonched: the leaves are rach composed of three or hive smaller, two or four set opposite and one at the ond; they are oblong, serrated at the ediges, and sham pointed ; the end leat is longer than the others. The lowers are little: they stand in romd chtsters on the tops of the branches. The mot is of a singular form; it: is composed of several long parts iike carrots. I hey are of a good taste, and sone people est them at their tubles.

I decortion of them works by urine, and is good acrainst the gravel. Whe roots borled in milk, ale an cxcollesit resturitive to people who hare suffered long illnewse's.

\section{Shoe Trex, Pramus syluestris.}

T!E common low simb in onr hedges, which we call the biartiom It is a plum-tree in minmture. It grwstive or six feet him ; the trink and branches are all covered with a dark purplish or bhelish bark. The fraves are rountish, and of a gued green, clecrantly dentated almit the edres. the formens are small and white. The fruis is 
Itile flimn. of a very ausiere taste when unripe, but pleasant when mellow.

The juife expresed from unripe sloes, is a very soont remedy for fluxes of the belly. It may be boled down to a firm consistence, and will so kcep the whole year. We used to find this dried juice kept by druggists mder the name of German acacia, but they neglect it.

\section{Smatige Ápium.}

A com3on wild plant, about ditch sides, with the appearance of celery. These are very momerous and large. The stalk rises two feet and " bralf in height, and is round, smooth, striated, and branched. The leaves on it are like those from the rorit, composed of many small parts, which are browa and indented, but they are smaller. The flowers stand in little umbeis at the divisions of the honches : they are small and of a vellowish white. "ilite seors are small and striated. 'The mots are long, not very thick, white, and of a strong, but not disigrecable tante.

The rovis are most. used; a strongry infasion of them frets gatiered, wolks bribly ly urine. It in gow! agane the pravel, and in iundices a... other

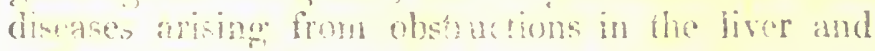

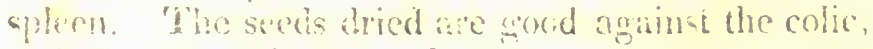
and cimongtien the stomach.

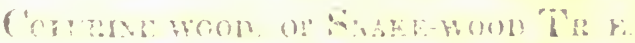

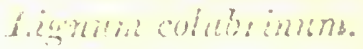

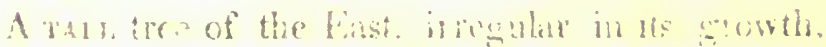
but nen whthot beally. The lark is rowh and

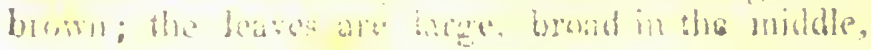





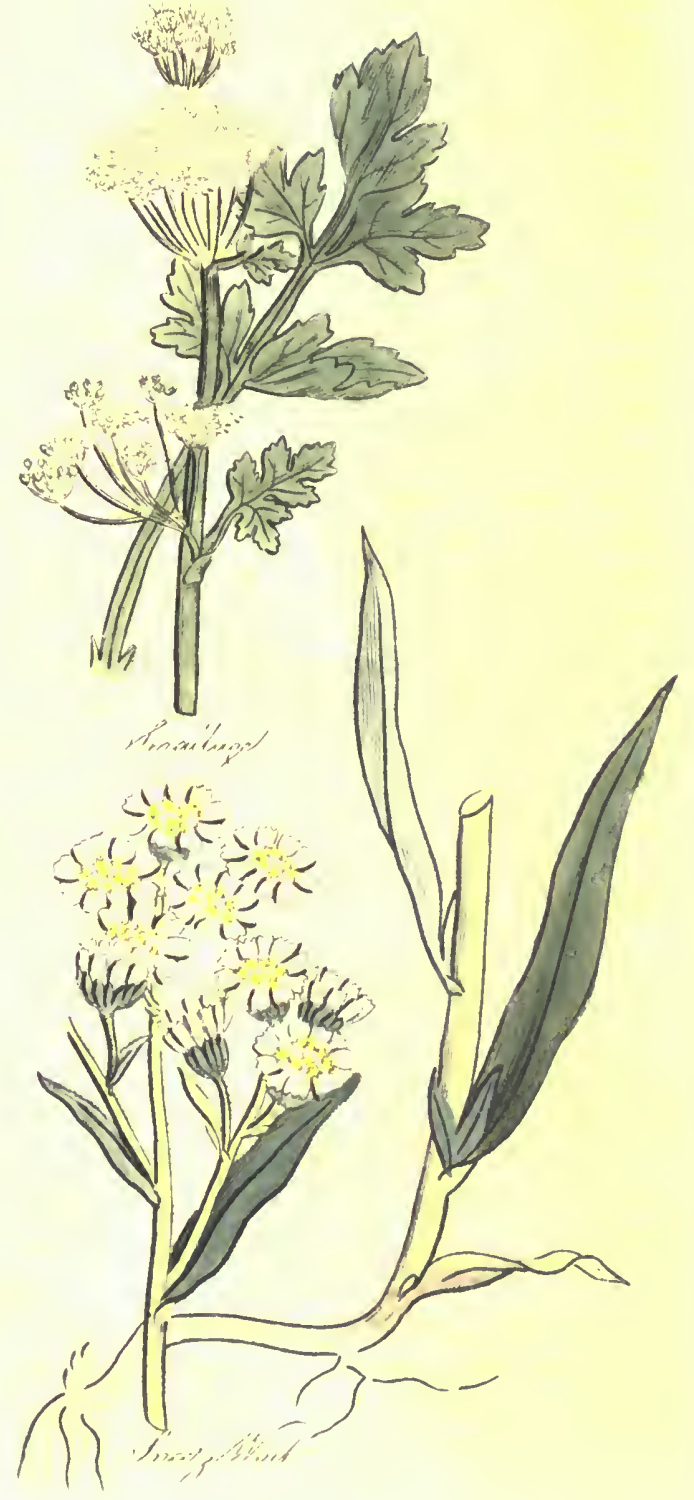


oblong and sharp at the pnint. Tliey are of a deep green culour, and tirn subtance : the flowers are small, they grow in clustron mow the branches, not at their extremities, but in diffrent jarts of them, 'The fruit is large, and muls of the shape of a walnut. It is yellow when ripe, and contains at great many round that sereds. These are exactly of the shape and form of what we call nux romica, but they are not half so big. Some have, for this reason, supposed the real nux romica to be the fruit of this tree; but it in produced by another of the same genus. The wood of the inaller branches is used: this is what we called lidnum colubrinum, adder-wood, and snake-wood. It is famous in the East for curing fevers and destroying worms; they also say it is a remedy againsi the bites of serpents, and hence comes its name. 1 te have been tempted to give it in some cases; but it seems better suited to the constitutions of the people among whom it grows than to ons: it brines on ronvulsions, if given in too lilupe a dose, of it too fresh. It louse its strength by degrecs in herping ; but I dou't know how it can be presible to determine what dose to give of sirch a medicine.

\section{SNeEZEWort. f'larmica.}

A veny pretty wild plant with daisy-like flowers, and a nomow dentated leares. It grows two fert high. The stalk is round, firm, upright, and but litte branched. The leaves are very numerms, and they stand irmulaty; they are an inch or more in lesoth, and very narrow, rough to the touch, and of a bright green. The flowers stand it the tops of the stillis, so that they form a kind of round head: they are less than daises and their inaves broader. 
The leaves of sucezenort, dried and powdered, taben by riay of stur, are excellent acoinst tise head-ach. The roots dricd are almost as firy as pillitory of spain, and they cure the tonth-art in the same mamer. A piece held in the montir, fulis it with rhum in a minute.

\section{Solonoxis Seal. Polygonalum.}

$\Lambda$ muctry plant, wild in some places, and frequent in sardens. It grows a foot and half light. The talk is round, striated, and of a pale. sreen: naked half way up, and from thence to the tei orlamented with large oval leaves of a pate seren, hmit, smooth, ribbed, and not at all mulented at the ederes. The flowers hange firm the moler jatt of the stalk; they are small and

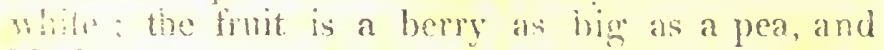
bials when ripe. The reor is white, oblung, imentir, and crepes under the surlace of the stomani

'Whe rent is the part uneri : it is conmended anemery for an outword application againd burisus. 1tor root driced and powdered is goond

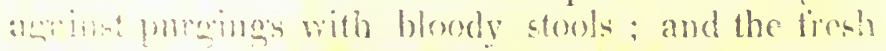
sunt beat un into a conserve with sugar, agamet the bitites.

\section{Sorewort. Saporaria.}

A wers plaut, but not very common. It is

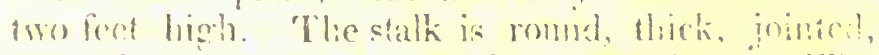

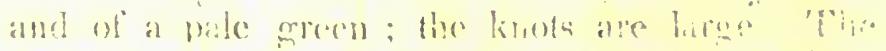

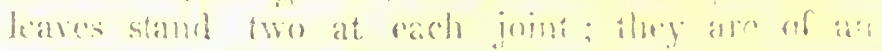

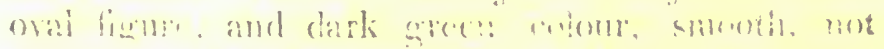

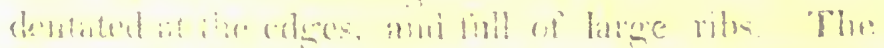

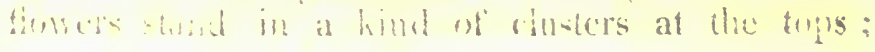




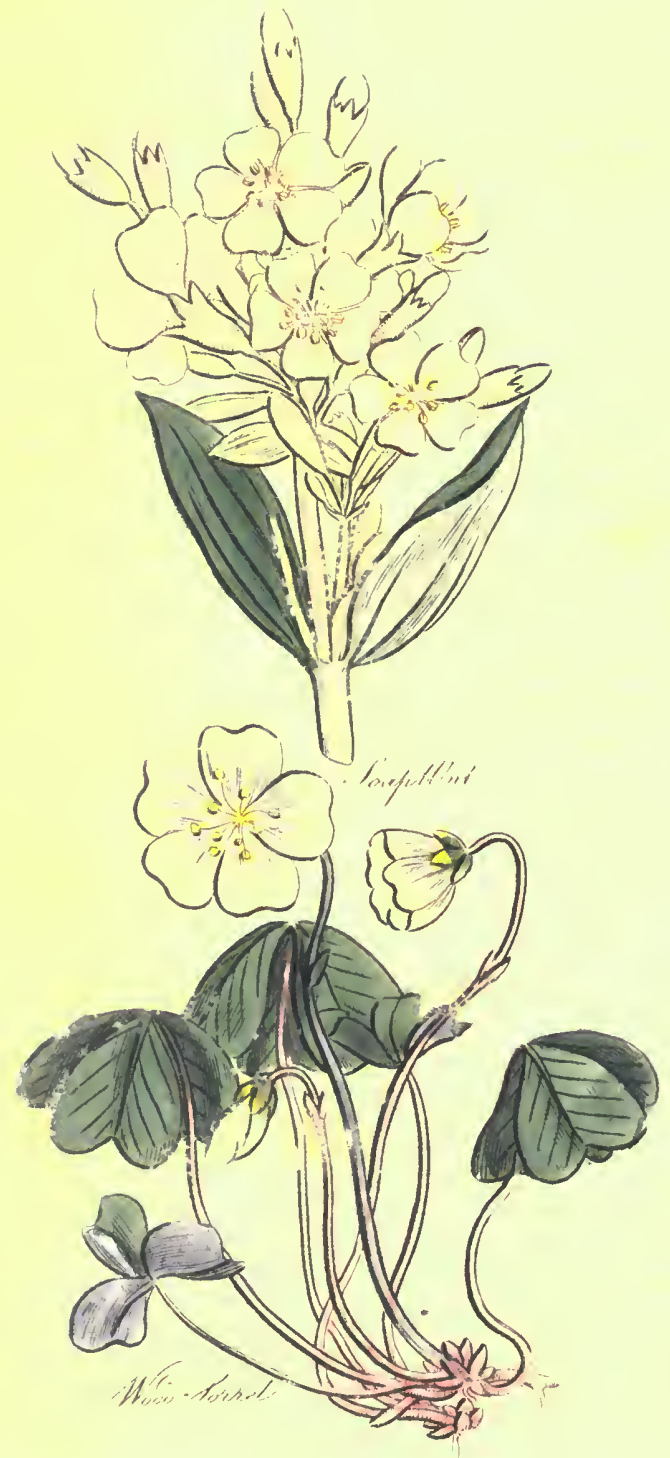



they are white or redish, and not very large; the root is knobled and has great many fibres running from it: it is of a disagreeable mawkish taste.

The root is used ; and it sinuld be fresh taken up; a decoction of it opens obstructions, and promotes urine and persputation. It is an excellent sweetener of the blood.

\section{Sorret. Acelosa.}

A commos plant in our mearlows, with broad and oblong leaves, striated stalks, and reddish tufts of flowers. It is a foot and half high. The salk is round, not very firm, upright and a little bianched. The lenses are of a deep grem, anculated at the bace, blunt at the point, and not at all indented about the odges. Whe flowers stand on tile tops of the stalks, in the manner of those of docks. of which sorrel is indeed a small kind. Whey are recidish and husk ; the root is small and frbous ; the whole plant has a sour taste.

The haves caten as a sellad, or the juice taken, are excelient against the soury. The secis are antringent, and may be given in powder for fluxes. The root dried and powdered, is also grood against mangers, the overllowing of the menses, and s.lpalings.

'There are two other linds of sorrel, nearly of hin to this, and of the same virtue: one small, ralled sneep's sorred. common on dyy bauls ; the uther bags, with hond leaves. called gavien

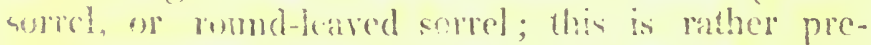
ferible to the common kind. Pesides these, there is a phat called in binglish a wirrel. so different from them ali, that it most be rescribed sepazintcly. 


\section{Wond Sorner. Luiula.}

A reRY pretty little plant, common about our wood sides, and distinguished by its bright green elegant leaves, and pretty flowers. The leaves rise in considerable number from the same root; they stand three together upon separate, long, and very slender foot-stalks, of a reddish colour ; each is of a heart-like shape, the broad and indented part hanging downwards, and the three smaller ends meeting on the summit of the stalk. The flowers are whitish, tinged with purple, very bright and delicate; they stand also on single stalks, and rise immediately on the root. The seed-vessels are large, and when ripe, they burst asunder with the least touch, and the seeds fly about. The root is small and irregular.

The leaves are used; they are to be fresh gathered ; their roots are very agreeably acid, and the juice of them makes a pretty syrup. 'The ieaves also beat up with three times their weight of sugar, wake an racellont conserve. 'l'hey are gond to guonch thirsts in exers, and they bave the same virtue with the vather nowast the scury and in sweetening the blomel.

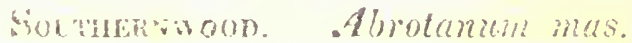

A sianlas plant, native of many parts of

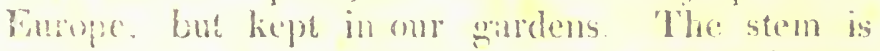
wowly. and tomph, and is rovered with a brown lark. 'Tise lorves are divided into line slender parts, and are of a pale green, whitish rolomr, and strmg small. The flowers are small and yellowish; they grow in weat numbers on the top of the stalk, sand are nahed and of a rough appearance. The seeds are tongis: and of a pale brown. 



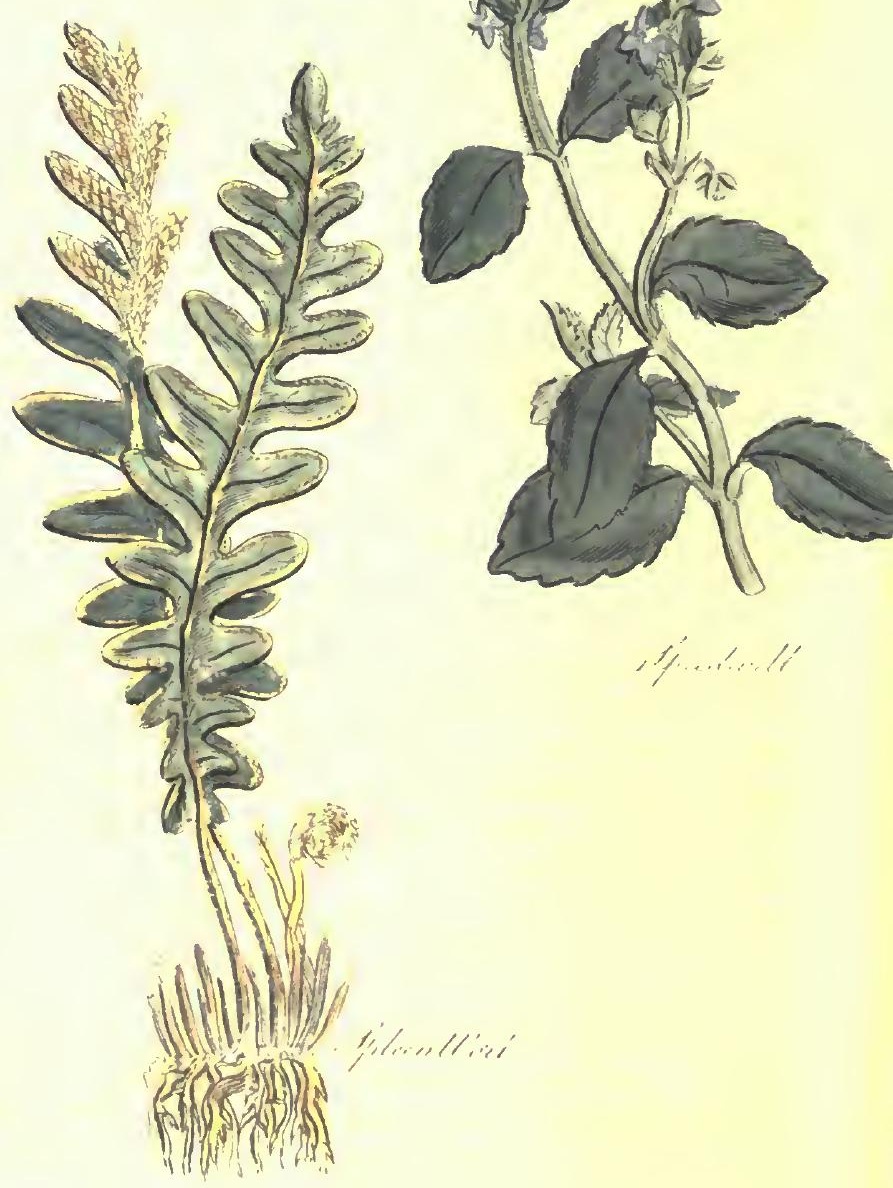


The tops of the young branches are used; a decoction of them is good against worms, but it is a very disagreeable medicine. Beaten into a conserve with three times their weight of sugar, they are not very unpleasant, and they are in this form good against nervous disorders, and in all hysteric complaints.

\section{Sowthistle. Sonchus asper.}

$\Lambda$ commos weed in our gardens, and about our houses. It is three feet high ; the stalk is round, thick, green, and upright. The leaves are long, and not very broad; they are indented at the edges, and prickly between the indentings. When any part of the plant is broken, there runs out a milky juice. The flowers are large, and yellow: they are somewhat like those of dandelion, and stand in a kind of scaly cup. The seeds have down affixed to them. The root is long and white.

The leaves are to be used fresh gathered; a strong infusion of them works by urine, and opens obstructions. Some eat them in sallads, but the infusion has more power. There are three or four other kinds of sowthistle, common in some places with this, and they have all the same virtues, but this has them most in perfection.

\section{Srexnwel. I eromea mas}

A common little plant in our iry pastures, and on beaths. 'The stalks are six or eight inches Inng; the leaves are short, and of an oval figure. The stalks are not upright: they trail along the sround, only rising at thin upper parts. The wates alle of a pale green colour, a little hairy, 
and dentated at the edges : the flowers are small and blue; they grow in slender spikes, arising from the bosoms of the leaves; the root is small and fibrous.

The whole herb is used, and it is best fresh. An infusion of it drank in quantities, works by urine, and opens all obstructions: it promotes the menses. There was an opinion lately that llis nont would cure the gout. The dried leaves piclied fom the stalks, were sold in on makcls, and people made a tea of them. The obinion was so previtent, that the plant was in a inemener destreyed hor many miles about Loncom, brit like all other things, that want the truth for their fourdation, it came to nothing.

\section{SPRIGNer. Biflm.}

A wirn plant not altosether unlike fennel. It grows two or three fect high. The stalls are romind, striated, and bmenched. The leaves are karge, and divided like toose of fennel, but into narrower and funer parts, and they are of a very dark green colour. The flowers are little and white, lint they stand in cinsters at the inps of the stalls, and are comspicions by their number. The root is long and brown, and there are always a quantity of flameste at the houd of it like hairs : these are the fibres of the statlic of former loaves.

Whe met is nsed, and it is best fresh takem up. An inhicion of it is excellent medicine in the gravel; it also oprons otistructions, and promotes the menses. The root drier and given in prowler strengthens the stomach, creates an appetite, and is good against the colic. 


\section{Sprage. Spinachia.}

A commox herb in our kitchen gardens. It grows zwo feet high ; the stalk is round, thick, and juicy ; the leaves are broad and cleft at the bases, so that they resemble a broad arrow head : the flowers are inconsiderable; the seeds grow on other plants of the same kind, and are rough and prickly : the root is white and oblong.

The leaves are enten at our tables; but their juice may very well be recomnended as a medicine. It works by urine, and is good ggainst the gravel. The leaves suen trequently, kecp the body open.

\section{SHeEnwort, Asplanimin.}

A sivgluar plant, of the nature of the ferins, but not mulike any of them in form. The root is fibrous. From this the leaves rise in great numhers toggether, each being a distinct and separate plant; they are narrow, and five inches long, deeply indented on each side, but very irregularly, and covered on the under part with small seeds. When they first grow from the root, they are folded inward, so that only the under part appears ; and they have a very peculiar aspect, more like some insect than the leaf of a plant. It grows on old walls, and is green all the winter, but it has most virtue in spring.

The whole plant is used. It is best given in infusion, and must be continued for some time; it opens all obstrmetions of the liver and spleen, and is excellent in disorters arising from that cause. They say the powder of the dried leares cures the rickete, bivt this wants proof. 


\section{INon Shine:and, Nardus Inäica.}

Av East Indian plant, of the grass kind, with triangular stalks, and yellowish flowers. It resembles not a little that common yellow tufted grass, which is frequent in our meadows in spring. It is six or eight inches high. The leaves are long, narrow, and of a pale green ; they are very numerous, and stand in a thick tuft almost growing together at the bases. The stalks rise among these ; they are naked, triangular, and of a pale, green colour; the flowers stand in tufts, of the bigness of an horsebean, on the tops of the stalks; they are blackish, but ornamented with yellow threads, which give the whole a yellowish appearance. This is the plant, some samples of which have been of late brought over as the Indian spikenard, and there is reason and authority for supposing they are so. The tops of the roots have that sort of tuft of hairy matter, which we call Indian spikenard, growing to them ; and it is of the nature of the hairy top of the spignel root, owing to the fibres of decayed leaves. Breynius also calls the plant which affords the Indian spikenard, a kind of cypertis grass.

The tuft of fibres at the tops of the root of this plant, is what we call Indian spikenard; they are brown, flattish, matted together, and of a pleasant smell : they are good in disoniers of the nerves, and hysteric cases; but so many better medicines are at hand, that it is rarely used.

\section{Srovge. Spomgia.}

A SEA plant of a very singular kind and form. It has ncither leaves, stalks, nor branches, nor has it the colvur or aspect of our ordinary plants. it more apjurachas tis the nature of the mushronms, 


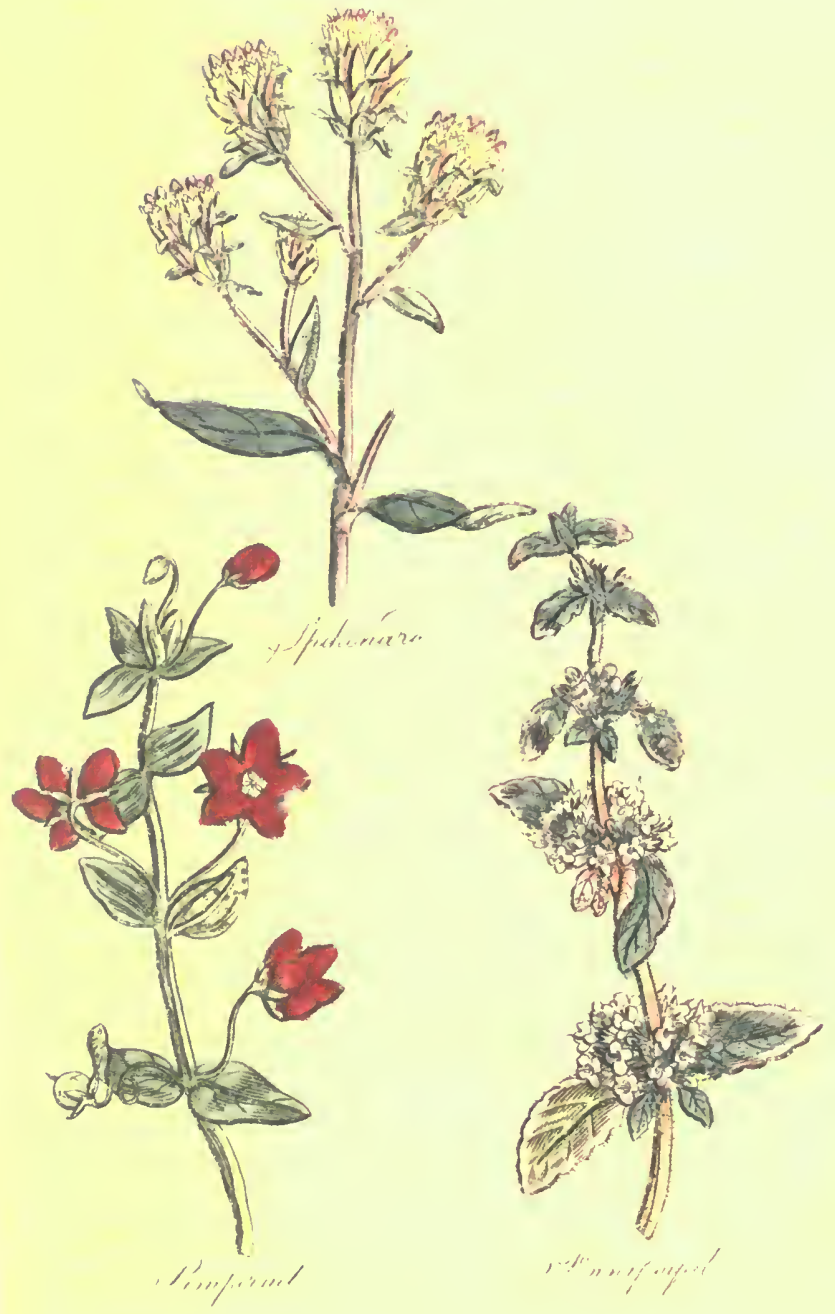



than of any other of the vegetable kinds. It grows to the rocks, and swells out to an irregularly shaped mass of matter, full of holes, of a yellowish colour, and retaining a great deal of water, which is easily pressed out, and is reccived again on dipping it again in the wet. It is of a roundish figure, and sometimes hollow. Sponge in the shape of a funnel is frequently seen, and has been described as a particular species; but this is only an accident in the growth.

It would be very imprudent to swallow sponge in its natural form; but calcined, it is of excellent service to sweeten the blood, and is good against the scurvy, and the evil: great care is to be taken in the burning it. It must be made brittle and fit for powdering, but if it be calcined too long, all the volatile parts will be driven off, and it will be worth nothing.

\section{Great Spurge. Esula major}

WE have many kinds of spurge wild in England, and some of them large enough; but this used in merlicine is a different species. It is native of Germany, and is kept in our gardens. It grows a yard high ; the stalk is romo, thick, reddish, and divided into branches. The lcaves are numerous, and stand irregularly; they are narrow and of a pale grcen, and are broadest at the end. The flowers are little, and of a pale yellow, but the seed-vessels are large, and make a conspicnous figure on the tops of the branches. The root is very thick and long ; it consists of a firm heart covered with a thick rind. Thie whole plant, when broken, affords a nilky acrid juice.

The bark of the root is used dry; and even in that state is very rough in its operation. It worky 
by stool and romit, and is good in the rheumatism and dropsy ; but it is not every constitution that can bear the use of such remedies.

\section{Lesser Gruzige. Esula minor.}

A Iesser plant than the former, but suflicienth robust; it is a native of the same part of the world. but is common in our grardens. It is a foot high. The leaves are longish and very narrow, but rounded at the end : the stalks are thick, round, and red; the flowers are smial and !ellow; and the seedvessels large and three comered. The whole ylant is full of a starp milky juice, hut most of all the root.

The bark of the root is lised. It works by romit. and stool as the former; buthough with less violence, yet too rough for most constitutions. It is good it the rhematism.

\section{Squir. Scilla.}

A very common plant by the sea side in Italy and other parts of Europe, but not native of this country. It grows a yard high, and when in flower, is very beautiful; the stalk is thick, romol, fleshy, and greer, or else reddish. The flusers are white; they are small but they have their beanty. They stand in a long spike down a thind part of the stall : the leaves are very large and bong; they are of a deep green colomr, and grow immediately from the root: the root is ronnd, and of a pomnd weight ; it is composed lite an onion of many coats one wre another. and is full of an acrid slimy juice. The colour is white or red, and hey call it the white on red squill. 



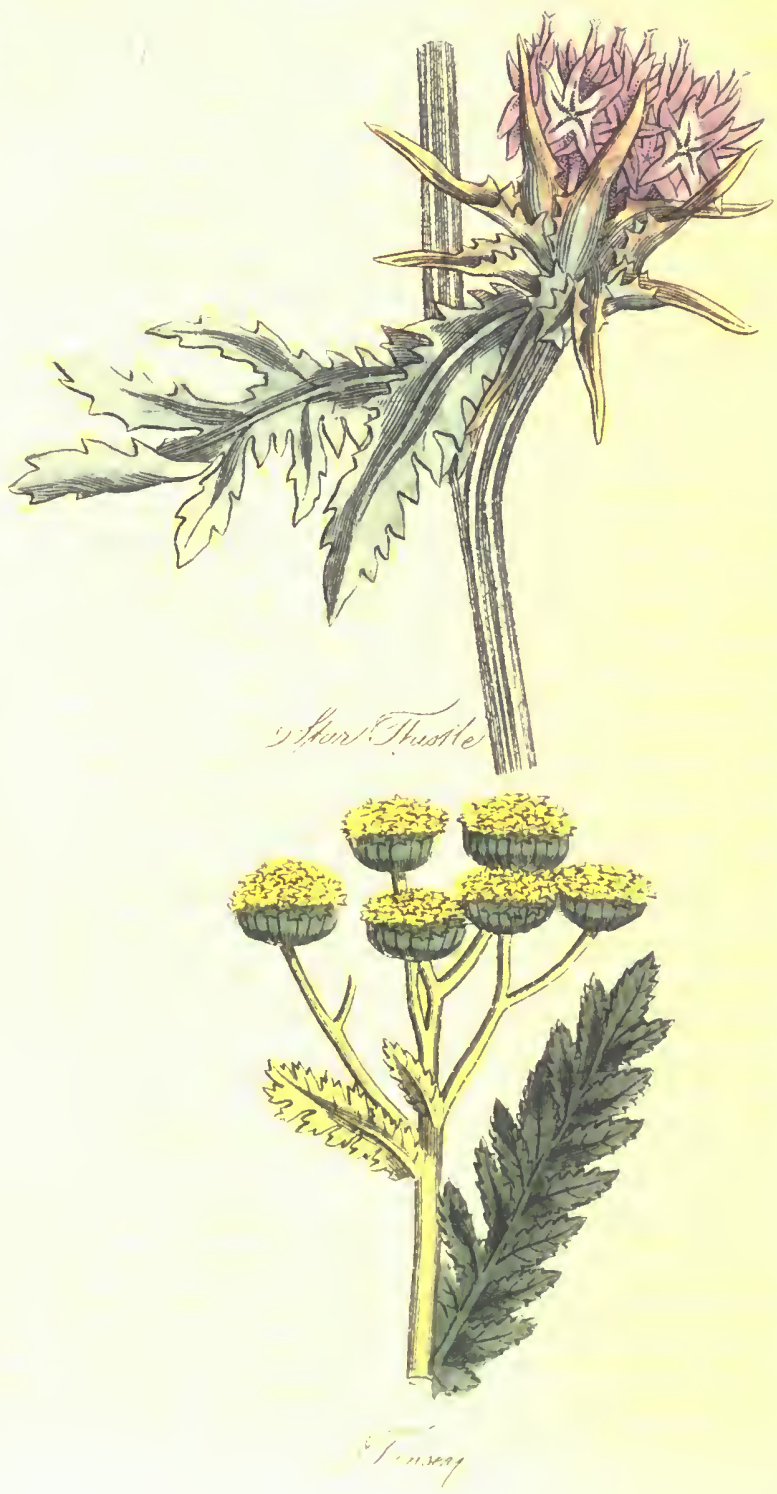


The root is used dried, or infused in vinegar or winc, and that atrerwards made into a syrup with loncy. These three preparations are called the wine of squills, vinegrar of squills, and oxymel of squills; they are all good against asthmas, and difficulty of breathing. The oxymel is nost griven for this purpuse; the vinegar causes vomitang, and clearses the stomach ; the wine of sprills works by urine, and is good against the jaundice and dropsy.

\section{Sinzwort. Aster aticus}

A conuos wild plant, in many parts of Europe and in the Grecian islands, but mot here: we have it in gardens. It is a foot and half high. The stalk is round, hairy, and branched; the leaves are oblong, moderately broad, and rounded at the ends, and of a dusky green. The flowers are yellow and large ; they resemble the marigold ; it is singular that there stand some leaves under this flower disposed into rays like a star ; the root is long.

The fresh leaves are used ; and that only externally. Bruised, and laid on as a pultice, they are a cure for buboes, and other hard swellings. 'The plant is called also ingunialis, from its peculiar effect in di-. sipating buboes of the groin.

\section{Star Finstul. Calcitrapa.}

1 wiLd plant on our heathe, bit not rery common. It is two feet high, and extremely branched; the stalks are romol, hard, and whitish. The principal leaves rise from the root, and are disposed in a circubr manner on the gronud. 'They are oblonge, and divided along the sides 
quite to the middle rib: there are some smallez on the stalk, but few. The flowers are numerous : they are red, and of the form of the flowers of thistles. They grow out of a scaly and thorny head. The seeds are winged with down. The root is oblong.

The root is used; a strong infusion of it is excellent against the gravel, and is good also in the jaundice. It opens obstructions, and works by urine.

\section{Stanry Headed Answ Tree, Anisum stel- latum.}

A TALr and very beautiful tree, native of the East, and much esteemed there. The trunk is covered with a thick bark: the branches are irregular and spreading. 'The leaves are very large and beautiful; they are composed each of ten or twelve pair of others set on a common rib, with an odd one at the end; they are longish, broad, serrated at the edges, and pointed at the ends, and are of a beautiful pale green colour, and of a fragrant smell when bruised, such as that we perceive in the young leaves of the wahnut tree, but with a mixture of somewhat aromatic. The flowers stand at the tops of the branches, on divided pedicles; they are white and vesy fragrant. The fruit is of a singular figure, of the shape of a star, and of a woody substance ; it is composed of five or more rays, and in each is a single, smooth, brown sced. They have the smell of aniseed, and thence have been called by the name, for there is not the least resenblance between the plants which produce the two; one being a small herb, and the other a large and fine tree. 
The fruit is only used, and we sometimes see it at the drugrists; if the prosent practice encouraged it we might have it common enough : and it is one of those drugs which we neglect, while we are fond of such as do not deserve the distinction. It is an excellent medicine against coldness of the stomach, colics, and those head-achs which arise from indigestion. It also works powerfully by urine; and with it possesses all the virtnes of aniseed and many others; and even in a very superior degree: it has not its disagreeable flavoui. An oil drawn from it by distillation, is swcet and exce!lent; it has all the virtues of our oil of anisced, but not its disagreeable taste, and it does not congeal like it in cold weather.

Staves-Acre. Staphis agria.

A VERY pretty plant, native of Italy, and kept in our gardens. It is two feet and a half ligh. The stalk is round, thick, firm, and upright, and a little hairy. The leaves are of a roundish figure but divided deeply into seven parts, and these serrated at the edges ; they are large, and of a deep green, and stand on long foot-stalks. The flowers are of a deep blue, large, and very like the flowers of lark-spur: they grow in a spilie at the tops of the stalks; the seed-vessels are notched, and the seeds rough.

The seeds are used. Some venture te give them inwardly in small doses against the rheumatism, and the venereal disease. They operate by vomit and stool, and bring a great quantity of water from the mouth. The powler of them is most used to kill vermin, by sprinkling it on children's heads that have been kept uncleanly. 


\section{Goubla Srocan. Stochas citrina.}

A PRETTY plaut, native in the warmer parts of Europe, and liept in our gardens. It is a shrubby herb, two feet high, and heeps its leaves all the year. The stem is woody; the leaves stand thick on the lower branches, and they are longish, narrow, and whitish, especially on the under side. The flowers are yellow, and stand at the tops of the stalks; they are dry and chafly, and may be kept for a long time. The whole plant has an agreeable smeli, when rubbed between the fingers.

The leafy stalks are used; their tops are best, and those fresh gathered: an infusion of them works by urine, and opens obstructions. It is good in jaun. dices, and obstructions of the menses.

There is another plant called Arabian stoechas, or Erench lavender. It has been described already mider the head of lavender, to which it belongs, for it is altogether diferent from this plant.

\section{Sionax Thee. Sigrax arbor.}

A swats, tree, native of the East, and some parts of Europe; but in Europe it yiclds none of the resin we call storax. We have it in some gardens. It is twenty feet high; the trmk is covered with a brown bark: that on the branches is greyish; the leaves are of a brownith or a dusky green on the npper side, and whitish underneath: the flowers are white and hares the fruit is like a nut, rumbliti and litte, and is covered with a woolly coat; thee of the tlowers grow together usually, and are succeded by three st these.

We un no part of the tree. but a resinons substance. rined: is protured from it. This is kept

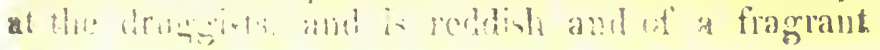


smell but very foul. It is gond in all diseases of the breast and lungs, being an excelient bitsam. It is also good in all nervous and hysteric complaints, and it promotes the menses.

\section{Shrawnem Plant. Fragaria.}

A nex common little plant, both in our wonds and gardens. The leaves stand three upe' each stalk, and they are large, broad, sharp at the point, and serrated about the edges; the stilks trail nipon the ground, and take ront at the joints: the flowers are white; they stand four or five together upon a iong stalk rising from the root and without any veins : they are white, and moleritely large ; the frnit is well lnown. When ripe it is red, and of an agrecable taste.

The fresh leaves are used; an infusion of them is grood liynor to wash at sore moutin or throat; taken in large yuantities, it works by urine, and is good against the jaundice.

\section{Succorr. Chichorcum.}

A comyos plant in our mardons. It is near a yard high, but of no great beany. The stak is round, striated, thick, erreen and strong. 'The principal leaveg grow from the rout ; they are long, narrow, and deeply indented, and are of a bluish grren, and hairy; those on the stalks are smaller, and have mo foot-stalis. The flowers are of the shape of those of dandelion, but they are biue: the seed is winged with down. The flowers grow to the sides of the stalks, not at the tops, as in dandelion. The root is long and brown on the surface; it is full of a milky juice, and white within. 
The ato is used; an infusion of it opens ot. struetions; it is gond against the jaundice. A decoction of the whinle plant, fresh gathered, works poterfully by urine, and is good against the gravel. it also grently promotes the nienses.

\section{Sugar Care Arume sacharifera.}

A kisn of reed, mative of the East and West Indies, of the Canary islands, and of some other places; and cultivated in all our plantations. It is eight or ten feet high. The stalk is round, hollow, hard, jointed, and upright; it is very like that of a common reed, only so much thicker. The leaves are like those of the reed, but vastly larger; and the fowers are in the same manner, dry, brown, and chatiy, but the cluster of them is a yard long ; ilse roots are long, creeping, and jointed in the manner of the stalk. In very hot countries the sugar will sweat out at the cracks of the stalks, and stand in form of a bright powder; this is notive sugar, and is what the antients meant when they talked of honey growing upon reeds. We press ont the juice, and boil it to the consistence of brown sugar, which is afterwards refined, and becomes the white powder or loaf-iugar.

It were idle to talk of the virtues of sugar, its uses are sufficiently known, and are very great.

\section{Evach R/ous.}

A smfon, mative of warmer countries, but common in our gardens. It is of a singular appenrance. It doses not grow more than ten or twelve feet high; the wood is brittle, and the bark is brown. The leaves are long and very beautiful, each consists of a great many pairs of smaller 
Jeates, whil an ond one at the end; the she singly, oblong, and of a riark green, aid serated at the erges. The flowers are white; they grow in very laroe, thick, and long clusters, and are succecucd by flat seeds, hairy and roundish and of an austere astringent taste. There are several other kinds of sumach in the gardens of curions perple, some of them much more beautifui, but this is the kind that is to be preferred for its medicinal virtues.

'The seeds, dried and powdered, stop purgings, and the overflowings of the menses. The fresh tops have also grrat effect in strengthening the sto. mach and bowel-; they are best taken in infusion. The bark of the rout has the same virtue; but the seeds have it in the greatest degree.

\section{SWnLow-wort. Asclepias.}

A connor plant in gariens, but native of the warmer climates. It is two feet high. 'The stalks are round, slender, of a dark colour. and jointed; the leaves are large and longis?n, and of a deep green; they stand two at each jnint. The flowers arc mall and white, and each is succeeded by two pods growing together; the root in flbrong and preading.

The mot is used; an infusion of it frash is pood agrimst the jaundice; it worrs by unine and opless obstrutions. Dricd and given in power, it opre-

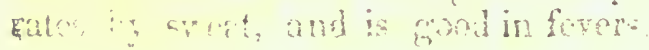

$$
\begin{aligned}
& \text { r }
\end{aligned}
$$

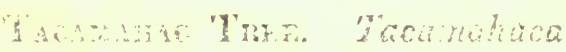

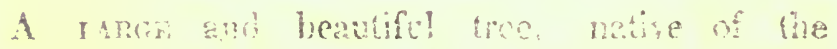
East, and of Amorica It is fifty or sisty feoto 
high. The bark is brown on the trunk, and grreyist on the branches. The leaves are large and Iongish, sharp-pointed, and dentated at the edges; they are of a duky green on the upper side, and browniah undernoth. The flowers are inconsiderable and ydlowish. The fruit is small and rombl. The buds of the tree are very fragrant; a brown kind of resin issure from them, whoh sticks to the fingers, and this has that pleasant sillell.

We use no part of the tree, but a resin which is produced fronia it. The diugrigts keep this. It is brown; some of it is in granis, and sone in a mase. It in bed anly externally ; a plaister made of it, squent on leatizer. is applied to the fore-

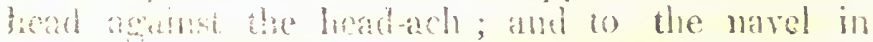
hasteric custe, but it does not seem to have much

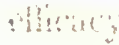

\section{Thuntor luex. pumeming}

I reny pretty tree, native both of the Fast atud Went lndies, and liept in many of onr satrdens. She trum is covered with a pale colomed romptr bark; the branches with a smontiocr. The ledves are each compesed of a great many pairs of smiller, disposed on a common rib, with no odd one at the rond. They are small, oval, and of a pale or whitish green. The flowers are large, and rery pretty; they are part yeliow, and part white; the white leares of them stained sfeen with reil. Thlev stand in cinsters, balf a dozen together. 'The fruit. is a flit pod, broad, hown, and hard ; these contain a pulpy substance, and the secels a stringy mants with them. 'The ponlp, stringes and sords ate

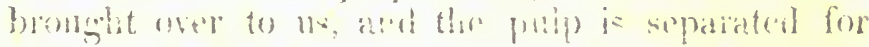

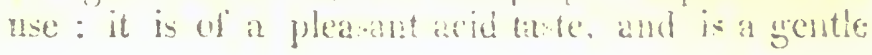


and excellent purge; it works also by urine. It is good in the jamdice. Thic pulp is usefui also to cool the mouth, and guench thirst in fevers. It is not much used singly as a purge.

\section{Tamansk. Tamariscus.}

A utrte tree, frecuent wild in France, and kept in our gardens: it grows, hewever. much larger in its native climate thin here. The balk is brown on the trmk, and paler on the branches, and the young shoot. are red and rery slewier. 'Tho leaves are very beantiful ; they are of a fine bright green, delicatedy divided into small pats, and regular. The flowers are very small and red ; bit they stand in spike, and rery close together ; and as fonr or fue of these spike alio often stand together, they are very commicuous; the seeds are small, and lodged in a downy substance.

The batk is used dried, and the tops of the Branches fresh; both have the same virtue; the one is hest in lecostion, the other in a light inmoinom. mate in the manner of tea. Fither is rood an open obstructions. The: promote the nenses, are? send in the joundice, and it is said against the sikets.

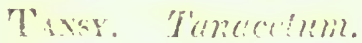

i conmov plant in our gartelis. It is a and hipt: the stalks are roumd, firm, upright, and of a pale green ; the leaves are laree, oldong. broat, and rery beatifully formed; they ante each composed of sereral pais of smallor, set on each side of a common rib, with an ond bar at the end. These are narrow, long, printed, and serrated at the edges. The flowers stand in lagere chuter: at 
the tops of the sialks, and they are roundish, yellow, and naked. The root is a cluster of large creeping fibres. The whole plant has a strong smell.

The Icaves are to be used fresh gathered; a strong infusion of them opens obntructions; it works powcrfilly by urine, and gently promotes the menses. 'The flowers dried, powdered, and mixed with treacle, are a common medicine for worms, and they visibly destroy them.

\section{Wild Tass. Argentina.}

\& comsos wild plant about our way sides, and a great ormament to them. It rises to no height. 'The stalks creep upon the ground, and take root at the joints; but it is easily distinguishad by its silvery leaves and yellow flowers. The stalks are round and reddish. The leaves rise from these; they are very large, and each composed of a grent many pair of smaller. set on both sides of a common fib, with an odd one at the end. They are of the shape, and milch of the size of tive leaves of tamy ; and the smaller leaves of which they are composed, are oblong, narrow, and serrated; but thry are of a must heantiful colour; a the vilvery green on the upper side, and a perfert silvery white on the under. The flowers suind ois shrit fors stallis, and are larese and yellow, somewhat like the flowers of the crov-fous, but more bonuliful.

The Heaves are used; a strong infusion of them is wiven with suceens argitist the bleeding of the piles, and Howdy wonls: and made less strong and swertened a little with honery it is excellent for a sore thront. The women use if also to take away freckles, but this serens idle. 


\section{Tameacos. Dracunculus.}

A comon plant in our gardens. It is two Ecet high. "The stalk is round, upright, firm, and green; the leaves are very numerous, and stand irregularly. They are longish and very narrow, and of a deep green colour; the flowers are little and greenish, in forn like those of wormwood: they stand in spikes at the tops of the stalks. The whole plant has a strong smell, somewhat like fenuel.

An infusion of the fresh tops works by urine, and gently promotes the menses.

\section{TEA. Thea.}

A surub, native of the Fest, and cherished there with great care. It is six of scven feet high; the branches are sender; the leaves are numerous, oblong, serrated round the edges, and sharp pointed. The flowers are as big as orange flowers, and white; they stand in a very small (up) : the fruit is dry, and of the bigness of a nut, containing one, two, or three cells.

All the kinds of tea wre the leaves of this shrub; they only differ as the are gathered in different states: the bohea tea is cathered when the leaves are in the bud, and more heat is uoed in drying it. The severat sorts of green are get foun the young shoots or older branclues, in spring, in summer, or in autumn, and dried with ditierent derrees of care, according to their value.

Gond green twe drank moderntely, strengthens the stomach, and asjists digestion; it is good against sicknesses, and will prevent the colic: but when bad tea is drank, and a great deal of it, nothing is more pernicious. Bohea tea is more 
astringent, and it is restorative and strengthening ; this should be dran' with cream, hut with only a moderate quantity of singar.

\section{Tenze. Dipsacus sylucstris.}

A Tale and statcly plant, common by road sides, with laige bur-like heads, and litte red flowers glowing out of them. It is sin fect high : the staik is single, thick, white, and rery strong. The leaves wrow two bowether, encmpassing the stalk at their base, and make a hollow there which will hold water : they are prickly on the ander part along the rib. The hads are as big as an apple, and soncwhat oblong: they are of a pale colvur. The root is long.

The root is nsed ; it is bitter, and giren in infusion, strengthens the stomad and creates an appetite. It is also good against ofstructions of the liver, and the jandice; perple have an opinion of the water that stands in the hollow of the leaves being good to take awaly freckles

There is andture chind of trazle, called the manured teazle. The lisats are nsed in derswing of cloth ; the virturs ane the same, and they diller very little in their gonstil form.

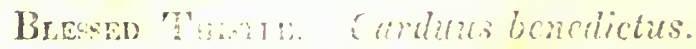

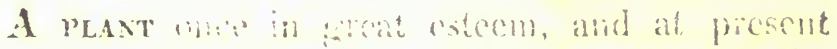

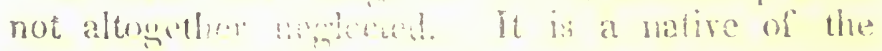

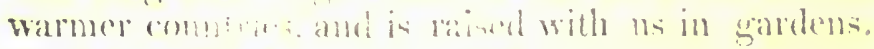

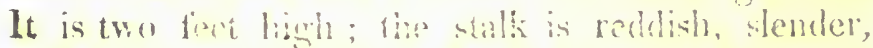
and weali ; wry mach blanched, and scance able? to kecp upright makler the weight ot leares and heads. 'Ine lowes a*e long, narrow, cut in on both sibne, and of an obscuie green. 'The flow. 



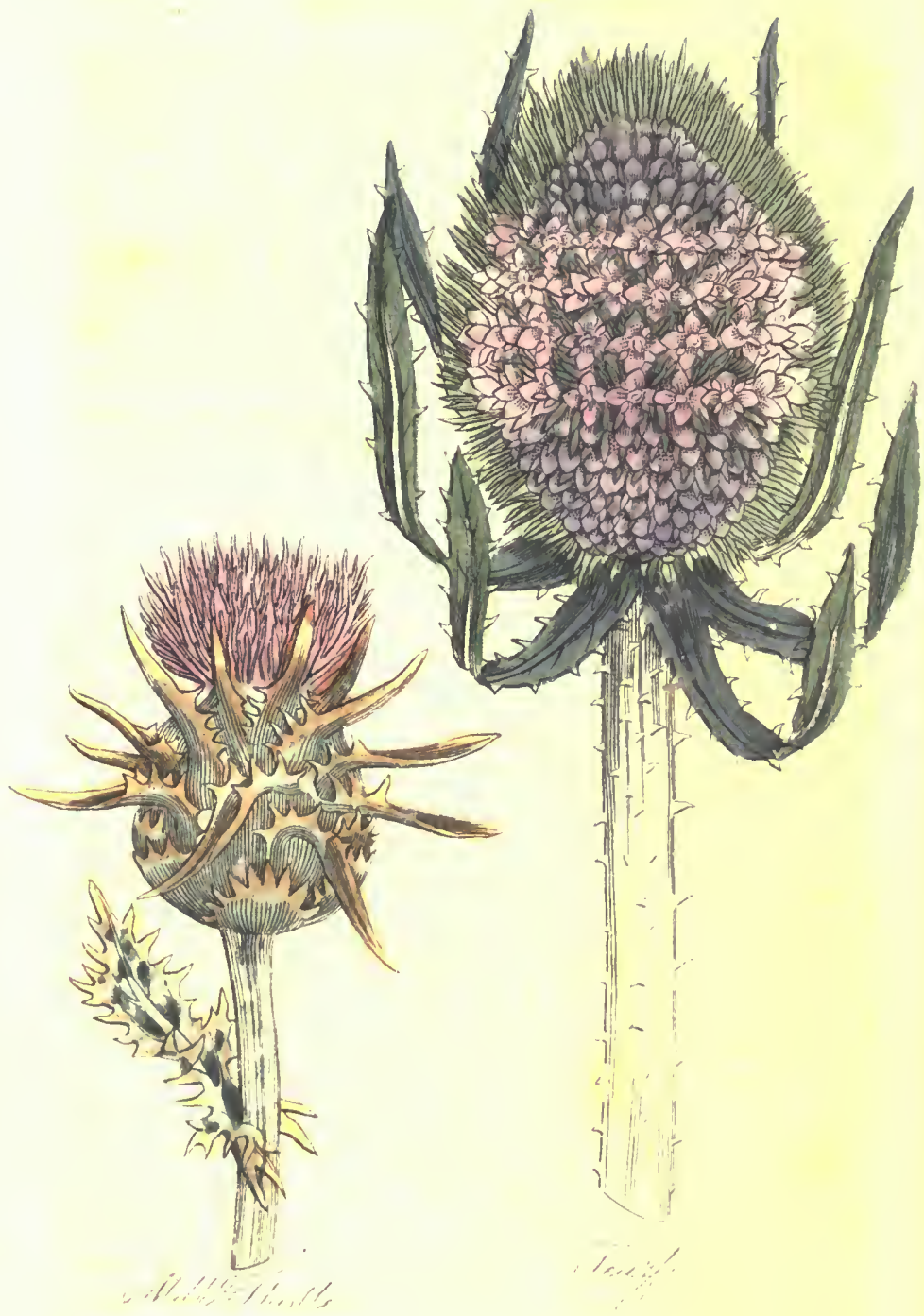


ers are yellow; they stand in a kind of grcen leafy heads: the little leaves composing these heads are prickly; and each of the cups of the flowers ends in a long brown spine dented on both sides.

It is bitter and stomachic. An infusion of it laken in large quantities, will excite vomiting : in smaller draughts, it is good to create an appe: tite, and prevents sicknesses and reachings. The leaves, dried and powdered, are good against worms. It was at one time suppossed to pussess very great firtues against fevers of all kinds: but that is now disiegarded.

\section{Mhe Thistle. Carduus marice}

A renY beautiful plant, common by roadsides, but wanting only to have been a native of Sirccec, or the Indies, to be esteemed one of the most elegant regetables in the world. The leaves rising from the root are two fcet !ong, and more than a foot brnad, of a beautiful deep green, variegated ail over with irregular lines of a milk white, dentated deeply at the edges, and prickly. They spread themselies into a round of more than a yard diameter, and when they grow out of the way of aust, make a most charming appearance. A single stalk rises in the midsi of these. It is five feet high, round, thick, veiy fitm, upright, and divided at the top into a few brancies. The leaves on it are like those from the root, and variegated with white in the same manner. At the tops stand the Alowers, which are of the nature of those of other thistles, but twice as big, and vastly more beautiful. The flowery part is of a deep and fine purple; the head itself is composed of beantiful scales arrianged with great regularity, and each termi- 
nating in a single and very strong prickle; the root is long and thick; the seeds are winged with down.

The root and secds are uord. An infusion of the fresh root remuve obstructions, and norks by urine; it is good agatinst the jaundice. The seeds beaten up into an emulsion with barley-water are good in plcurisies. The young leaves with the prickles cut off, are excellent boiled in the way of caib)age; they are very wholesome, and exceod all other greens in taste.

\section{Thors Ample. Stramonium.}

A VERY beautiful plant, native of warme: climates, but frequent in our gardens; we sometimes meet with it, as it is called, wild; but it is no native of our country. Seeds have been scattered from gardens.

It is three feet biwh; the stalk is round, thick, and divided into many branches. 'The leares are very iarge, oblong, broad, and of a bright green : divided at the edges, and of a pretty appearance, but a very ill smell. The flowers are very large, and white; they are hollow, and long ; npen, and congulated at tice hrim. The fruit is as big as a larire walnut, and is corered with prickles; the rout is rery long and thick, white, and of an ill smeli.

The leaves are used externally; the country people lay them upon burns and inflammations ; but this is nit always safe. The root and reeds are of a slespy quality; but they are not thouglit snie (1) Se giten inwardly. (Opium is a less dangeroue maticine, so they ate not used. 


\section{Goat's Thorn, Tragacantha.}

A currea white looking prickly shrub, native of the East, but kept in our gardens. It is not above two or three feet high, very spreading and full of branches. The stem is of a tough and very firm substance, covered with a whitish rough bark, the branches are as tough, and the bark is pale but smouther. The leaves are long and narow; they are rach composed of a greit many pairs of smaller set ou a middle rib, which is continued into a thorn, and when these leaves fall off, remains a white tion of that length. The fowers are white and small; they are of the shape of a pea blossom, but fatter; the pods which folluw are short and hat.

No part of the shrub itself is used, but we have a gum prolued by it, and called by its name in the shops; this is what they alsn call gum dragant, it is white and tough and is in long twisted pieces; it sweats out of the bottom of the trunk in the hert of summer. It is good in coughts arising from a sharp humour: and in sharphress of urine, and sharp stools, but it is a disagrceable medicine; is is very difficultly powdered, and the solntion is not pleasant.

\section{Thonougnwax. Pcrfoliata.}

A verr beautiful wild plant among our corri, distinguished by the stalk growing through the leaves. It is three fect high. The stall is round, furm, upright, whitish, and toward the so divided into some branches. The leaves are brota and $\forall$ ral; the stem runs inrough then tousal the 
bottom, for they have no foot stalks, and they sur. round it in their largest part, ending in a blunt point. 'They are of a bluish green colour, and not dented at the edges. The flowers are little and yellow, they stand in clusters, or a kmd of umbels at the tops of the branclies, with a parcel of small Inayes placed under them. The root is white, obloner. and slender.

I'he leares are used by the country people against wounds and bruises externally, the seeds are given inwardly, to prevent the ill effects of internal hinrts.

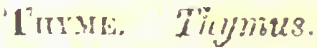

A rommon plat in our kitclicn gardens, with hard and woody stalks, small leaves, and pale red flowers. The lieight is eight or ten inclies; the branches are numerous. The leares stand two at each joint, and are of a dusky green; the flowers are disposed in a kiud of short spilies at the tons of the stalks; the whole plant has a strong smell, and an aromatic taste.

A tea made of the fresh inps of thyme, is good in asthmas, and stuffings of the lungs; it is recommended against nervous romplaints; but for this purpose the wild thyme, called mother of thime, is preferable. There is an oil made from thrume that cures the tonth-ach, a drop or two of it lievigg put umon lint and applied to the tonth: this is commonly called oil of origanum.

\section{Told Tlax. Linaria.}

A roumos wild plant, with narro, bhisels laves, and thick spikes of yollow flowers. It grows 
on dry banks, and is a font and half high. The stalk is round and thick, firm, upright, and single. The leaves stand irregularly; they are oblong, narrow, smooth, not dented at the edges, and pointed at. the ends: the flowers stand in a short and thick spike; they are large, and many of them are gerieraily open together; they have a spur behind, and their forepart is of two yellows, a darker in the midule, and a paler on each side.

The tops are used fresh gathered, or the whole herb dried. An infusion of them is excellent against the jaundice, and all inward obstructions : it gently promotes the menses, and works by urine. A fine cooling ointment is made by boiling the fresh plant chopped to pieces in lard, till it be crisp; the lard is then to be strained off, and is of a fine gereen colour.

\section{Toracco. Nicotiana.}

A rack and beautiful plant, native of the West Indies, but kept in our garciens. It is five feet high; the stalk is round, thick, upright, single, and a little hairy. It las a clammy dampnews abont it, by which it sticks to the hands in touching. The leaves are very large, oblong, and pointed at the ends. 'They are of a dusky green colour, and feel also clammy like the stalk. The flowers are red and large ; they are long, hollow, nud open at the mouth. The seed-ressel is oval, and the sechs are small.

The leaves are gond fresh or dried. A slight infusion of them fresl gathered is a powerful vomit; it is apt to work too roughly, but for constitutions that will bear it, is a good medicine against rheurratic pains. An ointment made of the fresh ones with lard, is good against the inflan- 
mation of the piles, the distilled oil is sometimes dropped on cotton to cure the tooth-ach, applying it to the tooth ; the powder kills all kinds of vermin. As to the custom of chewing and taking it as snuff, little can be said for them, from practice, and nothing from rason : nor much for smoking. If these custons had any good tendency, it would be taken off by the constant practice.

There is a lesser, greener kind of tobacco, called English tobacco. It has the same virtues with the other, but in a more remiss degree. The leaves are ofter sold for those of the other.

\section{Tormextr. Tormentilia.}

A reny common wild plant. but very prett: and of great virtue. The stalks are eight inches lons, but they con't stand upright. 'They are very siender, round, and of a biownish colour. The leaves stand seven or thereabout towener at a joint, wit ining from one base; they aie narrow, longish, pointed at the ends, and seriated at the edges, and if a deep green. The liowers are small, but of a bedutiful shining yellow: they grow on slender font stalks, and are of the shape and colour of the crom-lint flowers, only more beautiful; and much less. The roots are large, thick, and crooked, brown on the vutside, and reidish within, and of an austert Listite.

'i he ront is the part used, and it is best dried ; it ray to givon in powder, or decoction. The powder in cacellent agaiust the bleeding of the piles, blendy stonts, and the overflowings of the menses. Two ounces of the root arded to a quart of hartslom drink in the briliner, gives it a pretty colour, and cithts to its virtue; the root is coedial as well as astringent, and operates a little by sweat: this de- 


\section{FAMILY HERBAL.}

coction is therefore very serviceable in fevers, attended with purgingrs. It checks this moderately, and is grood against the ferer at the same time.

\section{Trefe of Life. Arbor vitice}

A small tree of irregular growth, a native of America, but common in our sardens. The trunk is covered with a rongh brown bark: the branches are numerous and irregular ; the young twigs are flatted and the leaves of them aye very flat, and of a scaly texture; they are of a bright green, narrow, and somewhat like the leaves of cyprus, only not prickly ; the flowers are whitish, small, and inconsidereble: they stand towards the tops of the branches. The whole tree has a strong and not agreeable smeil, it brings knto one's mind old bad cheese.

The young shoots and tops of the bwanches, are used fresh. An infusion of them is good against obstructions of the lungs, but it must be silgint, and the use continued.

\section{Gun Anme Tres Anime anon.}

A LARge and beautiful tree, native of Amerion. Its trunk is covered with a rough bown bark; the leaves are large and oblong; they nre not unlike those of the common bay-tree in forin, and they always grow two at a joint, nne nprosite to the other. They are very numernus; and the branches of the tree spread a great way; they are not all naked, but the head seems at a distance a Folid mass : the leaves are of a firm texiure, but when held up to the light, innumerable hois are seen in them, as they are in the leaves of St. John'gwert. The Howers are shaped like nea blossoms; 
they are of a purple colour, and stand at the tops of the branches. The fruit is a large pod.

The only substance we owe to this tree, is what we commonly call gum anime, but that is a very ill name, it is properly a resin. It is whitisl, brittle, and very fragrant. We sometimes also see at the druggists a greenish, brownish, or reddish resin, alled gum anime; this cumes from the Fast, and is what was originally known by that name; but at present the other only is used. It is a fine balsam, gnod in consunptions, and against the whites: and it is put into some ointments, for old ulcers, with great adsantage.

\section{Treron. Trifolium Purpurcum.}

A rommon wile plant in our meadows. It is eight inches high; the stalk is round, and not very upright; the principal leaves rise immediately from the root; they stand three together upon lonir footstalks, and are of an oval figure, but pointed; of a pale green colour, a little hairy, and have generally a white spot in the centre of each. The leares on the stalks, are of the same form, but little: the flowers stand at the tops, in a kind of short, thick, spilies; they are small and red, and are followed by little flat pods.

The flowers are used; they are best fresh swathered, and given in infusion. They are good agininst the bleeding of the piles; and while they ase batsanic and astringent in the bowels, they work is urine.

Termeric. Curcuma.

A vatre of the Fast Indies, and a very siis. gular flint. The leaves rise immediately from 
the root, and are long, broad, pointed at the ende, not denterl at the eitges, and of a very deep grreen colour. On other pats of the root stand the stalks, which bear the forrers; these are a foot high, and of the thickness of a goose quill. They have only a kind of films instead of leaves; the flower's stand in short thick spikes, and are of a red colour, longivin and slender; they look rery pretty in the spike, but do not law longr; the root is oblong, thick, and of an inregular figme, whitish on the outside, and of a deep vellow within; it creeps under the surface of the soround

Our druggists keen these roots dry. They are good against the jaundies; they open all obstmetions, ard promote the menees, and wonk by urine.

\section{Thrp:or, Turpotheim}

$\therefore$ PLANT of the bind-weed kind, native of the Eas Indies. It grows to twilye feet in length, but the stalk is slender and weak, and ramnot support itself upright. The leaves ay. ohom:gr, brad, and obtusely pointed. The flowers a"e white, and large ; they very nucin resemble those of the common erreat bind-weed. and the seed-vesel in large and fill of little seeds; the r.ot is very long and sientler.

The laik of the root is sent try. It is spoperiy indeed the whole root, $w^{\prime}$ the hard sondy part taken out of its centre. It is kept by oiu drugisise; it is a brisk purge given in a proper dose, hut it is very rarely used at this nime. 


\section{'I'rnvip. Rapum.}

A putvi too common in our gardens to require a curions description. The root is round and white, or purplish. The leares are large, long, sough, and of a deep sreen; they are deeply cut at the edges, and large and round at the ends : the stalks are a yard high, round, smooth, firm. upright, and branched; the leaves on them are small and smooth; the llowers are little and yellow, and they sitand in a kind of long spikes; they are followed by long pods.

The wonts are sin frequently eaten, that few wonld think of their prosessing any medicinat virtues, int being cut into sires, and stewed with sugur, till ther jue wibly the sugar, becomes a syrup; this is a very gand medicine against a conesti

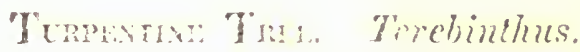

A rus tree in the liast, where it is native: we have it in gardens, bnt it never arises to any weat height here. The batk is brown and rough : Vie branches are numerous and stand irregularly; the leawe are cach composed of a double row of smaller set on a common rib, with an odd one at the end. 'These are oval, and of a deep shining grecon. 'The flowers are small and purple; they apprear in form of clusters of threads betine the feaves: the ficit is long. but with a liernel of a recinous taste. 'Lar wh le shrub has also a resinolls smell.

We use no part of the tree bat the fine Chio turfrentime, the mint esterened of all those balsams, is uhtaind fornt it; in the island whence it has its mime. It is at pleasant and an excellent medi- 
cine; it works by urine, and is an miversal balsam. It is gond in conghts and all other disorders of the lungs; and it stops the whites, and the weaknesses after venereal conplaints.

There are several other kinds of turpentine in use in the shops produced lrom the diflerent trees; the fenice turpentine is from the larch tree; the Strobmrg turpentine from the rew-leaved fir ; and the common turpentine from the wild pine. They all have been mentioned already, under the wames of the several trees which produce then ; but this is the fusest kind. What is called Cyprus turpentine is obrainad trom the same tiee with the Chin turpentinte, the rytht turpentine tree, but it is congser and browner, ohnervise the same with the Clrig.

\section{Tetsis. Androsimam.}

A reny singular and heautiful plant, and of

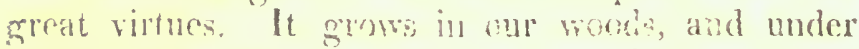
hedges, hut nut very consmon : it is kept in many garlens. It grows two fred in height. The stalks are firm and sinoe't, of a reddish colour tolerably upright, and not at all hranclisd, excrpt for some young shoots near the top. The leares stand two at cach joint opposite to onc another, and at no reat dintance : they are reys large, and of a shape approuthing to oval. Their colour is a brownith oreen; they are smonth and not scrared at the colges. The flowers are not very large, but of a beantiful yollow; they resemble these of st. John's wort, and are like them full of yellow threads, which, when rubbed, glain the hands red 7 ine mitit is a linerl of bersy, black when ripe, and contaming a ereat cambtity of small creds. The while piant in auturio 
frequently appears of a blood red colomr, very singrular and beautilul. The ront is small, reddish, and irregular ; it creeps under the surface.

The teaves are an excellent cure for fresh wounds. Scarce any thing is equal to them. The young and tender onses at the tops of the branches are to be chosen; they are to be bound upon the wound, and they stop the blong and perform a very speedy cure. I have had very hate and very singular instances of the effects of this herb. Many of the common plants are celebrated for this virtuc, but the effect of this is surprising.

\section{Twy Buare Iifoliam.}

A ren singular and pretly plaut, colimon in

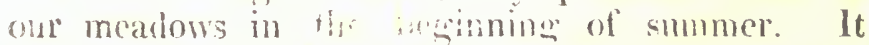
is a foot high ; the stalk is round, entecn, tender, and uprightit; it has only two keares on it, and they grow trom the root. Bhey ane rery linge, broad,

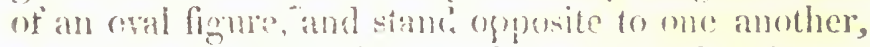
alont the midlle of the stalk of sometwhat lower. The flowers are smatl and ereen; they are of an mecomom ligme, somentuat like that of the orehis, and they sand in a long spritie; the seeds are very small, and the root is small, slender, and white.

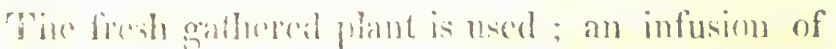

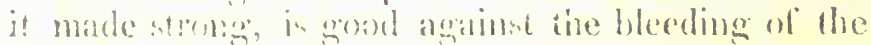
briles, and the jube is recommended to be applied to dhem externality

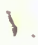

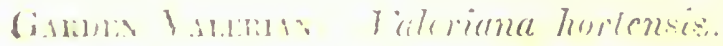

A rath and beantiful plant, native of the 
mountainous parts of Jaly, and common in our gardens. It is three foet high. The stalk is upright, rotind, strated, ani horlow. 'l'he leaves which grew from the root, are long and somewhat broad; some if these are divided deply on each side, others are entire; all have a brual and round end. 'flhoes on the stallis are smalin', and they are all deeply cirided. The flowers stend in large tufts, in the fom of monbels. at the tops of the stalks and bronclese ; they are small and white. 'The root is long, irrngular, and moderately thick; it creops muler the surtice of the ground, and has a strong smell; its colour is brown, and it is fu!l of fibres.

This root is used dry ; the drugrgists call it pine: it is good in fereis and suppressions of the menses, for it is diaporetic, and geod against all obstructions. It writis also by urine, and it is warm upon the stomach, and good awainst chisorders of the nerves.

\section{Wild Valerias, Valeriana syluestris.}

A rarr and handsome plant, frequent in our wroots and upon haths, not mulike the garden valerian in its form and manner of erowth, and of ereater vitues $I t$ is a sam lisgh. The stalks are round, striated, might, hollow, and of a pale green. The leaves are large end beautiful; they are sach compond of screral pairs of smaller set on a commen rib, and with an ods one at the ent. Those alo lons, narow, dentated at the suges, of a taint green colonr, and a little lairy. The llowers stand in large tufts like wabue at the hope of the stallse, and are sillail and whit with a linel of reddish. The root is of a whitish colour, and is composed of 
a great many thick fibres. It is of a very strong and disagreeable smell.

The root is used; it is best dried and given in powder, or in infusion.t It is an excellent medicine in nervous disorders. It is said that it will cure the falling sickness, but its good effects against headachs, low-spiritedness, and tremblings of the limbs. are well known.

\section{Faxilla Plaxt. Tamilla.}

A clmarag plant, native of America. It grows to thirty feet or more in length, but the stalk is slender and weak, and climbs upon trees to support it. It is round, striated, sireen, and tougl! The leaves are numerous and placed irregularly; they are a foot lung, considerably broad, and lite those of the common plantain, of a dusky green, and have high ribs. The flowers are small in shape like a pea blossom, but of a greenish white colour. The pods are long and flatted, of a brown colour, of a very fragrant sme!l, and full of excedingly s!mal! sceds.

This pod is the part user ; it is a cordial and restorative; it opens obstructions, and prumotes the menses ; it operates by mine, and by sweat, but it is not much used. Sorje put them into chocolate. to give it a flavour, and to mave it more coidial and restorative; this is done in the grinding up the nuts to the calie, and we bey it by the rame of Fanilla chocolate.

\section{Vertais, Terbona}

I comuos wild plant, about our path-ways with slemeler spities, and a few little fowers. It is two feet high; the stalks are numerous, square, very 


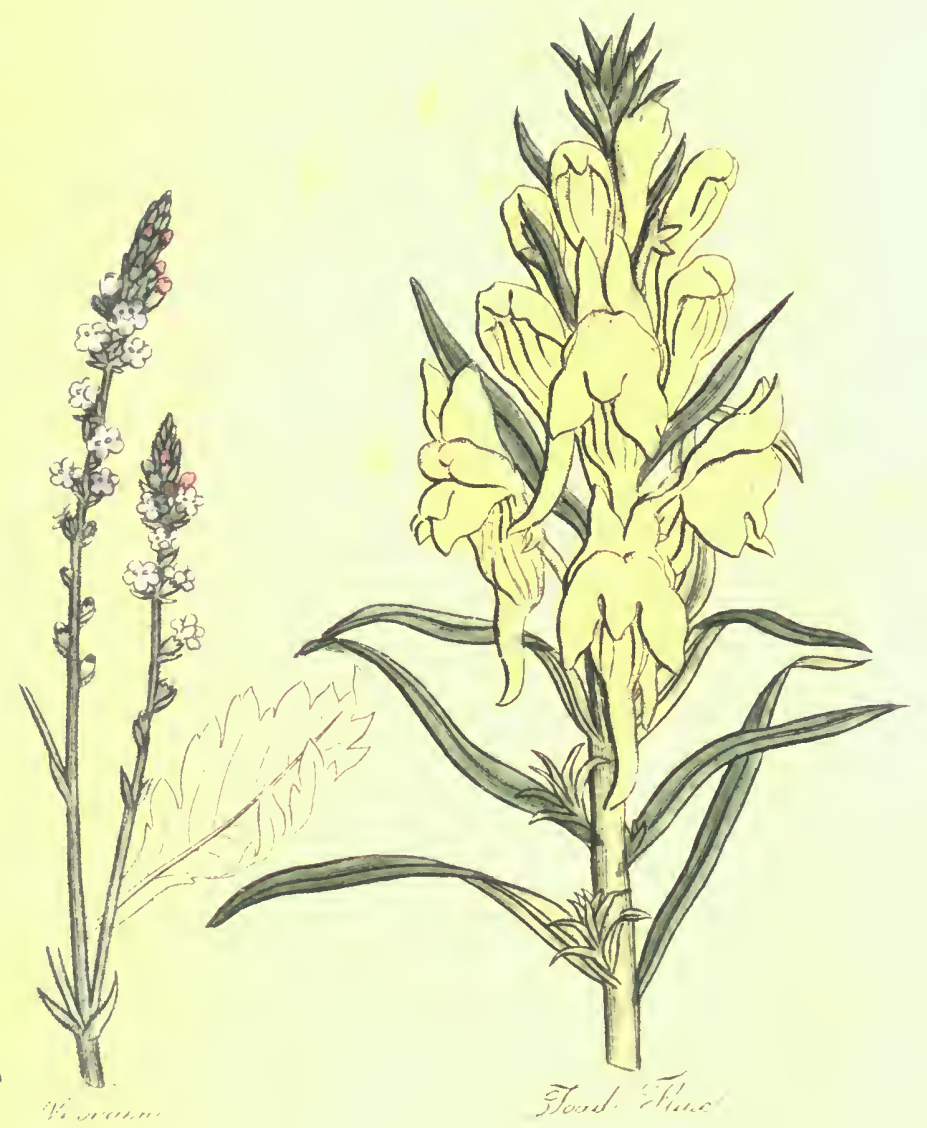



curong, a little hairy, and often purplish. The leaves grow two at each joint ; they are oblong, narrow, notched at the edgres, of a dusky green, and of a wrinkled and rough surface. The flowers are white, with a tinge of purplists: there is a long spike of their buds, and of the remaining caps, but only two or three flowers are open at a time.

The fresh gathered tops are used; an infusion of them is good against obstructions of the liver and spleen: it is warm npon the stomach, and a continued use of it will remove nerrous complaints.

\section{Vine. Titis.}

A Wedk shrub, too familiar in our gardens to need much descrimion. The trunk is covered with a rough bark : the branches are long, weak, and straggling; the haves are roundish in the whole figure, but instented deeply into five or seven divisions, the inwer are inconsiderable: the fruit is round, or biong, juicy, and produced in great Bunches.

We use no part of the common vine, as it grows with us; but not to mention the several kinds of wiue that arc useful on different occasions, the dried fruit in the form of what we call raisins and currants, is in constant repute. Raisins of the sur, Nalaga raisins, and currants all have the same virtue; they are grood in coughs, and sorencss of the lungs, and in consumptions.

Vinegar is also a product of the grape: it is wine become sour, and spirit of wine and brandy of the very best kinds, are made from wine also by distillation. The substance called tartar, of which the cream of tartar is made, is only a salt of the grape, which sticks to the wine cashs. So that we 
owe to the grape, more medicines than to any one simple whatsoever.

\section{Violet. Viola}

A cownos wild plant in our wooks and hedges, but of a firgrance superior to all that we received from the rich liast. It is a little, low, creeping plant, obscure even when in flower: the flaths are round, green, and creeping; they do not rise up, but speread themselves along the gromud, taking root at the joints; the leares rise from these rooted parts ; lewy are larige and stand cach on a long font stalk. They are of a leart-like shape, and dowed round the celpes, and of a deep green. The ibowers are snal! and of a decp and beantiful purple ; they stand singry on short foot stalks arising among the leares, and coned by them.

thle flowers are the part neel; bribing wated is to be poured upon them just entugh to cores them, and it is to stand all night when it is strained clear ofit, the sugar is to lis added to it, at the rate of toro prounds to sach pant, and it is to

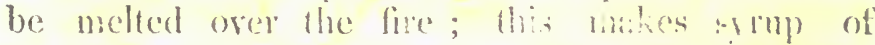
violets, an excellent ontle purer for childen. The benves are dreed al:o, and are need in the decoctions for clysters. An infusinn of them works by urinc.

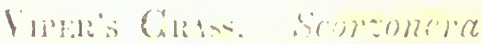

A This, and lomdsome phent, native of the

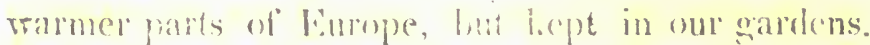
It is three foret high; the stall is round, thick, upright, and firm; tha leate are numerous and stund irregularly: they ate long, narrow, of a 


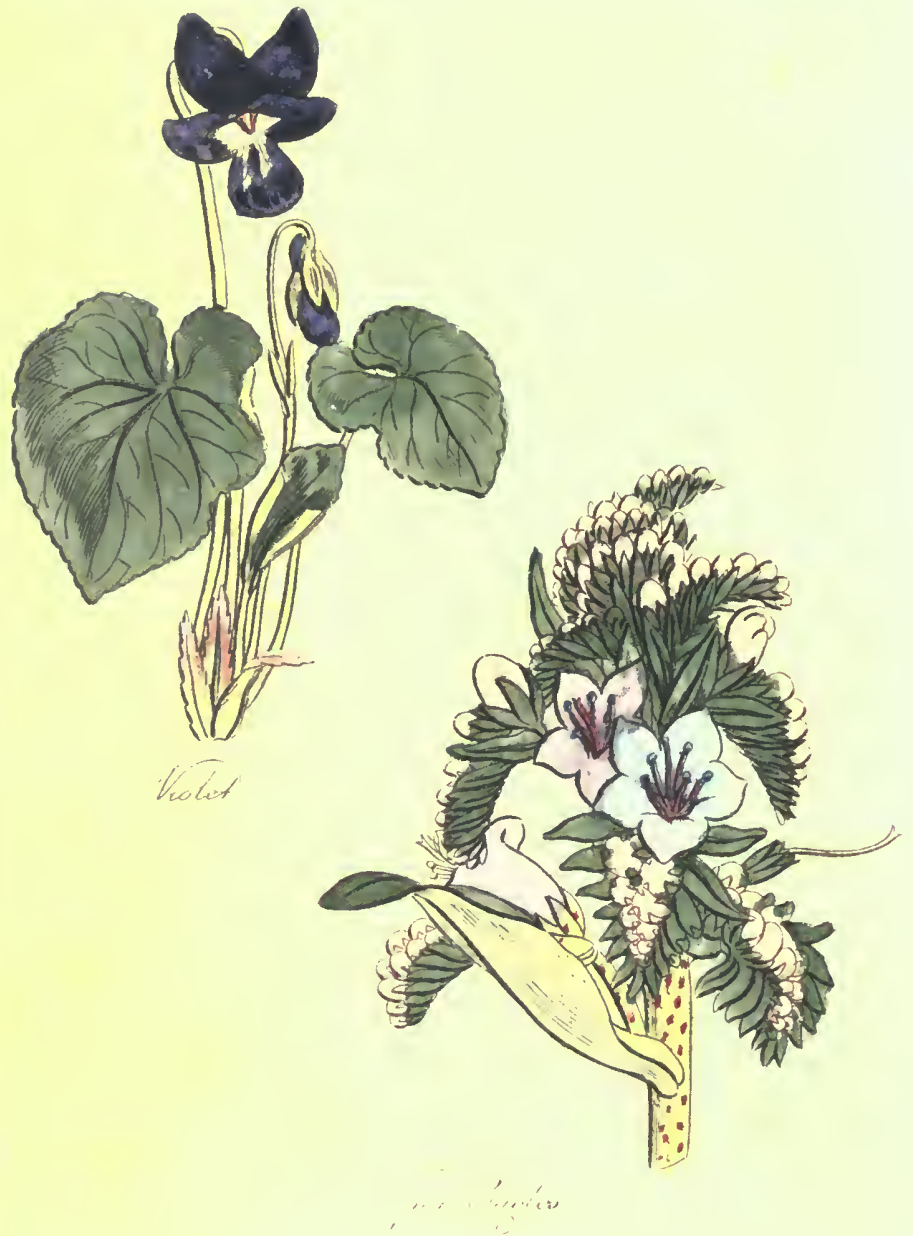



pale green, sharp pointed, and not dentated at the edges. Those from the root are long and natrow also, but they are considerably larger. The llowers grow at the top of the branches; they are large like dandelion flowers in shape, and of a most beautiful pale yellow; the seed has a white down annexed to it. The root is long, thick, and brown.

The root is the part rised, and it is best fresh taken up. It is given in infusion, and it is cordial, and operates by sweat; it is good in fevers, but little used.

\section{Viper's Bugloss. Echium.}

A COMMON wild plant, about our path ways, and on ditch-banks, known by its spotted stalks, and fune blue flowers. It is a foot and half ligh; the stalk is round, thick, firm, hairy, and upright ; it is of a whitish, colour stained with spots and lines of blue, red, and purple. The leares are longish and narrow; they are rough, and of a deep dusky green, broad and blunt at the point, and have no foot stalks. The flowers are large. and of a beautiful blue, with a red stamina in the middle.

The leaves are used; those growing from the root are best; an infusion of them is cordial, and operates by sweat; it is grood in fevers, and against head-aclss, and all nervous complaints The Vugriar Snakeroot Plant. Serpento-
rig Virginiana.

A LITTLE plant of the birthwort kind, but different from the several surts of that plant, described already in their places, in its roots, and 
in its manner of growing. It is two feet high, when it grows in a favourable soil, and has bushes or any thing else to support it. The stalks are weak and green; the leaves stand irregularly on them, and they are oblong, narrow, and auriculated at the bottom. The flowers are small, hollow, and of a deep dusky purplish colour. The root is composed of a vast quantity of strings, which are of a dusky olive colour, and of a strong smell and aromatic taste. The ronts of this plant were the first that came into use, under the name of Virginian snakeroot, but there are upon the spot two other plants of the same kind, though different species, which have thready roots of the same form, and they are indifferently taken up for use; they all seem to have the same virtue, so that there is no harm in the mixture. "There is sometimes another root mixed among them; but that is easily distinguished, for it is black, and these are all of the same dusky olive colour. This last adulteration should be avoided.

The Virginian snakeroot is an excellent medicine in fevers; it operates by urine and by sweat, and will often take off inveterate head-achs. It is also given by some as a remedy against worms; and it was originally famous against the poison of the rattle-snake, and was a remedy we learnt from the Indians. It is good against worms in childreli, and may be given in small doses for a continuance of time. Scarce any thing is morc effectual.

The Vome Nut Trea. Nux vomicr.

A TALI, and spreading tree of the liast, very like that which affords the wood called snake. wood in the shops, and by some supposed the 
mene wirh it, but that is an crror: the kernels of the fruit of that tree, are indeed of the shape of the vomic nuts, but they are not half so big. The tree is larce and spreating: the branches are numerous, and the leaves are large: they stand in pairs opposite to one another; and are oblong; bioadest in the middle, and rounded or blunt at the end, and of a very bitter taste; the flowers are small, and stand in clusters at certain parts of the young branches: the fruit is of the bigness of an apple, and is yellow when ripe. The kernels in this are what we call nux vomica; there are fifteen of them in each fruit, and they are lodged in three divisions.

These kernels are the only part used ; our druggists keep them; they are round, flat, and of a whitish colour, very firm, and tough. They have heen used as poison to dogs, cats, and other animals; but there are those who give them to the human species, in small doses, without mischief, and with very good effect. Quartan agues that have stood it against the bark, have been cured by them; but if the dose be too largye, they bring on convulsions, and thare is great reason to believe, that in very large ones they would kill. At present we have choice of so many medicines for every disorder, that it is almost unpardonable to give such as are suspicious. Some people have ventured to give even ratsbane, as a medicine, mixed with other things, and in the twentieth part of a grain for a dose; but reason condemns this rash way of practice, and doubly, is there is no necessity in authorize it. 


\section{W.}

\section{The Walnut Tree. Juglans.}

A COMMON tree in our gardens; it grows to a great bigness, and is very much branched. The leaves are very large and long; each is composed of a double row of smaller, and has an odd one at the end. These are each of an oval figure and yellowish green colour, and of a pleasant smell. The flowers are little ; they are yellowish, and arranged in loose catkins. The fruit is covered with a green thick coat, and has wilhin a kernel divided into parts, and of an uneven surface.

'l'he bark of the walnut tree is a good emetic; it may be given in infusion, or dried and powdercd; if ronits easily and plentifully. The skin that covers the kernel is good against fluxes.

\section{Wall-Flower. Leucoium.}

A COMMION wild plant, but not without beauty; it is frequent on old walls, and has yellow and swect-scented flowers. The stalks are woody, and a foot and half high; the leaves are very numerous, longish, narrow, and of a dead green. The flowers stand in a kind of spikes, at the tops of the stalks, and are yellow and moderately large. 'The seeds are contained in long pods.

The flowers are used; and an infusion of them fresh is rood against the head-ach, and in all nervous disorders. They are also good to steep in oil, to which they give a cordial warmth, and make it good against pains in the limbs. But they are pot either way much used at present. 



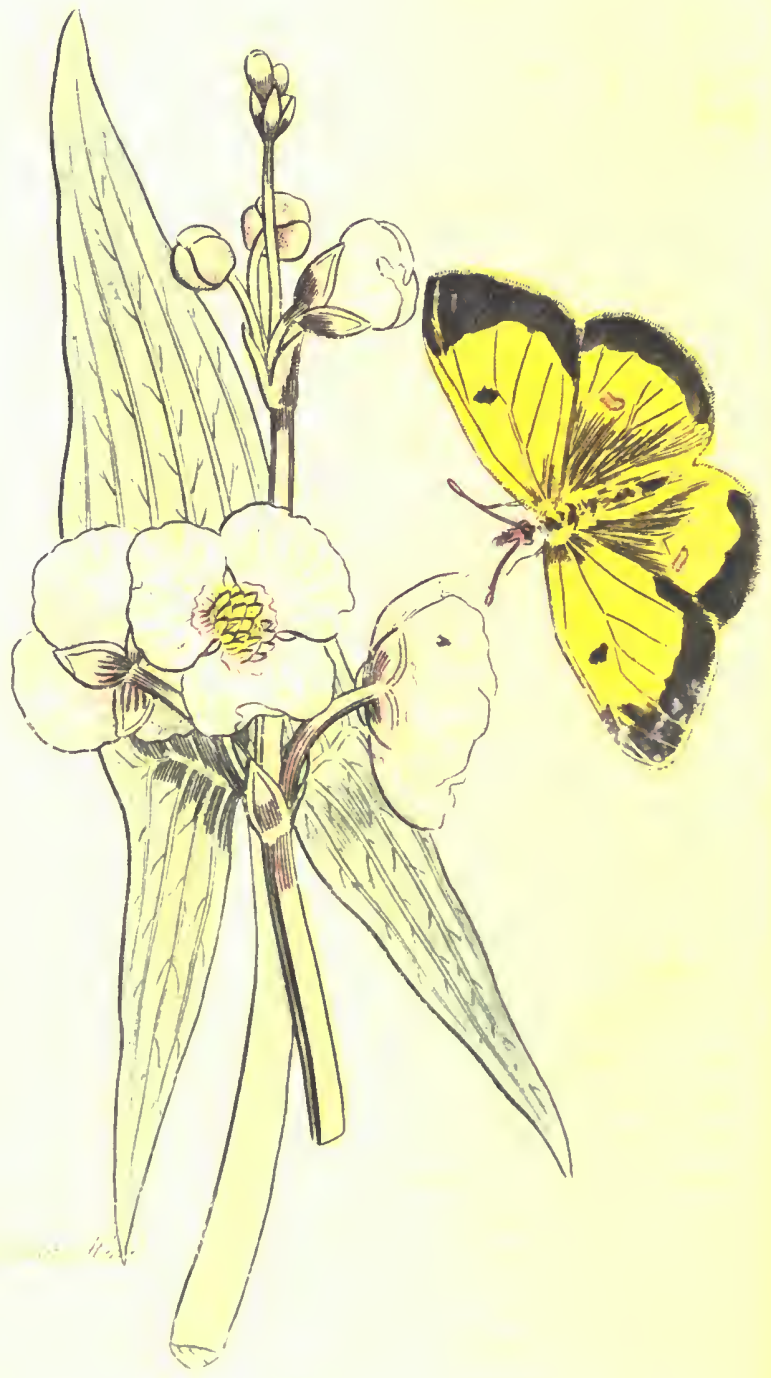


ifater Arrow Head. Sagitta aquatica.

A VERY pretty plant, common in our ditches, with leaves like the bearded heads of arrows, and with pretty white flowers. It is two feet and a half high, but generally the greatest part of the stalk is buried in water, very little appearing abore, except the spike of flowers. The leaves stand each upon a pedicle, which is round, thick, and very long; they are of a beautiful green, and are broad, and bearded at the base, and sharp at the point; the flowers are white, tolerably large, and very bright; and the stalk, on which they are supported, is also round and thick.

The common people in many places have a custom of applying these leaves bruised to infammations; they cool and give ease, but it is not always right.

\section{Water Prentaik. Plantago aquatica.}

A VERY common tall plant in ditches, and having not the least resemblance of any kind of plantain, except in the leaves; from which, however, it has received its name. The root is composed of a great quantity of fibres. From this, there rise in spring a number of leaves, oblong, broad, smooth, and of a beautiful green colour, and having in shape, though not at all in colour or consistence, some slight resemblance of plantain: they are perfectly smooth, of a glossy surface, and brittle. These stand for many months without the stalk; and doubtless in this state it got the name. The stalk is two fect or more in height ; round, firm; and upright; and at the top it sonds out a vast number of branchea, 
which send out other smaller ; and even these last are again divided. On the tops of the last divisions stand the flowers with their buds, and the seed-vessels; so that the whole has the appearance of a cone. The flowers are little and white, and consist of three lcaves each; they stand but a little time, and only a few are seen together.

The seed is the part used : the plant is to be suffered to stand, till this is thoroughly ripe, and then cut up gently, and laid to dry two or three days upon a table : a smart stroke or two, will dislodge a great quantity of the seeds; they are very good against the overflowing of the menses, find all other bleedings; and are given in powder, in electuaries, small doses being to be taken at a time, and often repeated.

\section{Rue-leaved Wuithow-Grass. Paronychia rutacco folio.}

A COMMON little plant, early in spring, on our walls and houses, and of a very singular aspect; it is red, and has pretty white flowers. It is not morethan four inches high; the stalks are round, upright, and a little hairy; and they are covered with an unctuous clamminess, which makes them stick to the fingers in handling. The leaves are little, and also red; they are each divided into three parts at the extremity, in the way of fingers: they stand irregularly on the stalks, and they are thick, fleshy, and clammy in handling. The flowers stand at the tops of the branches; they are little, but of a very bright white, and look very conspicuous. 'The whinle plant dies away as soon as ithas ripened the seed, and is not to be seen ggain till the wext epring. 


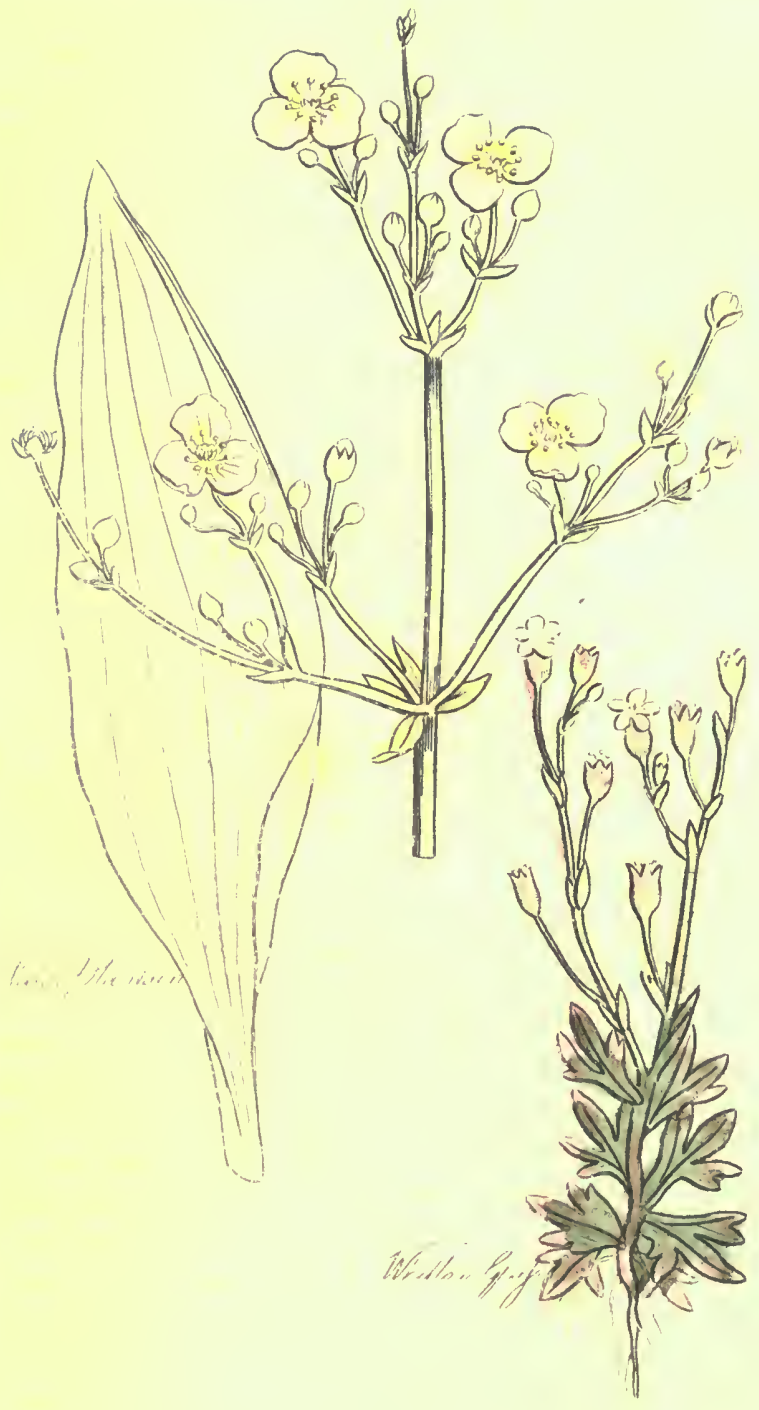



The fresh gathered plant is to be used entire: a strong infusion of it is a very great sweetener of the blood. It is excellent against the scurvy in whatever form; and there are accounts of its curing the king's evil, that seem very well attested. A syrup may be made of its juice, or of a very strong infusion of it; or a conserve of the lcaves: for the dried plant has very little virtue, and it in to be had frosh only a vely small part of the year.

\section{The Wnite Wunow. Salix vulgaris alba.}

A VERY common tree in wet places, and this which is used in medicine is the most common of all the several kinds of it. It is also the largest. It grows to be a tall tree : the bark is whitish, and rough upon the trunk, and grey upon the branches: the leaves are oblong, narrow, and whitish, essecially on the under side: they stand irregularly on the branches, and are a little serrated at the ediges, and pointed at the ends. The llowers are very inconsidurable, but they are arranged several twyether, in what are called catkins or palms. The seeds are small; they stand in the same calkins, mixed with fine white down.

rhe burk of the branches is used, and it is best Irica ; if is grod a waiust purgings, and the overdowinge of the merass, and is nost conveniently giten in powder, half a dram for a ciuge.

\section{Winter Ginem. Pyroba}

AN EXTREMELY pretty plant, wild in gnme parts of Lingland, but sot cominon. alle stalk is round, thick, upright, and fen inches histis. The

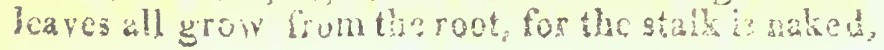


they are broad, roundish, and of a decpgreen colour: they are of a tleshy substance, and stand each on a separate foot-stalk of three or four inches Inng. 'The flowers are small, and of a very bright white; they stand in a kind of loose spike on the tons of the stalks. The ront is composed of a quantity of thick whitish fibres.

The leaves are used. A decoction of them with a piece of cinnamon, and a little red wine, is giver against the overflowings of the menses, bloody stools, and all hamorrhages, and against ulcers in the urinary passages, and bloody urine.

\section{WOAD. Glastume.}

A PLANT cultivated in fields, in many parts of England, for the use of the dyers, and commonly met, with iu places near those where it was sown, as if a wild plant; but it is not properly a native of our country. It is a tall, erect, and handsome plant ; the stalk is round, thick, firm, upright, and four feet high; but it is usually so covered with the leaves, that scarce any part of it is to be scen naked. The leaves are long and of a considerable breadth. They are large at the base, where they grow to the stalk, without any foot-stalks; and narrower all the way to the point. They are of abluish grcen colour, and the whole plant is covered with them, so the top has a pretty aspect. The flowers are little and yellow; they siand in grcat numbers about the tops of the stalks, which are divided into a multitude of small branches; and they are succeeded by small seed ressels. The root is loner and thick.

Although tie drers are the people who pay most regard to woad, and for whose use it is culo tivated, it has virtucs that demand for it a great 


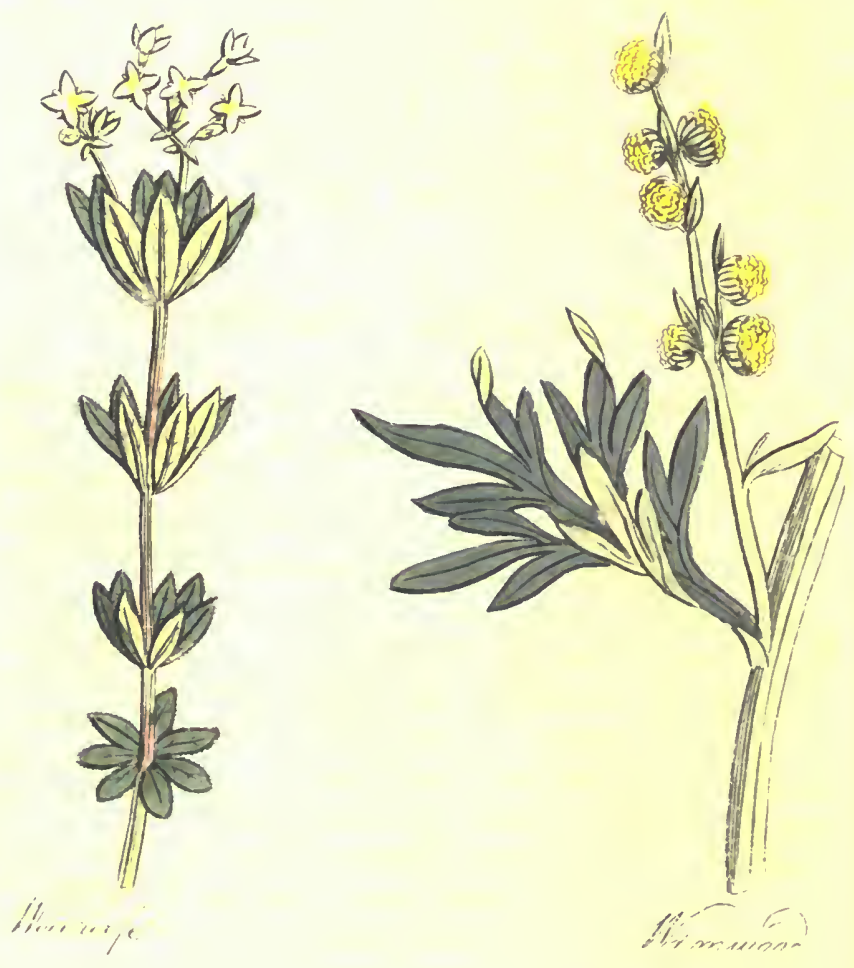
deal of respect in medicine. The top of the stalks, Before the flowers appear, contan the greatcst virque, and they are best fresh. 'They are to be given in infusion, and they are excellent a rainst obstructions of the liver and spleen; they work by urine, and so take effect; the use of this infusion must be continucd a considerable time: these are disorders that come on slowly, and are to be slowly te: moved.

\section{Woodrufre. Asperula.}

A COMMON little wild plant, in our woods and thickets: it is ten inches bigh. The stalk is squarc, slender, weak, and not able to support itself perfectly unight. The leaves stand several at each joint, encon passing the stalk in the manner of a star; they are oblong, broad, and of a deep green. In their form and manner of grnwth they much resemble those of common cleavers, but they are larger, though the plant is so muck less, and they are not rough as in that plant, but nearly smooth. The flowers stand at the tops of the stalks in little clusters; they are small and white; the seeds stand two togetber in a globular form. The ronts are little and fibrous.

The fresh herb is used, and is best given in strong decoction; it opens obstructions of the liver and spleen, and is a cordial, and stumachic. It is good in the jaundice.

The Worvesed Prant. Absinthium santonicum.

A KIND of wormwood, native of the East, and ust known so much as in our gardens. The plant is two feet high. The leaves are very fine- 
ly divided, like those of the true Roman worm wood, and of a pale green on the upper side, and a silvery white below. 'The stalks are'stitt, tirn, woody, and branched; they are of a whitish colour, and have a loose downy skin upon them : the flowers aresmall and brownish; they rescmble those of wormwood, and stand in a kind of loose spikes at the tops of the stalks.

The seeds are used : our druggists keep them; and very often the unripe huds of the flowers in their place, are mixed with then. They are gond against worms in children; the good women give them mixcd with treacle: and few medicines for this purpose have better effect. For people of nicer palates, they may be powdered, and made into boluses

\section{Treacle Wormseed. Camelina.}

TIISS is not the plant which produces what the drugrgists sell under the name of wormseed; that is the produce of an Egyptian kind of wormwond, just described. This is an Engligh berb of the podded kind, and very distinct in its whole appearance from that, and all of its sort. It is two feet high. The stalks are round, upright, firm, and toward the top divided into branches; the leaves are very numerous, and stand irregularly. They are longish, narrow, pointed it the sinds, mot at all dented at the edges, and of a dusky grem coinur. The flowers are little and yolhw; they stand in small clusters at tie tops of the branclies, and under them is a kind of spike of pods; these are long and slender, green at first, but of a hind of brown colour when spe; and in rach is a great number of secds: 
these are round, small, and of an extremely bitter taste, much more bitier than the common wormserd.

This secd is the part used. The grood women bruise it, and uixing it with treacle, give it to the children of robust constitutions against wrorus. It operates powerfully, by stool, and, if given in ton large a quantity by vomit. It is therefore to he used with discretion; but it will answer the purpose, and is preferable, for many reasons, to those mercurial niedicines, which it is the fashion of the times to give to people for those disorders; rapecially in the country, where there seldom is skill enough in the practitioner to manage, as he ought, medicines, which may be the occasion of o much mischief.

\section{Commox Tormwood. Absynthium rulgare.}

A WLD plant frequent by way sides, and on ditch-bank. It is a yard high. The stalks are rotud, striated, white, firm, and branched. The leayfe are large, but they are divided into a great numiler al small parts. They are of a pale whitish green, find starid isregularly on the stalks; many larcer, but of the same kind, rise from the root. The flowers stand in a kind of lonse spikes at the tops of the stalis; they are small and brown. The whole plant is of a very bitter taste.

The tops of the plant are to be used fresh gathered; a very slight unfusion of them is excellent for all disorders of the stomach, and will prevent sickness after meals, and create an appetite; but if it be made strong, it will not mly be disagreeahle to the taste, hut will disgust the stomach

The tops with the flowers on them dried and 
powdered, are gond against agues, and have the same virtue with wormsced in killing worms: indeed they are much better than the wormsed that is commonly to be met with, which is gencrally too much decayed. The juice of the large leaves of wormwood, which grow from the root before the stalk appears, is good against the droysy and jaundice, for it opens obstructions, and works by urine powerfully.

SeA.Wormwood. Absynthium seriphium?

A PLANT common in our salt-marshes, and about ditches, where salt water comes. It has somewhat the aspect of wormwood, but the leaves are much narrower in the divisions, and the whole plant is smaller. The stalks are woody, firm, upright, very much branched, and a foot and a half high. "The leaves are whitish and small. The flowers stand in loose spikes at the tops of the stalks; they are little and brown; and they very much, resemble those of the common wormwood, excepi for the size. The whole plant has a bitter taste but not disagrccable, and it has a pleasant aromatic smell.

The tops fresh gathered, and the whole plant dry, are used. They call it Roman wormwood at the markets and in the shops; and it is nsed for the other: it has the same general virtues. fill the three kinds indecd possess them in $\mathrm{cmm}$ mon; but the rommon wormwond is the most disagrecable to the taste, and sits worst upnn the stomach : this is better than that, but it is much more disacreable than the true Rnman wormwood. It is very strengthening to the stomach; it assists digestion, and prevents wind. It is commonly an ingredient in the bitter infusions, and 
tinctures of the shops, but it does very well alone ; boiling water poured upon it, and suffered to stand till it is cold theil strained off, is an excellent medicine to cause an appetite. Put into white wine, it also gives a pleasant bitter flavour, with the same virtues.

Roman Wormwood. Absynthium Romutrum.

A VESY delicate plant of the wormwond tind, native of the warmer parts of Europe, but kept in our gardeus. It is two feet and a half high : the stalk is rount, smooth, hard, upright, of a browist colour, and somewhat woody. The leaves stand irregularly on it, and they are small and divided into very fine secments: they are more like the leaves of the common sonthernwood in firure, than those of either of the other wormwoods. The flowers are little and brown, like those of common wormwood, but vastly smaller; they are very numcrous, and stand at the tops of the stalks in a kind of long and thick spikes. The ront is creeping and spreading, and coupesed of fibres. The whole plant has a bitter taste, but not at all like that of wormwood, extremely aromatic and pleasing. The flowers are very bitter, and have little of this aromatic flavour.

The fresh tops are used, and the whole plant iried. It is ercellent to strengthen the stomach; hut that is not all its virtue. The juice of the fresh tons is good against obstructions of the liver and splein, and has been known singly to cure the jaundice. 


\section{i. \\ Thnow, Milleforim.}

A COMMON plant in our pastures, and by way sides. It is two or threc foet lingh; the stalk is round, upright, firm and striated : the leaves are long, and not very broad, and they are the most beautifuliy divided of those of any known plant.

Their colour is a deep green, and the parts into which they are divided are excredingly fue, slender, and regularly amanged: the flowers stand at the tops of the branches, in the manner of umbels, in round and large tuíts ; they are white, but they often have a blush of red. The root is whitc and creeping, and the secds are white, broad, and fat.

The whole plant is uscd fresh gathered, but the best part is the tops of the shoots; these are to be boiled in water, and the decoction sweetem. ed with fine sugar; it is execllent against the blecdings of the piles, and bloody fluxes, and the nvertowing of the memses. It is also healing and good in ulcerations of the ureters: and it operates gently by urine.

\section{Z.}

'The Zedohry Plant. Zchoaria.

AN Eastern plant, very singular, and very beantifia!. The root creeps under the surface, and has many tuberous lumpa, some ing and some rnund: hut the long are preferred. The round hase by man been calind zerumbeth; thongh the zerumbeth is properly anoiler root: 

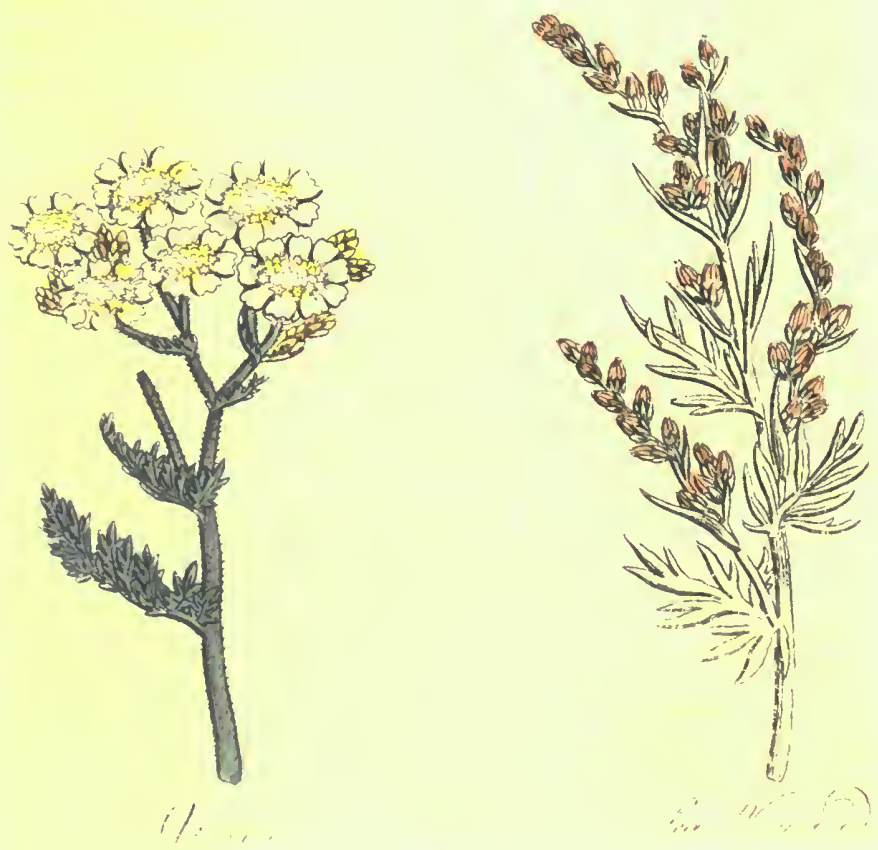

to be deacribed in its place. The laves of the zedoary plant are large, very broad, and not vatly lone; they staind in cluaters, chcircling one another at the bases: the flowers stand on separate stalks: these are only cight or ten inches lish. They are small, of an irregular shape, and purplish.

The ront is the noly part used; our druggriots keep it dry; it is a warm cordial, and smmache maticine: it strengthens the stomach, ansints digestion, and expels wind. It is good alor in all nervous conplaints, such as lowness of spirits, fuintings, trembling of the limbs, and resteswness. An ounce of zedoary, sticed thin, and put inn a ouart of wine, thalses a sincture for these porposes, and is very goud faken in the quantity of a smit plase, on going into a damp, on whit in sucpected to ba a tainted air.

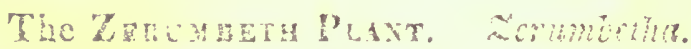

WIIE zerumbeth phist in some repects ro sonbles that which a a tords the zoroary, but it is larger. It is a native of the kist, and has not been yet got into our gardens. 'Whe leaves grow tomether in such a mamer as to form a kind of stalk; this is are fert high or more; lut it is only formed of the lower parts wrapped round one another, in tise monner of the leaves of our Alags. The loose part of each leaf is loing, narrow, and of a bluish green. The fowers stand upon seprate stalks; these rise abunt a foot bigh, and are of a brownish colour: they have ouly a sort of films upon them in the place of lesves. The flowers stand in a short and thick spike, at the tops of these, they are oblungers 
loliow, moderately large, and of a beautiful scarke. The root is long and irregalar.

The root is raed; our drughists keep it : it is warn and gond in all hervous cases. 1ts rirtues are very reaty the same with those of zedorry: and in general the round ronts of zedoary are sold under its name, though in reality it is a much longer, as well as larger rnot, than the zeduary itself. 


\section{APLENDR.}

Concerning the virlues of plants which have not yet beentried.

A $S$ the intent of this work is truly to be of use to A nankind, the author who is desirous of making that utility as extensive as poswible, camnot close it without observing, that, notwithstunding the great deal that is known of the virtues of Einglish plants, there is certainly at yeat deal more unknown ; and there is ron for great discoveries.

The plants mentioned in this work are only fon!" or five hnndred, and not all these of Finglish growth; if they were, they would yet be but a very snall number in proportion to the whole. The catalogue of those native of our own conntry, as published by Mr. Ray, amonnting to many thonsands; sreat numbers therefore remain yet untried.

To what purpose can a man devote the bours of his leisure better, than to the discorering among the number to the unregarded, virtues which may farther supply the catalogue of our own remedies, and make the roots and seeds brought from remote countries less necessary? What encouragement to the attempt, that there are such multitude of objects for the trial! and that the discovering but one remedy among them all for 
a disease lie knew not how so well to cure before, is a source of more true honour, than can be derived from all the nseless knowledge in the wold.

If any suppose the trial dangerous, they mislead themserves; and to cncomage so landible an mudnuking, I shall observe how little is the bazard, and how comsiderable the advantages, fron what we know already.

If a man were to be tumed loose upon an island where no person had set fout before, he might dread to taste of any plait he saw, herause he might not know, but every one he saw was liatal: and supposing him to have got orer this lear, the ignorance of the virtues of all would kecp him backward: but this is not at all the case with him, who shall at this time set abont inguiring into the virtues of plants in Fuginul. The poisonous planis, native of our suil, are haril!y a dozen and these are chatractered even to the ere, by something singular or dismal in the aspert. They are well known; and he has nothing to do but to aroid them. For the rect, he has so many, whose lises and guabities are alieady perfectly kincen, thial he has a great foundation to go npon in the saricit, because he can compare those he dock not know wit! them. Their tate will go a rreat way towald informing him; but this is nut all, their very ontward figures will direct him: fir in meneral fhose plants which agree in the external asject, agree likewise in their virtues.

"lewive an instance in the madshmallow. It is turing 60 worti by mine, and to be good against. t... savel. IVe will suppose no more known a coning this kind. A person desirons of exnig this madul knowledger, finds that by the ane of the ront, which is insipid, and its mu- 
vilayinons quality, he might have guessed this to be its virtue, from what he betore knew of medicine. 'The next plant he meets, we will suppose is the common nallow, and afterwards the little white flowned mallow, which lies upon the ground; he tastes the ront of these, and he finds they are like the other: he will therefore gitess, that they have the same virtues and upon trial, he will find it is so.

But this is not all: if he had examined the flower of the marshmallow, in what manner it was constructed, and how the little threads grew within it, he would have found that the nower's of these other two mallows were, in all respects, lile those of the other; and farther, he would have found, that the seeds of these two kinds were in the same manner disposed in circular lioalies: from this he might, without tasting their rosts, have been led to guess that their virtues were the same; or having guessed so much from this, he might have been thence led to taste th: $(\mathrm{m}$, and by that have been confirmed in it: but he might be carried farther; he would find the same sort of rome clusters of seeds in the hollyoak in lis garden ; and upon examining the single flowers, he rould see they were also alike: and hence he would discover that it was of this kiad; and he would rightly judge that the hollyoak, also possessed the same virtues.

This is a method by which many of the plants mentioned in this book, have been found to have sirtues which others neglected; for there are many named in the preceding pages, and named with great praise, of which others have made little account: these are the means by which the first guesses liave been made abont their virutues; and experiments have always confirmed them. 
It has not always happened that the virtues of a plant thus tried, have been in a degree worth setting in a lighlt of consequence; they have been sometimes slight, and the plant has been disregarded; but they have scarce ever missed to be found of the same nature.

These experinents, I have always thought honesty required me to make upon myself, and I never found hasm form the trials. I had no right to bung into the least pousible danger, the health of abors ; as to my own there was no probability wi: ham; brit if it had heppened, the intent would here sancified the accilent, and I shonld have been contented.

ribere is this great use in camining other plants whicin bas the same solt of flower's and fruits with those which we know to hate rirteres, that we may in this way discoing plante at home, to sisply the place of those we have from other combintes. It is ceitem the sun in warmer climates deres ripen the juices of vesolables farther than in ouls, but ret we find the plants of the same kind from whaterer part of the world they come, to prosess nearly the wame lind of virtues; generally indered they are the same. mly differing in degree. Thas all the mallows of Spain and taly, to bring the trial to the before-naned instance, possess the sane rirtues with the marsh-mallow, mallow, and hollyoals of England; and the case is the same with those which are truly mallows of the East and Wret Indies; thounh this does not hold good with respect to some of the plants of those commtries which have been brought hither under that name.

'iluns also, that ront which was at one time about to be bromeht rere much into use, wurker the name of the senegal lattic-sualse root, hut 
of which litte mention has ben made here, becansc the attention has not been turned upon norelty, but use, being bond to hedong to a kind of milkwort, or polygala. The roots of the common milkwort of oul pastnies being tried, have been found to posses the same virtues, though in a less degree. This plant would not have been regrarded, if the other hat not been iomend to be of the same kind; but to that we owe the knowledge of its rirtues.

There is a great reaton for secking in our own climate, planis of the same nature, and form, and kind, with those witich in other countries allord us remedies; that they ate gencrally of the same kind, and may be fitte: for our constitutions. This is certain, that as the sm ripens the juices of plants in lotter combries to mere sirne than with us, so it make men's constitutions more able to bear their effects.

The Chinese will swallow snch doses as are poison to one of us. This we know in hiany instances, and it onght to enconrage us in the present research; becanter, if the same doses which agree with them, are ton murh for us; we may also find, that other medicines, of the same kind of virtues, though in a lexs degree, may also be found to angee better with our constitutions. I would not carry so fill as some have done, that opinion of nature's having provided in erery comitry the remedies for the cliseases of that comtry: Cool is the author of nature, and he knowing there would be commere amomg mankind, knew that would not be necesary. But notwithetandiags that it may be necresing in some cases, and comvenient in matsy, for us to have druge from abroad, yet in somera it will be better for us to be cured by those herbs we may find at home; 
and they will be fomd upen tria! nure sufticiont for that purpesse, than we al present imagine. 'The means are at hand, but we have made very little use of them, proportioned to their number and their. value.

The observation already made, that the external form of plants may very well give the hint for a conjecture about their virtues, is much more general than might be imagined. Almost all the plants of the same kinds alre of the same virthes. But that is not all: for in general, those of the same class possess the same qualities; though different in degree: and this is a prodigions help to him, who shall set out upon the generous and meful plan of adding to the mumber of the useful phants. It is atso singular, that what might appear rigjections in this catse, being bomglnt to the trial, will often be found confimations of the truth there is in the observation.

Thus suppose a man, observing that letture is catable, should inquire into all the plants like lettuce, which are those that have flowers com. posed of many parts, and have the seeds winged with a white dowiy matter, to find whether they were catable; let lis camine how he would suc. ceed. 'The phants of' this class native of England, are the sowthistle. the lawkweeds, the dandelions, gratsbeards, succory, and cudive, all catablen. The hawkweeds are les agreable in the taste. but wholesome; and as to the wild lettuces, there who would bring the oplate cutality of the principal of them as an objection, strengthen the obscrvation : for the garden letuce also has an opiate quality. 'This wild one possesses it in a greater degree, but still in such degree, that it is an excellent medicine, not at all daugerous. It. bitten tante would present perples caturg it, for 
it is disagremible; but its virues are the same with those of lettree, only greater. There are some kinds of hawhweed also. which have a bitter milly juice, altogether like that of this letuce; and ther, aloo, have this opiate quality. I have tried many of them, but as they are none of them, romal to the great wild lettuce in this respect, it woild have been idile to have spent many words abont thein.

Thin gencral obserwation may be carried a great Acal hathir ; but it were the business of a rolume, not of a short appendix, to explain it at large. In generel, the seeds of umbelliferous plants, that is, thr.e which have little flowers in rounded clusters, cach succeeded by two seeds, are good against whice; thase of caratiay, anise, cummin, coriander, and all of that kind, are produced by plants of this figure. In the same manner, the revicitlate plants, as they are called, that is, those which have the flowers surromding the striks, as in mint and thyme, are of́ a warm nature; and howeres they diflen in degrese and cimmutrace, they have the same general virtues. Farther such planis as are insipid to the taste and andi, have generally little virtues; and, on the contary, those which have the most fragrant smell, and shapest tasts, hive the greatest virues, of whaterer hind.

In general also, those plants whinh have a strong but an agrecable taste, are nost warthy of be examined with respect to thir virturs; fin the are grencrally the most valuable: and on the contrary, when a very strong tast is also a rery tis. agreable one; or, in the same nammer. wiben 1. strong smell of a plant bas aldo something heare. disagresable, and overpowering in it. there $i$ : mischief in the herb, rather than ans useful youlits The primono plant of this comntry are very lew; 
but they are for the inost part characterized after this mamer : so that they are known as it were at sight, or by the first offer of a trial.

Thus we see how very little can be the danger of inquiring farther into the virtues of cui' own plants, by experiments; and how useful such an inquiry may be to mankind is sufficiently proved by the matter of the preceding volume.

What I have written, is with intent to cucourarge some who have opportunities to make the trial ; and for my own part, I shall not be wanting. What I have already discovered in this way, $i$ an pleased to see makes in inconsiderable addition to the present publication; what I shall discover farther, or !earn from ulie experience of others, shall hase its place in the succeding editions.

HIIIS.

Bungay : Printed br Brightly and Co. 

University of C Southern Reg Library Fac 